\title{
Finite element analysis of interaction between actin cytoskeleton and intracellular fluid in prechondrocytes and chondrocytes subjected to compressive loading
}

\author{
Sundar Viswanathan \\ West Virginia University
}

Follow this and additional works at: https://researchrepository.wvu.edu/etd

\section{Recommended Citation \\ Viswanathan, Sundar, "Finite element analysis of interaction between actin cytoskeleton and intracellular fluid in prechondrocytes and chondrocytes subjected to compressive loading" (2004). Graduate Theses, Dissertations, and Problem Reports. 1757. \\ https://researchrepository.wvu.edu/etd/1757}

This Thesis is protected by copyright and/or related rights. It has been brought to you by the The Research Repository @ WVU with permission from the rights-holder(s). You are free to use this Thesis in any way that is permitted by the copyright and related rights legislation that applies to your use. For other uses you must obtain permission from the rights-holder(s) directly, unless additional rights are indicated by a Creative Commons license in the record and/ or on the work itself. This Thesis has been accepted for inclusion in WVU Graduate Theses, Dissertations, and Problem Reports collection by an authorized administrator of The Research Repository @ WVU. For more information, please contact researchrepository@mail.wvu.edu. 
Finite element analysis of interaction between actin cytoskeleton and intracellular fluid in prechondrocytes and chondrocytes subjected to compressive loading

Sundar Viswanathan

Thesis submitted to the College of Engineering and Mineral Resources

at West Virginia University in partial fulfillment of the requirements for the degree of

Master of Science

in

Mechanical Engineering

Nilay Mukherjee, Ph.D., Chair

Charles F Stanley, Ph.D.

Andrei V Smirnov, Ph.D.

Department of Mechanical and Aerospace Engineering

Morgantown, West Virginia 2004

Keywords: Fluid solid Interaction, ANSYS, Finite Element 


\section{Abstract \\ Finite element analysis of interaction between actin cytoskeleton and intracellular fluid in prechondrocytes and chondrocytes subjected to compressive loading}

Prechondrocytes exhibit a change in their actin cytoskeletal arrangement when subjected to loading. This study looks at the implications of the altered solid- fluid interactions due to this change. A 2-D Finite element model of a cell was developed. A solid-fluid interaction solution procedure was validated and used to determine fluid flow/pressure in a cell when subject to deformation. These values were then used to calculate fluid flow induced stresses on individual actin fibers. The results suggest that prechondrocytes alter their cytoskeletal structure to reduce stresses as a result of fluid flow due to deformation of the cell. 
This thesis is dedicated to my parents

- iii - 


\section{Acknowledgements}

First of all, I am highly grateful to my advisor, Dr.Nilay Mukherjee, for providing me the opportunity to work under his guidance. His constant support, invaluable suggestions and insightful discussions, helped me clarify my thinking on various technical aspects. His mentorship is a rewarding experience, which I would treasure my whole life.

I would like to thank Dr.Andrei Smirnov and Dr. Charles Stanley for serving on my committee and providing assistance through out my research work. I would also like to thank ANSYS technical support people in Pittsburgh for helping me with all the problems I encountered in my research.

Special thanks to Vidhyashankar Venkatesan and Kaarthik Sikkil for explaining things clearly and helping me through out my research work. I would like to thank all my friends, who always stood by me, when I needed support. Their encouragement, appreciation and constructive criticism, shaped me into a better person and I am always thankful to them.

I would like to thank my parents for their constant advice and guidance, for always pushing me to go after my goals. Finally, I would like to thank the Almighty for showing me the right path in my life. 


\section{TABLE OF CONTENTS}

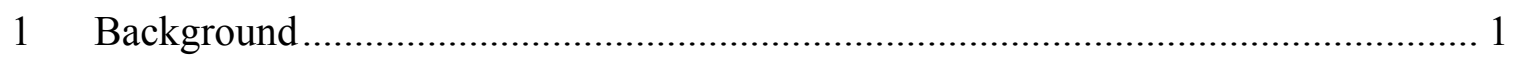

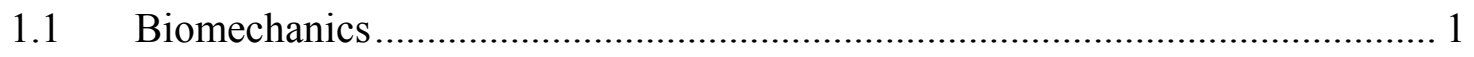

1.1.1 Cell Mechanics................................................................................... 1

1.2 Structure and function of Articular Cartilage .................................................. 1

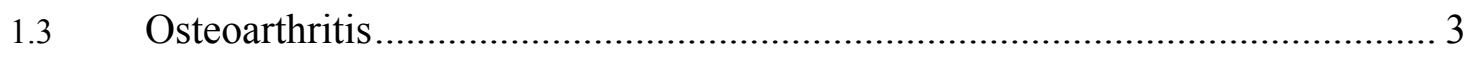

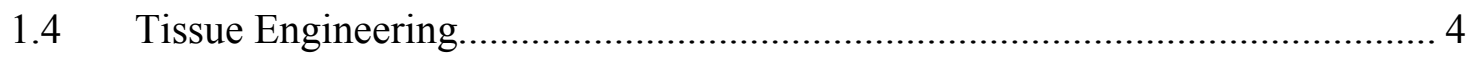

$1.5 \quad$ Behavior of cells to Mechanical Loading ……................................................ 4

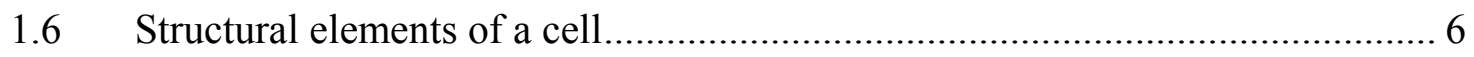

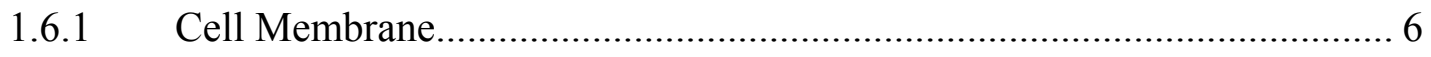

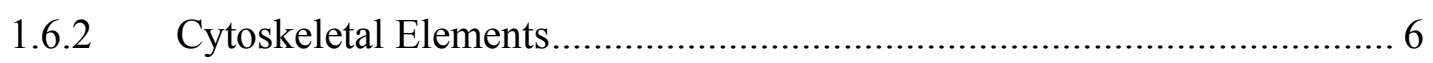

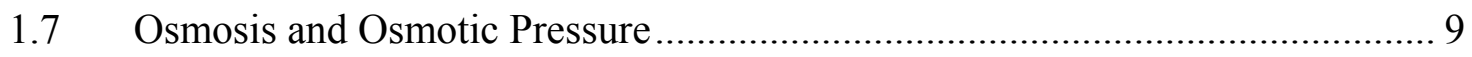

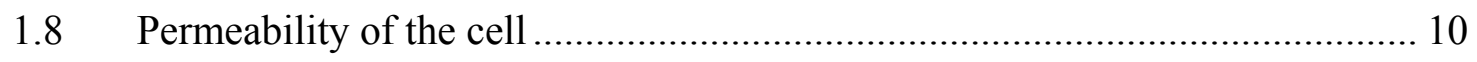

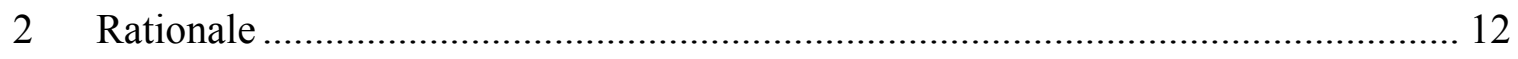

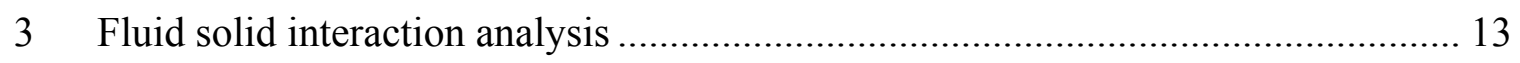

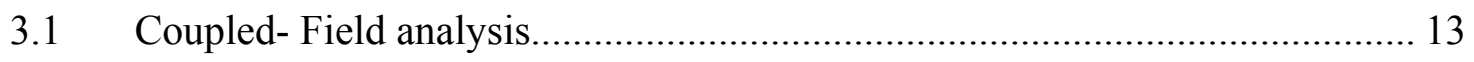

3.1.1 Sequential Method ........................................................................... 13

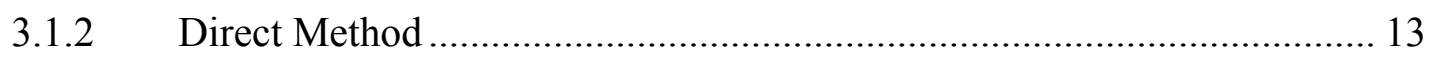

3.2 Sequential weak coupling analysis ............................................................. 13

3.3 Coupling algorithm for fluid solid interaction ............................................... 14

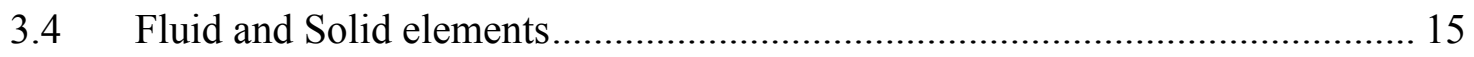

3.4.1 Performing fluid solid interaction analysis ............................................... 16 
3.4.2 Solution options for fluid-solid interaction analysis ........................... 16

3.5 Limitations of fluid solid interaction analysis ......................................... 19

3.6 Distributed Resistance ......................................................................... 20

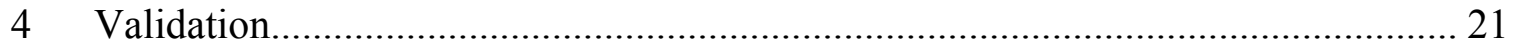

4.1 Fluid solid interaction analysis in a piston cylinder arrangement................... 21

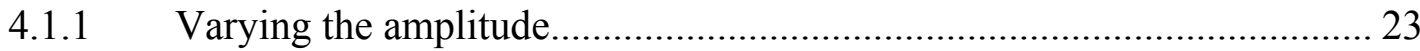

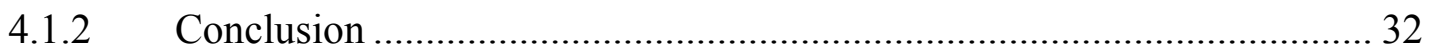

4.2 Analysis of a simplified oscillating plate.................................................. 32

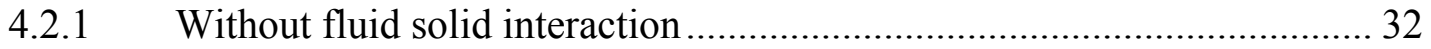

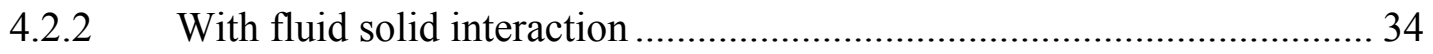

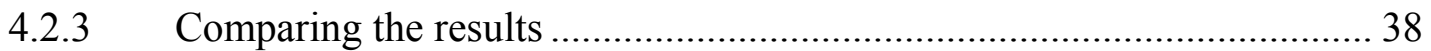

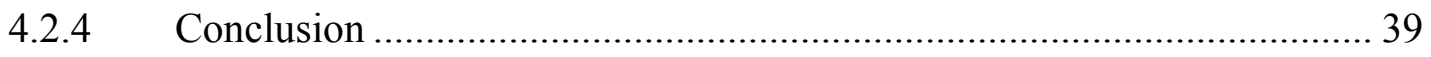

4.3 Stress acting on a plate subjected to different fluid velocities....................... 40

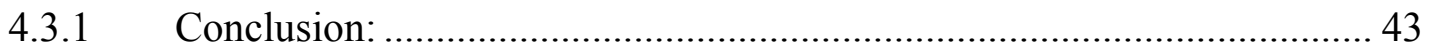

4.4 Stress acting on a plate when subjected to different pressures ...................... 43

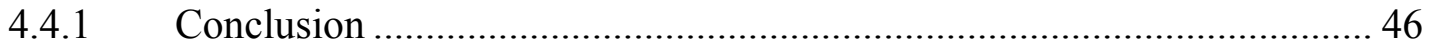

4.5 Theoretical Validation ......................................................................... 46

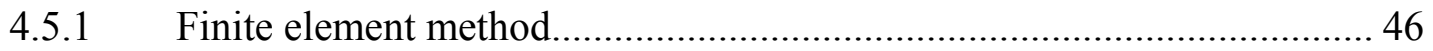

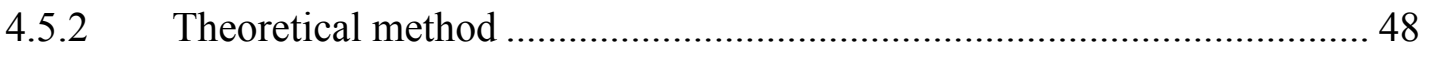

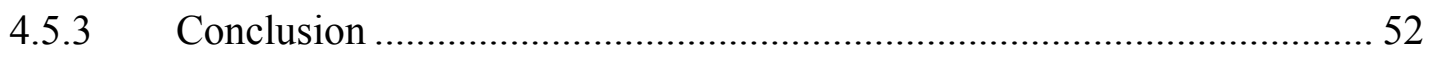

5 Modeling response of a cell to compressive loading ........................................ 53

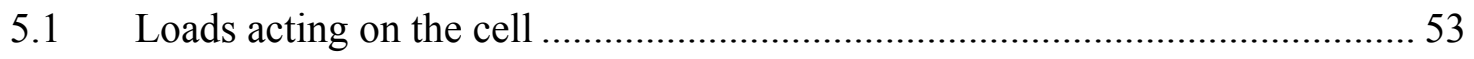

5.2 Cytoskeletal arrangement in a cell for different days ................................. 54 
5.3 Post processing of cell images using OPTIMAS .......................................... 56

5.4 Modeling the cell using MATLAB program ............................................... 57

5.4.1 Centroid calculation and curve fitting ............................................. 57

5.5 Algorithm for MATLAB program to model the cell with its inner elements... 59

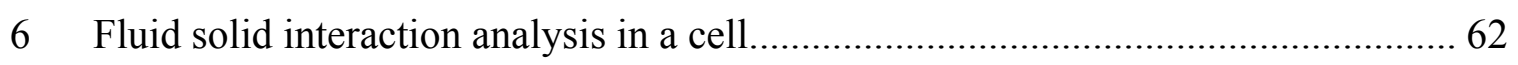

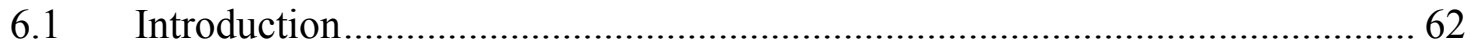

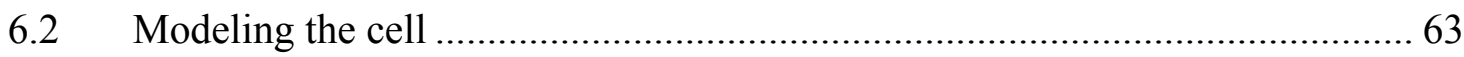

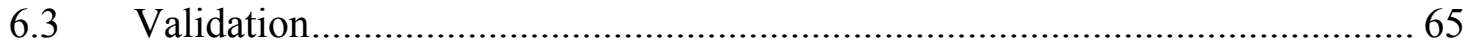

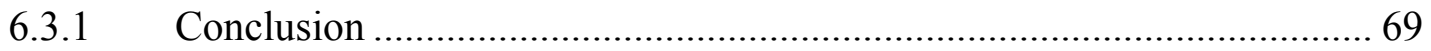

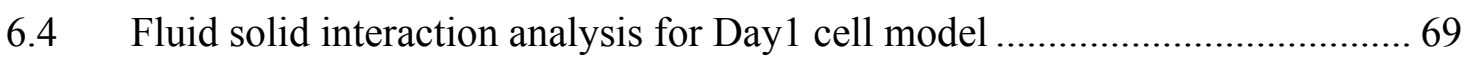

6.5 Fluid solid interaction analysis for Day12 cell model ................................. 75

6.6 Fluid solid interaction analysis using physics environment .......................... 79

6.6.1 Sequentially coupled field analysis using physics environment.............. 80

6.6.2 Stress acting on the actin filaments............................................... 81

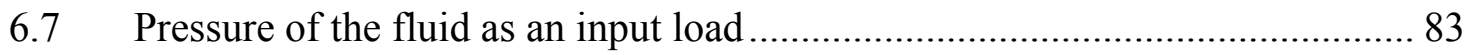

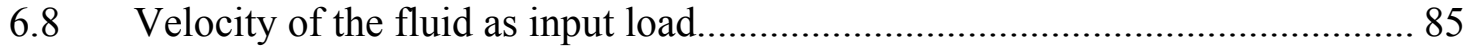

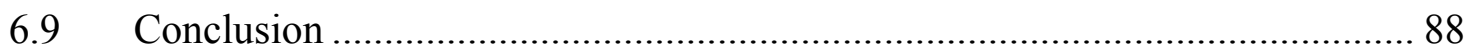

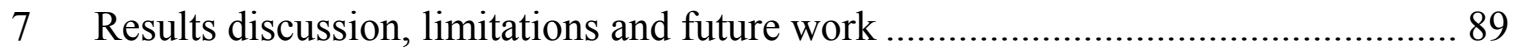

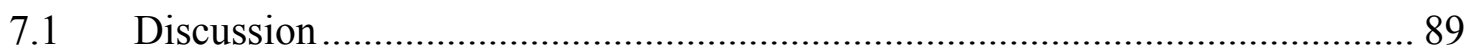

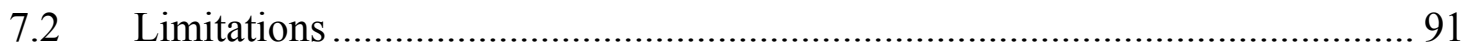

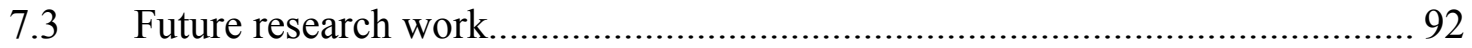

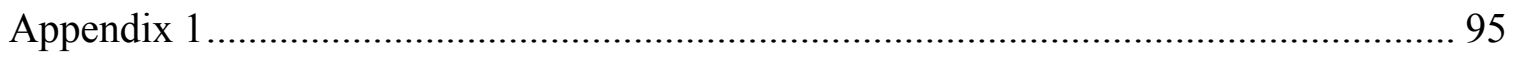

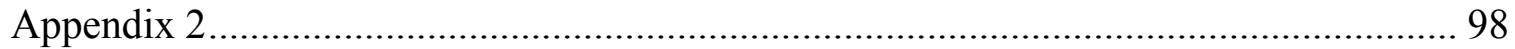




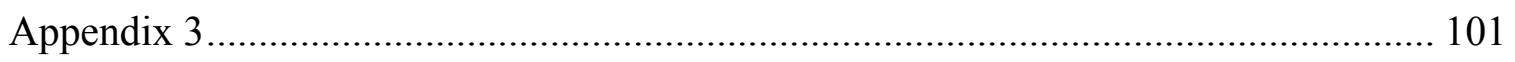

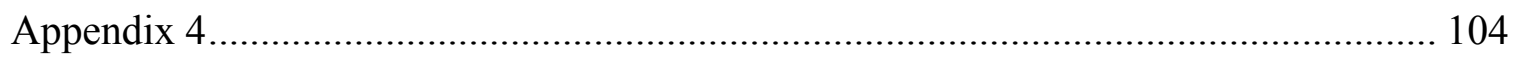

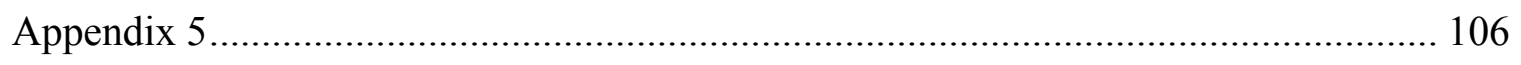

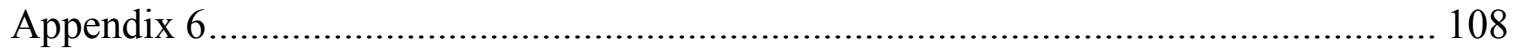

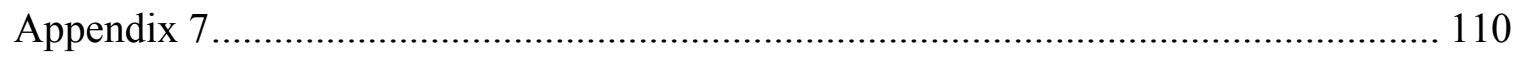

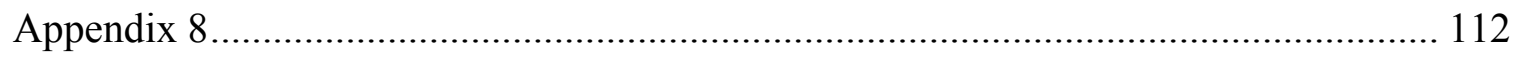

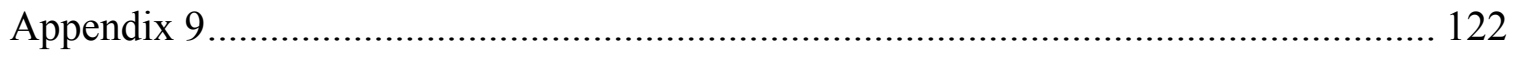

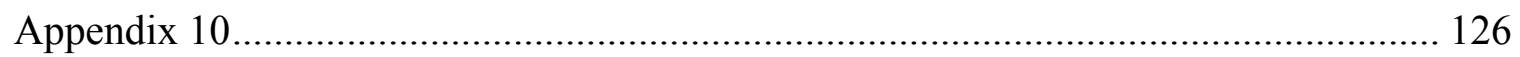

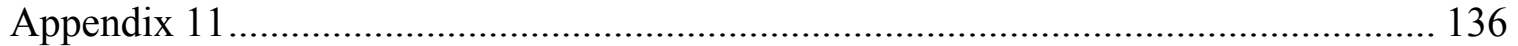




\section{LIST OF FIGURES}

Figure 1 A Histological section of cartilage with a schematic of chondrocyte organization along its depth (dahweb.engr.ucdavis.edu/dahweb/126site/bone.htm) .................... 2

Figure 2 Comparison between a health joint and diseased joint caused due to osteoarthritis (indoindians.com/health/signs_arthritis.htm) .............................. 3

Figure 3 Repair and growth of bone through tissue engineering (www.fibrogen.com/tissue/) 4

Figure 4 Cell membrane of human red blood cells (digilander.libero.it/.../lipidi/membrane.htm)[4] ......................................... 6

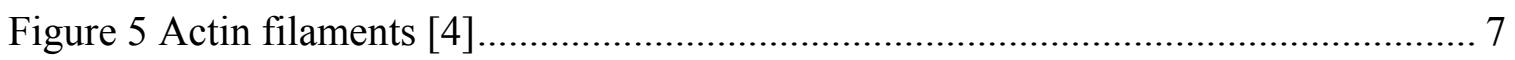

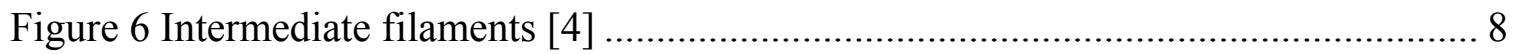

Figure 7 Electron micrograph and schematic view of the cross section of microtubules [4]

Figure 8 Piston and cylinder arrangement with boundary conditions

Figure 9 Pressure plot for the fluid element when amplitude is $0.85 \mathrm{~mm}$ and angular velocity is $2.5 \mathrm{sec}^{-1}$ 24

Figure 10 Von mises stress acting on the solid element when amplitude is $0.85 \mathrm{~mm}$ and angular velocity is $2.5 \mathrm{sec}^{-1}$ 25

Figure 11 Pressure plot for the fluid element when amplitude is $0.5 \mathrm{~mm}$ and angular velocity is $2.5 \mathrm{sec}^{-1}$

Figure 12 Von mises stress acting on the solid element when amplitude is $0.5 \mathrm{~mm}$ and angular velocity is $2.5 \mathrm{sec}^{-1}$ 
Figure 13 Pressure plot for the fluid element when amplitude is $0.25 \mathrm{~mm}$ and angular velocity is $2.5 \mathrm{sec}^{-1}$ 26

Figure 14 Von mises stress acting on the solid element when amplitude is $0.25 \mathrm{~mm}$ and angular velocity is $2.5 \mathrm{sec}^{-1}$.

Figure 15 Pressure variations for the fluid element for different amplitude at node 35 in the center of the cylinder. 27

Figure 16 Pressure plot for fluid element when amplitude is $0.85 \mathrm{~mm}$ and angular velocity is $3.0 \mathrm{sec}^{-1}$ 29

Figure 17 Von mises stress on the solid element when amplitude is $0.85 \mathrm{~mm}$ and angular velocity is $3.0 \mathrm{sec}^{-1}$ 29

Figure 18 Pressure plot for the fluid element when amplitude is $0.85 \mathrm{~mm}$ and angular velocity is $1.5 \mathrm{sec}^{-1}$ 30

Figure 19 Von mises stress acting on the solid element when amplitude is $0.85 \mathrm{~mm}$ and angular velocity is $1.5 \mathrm{sec}^{-1}$ 30

Figure 20 Pressure variations for the fluid element for different angular velocity at node 35 in the center of the cylinder 31

Figure 21 Boundary conditions for the model without fluid solid interaction 32

Figure 22 Pressure plot for the fluid element.......................................................... 33

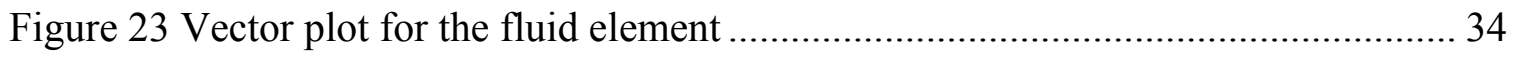

Figure 24 Boundary conditions for the model with fluid solid interaction..................... 35

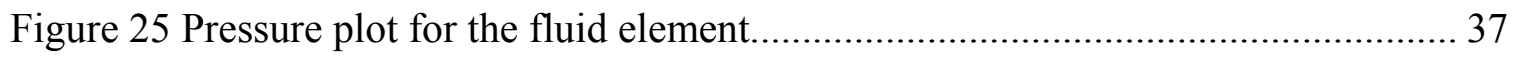

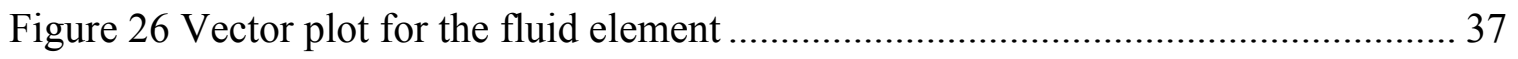

Figure 27 Von mises stress acting on the plate with fluid solid interaction analysis ....... 38 
Figure 28 Comparison of the pressure, velocity and displacement of the fluid for with fluid solid interaction analysis and without fluid solid interaction analysis 39

Figure 29 Von mises stress acting on a plate when subjected to fluid velocity of $10 \mathrm{~mm} / \mathrm{sec}$ 42

Figure 30 Von mises stress acting on the plate when subjected to a fluid velocity of $50 \mathrm{~mm} / \mathrm{sec}$ 42

Figure 31 Von mises stress acting on a plate with no pressure difference 45

Figure 32 Von mises stress acting on a plate with pressure difference 45

Figure 33 Boundary condition for the model. 47

Figure 34 Vector plot for the fluid element without pressure difference 47

Figure 35 Vector plot for the fluid element with pressure difference 48

Figure 36 Forces acting on the element 49

Figure 37 Variation of velocity with distance when there is no pressure difference....... 51

Figure 38 Variation of velocity with distance when there is a pressure difference 51

Figure 39 Cell in deformed and undeformed states. Size of the cell reduces in the Xdirection when a compressive load is applied............................................... 53

Figure 40 The radial deformation (Ur) of the cell with respect to angles....................... 54

Figure 41 Reorganization of the actin fibers in the cells from Day1 to Day12 ............... 55

Figure 42 The cell image with points obtained from OPTIMAS software (center). Cell image and points collected from OPTIMAS at a higher threshold value (170) (right). 56

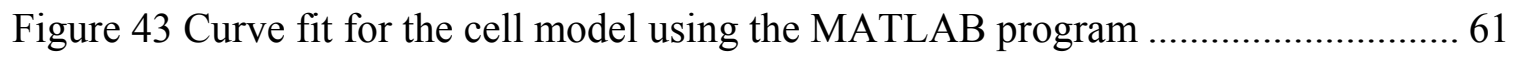

Figure 44 Comparison between the experimental and calculated Ur values ................... 63 
Figure 45 Pressure of the fluid element for a cell model with lower porosity value ........ 66

Figure 46 Pressure of the fluid element for a cell model with high porosity. 67

Figure 47 Von mises stress acting on the cell membrane without any inner fluid element 68

Figure 48 Von mises stress acting on the cell membrane with inner fluid element ........ 69

Figure 49 Dayl cell model (Pre-chondrocyte) with actin filaments............................ 70

Figure 50 Intracellular fluid pressure in Day1 cell model ........................................ 72

Figure 51 Von mises stress acting on the cell membrane in Dayl cell model ................ 72

Figure 52 Velocity of the fluid element in X-direction for Dayl cell model .................. 73

Figure 53 Velocity of the fluid element in $\mathrm{Y}$-direction for Dayl cell model................. 73

Figure 54 Day12 cell model (Chondrocyte) with actin filaments................................ 75

Figure 55 Intracellular fluid pressure in a Day12 cell model ..................................... 77

Figure 56 Von mises stress acting on the cell membrane in a Day1 cell model.............. 77

Figure 57 Velocity of the fluid element in X-direction for Day12 cell model ................ 78

Figure 58 Velocity of the fluid element in Y-direction for Day12 cell model ................ 78

Figure 59 Von mises stress acting on the fixed-free actin filaments for a Pre-chondrocyte

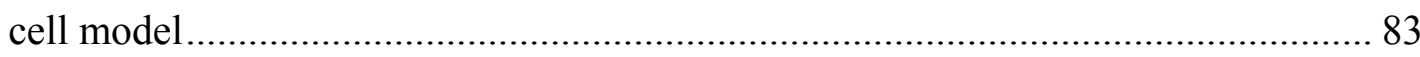

Figure 60 Von mises stress acting on the fixed-free actin filaments for a chondrocyte cell

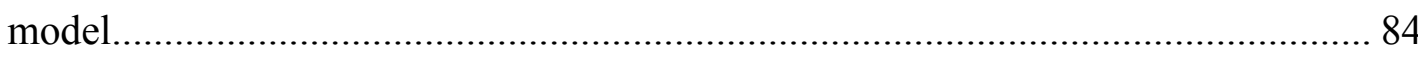

Figure 61 Von mises stress acting on the fixed-fixed actin filaments for a prechondrocyte cell model. 84

Figure 62 Von mises stress acting on a fixed-fixed actin filaments for a chondrocyte cell model. 85 
Figure 63 Von mises stress acting on the fixed-free actin filaments for a prechondrocyte cell model.. 86

Figure 64 Von mises stress acting on a fixed-free actin filaments for a chondrocyte cell model.. 86

Figure 65 Von mises stress acting on a fixed-fixed actin filaments for a pre chondrocyte model.. 87

Figure 66 Von mises stress acting on a fixed-fixed actin filament for a chondrocyte cell model.. 87 


\section{LIST OF TABLES}

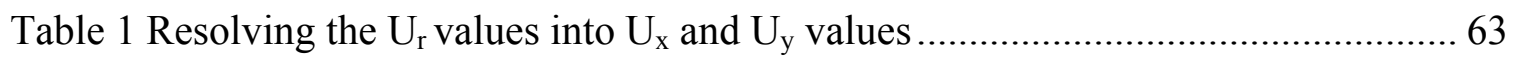

Table 2 Fluid properties and the Von mises stress acting on the four sets of Day1 cell model when subjected to compressive loading................................................ 74

Table 3 Fluid properties and Von mises stress acting on four sets of Day 12 cell model

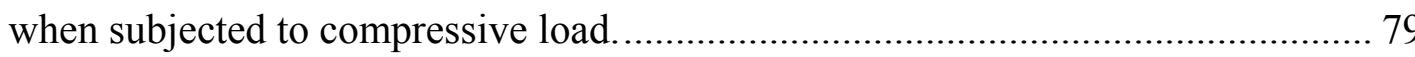

Table 4 Von mises stress acting on the fixed-free and fixed-fixed actin filaments when the pressure of the fluid is made as an input load ................................................ 90

Table 5 Von mises stress acting on the fixed-free and fixed-fixed actin filaments when the velocity of the fluid is made as an input load 


\section{Background}

\subsection{Biomechanics}

Biomechanics is the study of the mechanics of tissues of the human body like bone, cartilage, muscle, tendon, ligaments etc. The living tissues are often subjected to mechanical loading and they adapt to the mechanical loading by changing their structure and composition [2]. Biomechanics uses the laws of physics and engineering concepts to describe the motion of the body segments and the forces acting on them during daily activities, sport, injury etc. Recently, the cells in these tissues have been identified as mechanical sensors that are responsible for the adaptation of these tissues to mechanical loading.

\subsubsection{Cell Mechanics}

Cell mechanics deals with the structure of the cell as well as the interaction of the cell with its outer environment. A change in the cell mechanical property can cause a change in the cell and tissue architecture [2]. The movement of joints produces forces in the muscle and the force is then transferred to cell through tissue. Cell mechanics plays an important role in understanding the response of the cells to mechanical loading.

\subsection{Structure and function of Articular Cartilage}

Articular cartilage is a load bearing tissue that covers the ends of bones and allows the distribution of compressive loads over the cross section of bones, as well as providing a near frictionless and wear resistant surface for joint movement. It primarily consists of the Extra Cellular Matrix (ECM) that is made up of highly specialized cells called chondrocytes. The ECM is made up of water, proteoglycans, collagens and other proteins, which provide the tissue with its distinctive structure and mechanical properties. 


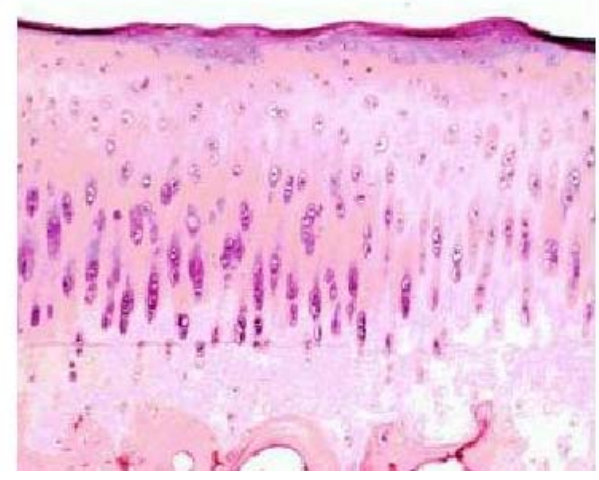

Figure 1 A Histological section of cartilage with a schematic of chondrocyte organization along its depth (dahweb.engr.ucdavis.edu/dahweb/126site/bone.htm)

Articular cartilage is divided into four zones based on the structure and composition of the ECM components through the depth of the tissue. The top zone is called the superficial zone and forms the gliding surface. The collagen fibrils in this zone are arranged parallel to the articulating surface in order to withstand high shear forces that this layer is subjected to. The middle zone, which is also called as Transitional zone, has collagen arranged in a random manner with more rounded chondrocytes. This makes it good for resisting compression. The third zone, called as Deep zone contains collagen arranged perpendicular to the surface thus anchoring cartilage to bone. The last zone is the calcified zone that separates the subchondral bone from the hyaline cartilage [1].

Articular cartilage comprises $5 \%$ of chondrocytes and $95 \%$ of extra cellular matrix. The extra cellular matrix consist of $75 \%$ of water, $5 \%$ of collagen, $20 \%$ of proteoglycans, enzymes, growth factors, lipids and adhesives. Chondrocytes play an important role in the control of matrix turnover through production of collagen, proteoglycans and enzymes for cartilage metabolism. The Water inside the articular cartilage allows for deformation of the surface by shifting in and out in response to stress [1]. Increased water content causes an increase in the permeability, decreased strength and decreased Young's modulus (less stiff). 


\subsection{Osteoarthritis}

Complete loss of articular cartilage results in Osteoarthritis, which is a chronic debilitating disease in which movement becomes painful along with joint stiffness [2]. Osteoarthritis is a degenerative disorder in which the rate of breakdown of articular cartilage exceeds that of its synthesis.

\section{The Effect of Osteoarthritis}

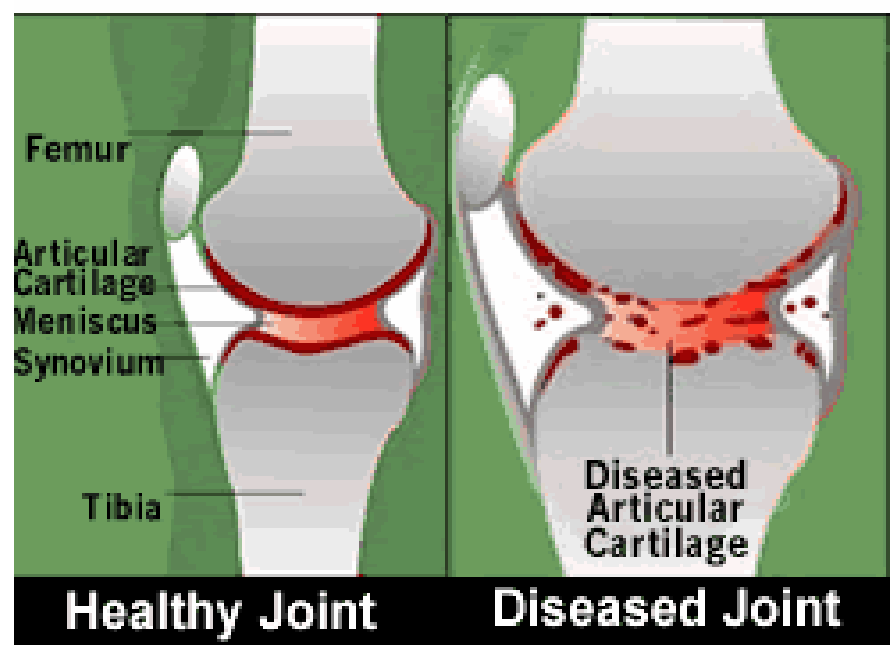

Figure 2 Comparison between a health joint and diseased joint caused due to osteoarthritis (indoindians.com/health/signs_arthritis.htm)

Cartilage acts as a cushion between the bones and allows smooth and painless movement.

When the cartilage is lost then the bones will grind together. This affects many joints in the body especially knees, ankles, fingers etc., Loss of articular cartilage also increases the amount of stress on the ends of the bones resulting in the growth of bone spurs at the margins of the joints. With increase in age the functional and mechanical properties of the chondrocytes deteriorate. Inadequate regeneration of the worn out cartilage causes osteoarthritis. To understand these pathologies it becomes important to study the role of chondrocytes. 


\subsection{Tissue Engineering}

Tissue engineering is a rapidly growing technology, which aims at replacing diseased or damaged tissues. In tissue engineering, living cells are cultured in 3D conditions in a scaffold, and this construct is introduced into degraded areas of the tissue in patients. The hope is that new tissue will biologically regrow to fill the areas of damaged tissue (Figure 3). The tissue proliferation and differentiation is strongly affected by mechanical stimuli. Hence appropriate loads must be applied during the growth process. It is also important to understand the properties and the role of the cells in the repair of tissues.

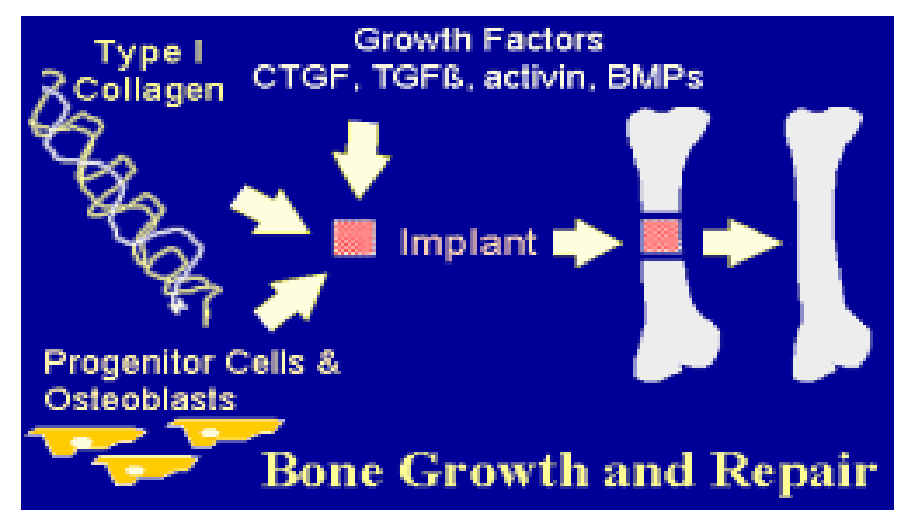

Figure 3 Repair and growth of bone through tissue engineering (www.fibrogen.com/tissue/)

\subsection{Behavior of cells to Mechanical Loading}

Mechanical influences on cells, tissues and organs are normally termed as 'Mechanical Morphogenesis' [3]. It is well known that mechanical loading affects the biological behavior of cells. Mechanical stimuli are known to regulate fundamental process such as cell division and differentiation. The cytoskeleton plays an important role when loaded and regulates a wide variety of functions. Mechanical loading is clearly pivotal to the development, function and repair of all the musculoskeletal system. The clinical opinion is that in treating musculoskeletal injuries the tissue should be protected 
from loading first and then it is carefully subjected to measured loading to promote remodeling [3]. The mechanical signal from the cartilage is transmitted indirectly to chondrocytes via the extra cellular matrix (ECM). Cell - Matrix interactions are thus critical for cartilage cells to respond to changing mechanical load and the cell membrane plays a pivotal role in transmitting extra cellular signals to the chondrocyte nucleus via the cytoskeleton. The mechanism through which cells respond to load is called mechanotransduction. Cells can sense and deform in response to external load on the tissue through proteins in the cell membrane called integrins, which connects cell to extra cellular tissue material. When the cell is subjected to loading a deformation is caused in the structural elements of the cells, which causes the receptors and ligands to bind together, passing a signal form the cell exterior to its interior. The fluid flow in cell also results in clustering of proteins in the cell membrane, which could result in a signaling cascade. Fluid flow also affects bio-transport processes in and around the cell.

The major type of loading in cartilage tissue is compressive. The key ability of cartilage to withstand compression is associated with its large content of proteoglycan [3]. This huge molecular domain draws tissue fluid into the ECM by capillary action. Thus the high water content of the articular cartilage accounts for its compression tolerance. The compressive load applied to the bovine cartilage explants can trigger chondrocyte apoptosis, proteoglycan loss and tissue swelling [3]. Cartilage cell death is an early response to tissue injury and is seen at stress levels below those that lead to ECM degradation. Thus, studying cellular response to mechanical loading becomes critical as a first step to initiating strategies for maintaining tissue health or regenerating worn out tissue. 


\subsection{Structural elements of a cell}

The cell is the most important basic unit of life. All life activities are based on cells. The cell plays an important role in tissue regeneration. Therefore it becomes important to understand the structural components of a cell. The cell consists of cell membrane, cytoskeletal element like actins, intermediate filaments and microtubules.

\subsubsection{Cell Membrane}

Cell membrane is the surface of a cell. The cell membrane is semi permeable and is made up of phospholipids, protein and sugar [4]. Cell membrane resists the internal fluid pressure built inside the cell. All molecules enter and leave the cell through the cell membrane. The thickness of cell membrane varies from 75 angstroms to 100 angstroms. The elastic modulus of the cell membrane is found to be $0.1 \mathrm{MPa}$ [5].
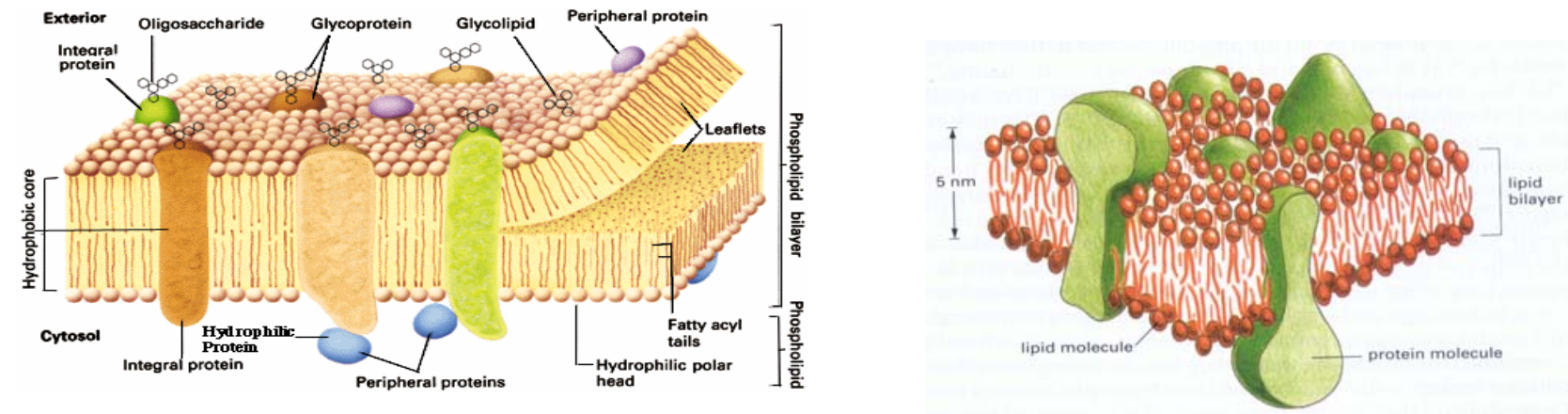

Figure 4 Cell membrane of human red blood cells (digilander.libero.it/.../lipidi/membrane.htm)[4]

\subsubsection{Cytoskeletal Elements}

The cytoskeletal elements consist of a complex network of tubules and filaments extending from the nucleus to the plasma membrane. The cytoskeletal elements are important in maintaining cellular structure, position and movement of organelles, protein trafficking and signaling. The cytoskeletal elements consist of actin filaments, intermediate filaments and microtubules. 
Actin:

Actin filaments are one of the major structural elements of a cell. Actin filaments are long rope like structures about $8 \mathrm{~nm}$ in diameter [4]. They play important role in structural stability of cell as well as in cell motility. They are attached to the extra cellular matrix through special complexes called integrins. The actin fibers are normally subjected to tensile load. The flexural rigidity of the actin was found to be $7.3 \mathrm{E}-26 \mathrm{nM}$ [6]. The Young's modulus is calculated from the flexural rigidity and it is found to be $363 \mathrm{MPa}$.
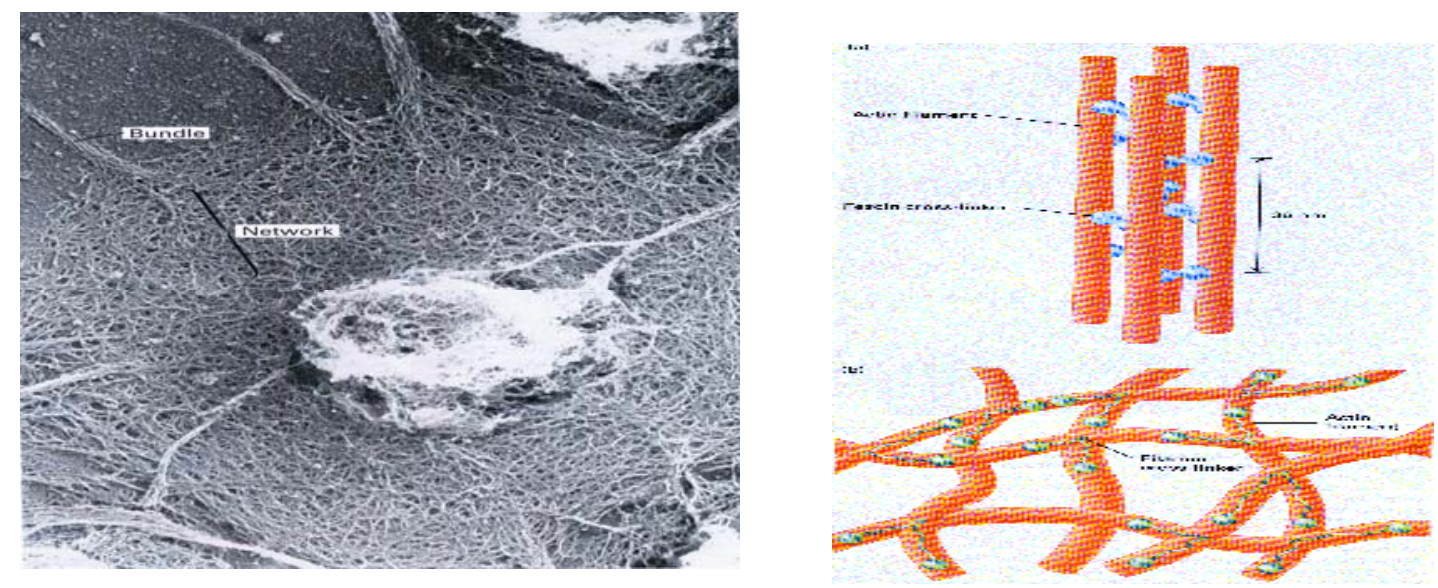

Figure 5 Actin filaments [4]

Intermediate Filaments:

The Intermediate filaments are the most stable and least soluble components of cytoskeleton. The diameter of intermediate filaments varies from 8-10 $\mathrm{nm}$. They serve as scaffold for cytoskeletal framework. The intermediate filaments are tissue specific. They can withstand high stresses and provide the cells with mechanical 
strength. The intermediate filaments can endure larger stretching force than actin or microtubules.
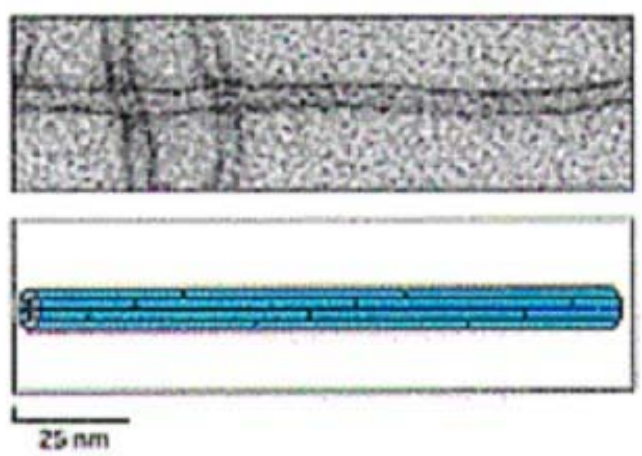

Figure 6 Intermediate filaments [4]

Microtubules:

Microtubules are long hollow tubes that can assemble and disassemble very quickly. Microtubules have varying length and are about $25 \mathrm{~nm}$ in external diameter and $2.7 \mathrm{~nm}$ in thickness [4]. Microtubules are known to take up compressive loads in a cell. The flexural rigidity of microtubules was found to be $2.1 \mathrm{E}-23 \mathrm{nM}$, which is about 1000 times stiffer in bending than actin filaments [6]. The young's modulus is calculated from flexural rigidity and is found to be $1200 \mathrm{MPa}$. 


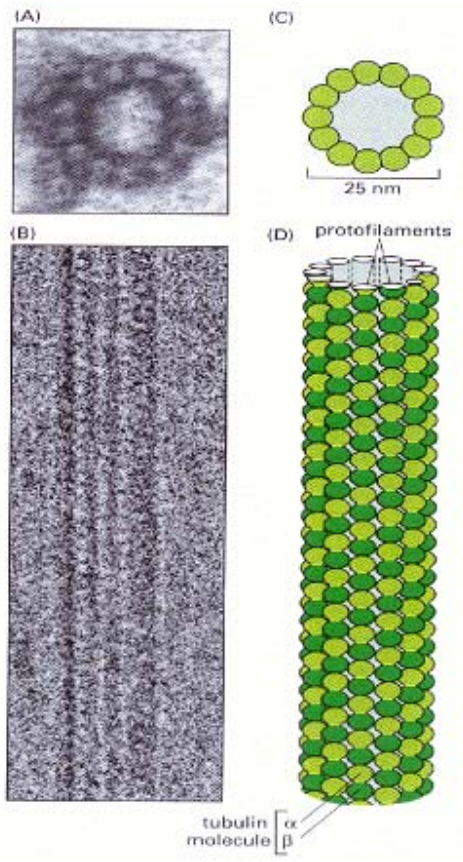

Figure 7 Electron micrograph and schematic view of the cross section of microtubules [4]

\subsection{Osmosis and Osmotic Pressure}

The fluid inside the cell produces a tensile stress on the cell wall. Osmosis can be regarded as a diffusion of water across the membrane. Osmotic pressure is the difference between inside the cell and its outer environment and causes the fluid flow between the cell and its environment. The osmotic pressure difference balances the turgor pressure in a cell. This is given by a formula

$$
\begin{aligned}
& \Delta \mathrm{P}=\Delta \Pi=-(\Pi \mathrm{e}-\Pi \mathrm{i})(7) \\
& \Delta \mathrm{P} \text { - Turgor pressure. }
\end{aligned}
$$

$\Delta \Pi$ - Osmotic pressure difference between inside and outside the cell.

The cell is fragile so it becomes important to maintain their exterior and interior osmotic pressure closely matched by maintaining the correct chemical composition of cellular fluids. The cell membrane is semi permeable and it allows the nutrients, oxygen, water 
and waste gases to pass in and out of the cell. The internal fluid pressure plays an important role in volumetric expansion of the cell and in resisting compressive loads. The cell diameter and volume increases in hypoosmotic medium and decreases in hyperosmotic medium [8]. The changes in osmotic environment have a strong influence on the viscoelastic mechanical properties as well as the morphology of the chondrocyte altering the biomechanical interactions between the chondrocyte and its extra cellular matrix [8]. The Osmotic swelling also affects the mechano-electromehanical events within the tissue that governs the cartilage biosynthetic environment [12]. To better understand about mechano-electromehanical events it is important to understand the properties of chondrocytes and ECM. The change in the cell volume because of the osmotic environment may either up regulate or down regulate the chondrocyte biosynthetic environment [12]. To understand the behavior of chondrocyte during osmotic loading it becomes important to know the properties of the fluid inside the chondrocyte.

\subsection{Permeability of the cell}

The cell membrane, which is a semi permeable one, plays an important role in maintaining the osmotic pressure and helps in the transport of nutrient and water molecule in and out of the cell. Osmotic loading experiments are done to calculate the aggregate modulus and the permeability of the chondrocyte. The material properties of chondrocytes were measured through various testing methods like micropipette aspiration, compression of cell-seeded gels, cytoindentation and atomic force microscopy. In the study of Morakot Likhitpanichkul et al., the chondrocyte was subjected to chemical loading and the aggregate modulus and the permeability of the cell was found by the time-dependent shrinking response of the cells. The chondrocyte was 
modeled as a spherical gel consisting of a solid matrix (the cytoskeleton) and two fluid phases (cytosolic fluid and a neutral solute) to analyze the response of the cell to chemical loading induced by concentration changes of a neutral solute in an external bath [9]. The aggregate modulus and the permeability were obtained by curve fitting the experimental data obtained from the time-dependent normalized volume of the cells under static hyperosmotic loading. From the experiment it was found that the cell volume decreases by $\left(\mathrm{r}^{2} 0.89+/-0.05\right)$ and the curve- fitted aggregate modulus and permeability were $10.6+/-4.6 \mathrm{KPa}$ and $6.2 \mathrm{e}-17+/-4.6 \mathrm{e}-17 \mathrm{~m}^{4} /$ n.s. [9] 


\section{Rationale}

Cartilage cells or chondrocytes behave as mechano sensors embedded in the cartilage matrix. They sense the loading environment and respond to it by manufacturing and secreting appropriate proteins that are responsible for the maintenance of tissue health. Hence a study of the local mechanical environment of the chondrocytes is important in understanding how cartilage responds to mechanical loading. In this study we focus on two aspects of cellular behavior

1. The proper actin cytoskeletal structure of chondrocyte is important for maintaining cartilage phenotype. Stress-fiber like appearance is usually not associated with the cartilage phenotype, whereas a "Punctuate" appearance is.

2. The fluid pressure in the cells is tightly regulated. Fluid is known to travel across the cell membrane in response to osmotic challenges.

It is infinitively obvious that when chondrocytes are compressed, there will be interactions between the cell cytoskeletal structure and the intracellular fluid. What is obvious is whether certain types of interactions are more favorable than others and why.

As a first step, we wish to study what the different interactions can exist. In previous experiments in our lab, pre chondrocytic ATDC5 cells were embedded in $2 \%$ agarose gel and compressed. The deformations of the cells were measured. The actin cytoskeletal organization of the cells was imaged. It was noted that there was a marked reorientation of the actin cytoskeleton of the cells with onset of the biomarkers of chondrogenesis. We wish to see that for applied deformations of the cell consistent with our experimental setup, whether significant differences existed between the fluid and the different actin organization of the cells at different shapes of chondrogenesis. 


\section{Fluid solid interaction analysis}

\subsection{Coupled- Field analysis}

A coupled-field analysis takes into account the interaction between two or more disciplines of engineering. The coupled field analysis was used to perform Thermal-stress analysis, Fluid- Structure analysis, Magnetic- Thermal analysis, Piezoelectric analysis and Magneto- Structural analysis. There are two types of coupled field analysis; they are sequential and direct method.

\subsubsection{Sequential Method}

The sequential method involves two or more sequential analysis, each belonging to a different field. The two fields are coupled by applying results from the first analysis as input for the second analysis [10].

\subsubsection{Direct Method}

The direct method involves just only one analysis that uses a coupledfiled element type containing all necessary degrees of freedom. Coupling was handled by calculating element matrices or load vectors that contain all necessary terms [10].

\subsection{Sequential weak coupling analysis}

The sequential weak coupling method uses ANSYS/FLOTRAN elements for the fluid elements and the ANSYS structural, thermal, or coupled field elements for solid elements. Some of the applications, which include the fluid-solid interaction problems, are problems involving coupling or thermal, structural, or electric fields with flow fields, problems involving flow induced structural motion, problems that involve flow caused by solid deformation etc. 


\subsection{Coupling algorithm for fluid solid interaction}

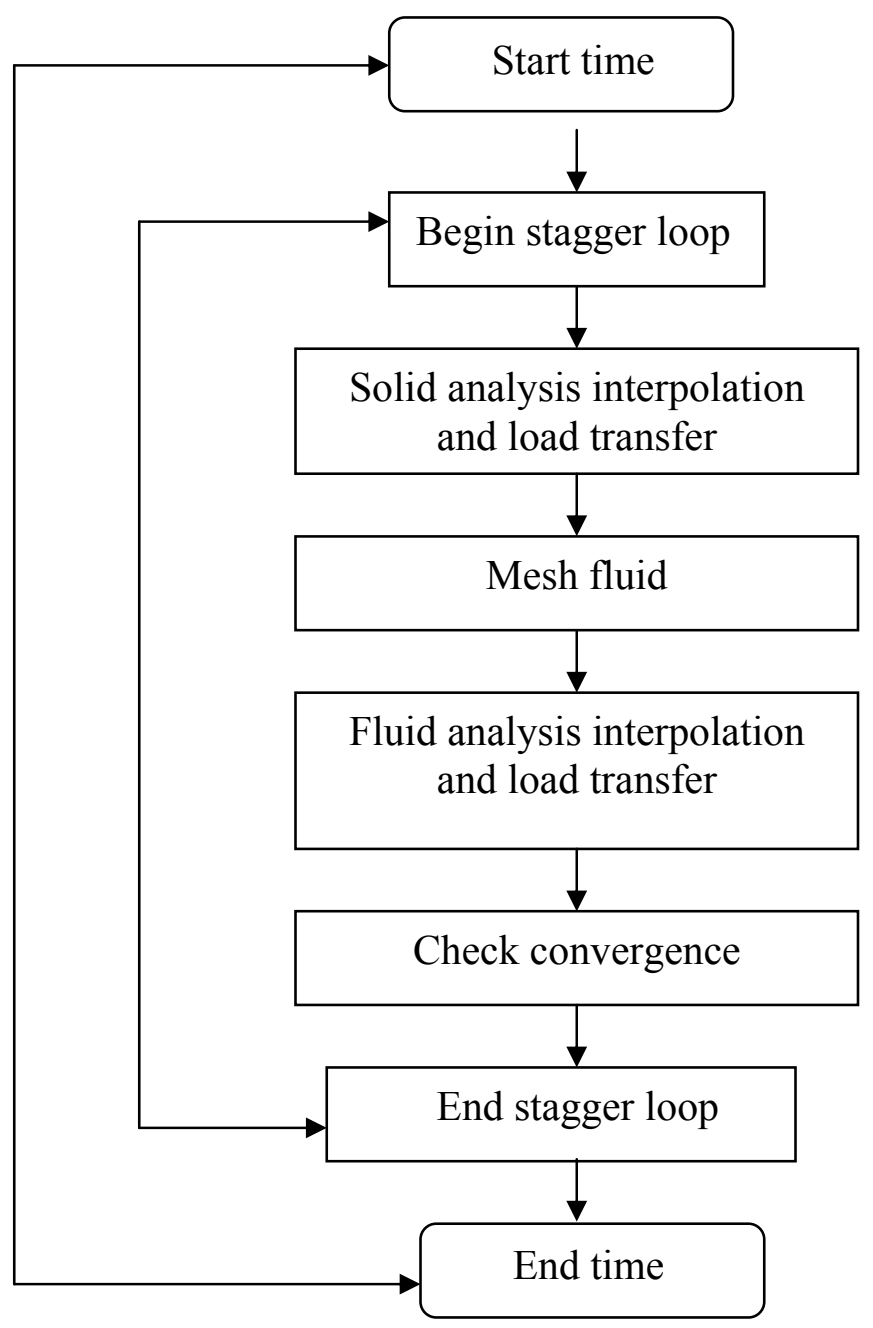

The weak coupling algorithm solves the equations for the fluid and solid domains independently of each other. The weak coupling algorithm transfers solid displacements, velocities, and temperatures and fluid forces across the fluid-solid interface. The algorithm continues to loop through the solid and fluid analyses until convergence is reached or until the maximum number of interactions is reached. Convergence in the loop is based on the quantities being transferred at the fluid -solid interface. The fluid and solid mesh are dissimilar along the fluid solid interface because 
both the fluid and solid mesh have different resolution requirements. The sequential weak coupling method supports load transfer across a dissimilar mesh. The weak coupling algorithm uses a linear search algorithm for the global search to locate the nodes belonging to finite element mesh. Two interpolation methods are available for load transfer. The interpolation method determines the quantities that are transferred at the interface.

Conservative Interpolation

In conservative interpolation the heat rate and the force in the three coordinate directions was transferred from the fluid to solid. Here the quantities are transferred as loads for the solid analysis. Displacements, temperatures and mesh velocity are transferred to fluid from solid.

Non-Conservative Interpolation

Heat flux and force density are transferred from fluid to solid in this interpolation. Displacements, temperatures and mesh velocities are transferred from solid to fluid. In our analysis we used non-conservative interpolation.

\subsection{Fluid and Solid elements}

The fluid elements used for fluid-solid interaction analysis are FLUID 141 and FLUID 142. FLUID141 is used for a 2-Dimensional problem and FLUID142 is used for 3-Dimensional problems. The fluid-solid interaction analysis uses structural, thermal or coupled field elements for the solid elements. The structural elements include Plane, Solid, Beam, Shell and Hyper elements. Thermal and coupled-field elements include Plane, Solid and Shell elements.

In our analysis FLUID141 is used for the fluid element and PLANE 82 is used for the solid element. 


\subsubsection{Performing fluid solid interaction analysis}

The procedure for doing a fluid-solid interaction analysis consists of five main steps. They are: - (1) creating finite element model of solid and fluid, (2) flag fluid-solid interface, (3) specifying fluid - solid interaction boundary condition, (4) obtaining the results and (5) post processing the results [10].

The first step was to model both the fluid part and the solid part.

Then the fluid part was assigned to flotran elements and the options to those elements are assigned depending upon the analysis. The fluid properties such as density, viscosity and bulk modulus are specified to the element and then meshed. Then the solid part was assigned to structural, thermal and coupled filed elements. A structural element was used in our analysis. The material property such as density, young's modulus and Poisson ratio was specified to the element and meshed.

The next indent was to give boundary condition and specifying fluid solid interface. The boundary condition was specified for both the fluid and solid elements. The fluid solid interface flag was used twice once for the fluid side and one for the solid side. The same interface number should be applied for both the fluid and solid interface where the load transfer takes place. Then the solution options such as convergence, relaxation, and time increment and end time are specified for the fluid solid interaction analysis and then the analysis was run.

\subsubsection{Solution options for fluid-solid interaction analysis}

Basic Analysis Option:

The fluid-Solid Interaction analysis was turned on and the solution order was defined for the fluid and solid analyses. The solution order determines which analysis is first solved. The type of analysis (transient or static) was specified for both 
the fluid and solid. Then interpolation method was specified for load transfer across the fluid-solid interface. Commands used for these operations are FSAN - Used to turn the fluid solid interaction analysis on or off.

FSOR - Used to set the solution order for the fluid and solid analyses.

The default is a fluid analysis followed by a solid analysis. In our analysis the solid analysis is followed by fluid analysis.

FSTR command was used to specify whether an analysis is static or transient. Default is transient analysis.

FSIN command was used to specify a conservative or non-conservative interpolation for the load transfer across the fluid-solid interface.

End time and time Increment:

The end time and the time step increment for the analyses are specified in this step. The FSTI command was used to specify the end time. The end time should always be a multiple of the time step increment. FSDT command was used to specify a time step increment. The sequential weak coupling method only supports constant time stepping. The DELTIM and FLDATA command was used to specify the time step increment for the solid and fluid analyses. The time step increment for the solid and fluid should be less than or equal to the time step increment for the fluid-solid interaction analysis.

Number of Iterations:

The maximum number of staggers iterations between the fluid and solid analysis should be specified for the fluid solid interaction analysis. At the end of each stagger loop, the weak coupling algorithm checks the convergence of the quantities 
transferred across the interface. The analysis proceeds to the next time step if the interface quantities have converged or the maximum numbers of stagger iterations has been reached. FSIT command was used to set the maximum number of stagger iteration.

Convergence:

The Convergence norm for the quantities transferred at the fluid -solid interface was specified for the fluid structure analysis. The quantities transferred at the interface depend upon the interpolation algorithm. FSCO command was used to specify the convergence value. The default is 0.0001 [10]. The convergence indicator for the interface quantities was computed by

$$
\text { Conv }=\log \left(\in_{\mathrm{x}} / \epsilon_{\min }\right) /\left(\log \in_{\max } / \in_{\min }\right)
$$

$\epsilon_{\mathrm{x}}$ - The convergence form of each of the interface quantities being transferred across the fluid solid interface.

$\epsilon_{\min }$ - The convergence criteria specified by FSCO

$\epsilon_{\max }$ - The divergence threshold.

The divergence threshold is set to 100 for the calculation.

Convergence for an interface quantity was defined by following conditions

When $\epsilon_{\mathrm{x}}<=\epsilon_{\min , \text { Conv }}<=0$ the convergence criteria was satisfied.

When $\epsilon_{\mathrm{x}}>=\epsilon_{\max }$, Conv $>=1$ and the solution was diverging.

The output frequency was applied to the fluid results file (Jobname.RFL) and the solid results file (Jobname.RST). The results for every time step are written to the fluid result file and solid result file. FSOU command was used to specify the output frequency. 
Relaxation:

The relaxation value was set for the load, displacement, and temperature and heat fluxes across the fluid solid interface.

FSRE command was used to specify the relaxation value.

FSST command was used to check the status of the fluid-solid interaction analysis options.

Restarting analysis:

The solution to the analysis can be obtained by issuing the SOLVE command. The fluid- solid interaction analysis can be restarted from either the last time step or the last converged solution in the results file.

FSRS command was used to specify the restart value.

Fluid solid interaction analyses do not support the multi-frame restart in structural analysis.

Post Processing the Results:

The results can be post processed by resuming the database. The results can be reviewed using ANSYS POST1 or POST26 commands. For animation POST1 command was used. For plotting graph POST26 command was used. Simultaneous post processing of the fluid and solid results files is not supported.

\subsection{Limitations of fluid solid interaction analysis}

1. Only the elements specified in the above list can be used for the fluid solid interaction analysis.

2. Shell and Beam elements can have fluid solid interaction only on one side.

3. The Distributive Domain solver cannot be used for fluid-solid interaction analyses. 
4. The structural damping specified for the solid using ALPHAD and BETAD will damp the oscillations of the structural regions.

\subsection{Distributed Resistance}

The term-distributed resistance refers to the macroscopic representation of geometric features not directly concerned with the region of interest. An example is a pipe flow, which encounters a screen. The distributed resistance to an element can be applied through real constants [11]. A distributed resistance is an easiest way to approximate the effect of porous media without actually modeling the geometry of those features. The resistance to flow modeled, as a distributed resistance is due to combinations of three factors, which are localized head loss $(\mathrm{K})$, friction factor $(\mathrm{f})$ or Permeability $(\mathrm{C})$ [11]. The total pressure gradient is the sum of three terms.

$$
\sigma \mathrm{P} / \sigma \mathrm{x}_{\text {resistance }}=\mathrm{K} \rho \mathrm{v}_{\mathrm{x}}|\mathrm{V}|+\mathrm{f} / \mathrm{D}_{\mathrm{h}} \rho \mathrm{v}_{\mathrm{x}}|\mathrm{V}|+\mathrm{C} \mu \mathrm{v}_{\mathrm{x}}
$$

Where

$\rho=$ Density $\left(\right.$ mass $/$ Length $\left.^{3}\right)$

$\mu=$ Viscosity (mass/ (length*time))

$\mathrm{RE}=$ Local value of Reynolds number. $(\mathrm{RE}=\rho \mathrm{V} \mathrm{Dh} / \mu)$

$\mathrm{V}=$ Velocity

$\mathrm{v}_{\mathrm{x}}=$ Velocity of the flow in the X-direction

$\mathrm{f}=$ Friction Coefficient $\left(\mathrm{f}=\mathrm{a} \mathrm{RE}^{-\mathrm{b}}\right)$

The program calculates the Reynolds number and friction coefficient. 


\section{Validation}

\subsection{Fluid solid interaction analysis in a piston cylinder arrangement}

A simple 2-D fluid solid interaction analysis was performed to note down how the load transfer takes place and how the behavior of the fluid changes with respect to load. A piston cylinder arrangement was modeled and the piston and fluid had dissimilar mesh interface. The number of nodes in the fluid element was higher than the number of nodes in the solid element. The piston displacement was prescribed by a sinusoidal distribution in time (asin $\omega t)$. The analysis was done for different amplitude (a) and angular velocity $(\omega)$ values. The pressure variation for the fluid element for different values of angular velocity and amplitude are noted and graphs are drawn between pressure and time. The boundary condition of the problem is shown in Figure 8.

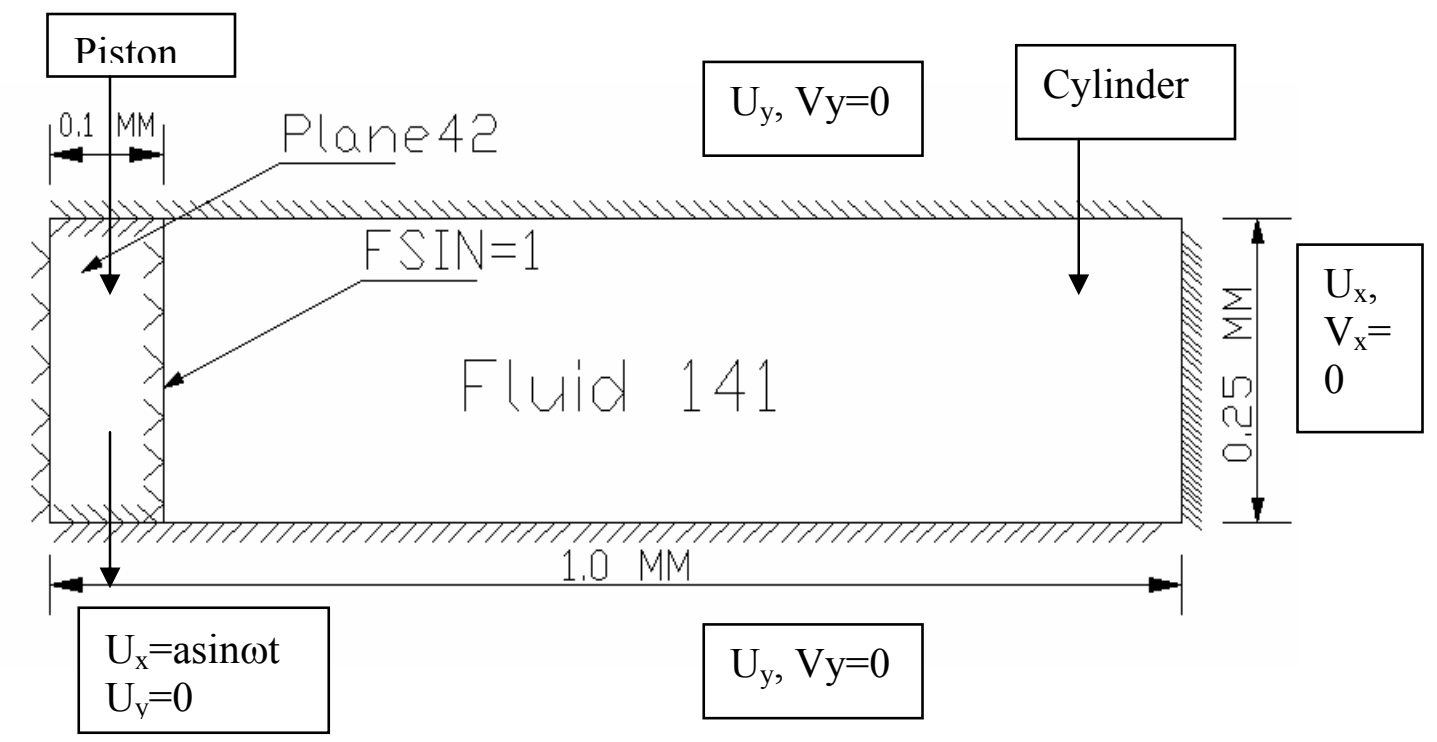

Figure 8 Piston and cylinder arrangement with boundary conditions 
Problem Specification:

The cylinder and piston dimensions are as follows

Cylinder length $=1.0 \mathrm{~mm}$

Cylinder diameter $=$ Piston height $=0.25 \mathrm{~mm}$

Material properties:

Young's modulus $=2.0 \mathrm{e} 11 \mathrm{~N} / \mathrm{mm}^{2}$

Density $=7800 \mathrm{~kg} / \mathrm{mm}^{3}$

Poisson's ratio $=0.3$

Fluid Properties:

Nominal density and viscosity

Boundary Conditions

Boundary condition for the fluid element (FLUID141)

At $\mathrm{x}=1.0 \mathrm{~mm}, \mathrm{U}_{\mathrm{x}}, \mathrm{V}_{\mathrm{x}}=0$

At $\mathrm{y}=0 \mathrm{~mm}, \mathrm{U}_{\mathrm{y}}, \mathrm{V}_{\mathrm{y}}=0$

At $\mathrm{y}=0.25 \mathrm{~mm}, \mathrm{U}_{\mathrm{y}}, \mathrm{V}_{\mathrm{y}}=0$

At $x=0.1 \mathrm{~mm}, \mathrm{FSIN}=1.0$

Boundary condition for the solid element (PLANE42)

At $x=0.1 \mathrm{~mm}, \mathrm{FSIN}=1.0$

At all the exterior nodes $\mathrm{U}_{\mathrm{y}}=0$ and $\mathrm{U}_{\mathrm{x}}=\mathrm{a}^{*} \sin { }^{*} \omega * \mathrm{t}$

Where

$\mathrm{a}=$ amplitude

$\omega=$ angular velocity

$\mathrm{t}=$ time 
Modeling:

The fluid part was modeled and the element FLUID141 was assigned to it. The Arbitrary Euler Lagrangian (ALE) option was made on for the FLUID141 element. Then the element was meshed and the boundary conditions are given to the fluid element. The fluid element has 45 nodes and the solid element has 12 nodes. The fluid solid interaction boundary condition was given to the nodes of the fluid part where the fluid interacts with the piston. Then the solid part was modeled and PLANE 42 element was assigned to it. The number of nodes in the solid element is lesser than the number of nodes in the fluid element. The material properties such as Young's Modulus, Poisson ratio and density are defined for the solid element. Then the model was meshed and the boundary conditions are given to it. The exterior nodes of the solid part are selected and it was given a sinusoidal displacement in the $\mathrm{X}$-direction and the displacement in the $\mathrm{Y}$ direction was constrained. The fluid solid interaction was given on the nodes of the solid part where it interacts with the fluid. The fluid properties and the solution options such as convergence value, relaxation value, output frequency, time increments and end time were specified after that and then the analysis was solved.

\subsubsection{Varying the amplitude}

The analysis was done for different amplitude values $\mathrm{a}=0.85,0.5$, and

$0.25 \mathrm{~mm}$. For all these values the angular velocity $\left(\omega=2.5 \mathrm{sec}^{-1}\right)$ was kept constant. The end time of the analysis depends on the angular velocity values.

$$
\begin{gathered}
2 * \pi * \mathrm{f}=\omega \\
\mathrm{f}=1 / \mathrm{t} \\
2 * \pi / \mathrm{t}=\omega \\
\mathrm{t}=2 * \pi / \omega
\end{gathered}
$$


Where,

$\mathrm{t}=$ end time for the analysis

$\omega=$ angular velocity.

Here the analysis was done only for half of the time cycle and the pressure variation in the fluid was noted down. The pressure variation along the cylinder and the von mises stress acting on the piston was noted down and the image was plotted as shown below.

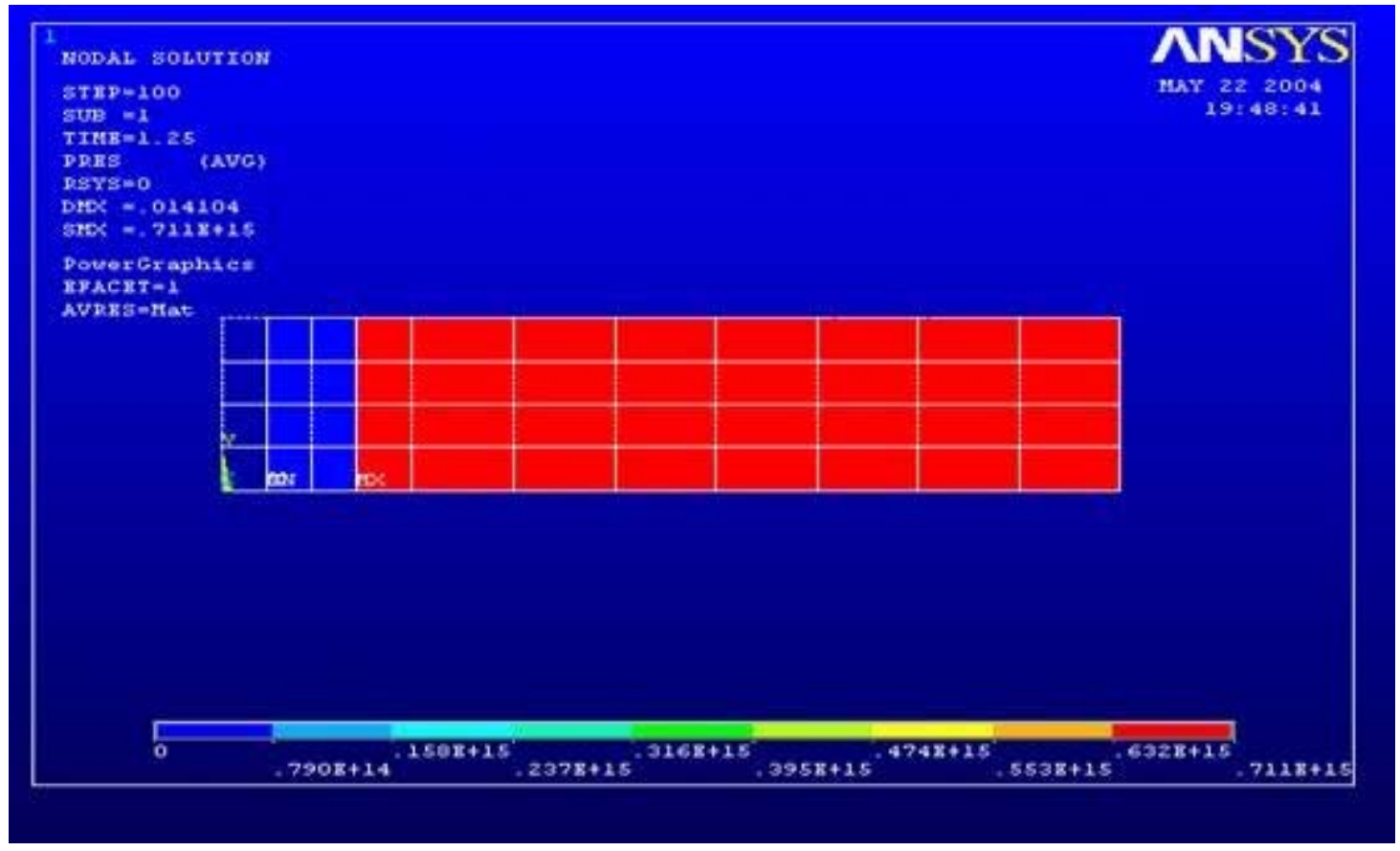

Figure 9 Pressure plot for the fluid element when amplitude is $0.85 \mathrm{~mm}$ and angular velocity is $2.5 \mathrm{sec}^{-1}$ 
$7 \mathrm{rrx}-1.25$

$3 x 0 y$

prox $=014104$

$\operatorname{srdx}=504 \mathrm{x}+0 \mathrm{7}$

Pouercraphics

BFACET $=1$

AYpzsmint

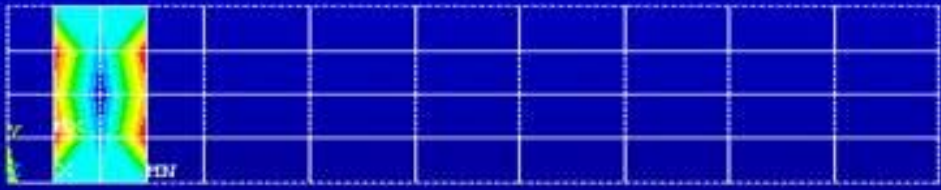

Figure 10 Von mises stress acting on the solid element when amplitude is $0.85 \mathbf{~ m m}$ and angular velocity is $2.5 \mathrm{sec}^{-1}$

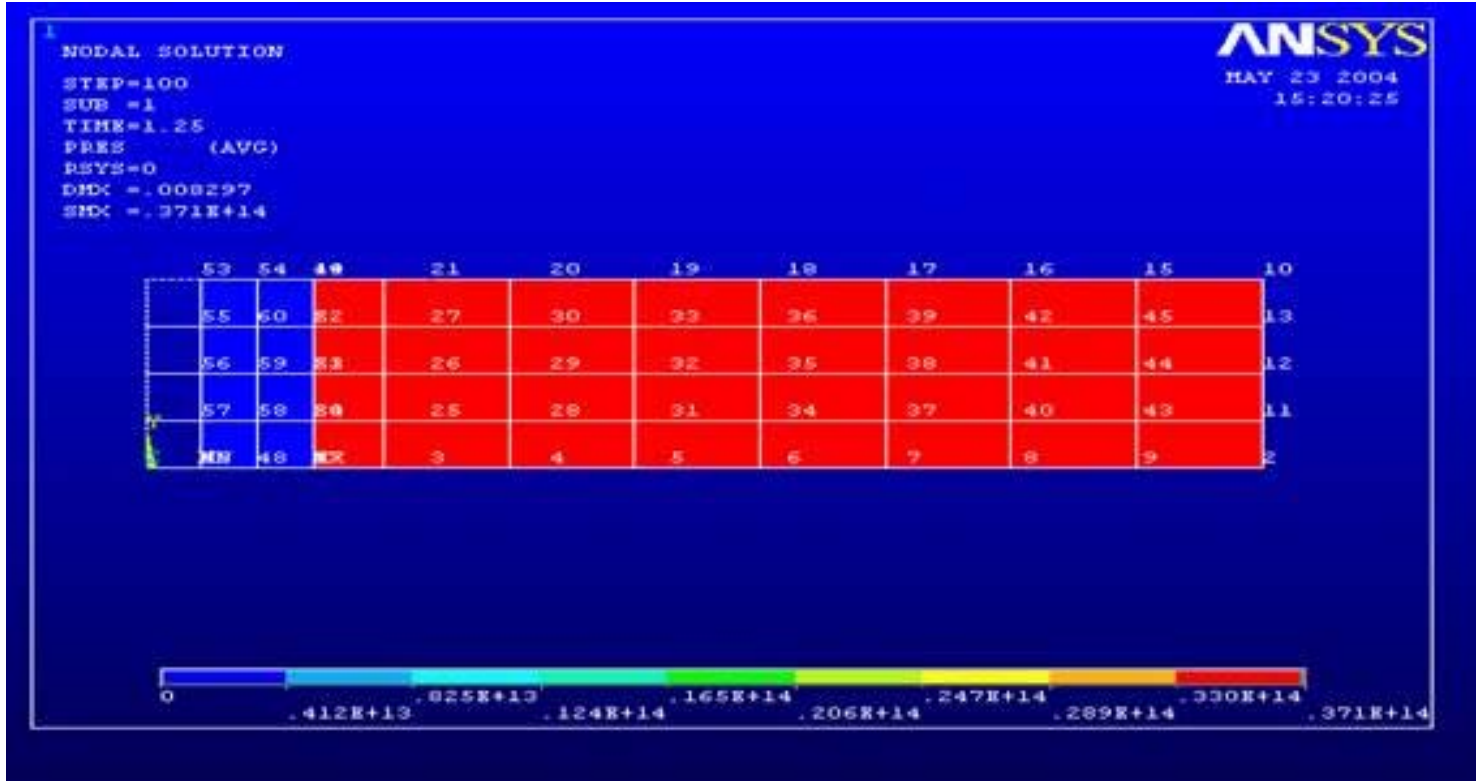

Figure 11 Pressure plot for the fluid element when amplitude is $0.5 \mathrm{~mm}$ and angular velocity is $2.5 \mathrm{sec}^{-1}$ 


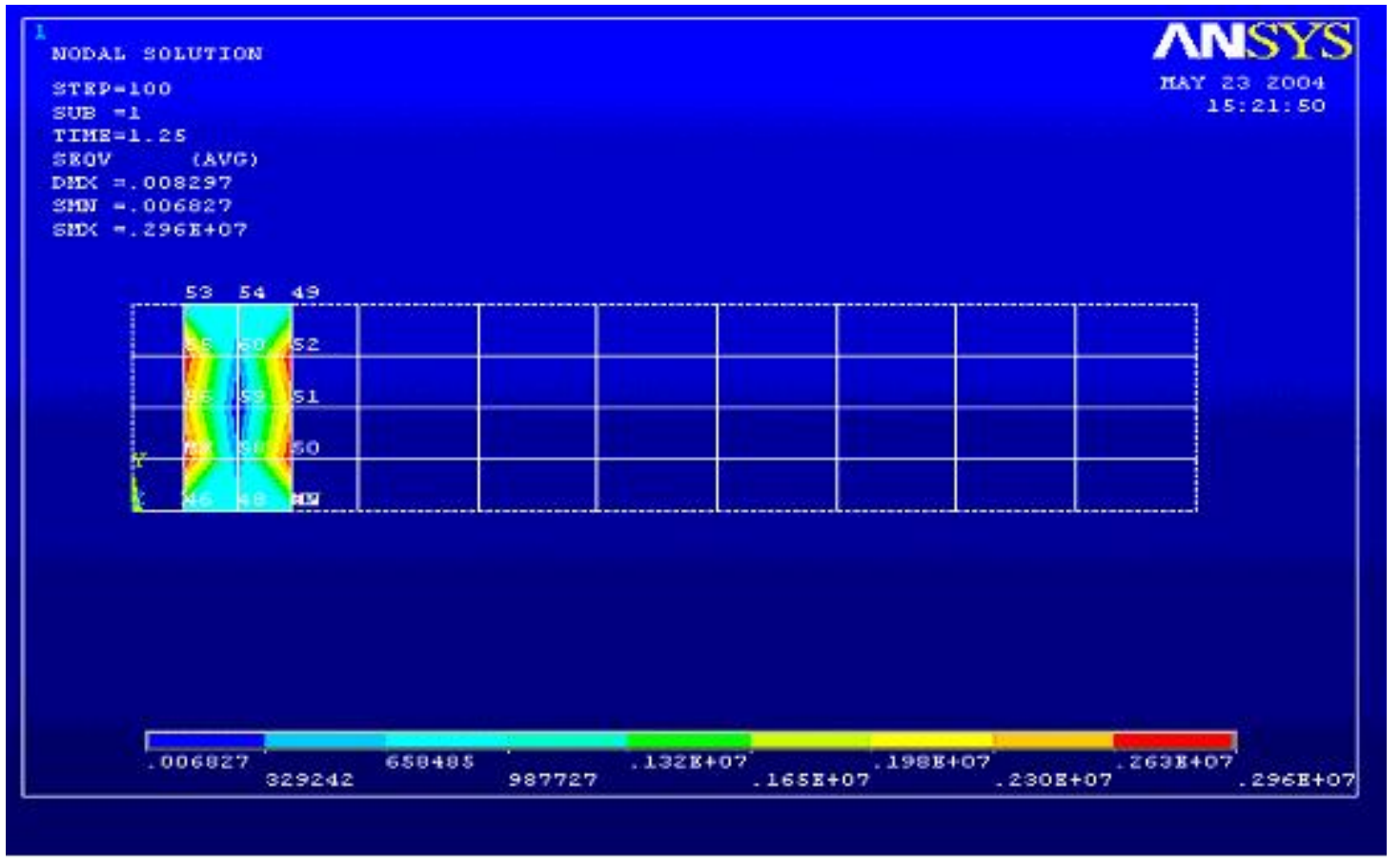

Figure 12 Von mises stress acting on the solid element when amplitude is $0.5 \mathbf{~ m m}$ and angular velocity is $2.5 \mathrm{sec}^{-1}$

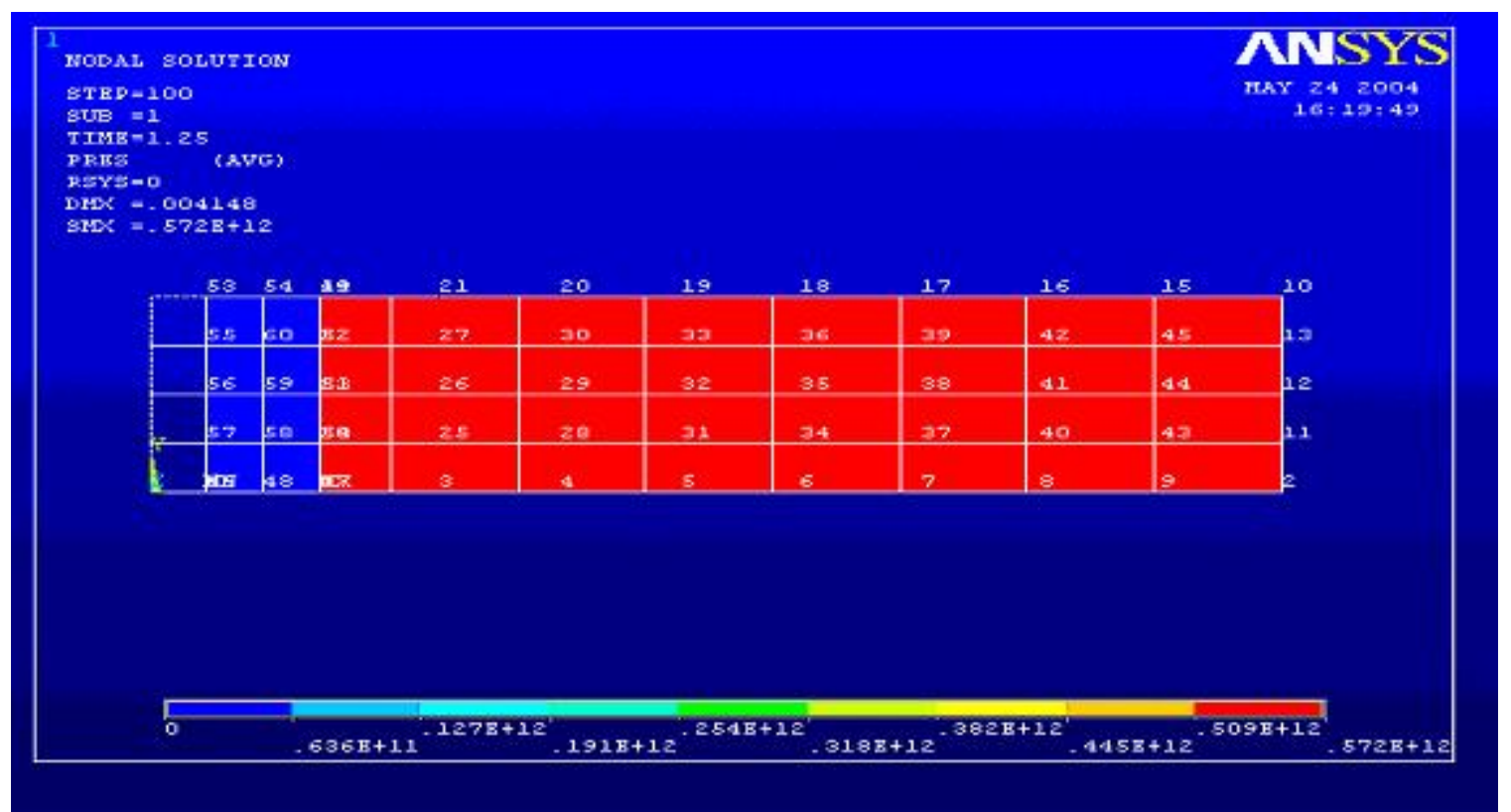

Figure 13 Pressure plot for the fluid element when amplitude is $0.25 \mathbf{~ m m}$ and angular velocity is $2.5 \mathrm{sec}^{-1}$ 


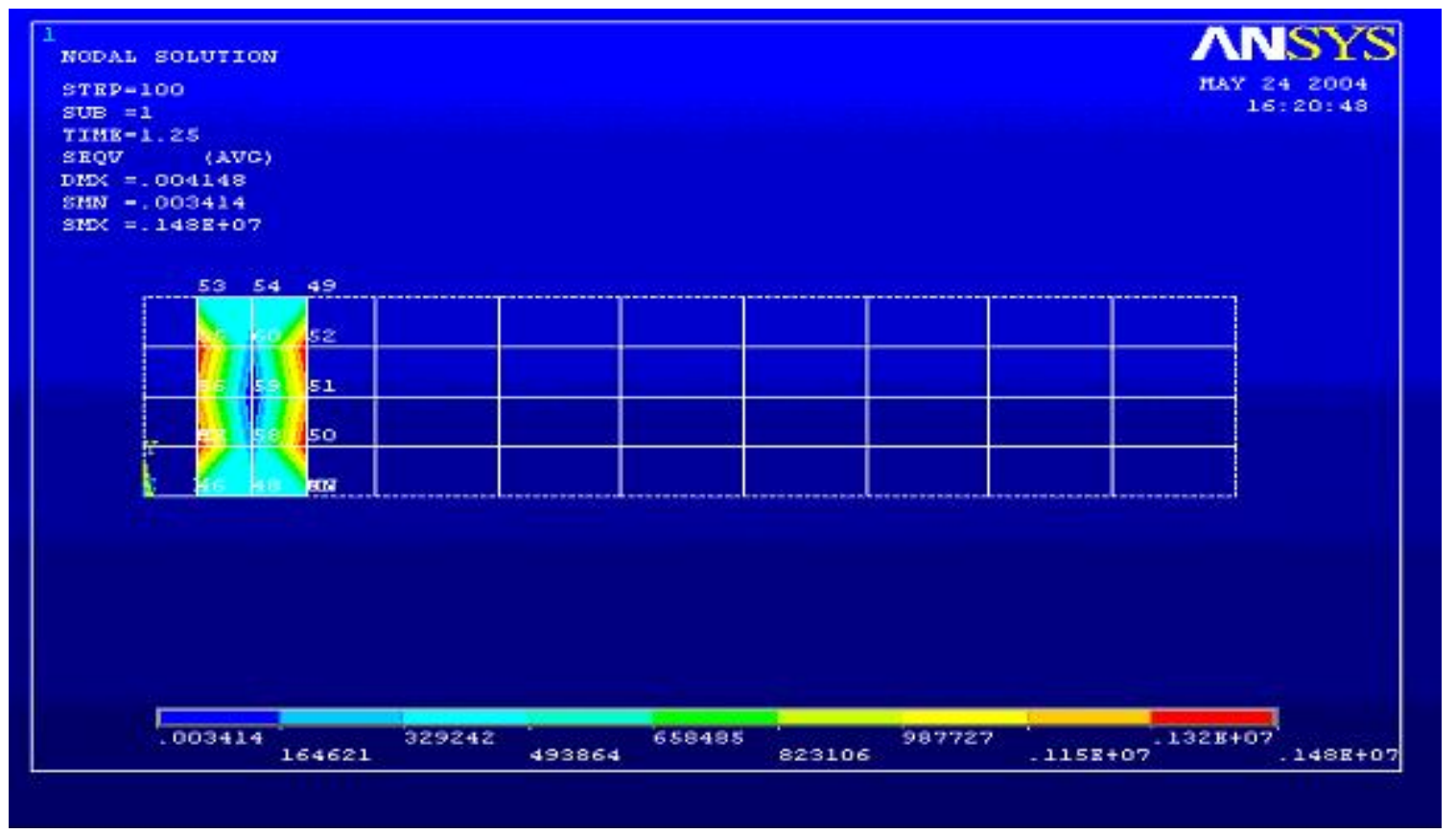

Figure 14 Von mises stress acting on the solid element when amplitude is $0.25 \mathrm{~mm}$ and angular velocity is $2.5 \mathrm{sec}^{-1}$

Variation of pressure for different amplitude

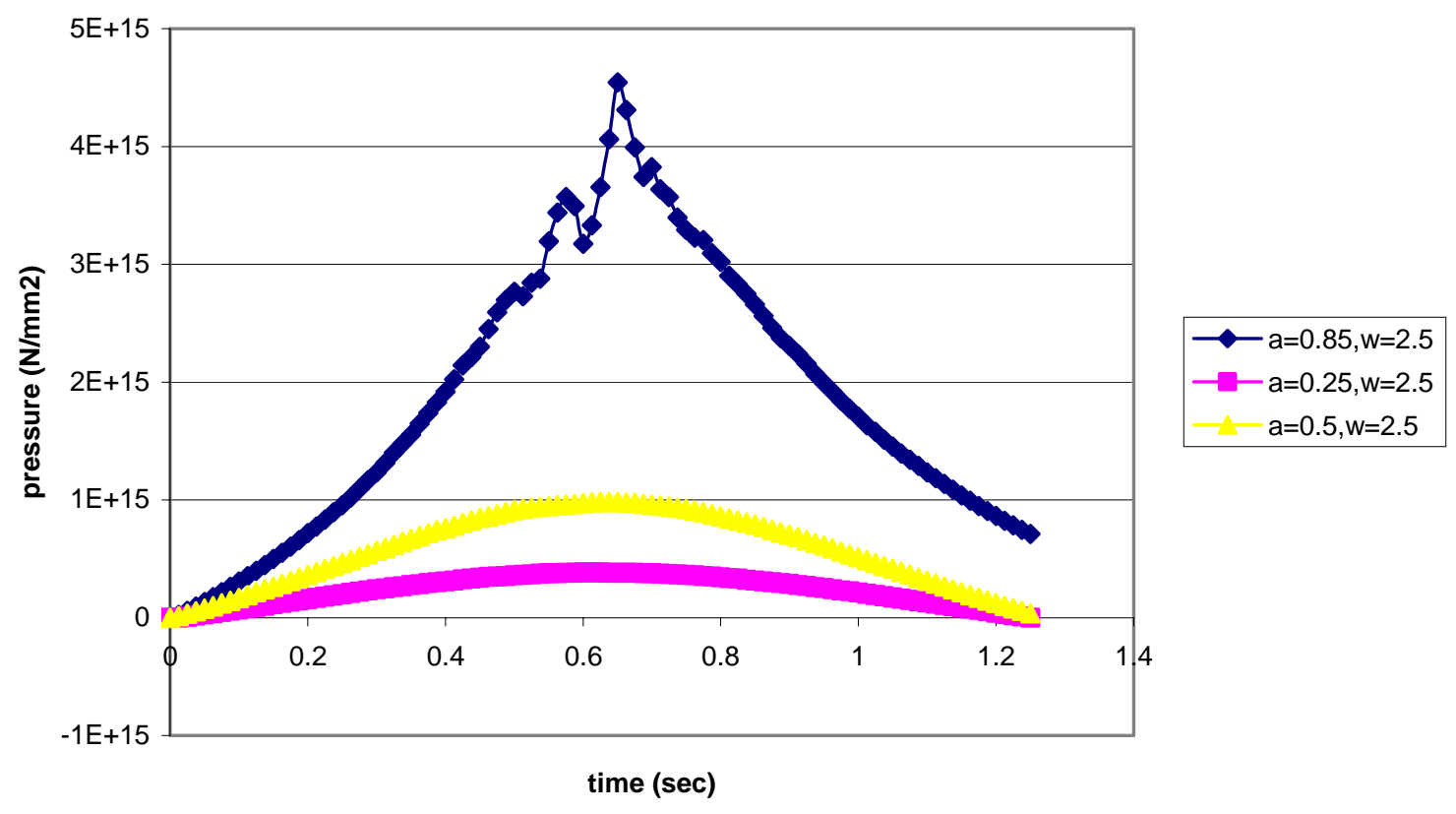

Figure 15 Pressure variations for the fluid element for different amplitude at node 35 in the center of the cylinder 
Observation:

From the above images and graph the following observations are made

1. The peak value of the pressure increases with increase in amplitude.

2. The pressure was uniform through out the length of the cylinder.

3. The von mises stress increases with increase in amplitude.

4. The variation in pressure over time became smooth with decrease in amplitude. This is expected because with the decrease in amplitude the piston movement becomes smooth and the variation of pressure also becomes smooth. Varying the angular velocity

The analysis was done for different angular velocities $\left(1.5,2.5\right.$ and $3.0 \mathrm{sec}^{-}$ $\left.{ }^{1}\right)$. The amplitude value was kept constant for all these analysis. The end time required for solving the analysis changes with change in angular velocity. The Pressure variation along the length of the cylinder and the Von mises stress acting on the piston was noted and the image was plotted as shown below. Graph was drawn to show the variation of the pressure with respect to time for different angular velocity values. 


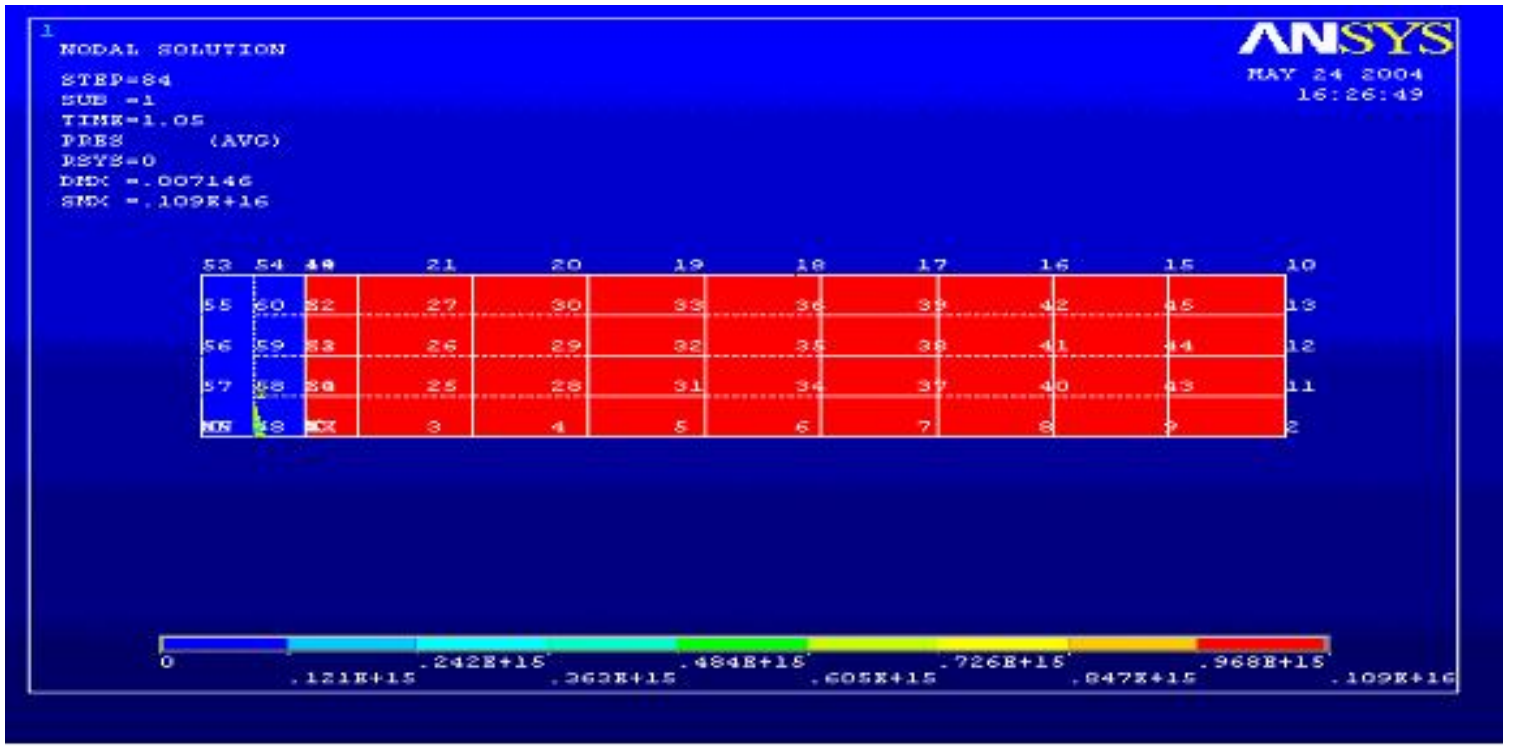

Figure 16 Pressure plot for fluid element when amplitude is $0.85 \mathrm{~mm}$ and angular velocity is $3.0 \mathrm{sec}^{-1}$

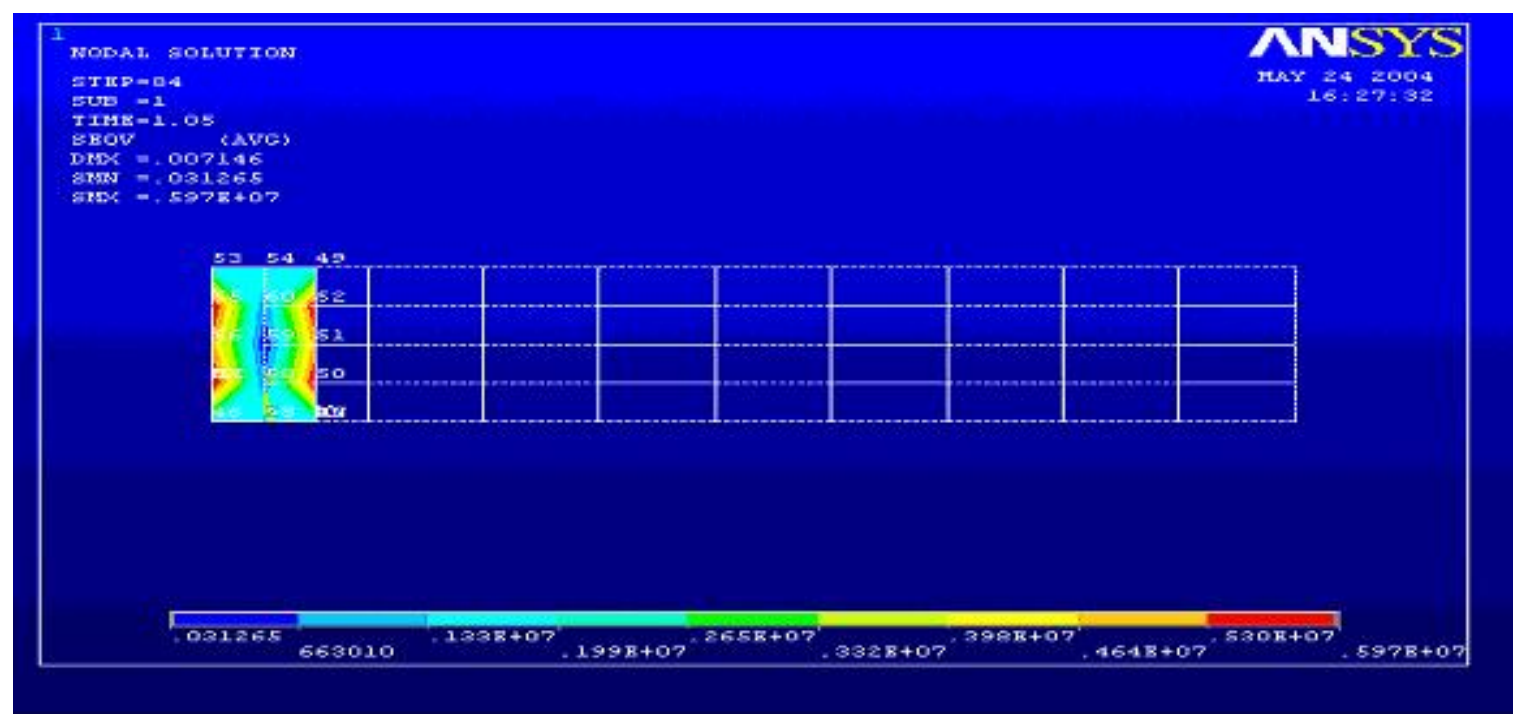

Figure 17 Von mises stress on the solid element when amplitude is $0.85 \mathrm{~mm}$ and angular velocity is $3.0 \mathrm{sec}^{-1}$ 
DrCX $=.007146$

$\sin \pi \cdot 233 z+16$

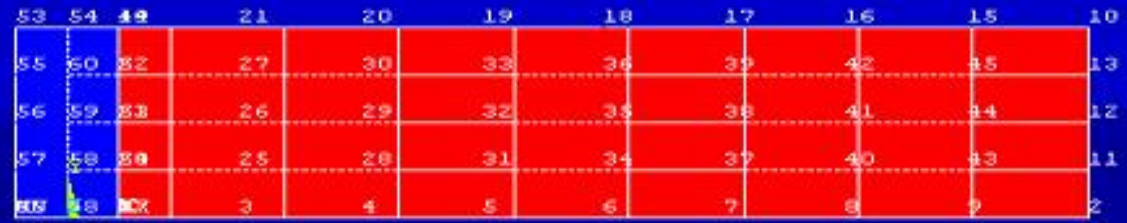

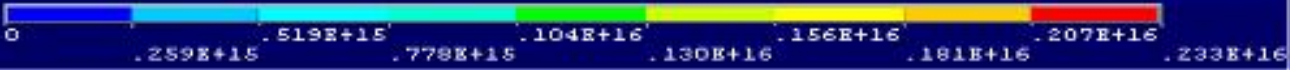

Figure 18 Pressure plot for the fluid element when amplitude is $0.85 \mathrm{~mm}$ and angular velocity is $1.5 \mathrm{sec}^{-1}$

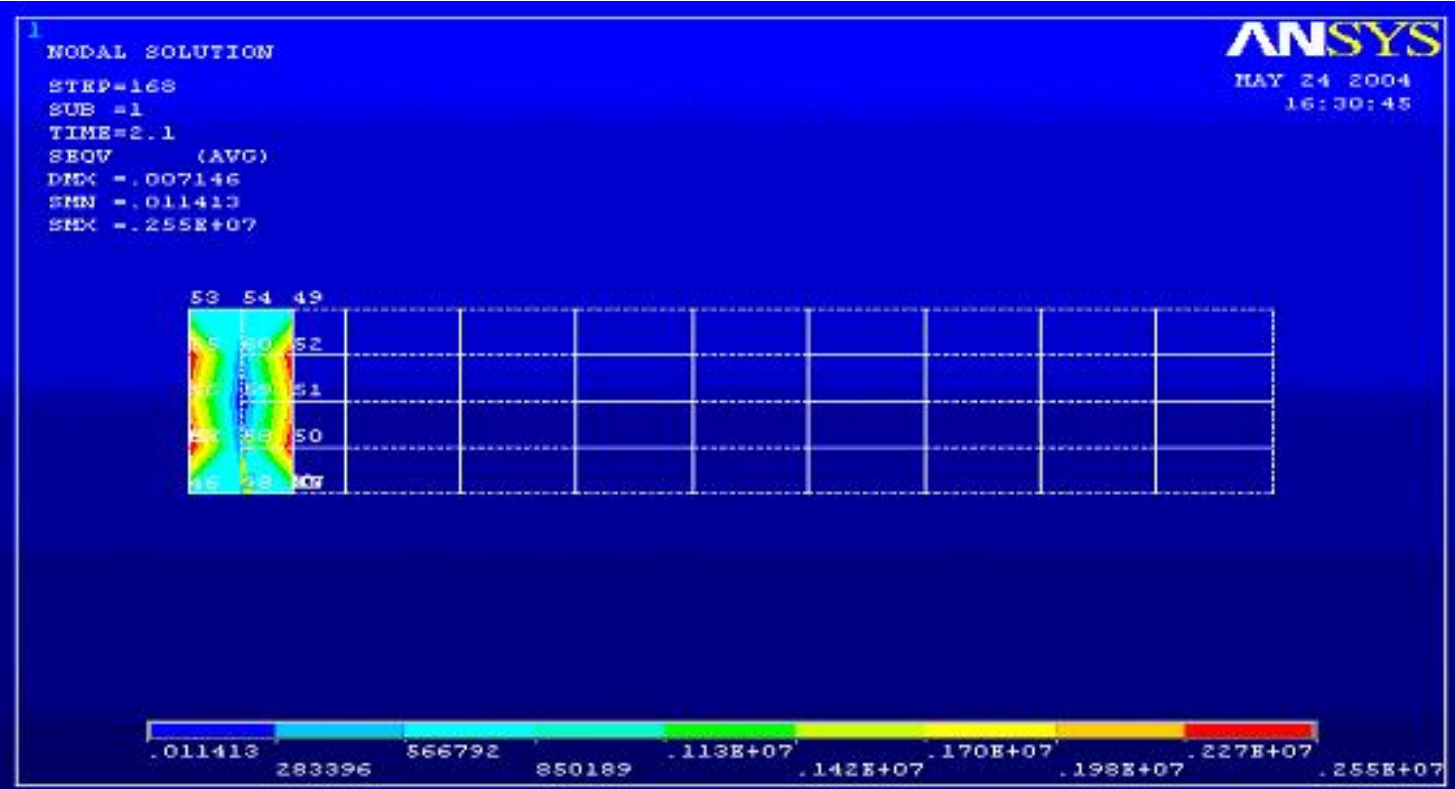

Figure 19 Von mises stress acting on the solid element when amplitude is $0.85 \mathbf{~ m m}$ and angular velocity is $1.5 \mathrm{sec}^{-1}$ 
Variation of pressure for different angular velocities

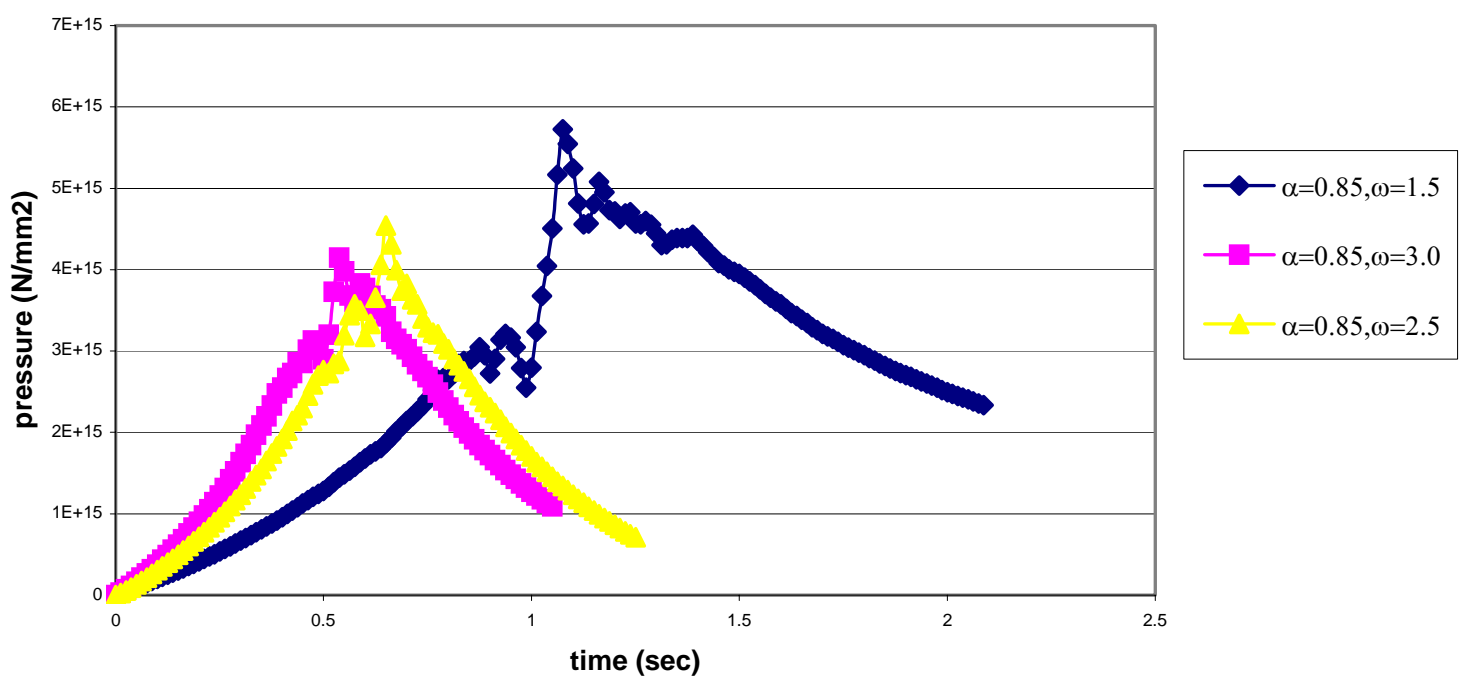

Figure 20 Pressure variations for the fluid element for different angular velocity at node 35 in the center of the cylinder

Observation:

From the above images and graph the observation are made as follows

1. The pressure peak value increases with decrease in angular velocity.

2. The Von mises stress increases with increase in angular velocity

3. The pressure variation was uniform along the length of the cylinder

4. The variation in pressure over time was same irrespective of different angular velocity values. This is because the amplitude values are same for all these analysis and so the piston movement is also the same. 


\subsubsection{Conclusion}

As expected the peak value of pressure increases with increase in amplitude and the profile was smooth with decrease in amplitude. The pressure was same everywhere in the fluid element. The Von mises stress acting on the solid element increases with increase in amplitude and angular velocity.

\subsection{Analysis of a simplified oscillating plate}

\subsubsection{Without fluid solid interaction}

A simple $2 \mathrm{D}$ analysis was done without fluid solid interaction and the pressure variation of the fluid between two plates was noted down. The bottom plate was fixed and the top plate was given an up and down motion as shown in Figure 21. The fluid was present between the plates and the pressure at both the ends of the fluid was set to zero.

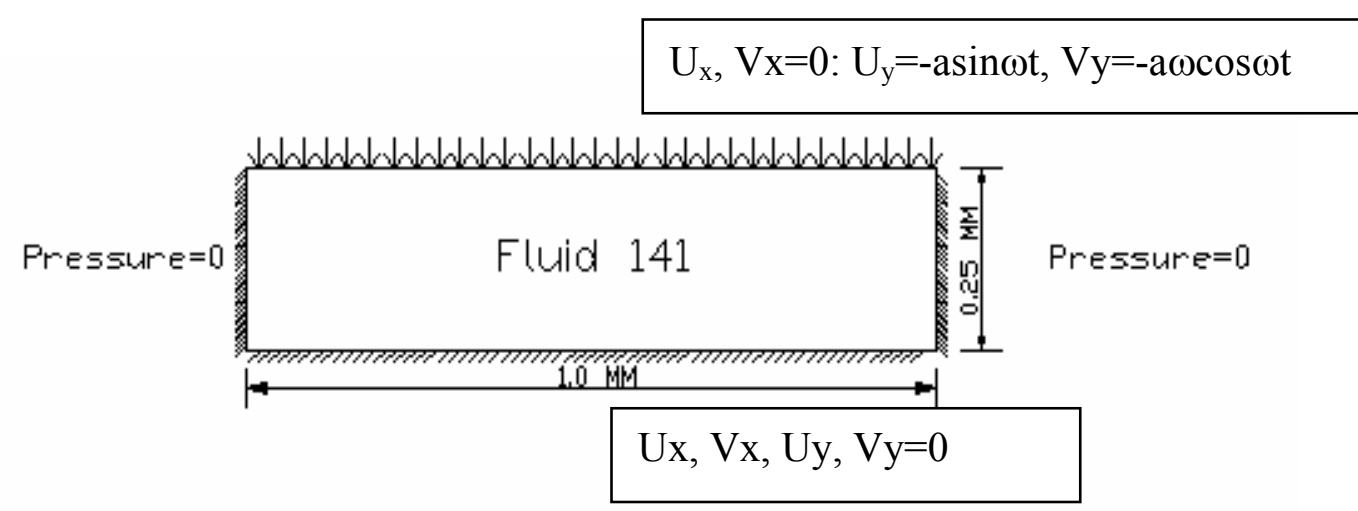

Figure 21 Boundary conditions for the model without fluid solid interaction

Problem Specification:

Length of the plate $=1 \mathrm{~mm}$

Distance between two plates $=0.25 \mathrm{~mm}$ 
Fluid Properties:

Nominal Density and Nominal Viscosity

Boundary Condition:

At $\mathrm{x}=0 \mathrm{~mm}$ and $\mathrm{x}=1 \mathrm{~mm}$ Pressure $=0 \mathrm{~N} / \mathrm{mm}^{2}$

At $\mathrm{y}=0 \mathrm{~mm}, \mathrm{U}_{\mathrm{x}}=\mathrm{U}_{\mathrm{y}}=\mathrm{V}_{\mathrm{x}}=\mathrm{V}_{\mathrm{y}}=0$

At $\mathrm{y}=0.25 \mathrm{~mm}, \mathrm{U}_{\mathrm{x}}=0, \mathrm{~V}_{\mathrm{x}}=0, \mathrm{U}_{\mathrm{y}}=-\mathrm{a} * \sin * \omega^{*} \mathrm{t}, \mathrm{V}_{\mathrm{y}}=-\mathrm{a}^{*} \omega^{*} \cos ^{*} \omega^{*} \mathrm{t}, \mathrm{ENKE}=-1$

Amplitude (a) is $0.0625 \mathrm{~mm}$ and angular velocity $(\omega)$ is $0.628 \mathrm{sec}^{-1}$

Modeling:

Fluid 141 was used for this analysis and the ALE option was made on for the fluid element. The properties for the fluid such as density and viscosity are specified and then meshed. The top and bottom nodes of the fluid element are considered as plates and the boundary conditions are given to them. The ENKE $=-1$ boundary conditions makes the top plate as a moving one. A sinusoidal displacement and velocity was applied to the top plate and the variation of pressure, displacement and velocity with time is noted down.

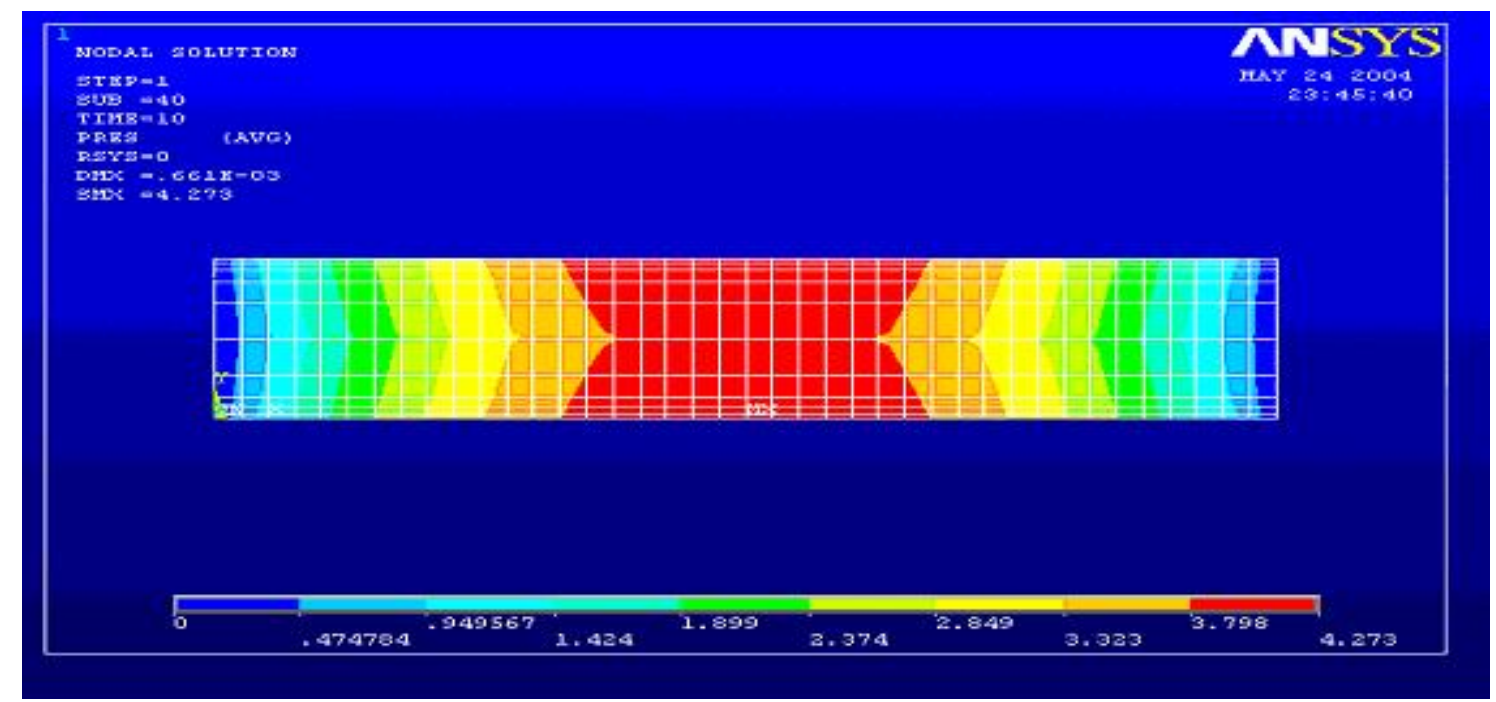

Figure 22 Pressure plot for the fluid element 


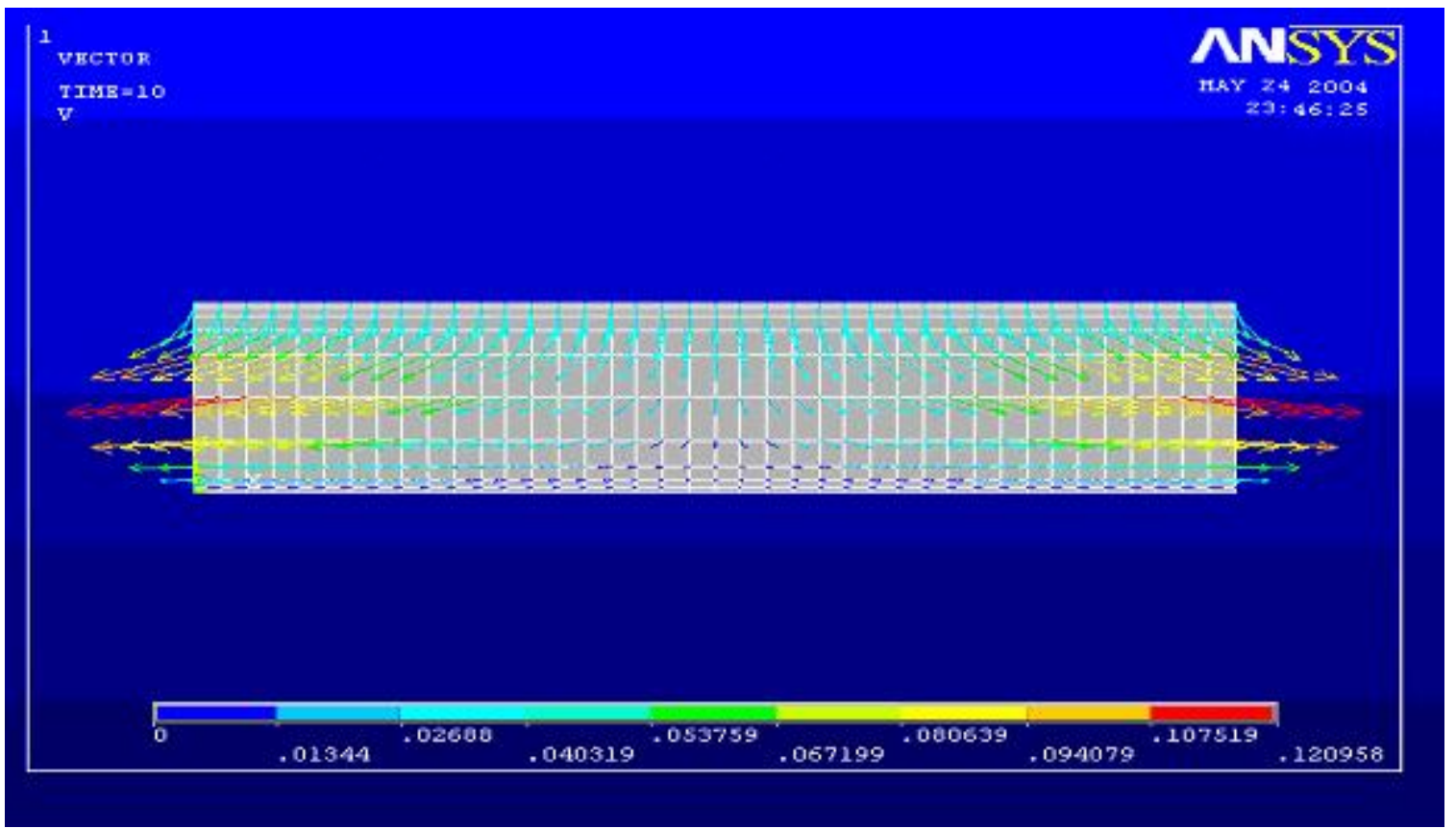

Figure 23 Vector plot for the fluid element

\subsubsection{With fluid solid interaction}

Here both the fluid and solid element was used for the analysis. The top plate was considered as a solid and a sinusoidal displacement and velocity was applied to it. Fluid solid interaction boundary condition was specified at the nodes where both the fluid and solid interacts $(\mathrm{y}=0.25 \mathrm{~mm})$ and the variation of pressure, displacement and velocity of the fluid was noted down. 


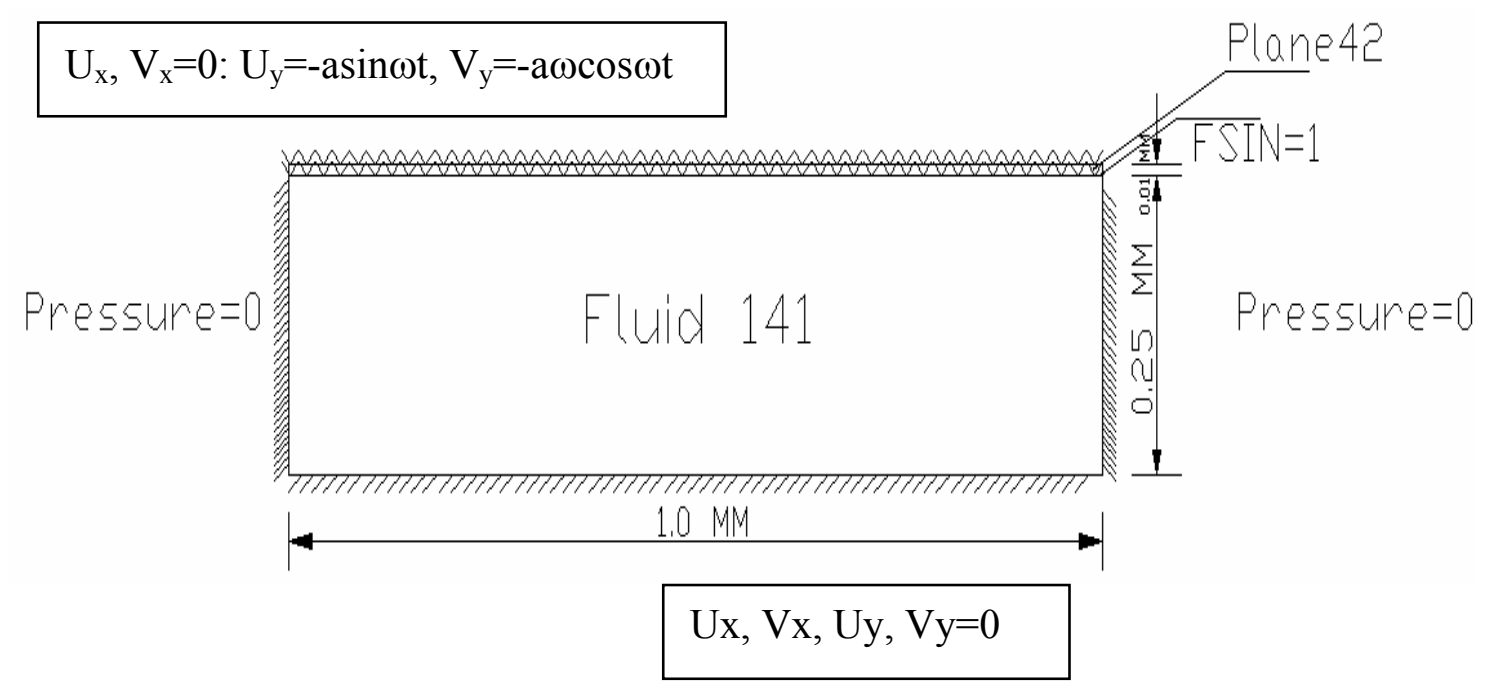

Figure 24 Boundary conditions for the model with fluid solid interaction

Problem Specification:

Plate dimensions

Plate length $=1.0 \mathrm{~mm}$

Gap between top plate and bottom plate $=0.25 \mathrm{~mm}$

Material properties:

Young's Modulus $=2.0 \mathrm{e} 11 \mathrm{~N} / \mathrm{mm}^{2}$

Density $=7800 \mathrm{~kg} / \mathrm{mm}^{3}$

Poisson ratio $=0.3$

Fluid Properties:

Nominal Density and Nominal Viscosity

Boundary Condition

At $\mathrm{x}=0 \mathrm{~mm}$ and $\mathrm{x}=1 \mathrm{~mm}$ Pressure $=0 \mathrm{~N} / \mathrm{mm}^{2}$

At $\mathrm{y}=0 \mathrm{~mm}, \mathrm{U}_{\mathrm{x}}=\mathrm{U}_{\mathrm{y}}=\mathrm{V}_{\mathrm{x}}=\mathrm{V}_{\mathrm{y}}=0$

At all the exterior nodes of the solid

$\mathrm{U}_{\mathrm{x}}=0, \mathrm{~V}_{\mathrm{x}}=0, \mathrm{U}_{\mathrm{y}}=\mathrm{a} * \sin * \omega * \mathrm{t}, \mathrm{V}_{\mathrm{y}}=-\mathrm{a} * \omega * \cos * \omega * \mathrm{t}$ 
amplitude $(\mathrm{a})=0.0625 \mathrm{~mm}$

angular velocity $(\omega)=0.628 \mathrm{sec}^{-1}$

Modeling:

PLANE 42 was assigned for the solid part and FLUID 141 was assigned to the fluid portion. ALE option was made on for the fluid element. The fluid element was meshed first and the boundary conditions are specified to all the nodes of the fluid element. The number of nodes in the fluid element is higher than the number of nodes in the solid element. The fluid solid interaction boundary condition was specified to the nodes of the fluid element where it interacts with the solid part. The fluid element interacts with the solid element at $y=0.25 \mathrm{~mm}$. The solid material properties are then defined and then meshed. The boundary conditions are then specified to all the nodes of the solid and the fluid solid interaction boundary condition is specified to the nodes where it interacts with the fluid. The fluid properties and the basic analysis option such as convergence, relaxation, output frequency, and time increment and end time were specified and the analysis was made to run. The variation of pressure, displacement and velocity with time was noted down. 


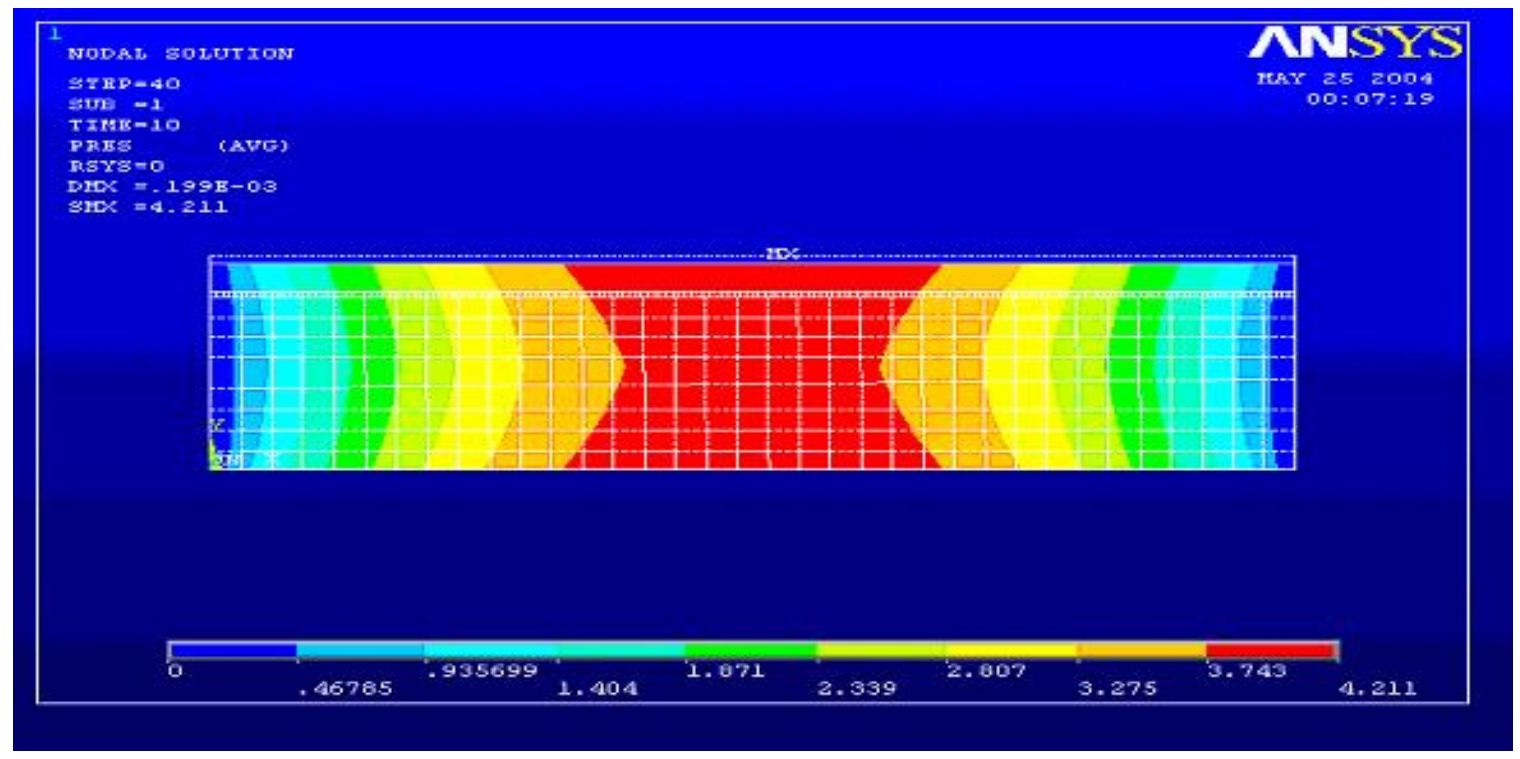

Figure 25 Pressure plot for the fluid element

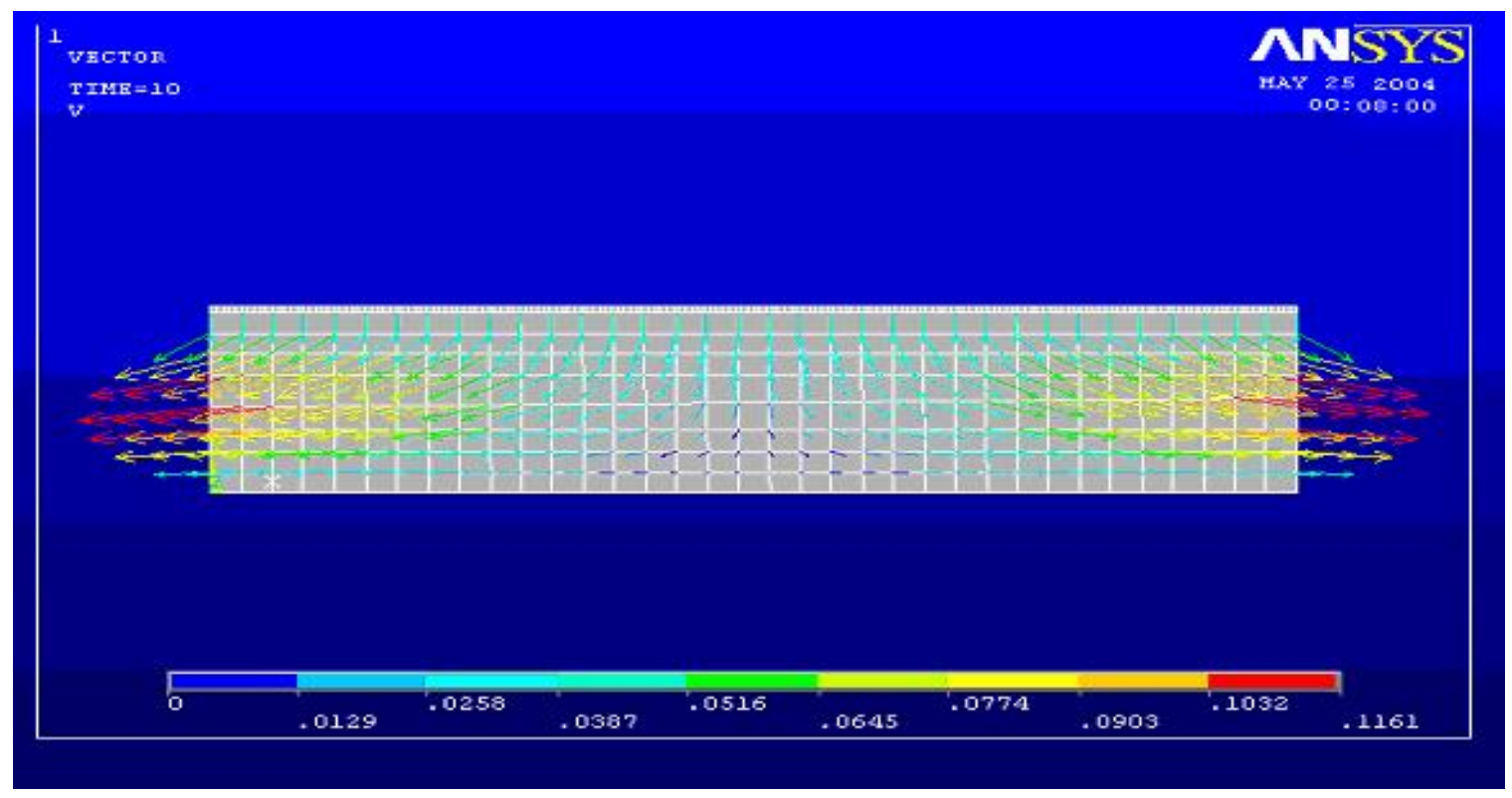

Figure 26 Vector plot for the fluid element 


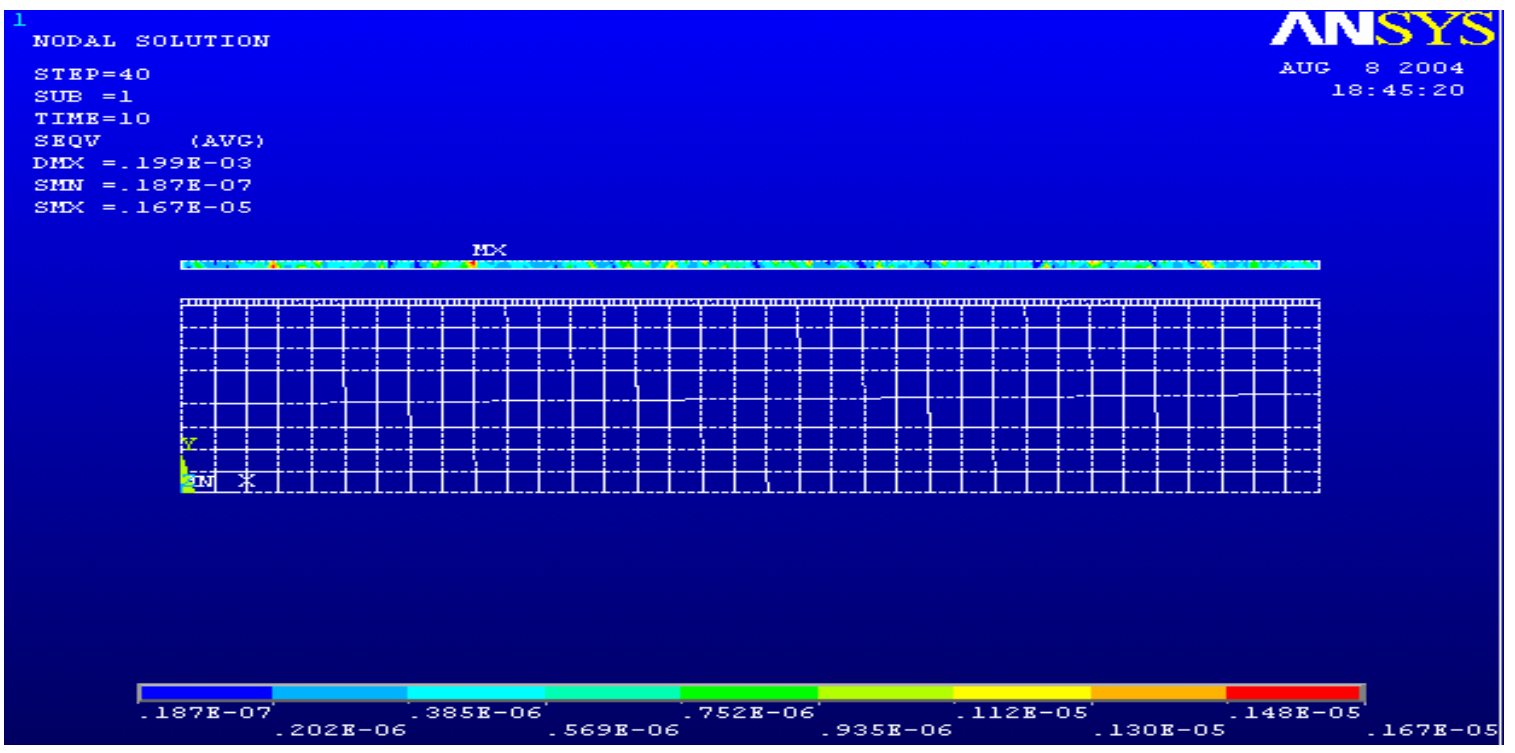

Figure 27 Von mises stress acting on the plate with fluid solid interaction analysis

\subsubsection{Comparing the results}

The results for both the analysis are taken and graphs are drawn between them. In both the analysis the applied displacement and velocity and the boundary conditions are the same.

Nodal pressure variation with and without fluid solid interaction with $a=0.0625$ $\mathrm{mm}, \omega=0.628 \mathrm{sec}^{-1}$

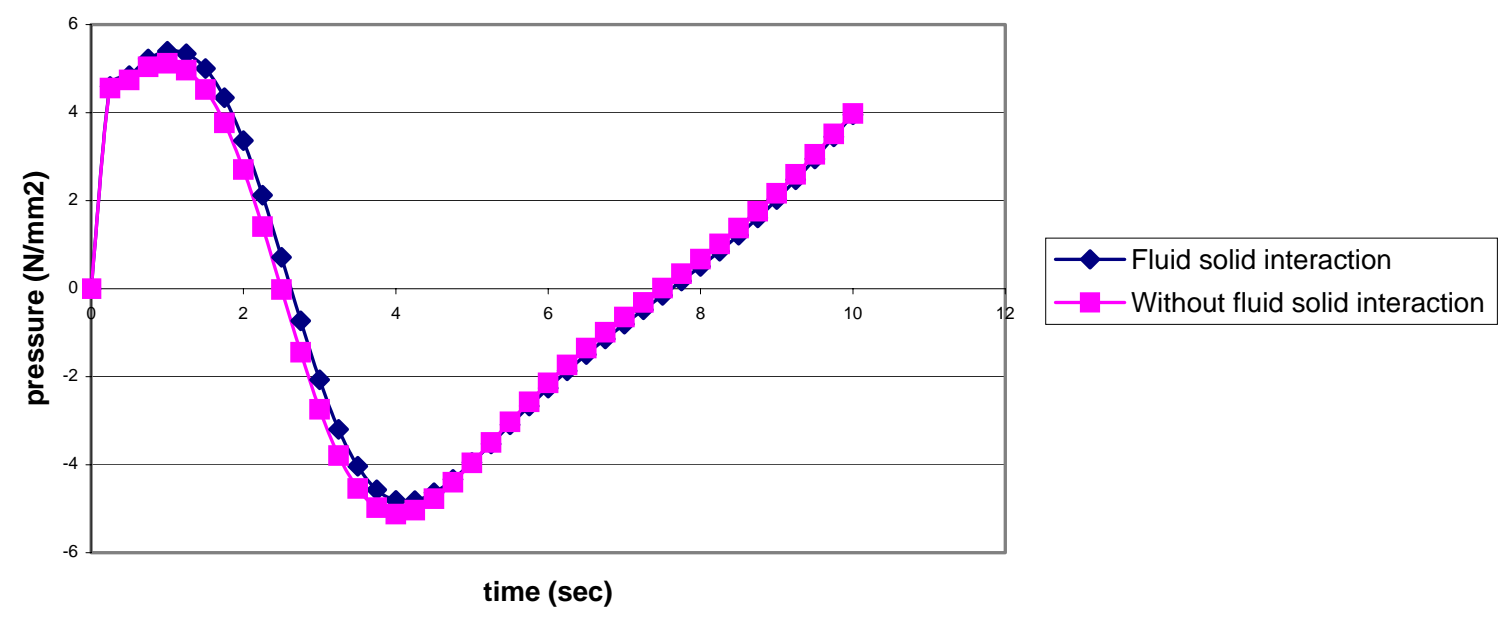


Nodal displacement with and without fluid solid interaction with $a=0.0625 \mathrm{~mm}, \omega=0.628 \mathrm{sec}^{-1}$

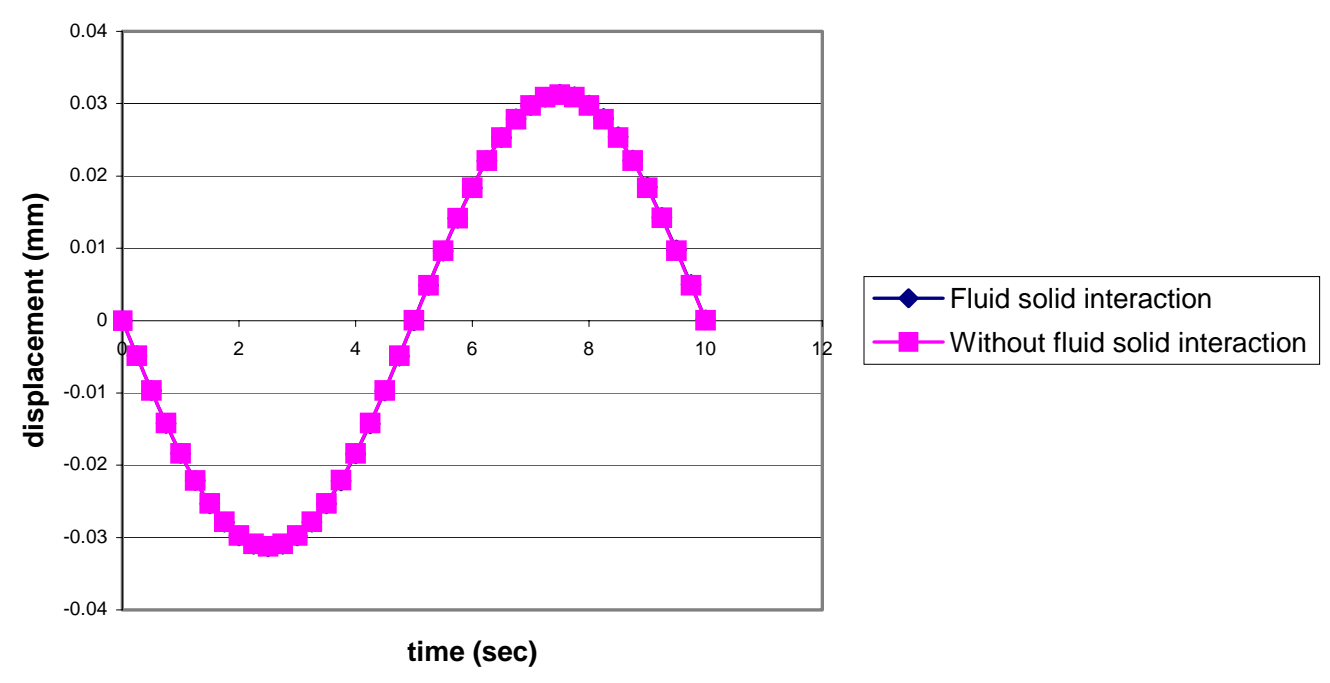

Nodal velocity with and without fluid solid interaction with $a=0.0625 \mathrm{~mm}, \omega=0.628 \mathrm{sec}^{-1}$

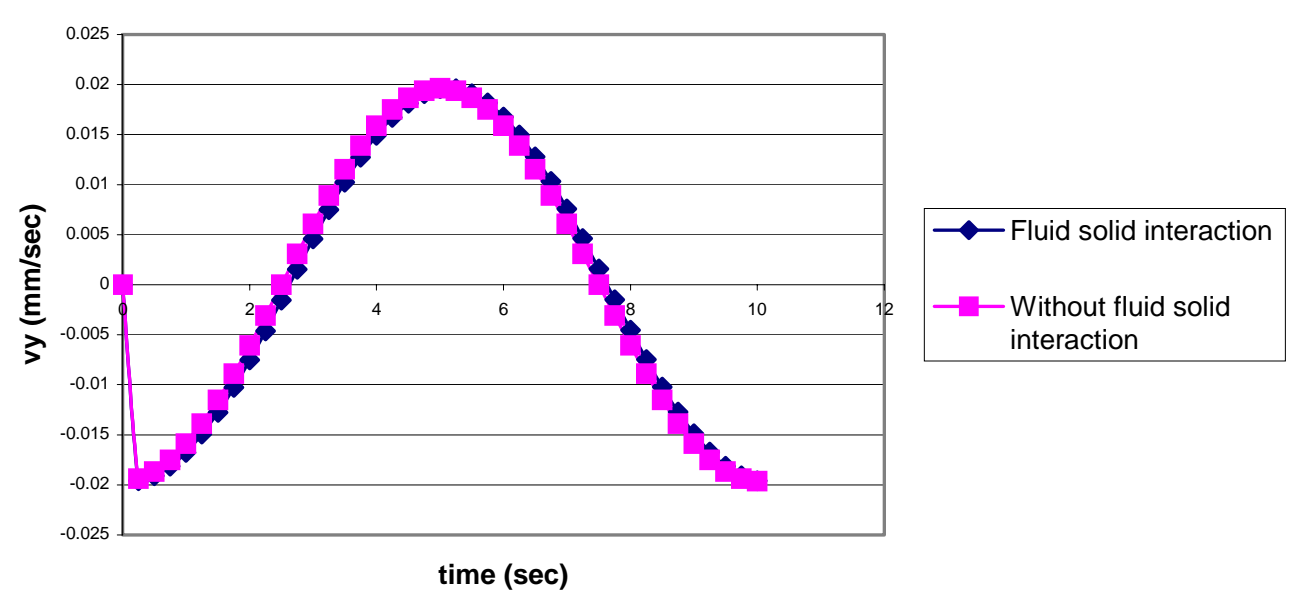

Figure 28 Comparison of the pressure, velocity and displacement of the fluid for with fluid solid interaction analysis and without fluid solid interaction analysis

\subsubsection{Conclusion}

Since the applied sinusoidal displacement and velocity was same we expected the peak pressure, displacement and velocity to be same. From the above 
images and graphs it was clear that the pressure, displacement and velocity value for both the analysis are also the same.

\subsection{Stress acting on a plate subjected to different fluid velocities}

A simple analysis was performed to find the Von mises stress acting on a plate when subjected to different fluid velocities. The analysis was performed with a fluid velocity of $10 \mathrm{~mm} / \mathrm{sec}$ and $50 \mathrm{~mm} / \mathrm{sec}$.

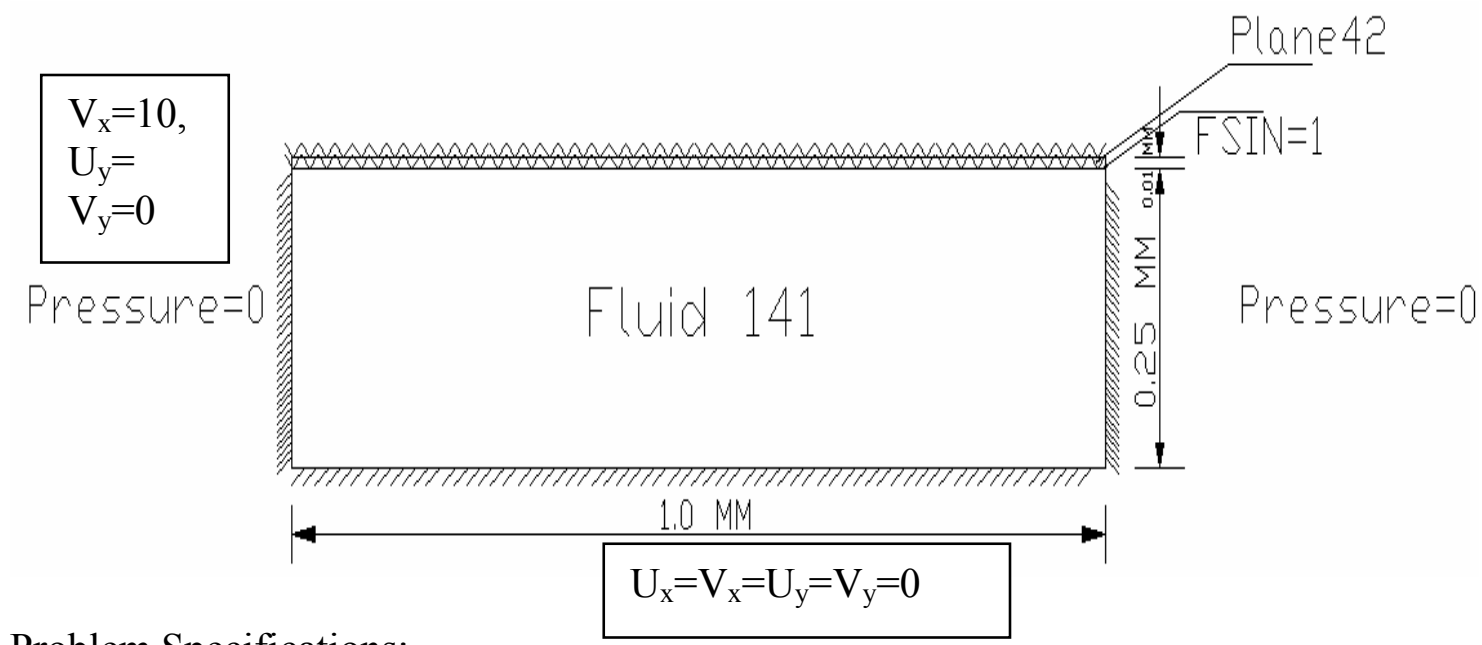

Problem Specifications:

Length of the plate $=1 \mathrm{~mm}$

Distance between two plates $=0.25 \mathrm{~mm}$

Boundary Condition:

At $x=0 \mathrm{~mm}$ and $\mathrm{x}=1 \mathrm{~mm}$ Pressure $=0 \mathrm{~N} / \mathrm{mm}^{2}$

At $x=0 \mathrm{~mm}, \mathrm{~V}_{\mathrm{x}}=10 \mathrm{~mm} / \mathrm{sec}, \mathrm{U}_{\mathrm{y}}, \mathrm{V}_{\mathrm{y}}=0$

At $\mathrm{x}=1 \mathrm{~mm}, \mathrm{~V}_{\mathrm{x}}, \mathrm{V}_{\mathrm{y}}=0$

At $\mathrm{y}=0 \mathrm{~mm}, \mathrm{U}_{\mathrm{x}}=\mathrm{U}_{\mathrm{y}}=\mathrm{V}_{\mathrm{x}}=\mathrm{V}_{\mathrm{y}}=0$

At $\mathrm{y}=0.25 \mathrm{~mm}, \mathrm{FSIN}=1.0$

At $\mathrm{y}=0.26 \mathrm{~mm}, \mathrm{U}_{\mathrm{x}}, \mathrm{U}_{\mathrm{y}}=0$

Material Properties 
Young's modulus $=2.0 \mathrm{e} 11 \mathrm{~N} / \mathrm{mm}^{2}$

Poisson's ratio $=0.3$

Modeling:

The model was first created and the element types and material properties were assigned to the model. PLANE 42 is used for the solid element and FLUID141 was assigned to the fluid element. The ALE option was made on for the fluid element. The fluid model was first meshed and the fluid solid interaction boundary condition was specified to all the nodes of the fluid (at $y=0.25 \mathrm{~mm}$ ) that interacts with the solid. The number of nodes in the fluid element is higher than the number of nodes in the solid element. The solid model was then meshed and the fluid solid interaction boundary condition was specified to all the nodes of the solid part, which interacts with the fluid. Same interface number is used when defining the fluid solid boundary condition. The solution options such as convergence, relaxation, and time increment and end time were then specified and the analysis was solved for two different velocities. The Von mises stress acting on the plate for a fluid velocity of $10 \mathrm{~mm} / \mathrm{sec}$ and for a fluid velocity of 50 $\mathrm{mm} / \mathrm{sec}$ was shown below. 


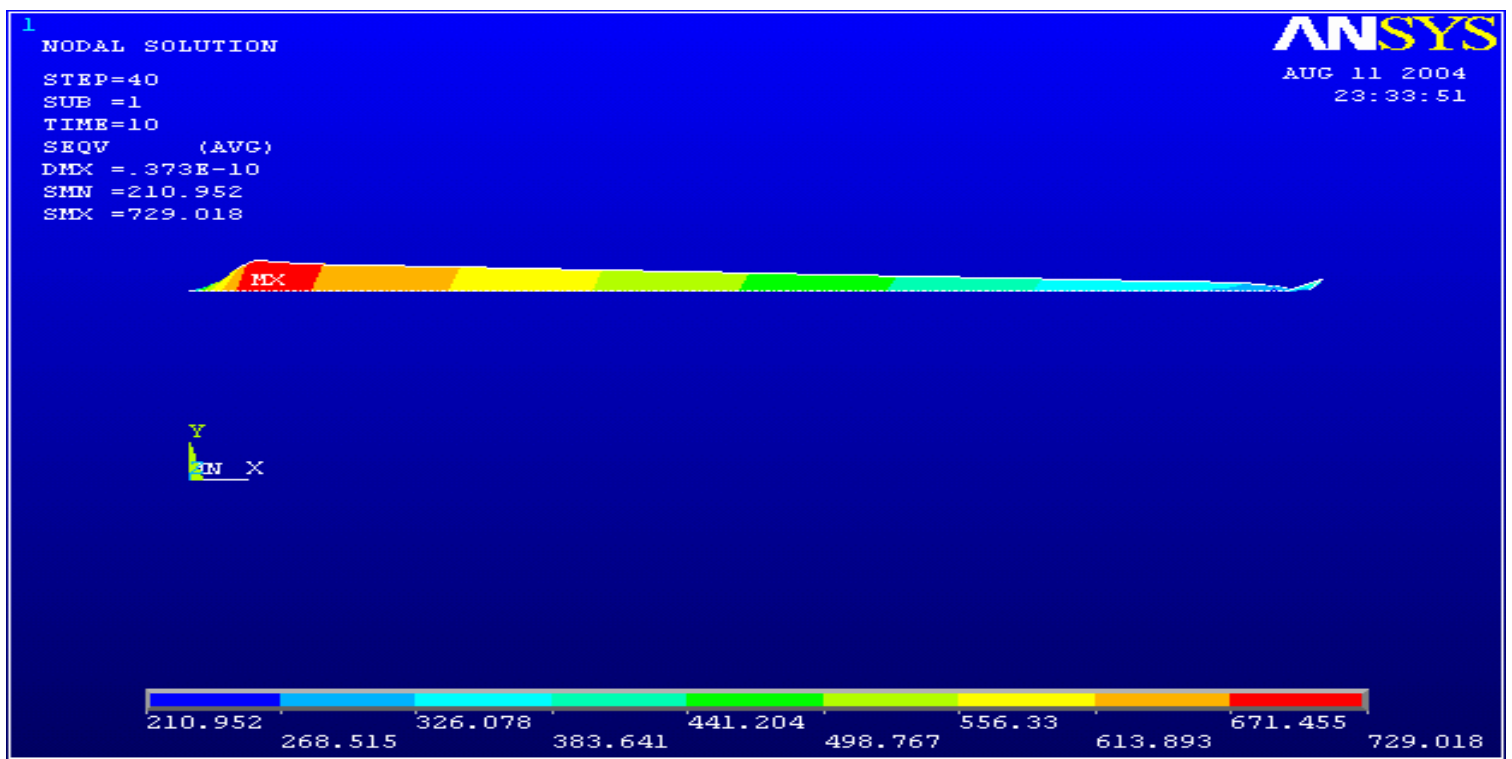

Figure 29 Von mises stress acting on a plate when subjected to fluid velocity of $10 \mathrm{~mm} / \mathrm{sec}$

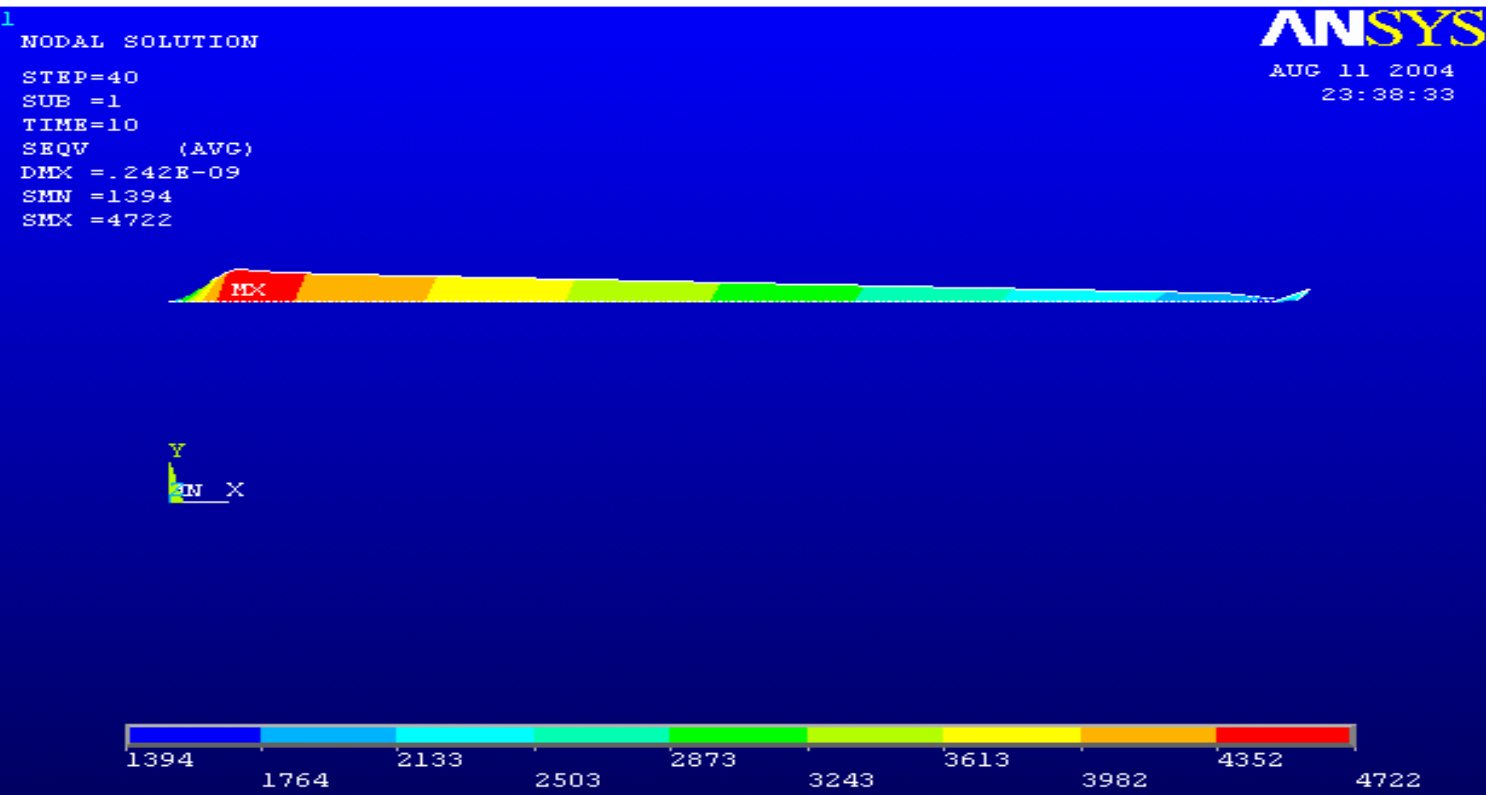

Figure 30 Von mises stress acting on the plate when subjected to a fluid velocity of $50 \mathrm{~mm} / \mathrm{sec}$ 


\subsubsection{Conclusion:}

As expected the von mises stress acting on a plate increase with increase in fluid velocity, which can be seen from the above images.

\subsection{Stress acting on a plate when subjected to different pressures}

Another simple analysis was performed to determine the stress acting on a plate when subjected to different pressures. A fluid flow was considered between two flat plates. Both the upper and lower plates were fixed. The analysis was done for two cases, without pressure difference and with pressure difference.

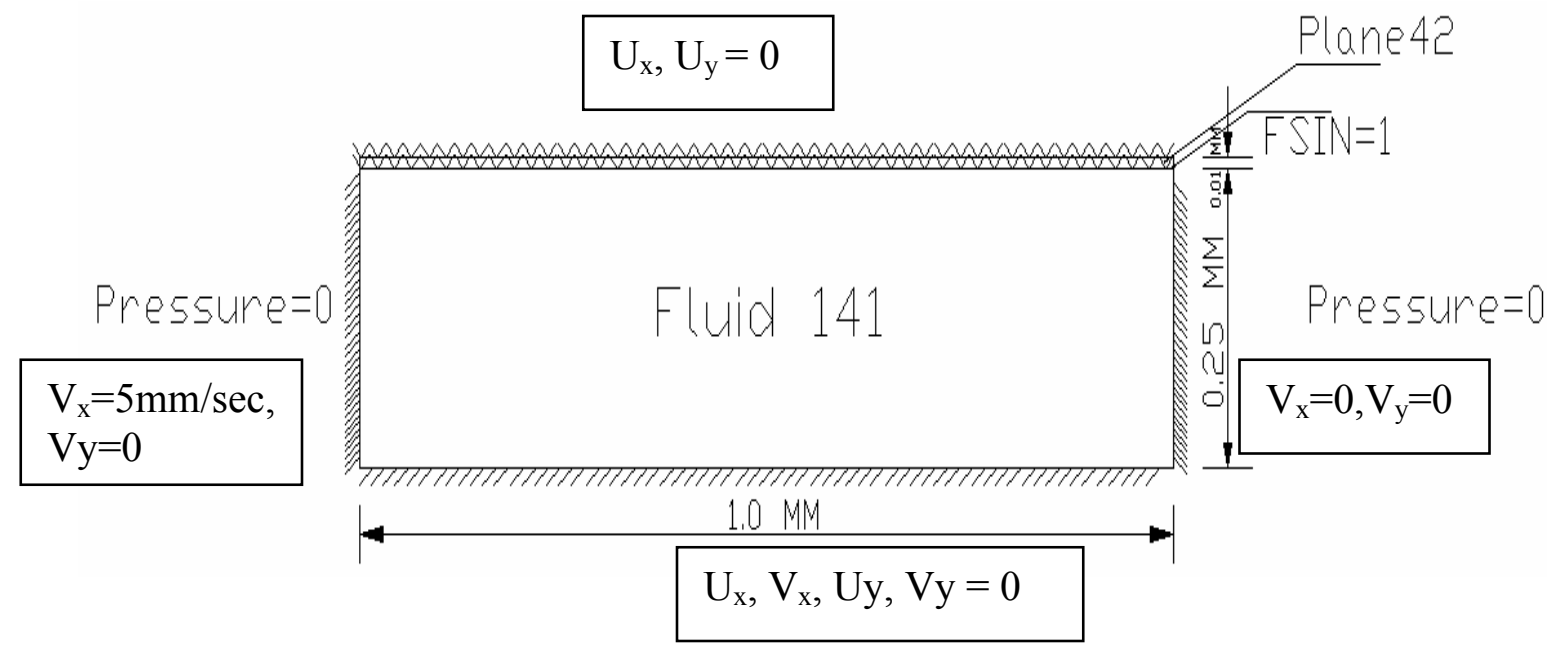

Problem Specifications:

Length of the plate $=1 \mathrm{~mm}$

Distance between two plates $=0.25 \mathrm{~mm}$

Boundary Condition:

At $\mathrm{x}=0 \mathrm{~mm}$ and $\mathrm{x}=1 \mathrm{~mm}$ Pressure $=0 \mathrm{~N} / \mathrm{mm}^{2}$

At $\mathrm{y}=0 \mathrm{~mm}, \mathrm{U}_{\mathrm{x}}=\mathrm{U}_{\mathrm{y}}=\mathrm{V}_{\mathrm{x}}=\mathrm{V}_{\mathrm{y}}=0$ 
At $\mathrm{y}=0.25 \mathrm{~mm}, \mathrm{FSIN}=1.0$

At $\mathrm{y}=0.26 \mathrm{~mm}, \mathrm{U}_{\mathrm{x}}, \mathrm{U}_{\mathrm{y}}=0$

At $\mathrm{x}=0 \mathrm{~mm}, \mathrm{~V}_{\mathrm{x}}=5 \mathrm{~mm} / \mathrm{sec}, \mathrm{V}_{\mathrm{y}}=0$

At $\mathrm{x}=1 \mathrm{~mm}, \mathrm{~V}_{\mathrm{x}}, \mathrm{V}_{\mathrm{y}}=0$

Material Properties

Young's modulus $=2.0 \mathrm{e} 11 \mathrm{~N} / \mathrm{mm}^{2}$

Poisson's ratio $=0.3$

Fluid Properties:

Nominal density and viscosity

Modeling:

FLUID141 was assigned to the fluid element and PLANE 42 was assigned to the solid element. The ALE option was made on for the fluid element. The fluid element was meshed first and the boundary conditions were specified to all the nodes of the fluid element. The fluid solid interaction boundary condition was specified to nodes of the fluid element where it interacts with the solid element $(y=0.25 \mathrm{~mm})$. The material properties for the solid element were then defined and then meshed. The number of nodes in the fluid element was higher than the number of nodes in the solid element. The boundary condition was then specified to all the nodes of the solid element and the fluid solid interaction boundary condition was specified to the nodes of the solid element where it interacts with the fluid element $(\mathrm{y}=0.25 \mathrm{~mm})$. The fluid properties and the solution options such as convergence, relaxation, and time increment and end time were specified and the analysis was solved. 
The analysis was solved for two cases. In the first case there is no pressure difference between the fluid element and in other analysis a pressure difference between the fluid elements $\left(250-0 \mathrm{~N} / \mathrm{mm}^{2}\right)$ was considered. The von mises stress acting on the plate for both these analyses were shown below.

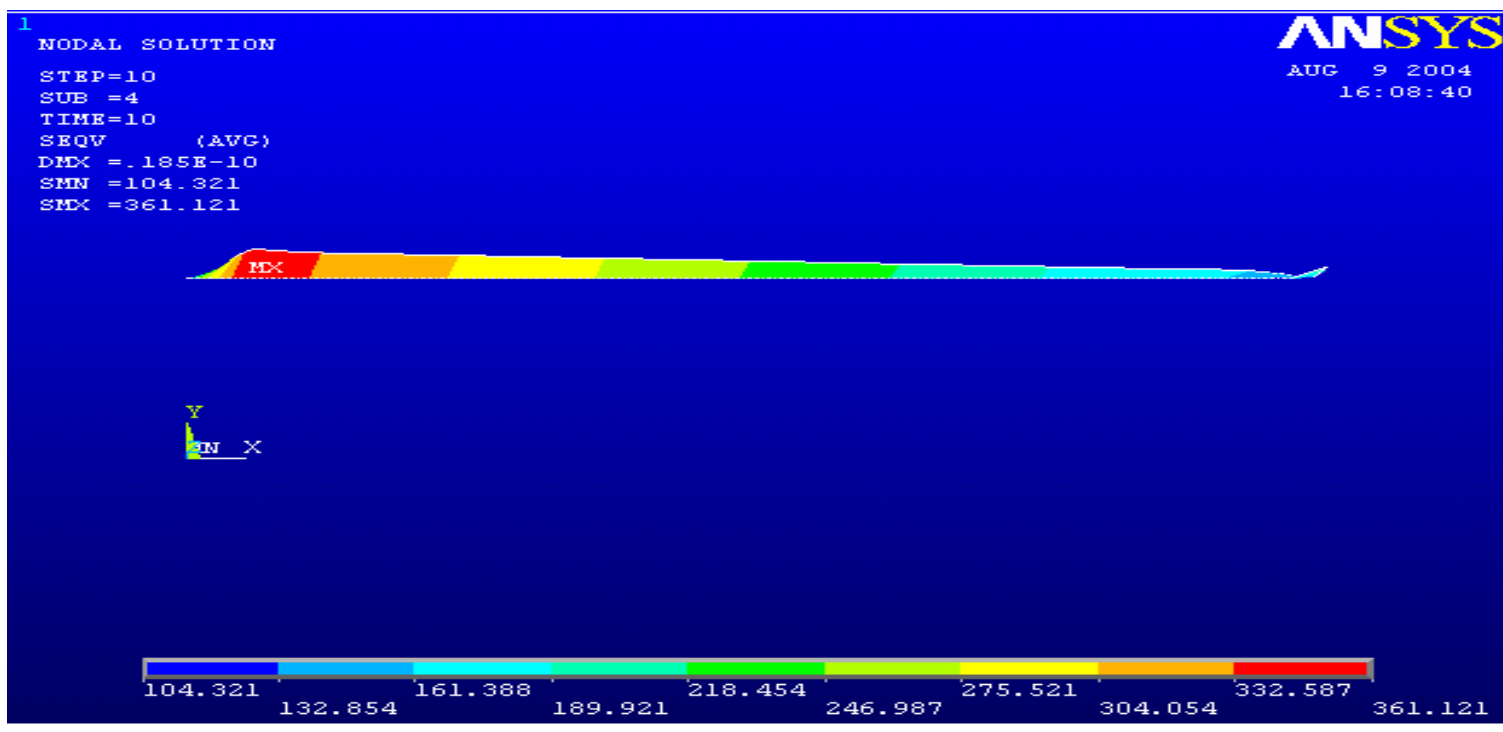

Figure 31 Von mises stress acting on a plate with no pressure difference

NODAL SOLUTION

$\operatorname{STE} \mathbf{P}=10$

SUB $=4$

TIME $=10$

SEQV

SHI $=169.82$

$\operatorname{SILX}=517.997$

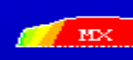

NNSYS

AUE 92004

$15: 55: 20$

ILX

$$
\text { Yn } \mathrm{X}
$$

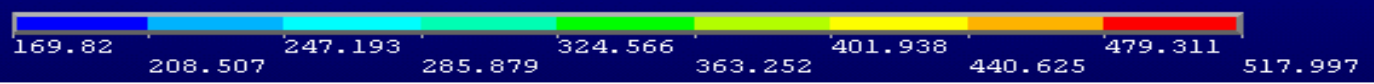

Figure 32 Von mises stress acting on a plate with pressure difference 


\subsubsection{Conclusion}

As expected the von mises stress acting on the plate increases with increase in pressure difference. This is expected because when there is a pressure difference the flow pattern varies increasing the stress acting on the solid.

\subsection{Theoretical Validation}

A flow was considered between two parallel plates. The upper plate was given a velocity in the $\mathrm{X}$-direction and the lower plate was fixed. The movement of the upper plate causes a change in fluid properties, which is found out by finite element method and by theoretical method. The results are then compared.

\subsubsection{Finite element method}

Without Pressure Difference:

Problem Specification:

Length of the plate $=1 \mathrm{~mm}$

Distance between two plates $=0.25 \mathrm{~mm}$

Boundary Condition:

At $x=0 \mathrm{~mm}$ and $\mathrm{x}=1 \mathrm{~mm}$ Pressure $=0 \mathrm{~N} / \mathrm{mm}^{2}$

At $\mathrm{y}=0 \mathrm{~mm}, \mathrm{U}_{\mathrm{x}}=\mathrm{U}_{\mathrm{y}}=\mathrm{V}_{\mathrm{x}}=\mathrm{V}_{\mathrm{y}}=0$

At $\mathrm{y}=0.25 \mathrm{~mm}, \mathrm{~V}_{\mathrm{x}}=10 \mathrm{~mm} / \mathrm{sec}, \mathrm{U}_{\mathrm{y}}=0, \mathrm{~V}_{\mathrm{y}}=0, \mathrm{ENKE}=-1$ 


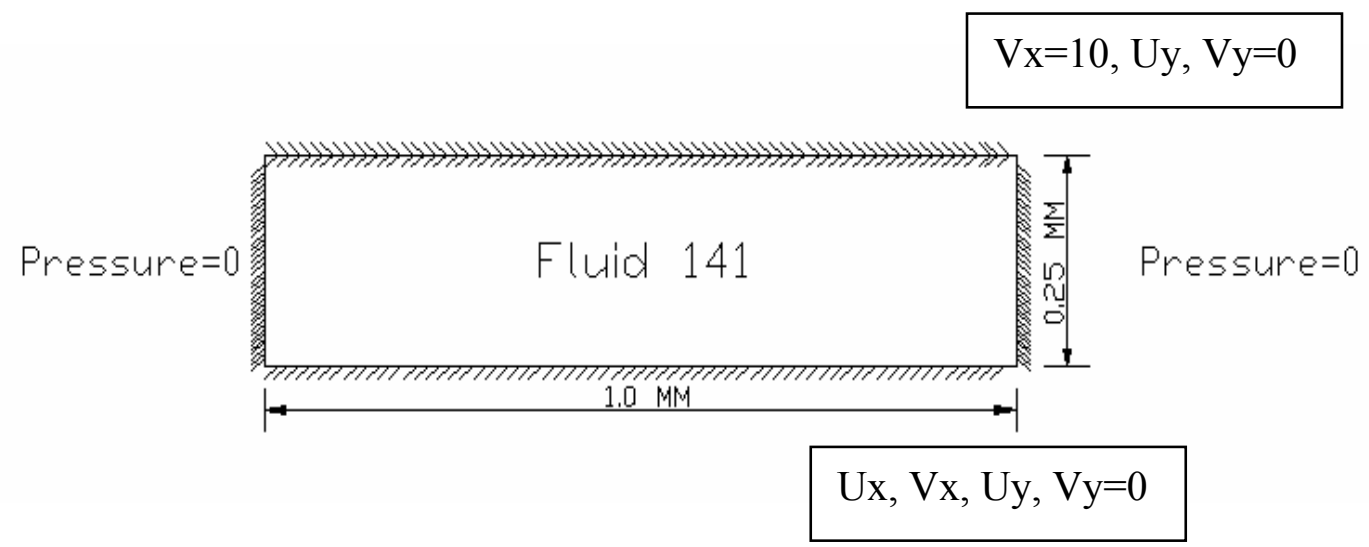

Figure 33 Boundary condition for the model

Modeling:

FLUID141 element was used for this analysis. ALE option was made on for the fluid element. The fluid element was meshed and the boundary conditions were specified to the nodes of the fluid element. The convergence, relaxation, time increment and end time were specified and then the analysis was solved. The vector plot was plotted for the analysis. Maximum velocity is noted near the top plate and the minimum velocity was noted near the lower plate.

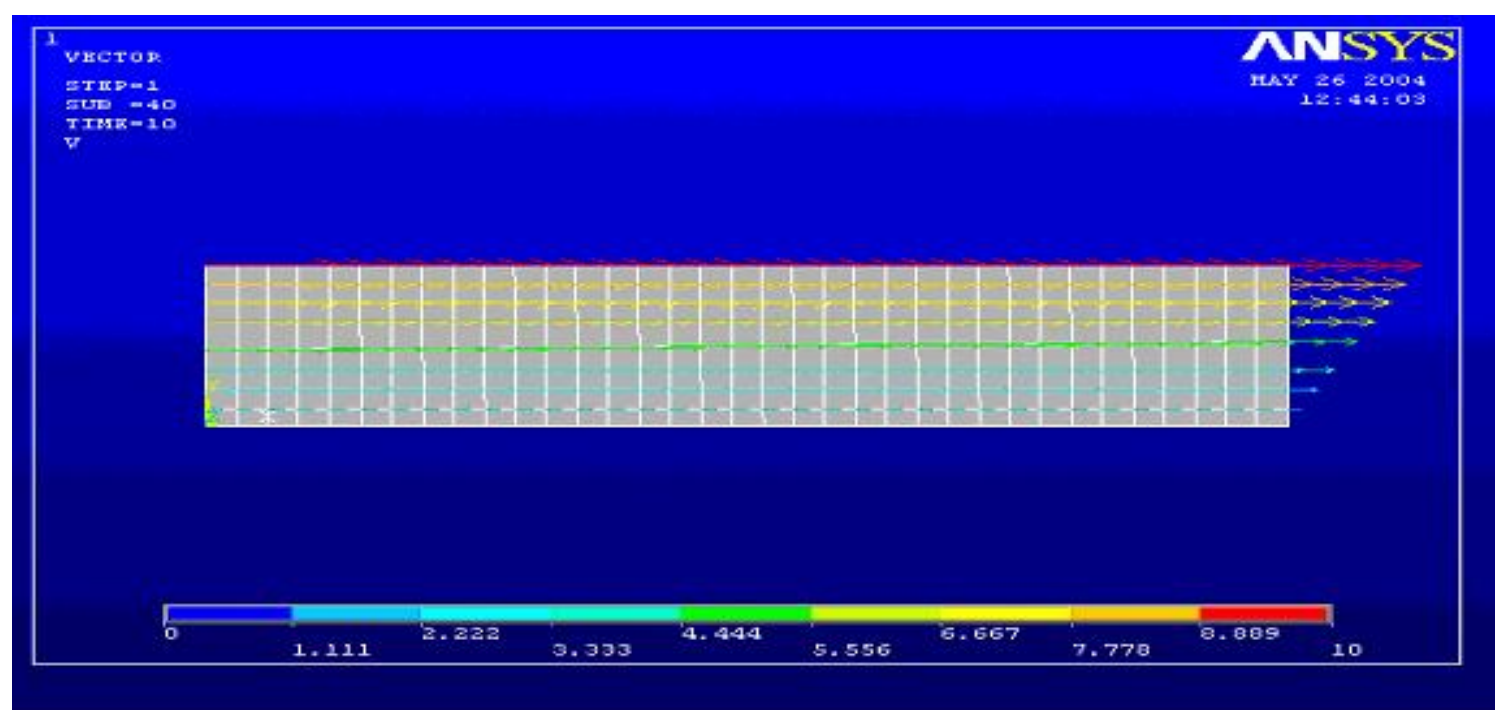

Figure 34 Vector plot for the fluid element without pressure difference 
With Pressure difference:

The same model was made to run with pressure difference between the inlet and outlet portion. The inlet pressure was made to $250 \mathrm{~N} / \mathrm{mm}^{2}$ and the outlet pressure was made zero. The model was then meshed and analysis was done. The vector plot for this case is as shown below.

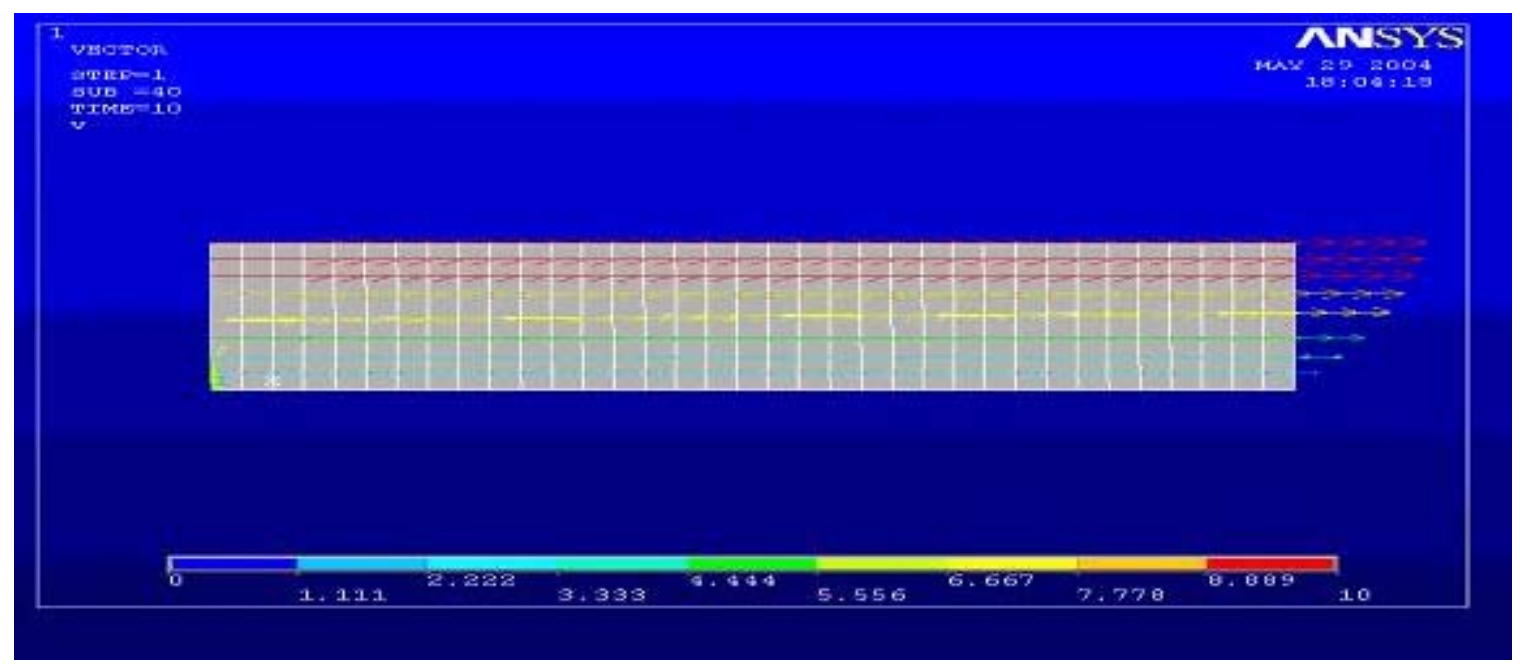

Figure 35 Vector plot for the fluid element with pressure difference

\subsubsection{Theoretical method}

The velocities for the fluid element at different locations for the same model were calculated by using theoretical equations. Two different models are considered for the theoretical calculation. In the first model there was no pressure difference. In the later case a pressure difference between the inlet and outlet was considered. 


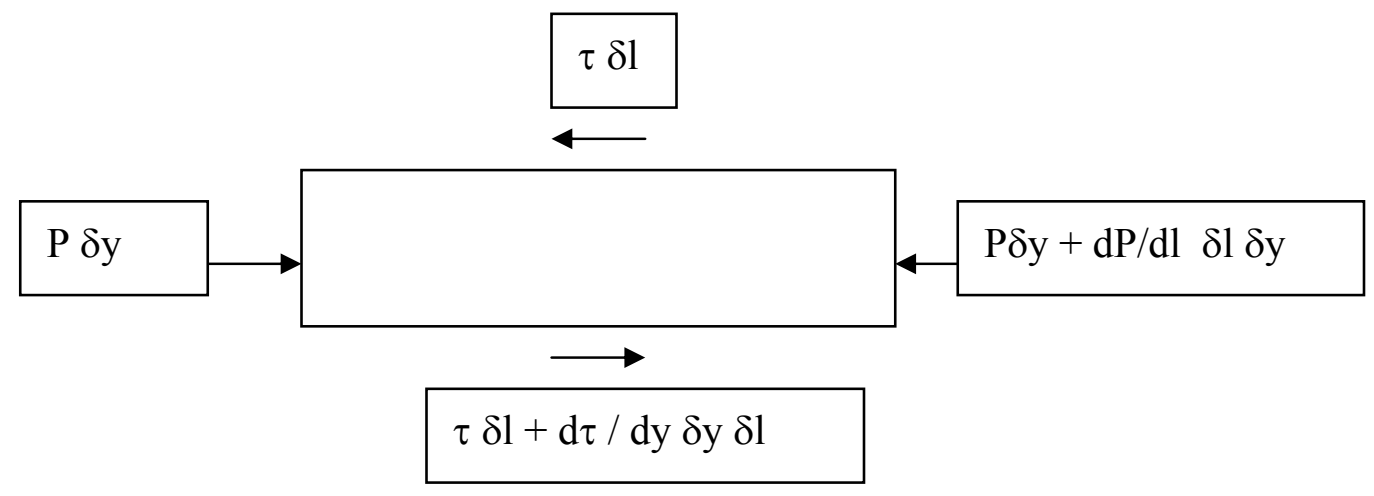

\section{Figure 36 Forces acting on the element}

A small element of the fluid part was taken and the forces acting on the model was noted down. These forces are equated down and reduced to a solvable equation.

The forces acting on the model was

$\mathrm{P} \delta \mathrm{y}-(\mathrm{P} \delta \mathrm{y}+\mathrm{dP} / \mathrm{dl} \delta 1 \delta \mathrm{y})-\tau \delta 1+(\tau \delta 1+\mathrm{d} \tau / \mathrm{dy} \delta \mathrm{y} \delta 1)=0$

$\mathrm{dP} / \mathrm{d} l \delta 1 \delta \mathrm{y}=\mathrm{d} \tau / \mathrm{dy} \delta 1 \delta \mathrm{y}$

$\mathrm{dP} / \mathrm{dl}=\mathrm{d} \tau / \mathrm{dy}$

$\mathrm{d} \tau / \mathrm{dy}=\mu \mathrm{d}^{2} \mathrm{u} / \mathrm{dy} \mathrm{y}^{2}$

$\mathrm{dP} / \mathrm{dl}=\mu \mathrm{d}^{2} \mathrm{u} / \mathrm{dy}^{2}$

Integrating with respect to ' $y$ ' we get

$\mu \mathrm{du} / \mathrm{dy}=\mathrm{dP} / \mathrm{dl} \mathrm{y}+\mathrm{C} 1$

Integrating again

$\mu \mathrm{u}=\mathrm{dP} / \mathrm{dl} \mathrm{y}^{2} / 2+\mathrm{C} 1 \mathrm{y}+\mathrm{C} 2$

$\mathrm{u}=1 / \mu \mathrm{dP} / \mathrm{dl} \mathrm{y}^{2} / 2+\mathrm{C} 1 \mathrm{y} / \mu+\mathrm{C} 2$

In this case $\mathrm{y}=0$ at $\mathrm{u}=0$ and $\mathrm{y}=\mathrm{a}$ at $\mathrm{u}=\mathrm{U} 0$ 
Substituting the above boundary condition we get

$\mathrm{C} 2=0$

$\mathrm{C} 1=\mathrm{U} 0 \mu / \mathrm{a}-\mathrm{dP} / \mathrm{dl} \mathrm{a} / 2$

Substituting $\mathrm{C} 1$ and $\mathrm{C} 2$ in the above equation we get

$$
\mathrm{u}=\mathrm{dP} / \mathrm{dl}\left(\mathrm{y}^{2} / 2 \mu-\text { ay } / 2 \mu\right)+\mathrm{U} 0 \mathrm{y} / \mathrm{a}
$$

Where

$\mathrm{u}=$ Velocity of the fluid

$\mathrm{dP} / \mathrm{dl}=$ Pressure difference between the inlet and the outlet pressure

$\mathrm{y}=$ distance from the lower plate

$\mu=$ Viscosity of the fluid

$\mathrm{U} 0=$ Input velocity given to the top plate

$\mathrm{a}=$ Height between the two plates

Using the above equation the velocities in the X-direction at different nodes are noted down. The y value was then calculated manually depending upon the nodal location. The velocity distribution was found and a graph is drawn between velocity and distance. When there was no pressure difference the $\mathrm{dP} / \mathrm{dl}$ term gets cancelled. Theoretical calculations are then done for the case where there was pressure difference between inlet and outlet. The boundary condition for this case was

At $\mathrm{x}=0$ pressure was $250 \mathrm{~N} / \mathrm{mm}^{2}$ and $\mathrm{x}=1$ Pressure was $0 \mathrm{~N} / \mathrm{mm}^{2}$

At $\mathrm{y}=0 \mathrm{~mm}, \mathrm{U}_{\mathrm{x}}=\mathrm{U}_{\mathrm{y}}=\mathrm{V}_{\mathrm{x}}=\mathrm{V}_{\mathrm{y}}=0$

At $\mathrm{y}=0.25 \mathrm{~mm}, \mathrm{~V}_{\mathrm{x}}=10, \mathrm{U}_{\mathrm{y}}=0, \mathrm{~V}_{\mathrm{y}}=0, \mathrm{ENKE}=-1$ 
The $\mathrm{dP} / \mathrm{d}$ l term was calculated for this case and then it was substituted in the above equation to calculate the velocity of the fluid in the x-direction. Graph was plotted between velocity and distance for both the case.

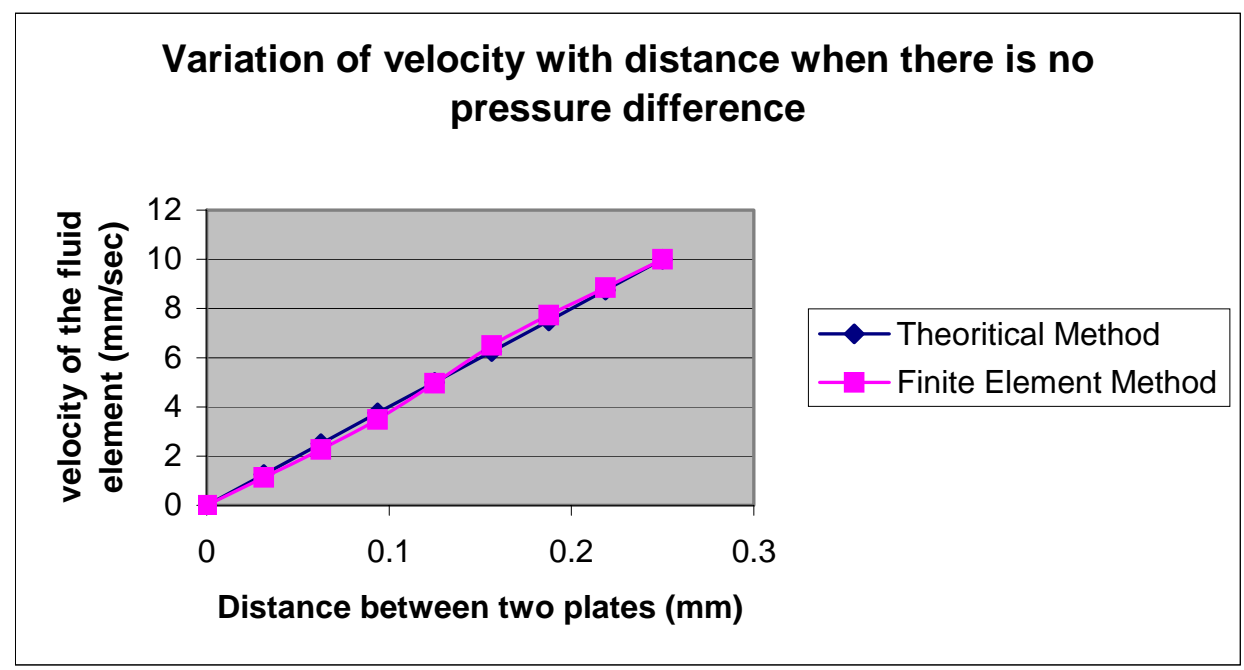

Figure 37 Variation of velocity with distance when there is no pressure difference

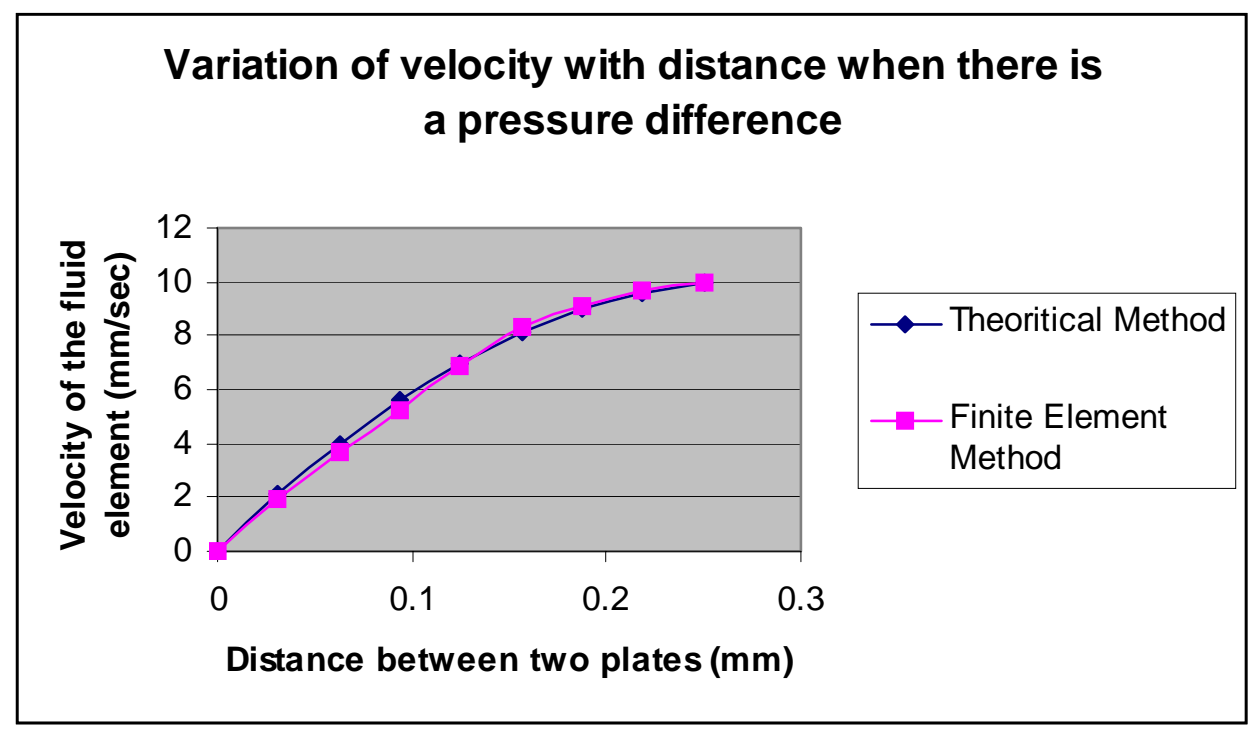

Figure 38 Variation of velocity with distance when there is a pressure difference $\left(0-250 \mathrm{~N} / \mathrm{mm}^{2}\right)$ 


\subsubsection{Conclusion}

From the above images and graphs it was clear that the value obtained by finite element method and theoretical method are the same. The velocity distribution was also the same for both the method. 


\section{Modeling response of a cell to compressive loading}

\subsection{Loads acting on the cell}

In articular cartilage, direct compression of cells via the extracellular matrix occurs. The dynamic compression also causes the fluid in articular cartilage matrix to flow, which imposes shear stress on the chondrocytes [13]. Compression of cell-gel constructs allows us to measure cell deformation in conditions analogous to $3 \mathrm{D}$, porous matrix that the cells are subject to in vivo. The cells are embedded in $2 \%$ agarose gel and the gel was compressed. The load is applied to the gel by using an indenter driven by a stepper motor. The construct is compressed to $25 \%$ strain. The cells are fluroscently labeled so it is possible to obtain undeformed and deformed images of the cell using a confocal microscope. These images are post processed using OPTIMAS. It was found that the size of the cell was reduced in the direction of loading and there was a slight increase of radius perpendicular to the loaded direction
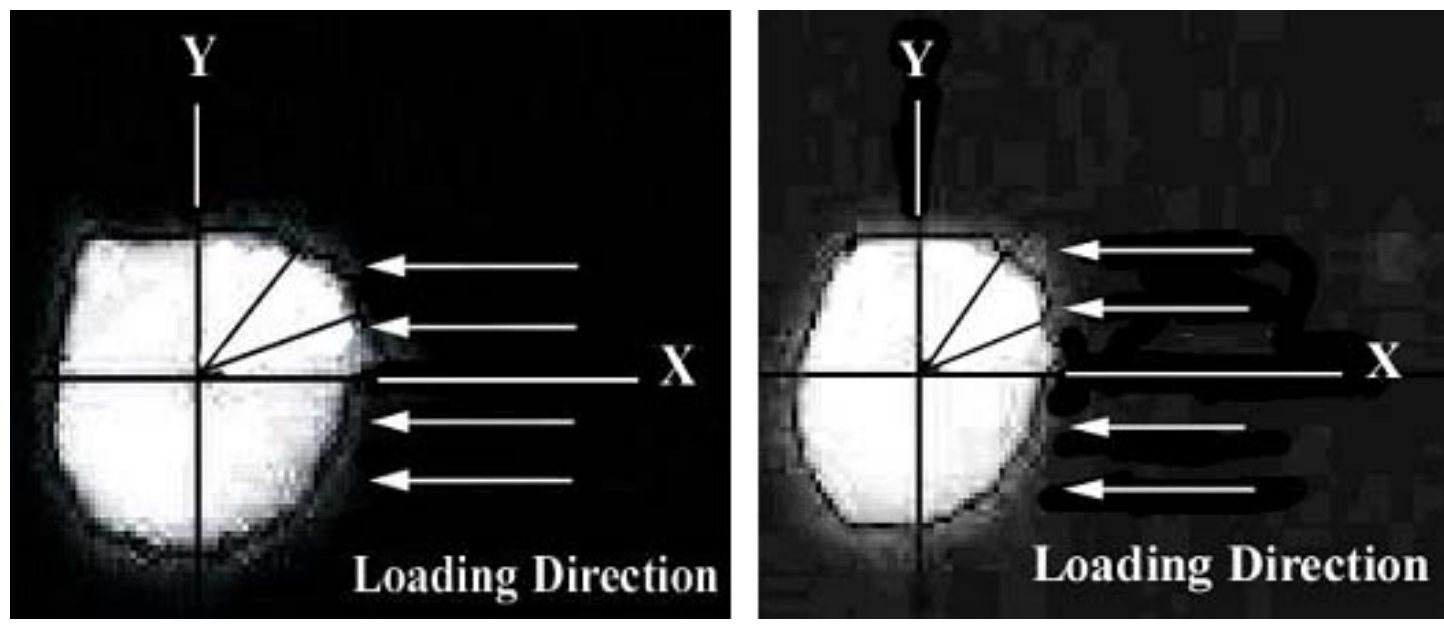

Figure 39 Cell in deformed and undeformed states. Size of the cell reduces in the $X$ direction when a compressive load is applied. 
The radius of the cell at different angles with respect to loading axis was measured for both compressed and uncompressed cells and the radial deformation Ur is calculated from the difference in radii of uncompressed and compressed cells at given angles (see Figure 39). A graph of Ur is drawn with angles with respect to loading axis. These values of radial deformation were used as inputs to finite element model.

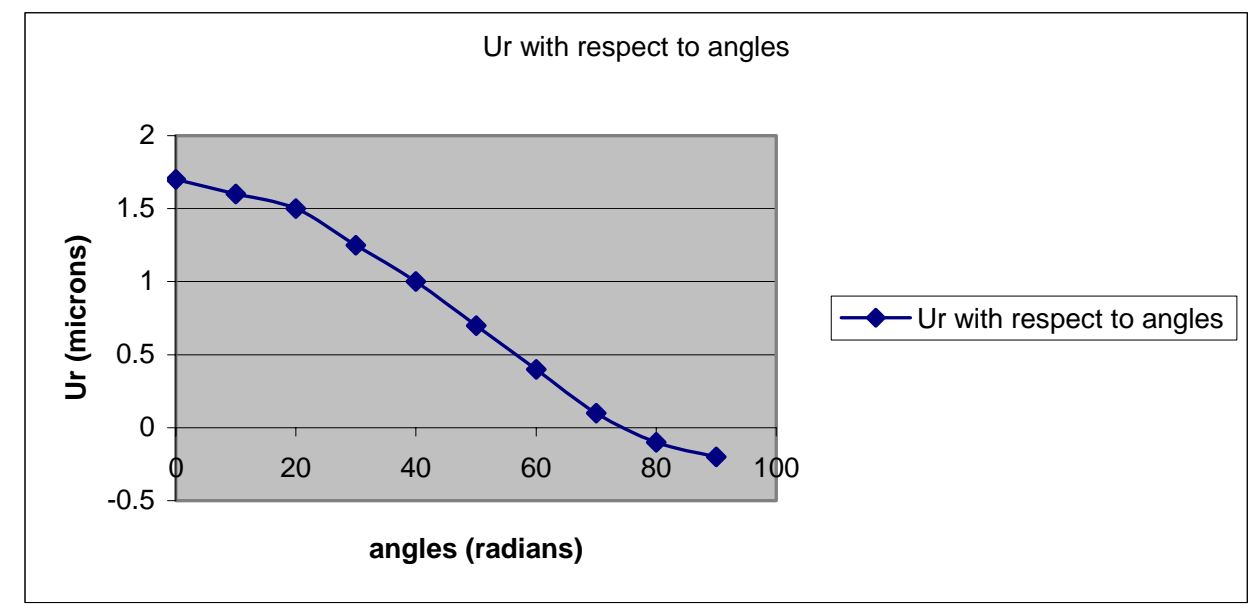

Figure 40 The radial deformation (Ur) of the cell with respect to angles

\subsection{Cytoskeletal arrangement in a cell for different days}

The chondrocyte cytoskeleton was composed of three types of protein networks. They are actin, microtubule and intermediate filaments. Studies have shown that the actin network plays an important role in a number of cellular events. In other experiments in our laboratory the cell cytoskeletal structure of pre chondrocytes changes over the number of days of 3D culture as they become more and more like chondrocytes. The cell cytoskeletal structure changes over the days of $3 \mathrm{D}$ culture. The cells were placed in a 3D culture for 12 days and the actin microfilaments structure was observed for day $1,5,8$ and day12 using fluorescent labeling and confocal microscopy. $5 \mu 1$ of ATDC 5 cells were added to $1 \mathrm{ml}$ of $2 \%$ agarose solution. The mixture is then injected to a 
mold to make gels of size $1.2 \mathrm{~mm} * 5 \mathrm{~mm} * 0.5 \mathrm{~mm}$ (width, length and thickness). The cell gel constructs are placed in slides and culture media was added to it. Then the slides are placed in an incubator and proper temperature, humidity and $\mathrm{Ph}$ are maintained which are required for cell growth. In order to replenish the nutrients the culture media was changed every 2 days. The slides were removed from days 1, 5, 8 and 12 and the cell gel constructs were stained for actin using standard protocol [22]. The stained cells are then observed under the confocal microscope at $400 \times$ magnifications and then zoomed to 6.7 times of its original size. The variation of actin at different days is observed.

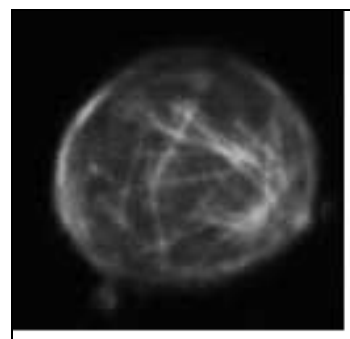

Day 1

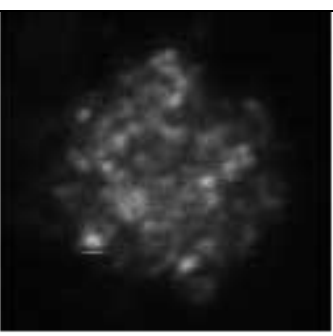

Day5

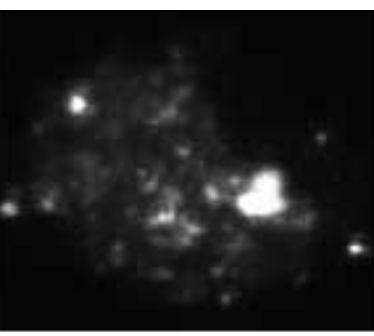

Day8

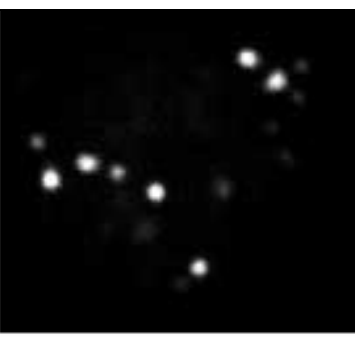

Day12

\section{Figure 41 Reorganization of the actin fibers in the cells from Day1 to Day12}

The actin cytoskeleton has a stress fiber like appearance when the ATDC5 cells are cultured in a plate. When the cells are cultured in an agarose gel the actin microfilaments become punctuate in shape. The actin filaments look like a cluster of long slender line in Day1 and it appear as a small dot in Day 12. These images are extracted using OPTIMAS and then modeled using a MATLAB program, which is used for the finite element analysis. 


\subsection{Post processing of cell images using OPTIMAS}

As discussed in the above chapter the cytoskeletal arrangement of the cell differs with time in culture. It was important to model these structures for finite element analysis. The actin cytoskeleton was represented as lines for Day1 and small areas for Day12. Using OPTIMAS software, the end coordinates of the lines can be obtained in Microsoft Excel format. The threshold feature in OPTIMAS software plays a vital role in generating the image of the cell. Lesser number of points was obtained at a higher threshold value and higher number of points was obtained at a lower threshold value. Determining the exact threshold value is an important aspect in the reconstruction process. The images at different threshold are obtained and then the images are combined in order to get a reconstructed image that usually corresponded with the confocal image.
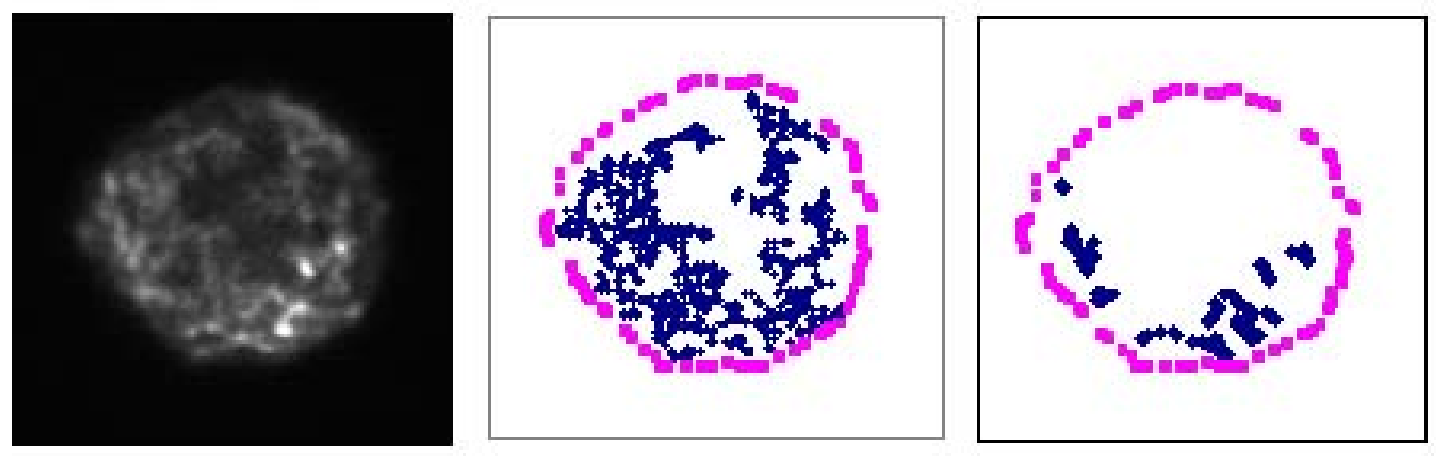

Figure 42 The cell image with points obtained from OPTIMAS software (center). Cell image and points collected from OPTIMAS at a higher threshold value (170) (right).

The coordinate points are obtained in microns by calibrating the scale of the image. The cell model with its inner actin filaments is then reconstructed by combining these coordinate points. The OPTIMAS software provides these coordinate points in Microsoft excel format. 


\subsection{Modeling the cell using MATLAB program}

The points obtained from OPTIMAS software are read and then stored in the ANSYS input file format using MATLAB program (Appendix 4,5,6). The points obtained from OPTIMAS are not in order and the curve obtained is irregular. The centroid of this irregular polygon was first found and then the using this centroid an ellipse curve fit was made for the cell outline. After this the inner points from the OPTIMAS were read and the inner actin filaments was modeled.

\subsubsection{Centroid calculation and curve fitting}

The curve obtained using the points was in irregular shape. An ellipse fit has to be done for these outer points of the cell. In order to fit an ellipse the centroid of this irregular shape should be found out. A FORTRAN program was written to calculate the centroid (Appendix 4). The polygon was first partitioned into triangles. The centroid of the triangle was calculated which is the average of the three vertices $(\mathrm{x} 1+\mathrm{x} 2+\mathrm{x} 3) / 3$ and $(y 1+y 2+y 3) / 3$. The sum of the centroid of all these triangles weighted by the sum of area gives the centroid of the polygon. The triangle was formed by one fixed end of the polygon and the two consecutive edges of the polygon.

The algorithm for calculating the centroid is as follows

1. Fix any one vertex $(\mathrm{x} 1, \mathrm{y} 1)$.

2. Select two points from the cell outline. Let the coordinates of the two points be $(\mathrm{x} 2, \mathrm{y} 2)$ and $(\mathrm{x} 3, \mathrm{y} 3)$

3. Form a triangle using these three points $(x 1, y 1),(x 2, y 2),(x 3, y 3)$

4. The centroid of this triangle was calculated by using the formulae (Xcentroid= $\mathrm{x} 1+\mathrm{x} 2+\mathrm{x} 3 / 3$ and Ycentroid $=\mathrm{y} 1+\mathrm{y} 2+\mathrm{y} 3 / 3)$ 
5. The area of the triangle was calculated

6. Repeat the above steps and form triangles with the cell outer points. The fixed vertex $(\mathrm{x} 1, \mathrm{y} 1)$ was used as a common vertex for all the triangles.

7. The centroid and area was calculated for all the triangles.

8. The sum of all the centroid and the areas was calculated.

9. The centroid of the irregular cell shape was calculated by dividing the sum of the centroid with the sum of areas.

10. The obtained centroid was then used in the MATLAB program to fit an ellipse.

Curve fitting:

The calculated centroid is used to curve fit an ellipse for the cell outline. The outer points of the cell are input into a MATLAB program (Appendix 5) to the ' $a$ ' and ' $b$ ' values for the best curve fit.

The algorithm for the curve fit is as follows

1. The unknown parameters ' $a$ ' and ' $b$ ' that are obtained from the ellipse equation are changed to get the best fit.

2. The $\mathrm{X}$ and $\mathrm{Y}$ coordinate of the cell obtained from the OPTIMAS software are assigned to the variable ' $\mathrm{X}$ ' and ' $\mathrm{Y}$ '.

3. A user-defined function 'expfun' was defined which accepts the parameters ' $a$ ' and ' $b$ ' from the random set created in step1. The function also accepts $\mathrm{X}$ and $\mathrm{Y}$ coordinate of the cell outlines as input parameters. The variable curve was fitted using $\mathrm{X}$ and $\mathrm{Y}$ centroid values and ' $\mathrm{a}$ ' and ' $\mathrm{b}$ ' values.

4. The error is the difference between the original value calculated from OPTIMAS and the calculated value. Error vector $=$ Fitted curve $-\mathrm{y}$ 
5. Minimizing the sum of squares of error helps to fit the curve.

6. The sum of squares of error can be minimized by using a MATLAB inbuilt function called 'fminsearch'.

7. The obtained values are plotted with original values.

8. The parameters ' $a$ ' and ' $b$ ' and given by the MATLAB output window for the best curve fit.

Here the top half and the bottom half are fit separately. The ' $a$ ' and ' $b$ ' values for both these half are calculated and the average of ' $a$ ' and ' $b$ ' are found out and used for curve fitting full ellipse.

\subsection{Algorithm for MATLAB program to model the cell with its inner elements}

The points obtained from OPTIMAS software, the centroid values and the ' $a$ ' and ' $b$ ' values for the ellipse obtained from the curve fit program are stored in a file. These points are read and using MATLAB program and the cell membrane with its inner elements are modeled (Appendix 6). The algorithm for this MATLAB program was as follows

1. Read the points obtained from OPTIMAS software.

2. Select the $\mathrm{X}$ coordinate points and save it as a vector in $\mathrm{XX} 1$

3. Select the $\mathrm{Y}$ coordinate points and save it as a vector in $\mathrm{YY} 1$

4. Read the centroid values and store the centroid values in a sheet named centroid.

5. Store the X-centroid in the first row and first column and the Y-centroid in second row and second column.

6. The ' $a$ ' and ' $b$ ' values are read from the ellipse program and they are named as a1 and $b 1$ 
7. In order to model the cell membrane $\mathrm{a} 2$ and $\mathrm{b} 2$ values are calculated. $\mathrm{a} 2=\mathrm{a} 1+0.1$, $\mathrm{b} 2=\mathrm{b} 1+0.1$.

8. Store the values from a1 to a2.

9. Calculate the y value for the points obtained in step 8 using the formulae, $\mathrm{Y}=\mathrm{Y}_{\text {centroid }}+\left((\mathrm{b}(\mathrm{i}) / \mathrm{a}(\mathrm{i})) * \operatorname{sqrt}\left(\mathrm{a}(\mathrm{i})^{2}-\left(\mathrm{X}-\mathrm{X}_{\text {centroid }}\right)^{2}\right)\right)$

Where $\mathrm{i}$ values ranges from 1 to 2 . This creates the upper half of the ellipse.

10. Store the values from a 2 to a1.

11. Calculate the y value for the points obtained in step 10 using the formulae, $\mathrm{Y} 1=\mathrm{Y}_{\text {centroid }}-\left((\mathrm{b}(\mathrm{i}) / \mathrm{a}(\mathrm{i})) * \operatorname{sqrt}\left(\mathrm{a}(\mathrm{i})^{2}-\left(\mathrm{X} 1-\mathrm{X}_{\text {centroid }}\right)^{2}\right)\right)$

Where $\mathrm{i}$ values ranges from 1 to 2 . This creates the lower half of the ellipse

12. Store the values of $\mathrm{X}, \mathrm{X} 1, \mathrm{Y}$ and $\mathrm{Y} 1$ values in ANSYS log file format and print the values in the output file.

12. Create lines between these points and save it in output file.

13. Read the inner points from OPTIMAS.

14. Create lines by joining these points and form a polygon area with these lines. 


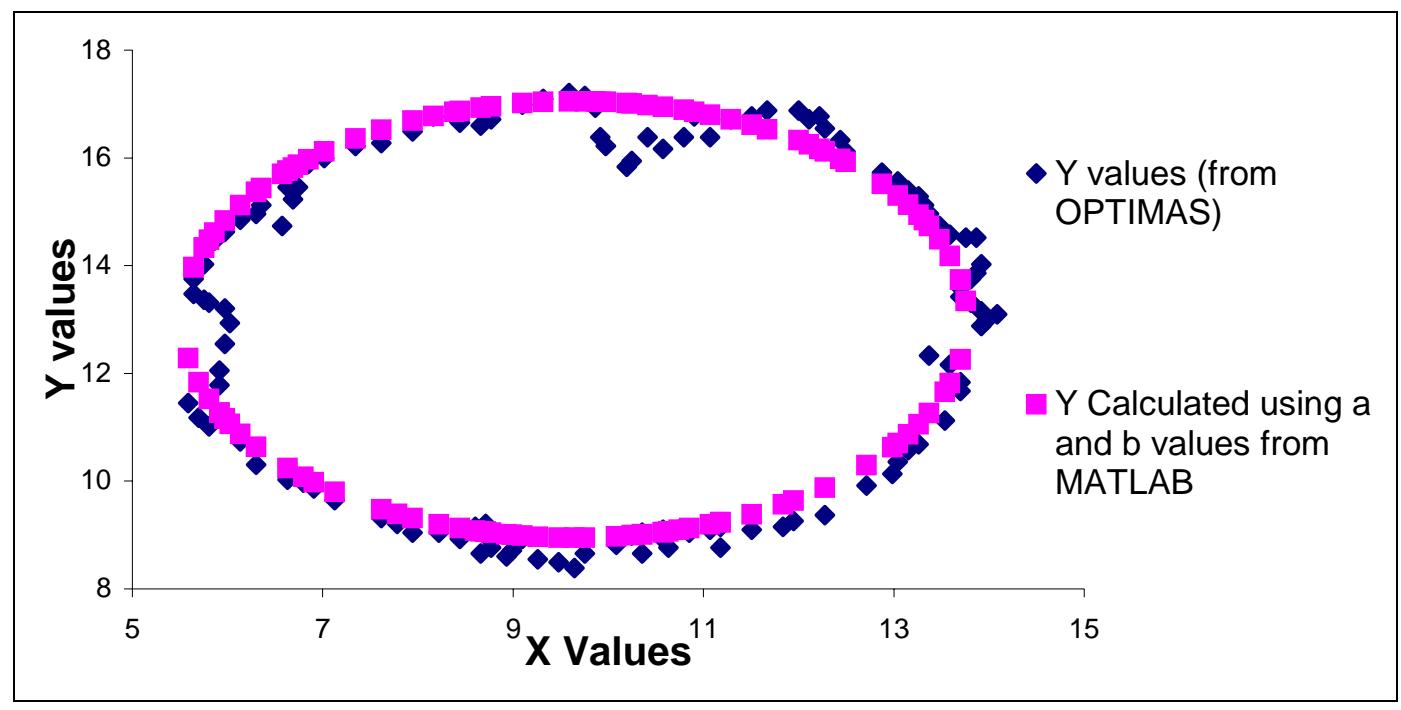

Figure 43 Curve fit for the cell model using the MATLAB program 


\section{Fluid solid interaction analysis in a cell}

\subsection{Introduction}

Cell was considered as a semi permeable membrane filled with fluid, which is subjected to various mechanical loads mainly compressive loading. Fluid exchange takes place between the membranes in response to the applied mechanical load. Osmotic pressure difference causes a turgor pressure inside the cell. Therefore the study of internal fluid pressure and the overall stiffness of the cell and how the cell behaves to the different internal fluid pressure are very important.

The cell image, which was obtained from OPTIMAS software, was post processed and modeled using MATLAB program. The output of the MATLAB program was stored in ANSYS log file format for exporting the model to ANSYS software. The outer points of the cell are stored as Key points in ANSYS. The radial deformation $\left(U_{\mathrm{r}}\right)$ of the cell for different angles when subjected to load was found out by using experimental methods. The $\mathrm{X}$ and $\mathrm{Y}$ coordinates of the cell outer points are noted. The angle between the centroid of the cell and the cell outer points was calculated. The new $U_{r}$ values for these cell outer points are calculated by interpolation. The calculated Ur values was then resolved into $U_{x}$ and $U_{y}$ values and then applied as displacement to the outer points of the cell (Table1). 


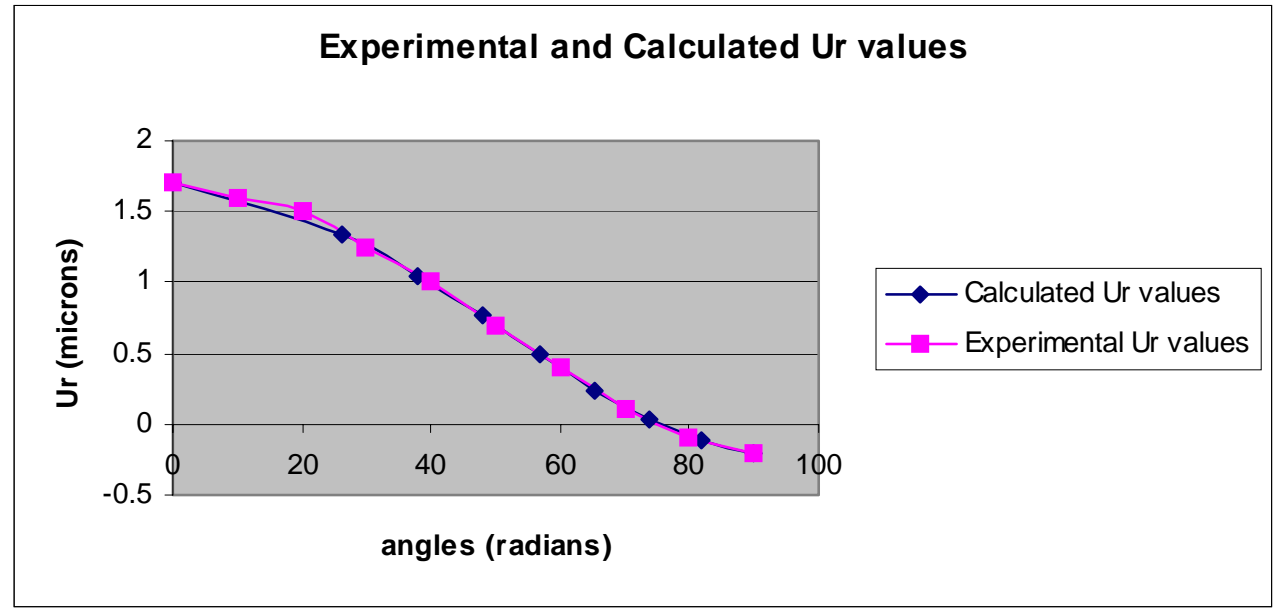

Figure 44 Comparison between the experimental and calculated Ur values

\begin{tabular}{|l|l|l|l|}
\hline $\begin{array}{l}\text { Angle between } \\
\text { the centroid and } \\
\text { the outer points of } \\
\text { the cell (Radians) }\end{array}$ & $\begin{array}{l}\text { Calculat } \\
\text { ed Ur } \\
\text { values } \\
(\mu \mathrm{m})\end{array}$ & $\mathrm{U}_{\mathrm{x}}=\mathrm{U}_{\mathrm{r}} \cos \theta$ & $\mathrm{U}_{\mathrm{y}}=\mathrm{U}_{\mathrm{r}} \cos \theta$ \\
\hline 0 & 1.7 & 1.7 & 0 \\
\hline 26.03 & 1.34 & 1.20 & 0.58 \\
\hline 37.91 & 1.052 & 0.82 & 0.64 \\
\hline 47.80 & 0.766 & 0.51 & 0.56 \\
\hline 56.79 & 0.4963 & 0.27 & 0.41 \\
\hline 65.38 & 0.2386 & 0.09 & 0.21 \\
\hline 73.70 & 0.026 & 0.007 & 0.02 \\
\hline 81.879 & -0.1187 & -0.0155 & -0.11 \\
\hline 90.0 & -0.2 & 0 & -0.2 \\
\hline
\end{tabular}

Table 1 Resolving the $U_{r}$ values into $U_{x}$ and $U_{y}$ values

\subsection{Modeling the cell}

The cell membrane is a semi permeable one through which fluid flow takes place. The semi permeable cell membrane was modeled using the distributed 
resistance concept in ANSYS. The distributed resistance to an element can be applied through real constants [11]. The resistance to flow modeled, was due to combinations of three factors, which are localized head loss $(K)$, friction factor (f) or permeability $(C)$ [11]. Permeability factor was used in our model to give the resistance for the flow and the value used in the distributed resistance should have the unit $1 /$ length ${ }^{2}$. The permeability value of the cell membrane was already found to be $4.16 \mathrm{e}-{ }^{17} \mathrm{~m}^{4} / \mathrm{N} . \mathrm{S}$ [9]. This value should be converted into a value that can be inputted in the ANSYS software. The flow rate of a fluid through a porous material was proportional to the hydrostatic pressure difference $(\delta \mathrm{P})$ across the specimen, inversely proportional to the length of the specimen (L) and proportional to the cross sectional area (A). This can be expressed as

$$
\mathrm{Q}=\mathrm{kA} \mathrm{A} \mathrm{P} / \mathrm{L}[15]
$$

The above equation is called as Darcy's law. The term $\mathrm{Q} / \mathrm{A}$ is the flow rate, flux or Darcy's constant $(\mathrm{u})$ which makes the equation as $\mathrm{u}=\mathrm{k} \delta \mathrm{P} / \mathrm{L}$. Darcy's equation can also be represented as $\mathrm{u}=\mathrm{k} \delta \mathrm{P}$, where $\mathrm{u}$ was the vector flow velocity. The hydrostatic pressure is normally expressed as pressure potential $\mathrm{P}=\mathrm{p} / \mathrm{\rho g}$, where $\rho$ is the liquid density. $\mathrm{P}$ has dimension L and was entirely equivalent to the hydrostatic head. Darcy's law is then expressed as

$$
\mathrm{u}=-\mathrm{K}_{\mathrm{S}} \delta \mathrm{P}[15]
$$

Where $K_{s}=K \rho g$. The $K_{s}$ is the permeability of the material, with dimension $\mathrm{LT}^{-1}$.

The inverse of intrinsic permeability value should be entered in the ANSYS software. Intrinsic permeability is a property of a porous medium, which determines the ease with which a fluid will move through a material. The permeability value depends both on the material and the fluid. The permeability value for newtonian liquids in laminar flow in 
inert non-swelling media was inversely proportional to the fluid viscosity $\eta$ [15]. Therefore the intrinsic permeability for the material is defined as $k^{\prime}=k \eta$ in which $k^{\prime}$ is a material property independent of the fluid and has dimension $\mathrm{L}^{2}$.

The intrinsic permeability value that has to be inputted in the ANSYS software was the permeability of material multiplied by the viscosity of the fluid inside the cell. The fluid inside the cell was assumed to be water and the inverse of intrinsic permeability of the cell is found out to be $0.301 \mathrm{e} 171 / \mathrm{m}^{2}$.

\subsection{Validation}

The cell was modeled with the inner fluid and cell membrane. The calculated porosity value was then applied to the cell model to make the model as a semi permeable one. Doing some simple analysis the cell model was validated.

Day 1 cell model with lower porosity value:

A Dayl cell model was taken and it was modeled without any inner elements. The porosity value was then assigned to the cell model and the material properties for the solid element such as young's modulus and poisson's ratio and the fluid element such as viscosity and density were assigned. The fluid solid interaction analysis was given for the model and the pressure of the fluid inside the cell was noted down.

Material properties:

Thickness: $0.1 \mu \mathrm{m}[4]$

Young's modulus: 0.1 Mpa [5]

Fluid (water) properties:

Density: $1000 \mathrm{e}-18 \mathrm{~kg} / \mu \mathrm{m}^{3}$

Viscosity: $0.798 \mathrm{e}-12 \mathrm{~kg} / \mu \mathrm{m}$-second [14] 
Porosity: $0.301 \mathrm{e} 51 / \mu^{2}$

Modeling:

Plane 82 was assigned for the cell membrane since it has a compatible

displacement shapes and is well suited to model curved boundaries. The plane 82 is a 2-D 8 node structural solid element, which has plasticity, creep, swelling, stress stiffening, large deflection and large strain capabilities. Fluid 141 was used for the fluid inside the cell since the element is a 2-D element. The ALE option was made on for the fluid element.

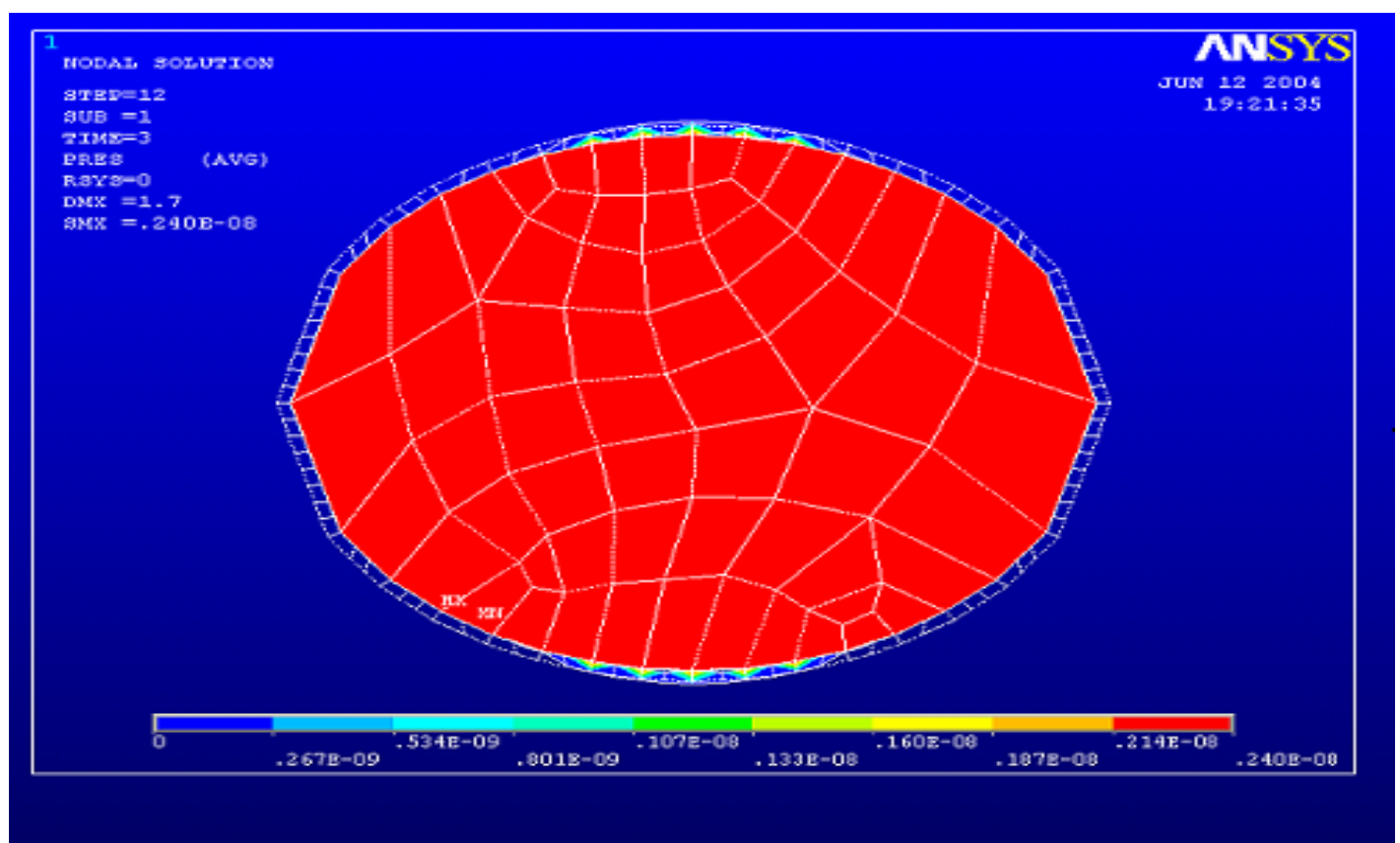

Figure 45 Pressure of the fluid element for a cell model with lower porosity value

The fluid element was meshed and the boundary condition was given to it. Fluid solid interaction boundary condition was given to all the lines of the fluid element and the solid element and displacement are given to all the lines of the solid element. The loading condition was made as a ramped and the analysis was solved for 3 seconds. The pressure variation of the fluid is noted down (see Figure 45). 
Day 1 cell model with higher porosity value:

Another analysis was carried out with higher porosity value. The material properties and elements are made the same and the porosity value was changed.

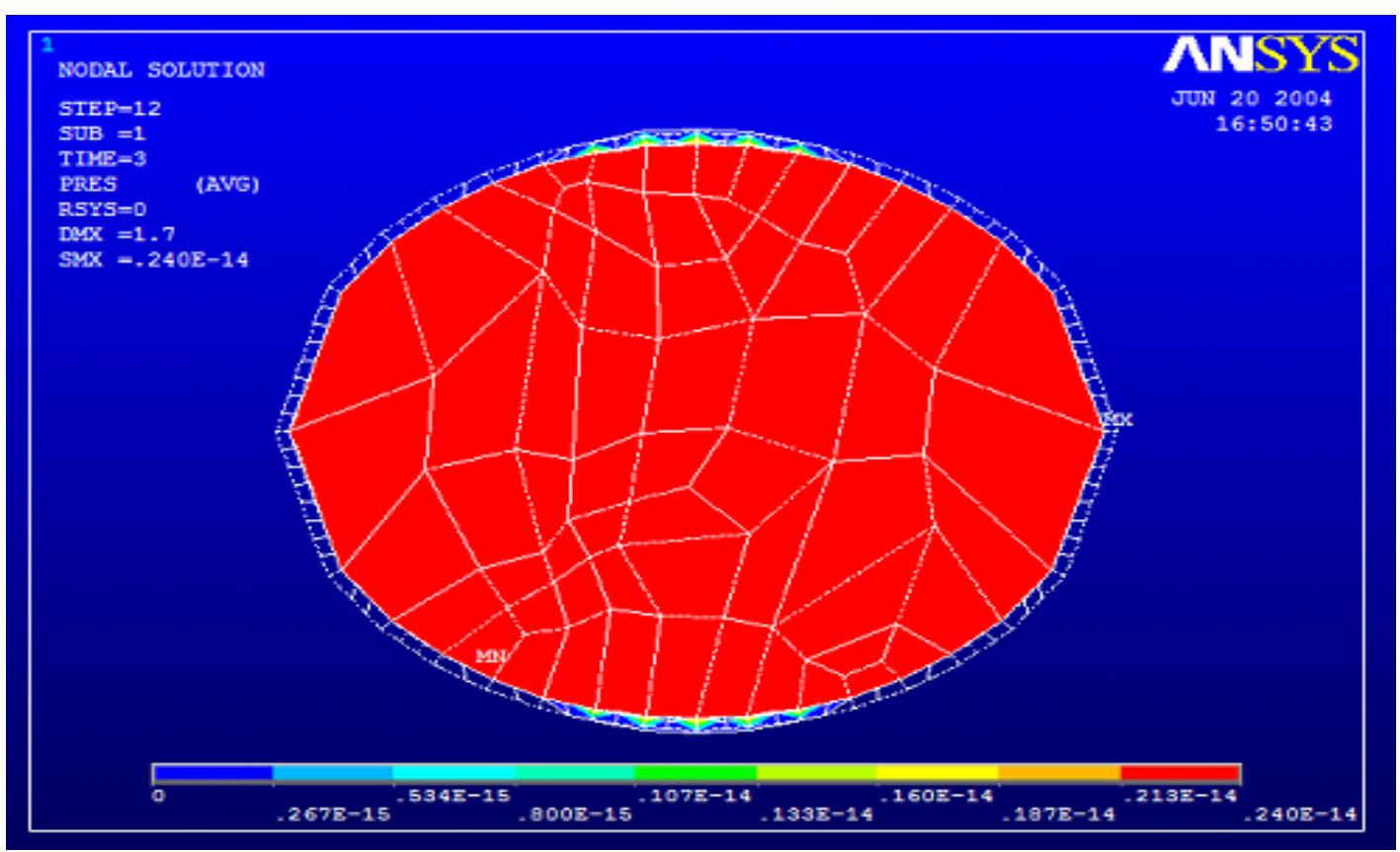

Figure 46 Pressure of the fluid element for a cell model with high porosity

The porosity value used for this model was $0.301 \mathrm{e} 101 / \mu^{2}$. The analysis was made to run for 3 seconds and the pressure of the fluid inside the cell was noted down (see Figure46)

Stress acting on the Cell membrane with and without fluid

An analysis was performed to find the Von mises stress acting on the cell membrane with and without inner fluid. Fluid solid interaction analysis is used to solve the model with the inner fluid and structural analysis is used to solve the model without any fluid. 
Material Properties:

Thickness: $0.1 \mu \mathrm{m}[4]$

Young's modulus: 0.1 Mpa [5]

Poisson's ratio $=0.3$

Fluid (water) properties:

Density: $1000 \mathrm{e}-18 \mathrm{~kg} / \mu \mathrm{m}^{3}$

Viscosity: $0.798 \mathrm{e}-12 \mathrm{~kg} / \mu \mathrm{m}$-second [14]

Fluid 141 element was used for the fluid element and Plane 82 was used for the solid element. ALE option was made on for the fluid element. Structural analysis was performed on the solid element with out any intracellular fluid and the stresses acting on the cell membrane was found out. The fluid solid interaction analysis was used to find the Von mises stress acting on the cell membrane for the cell model with intracellular fluid.

The Von mises stress acting on the cell membrane for both the cases were then compared

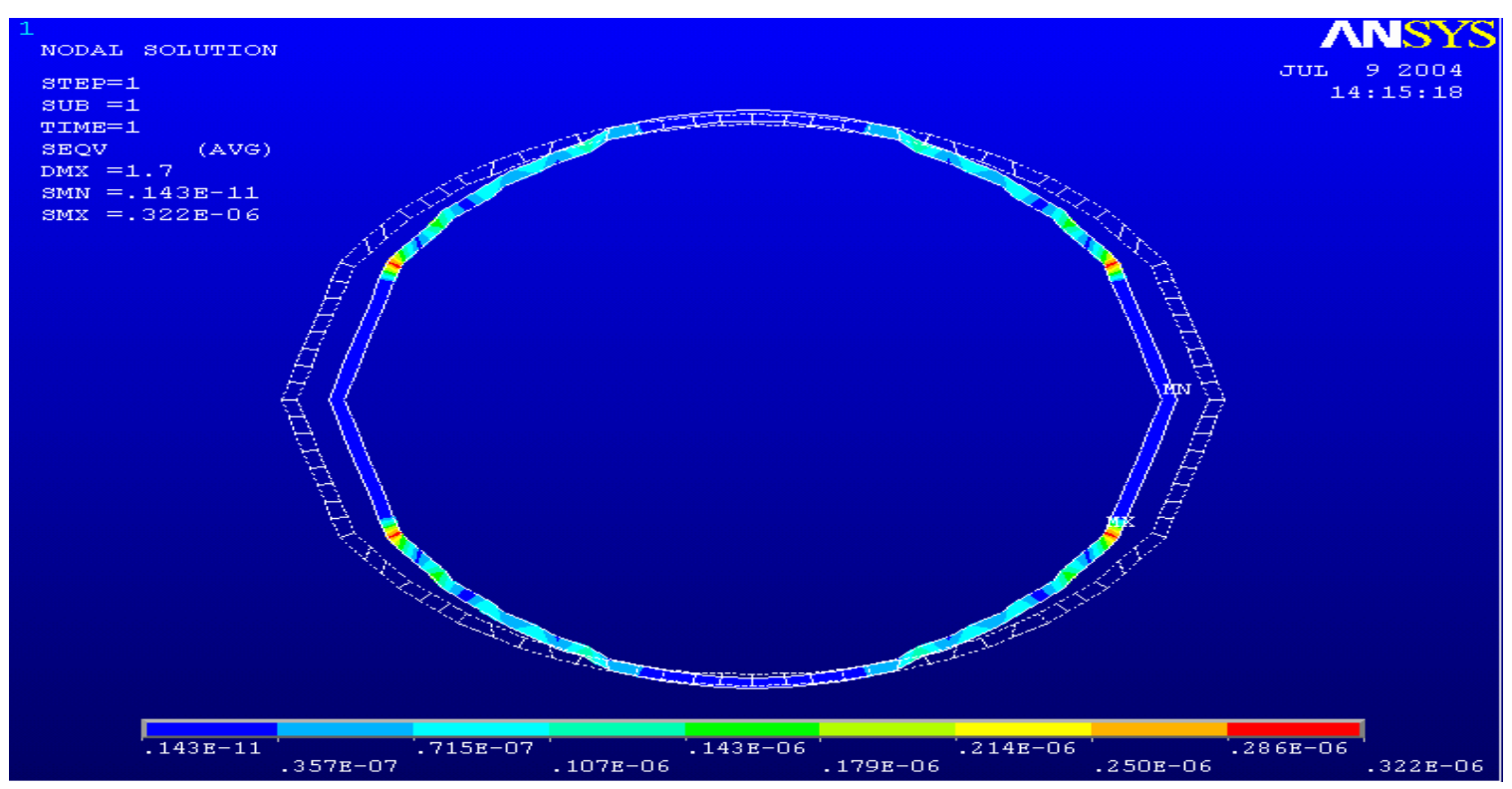

Figure 47 Von mises stress acting on the cell membrane without any inner fluid element 


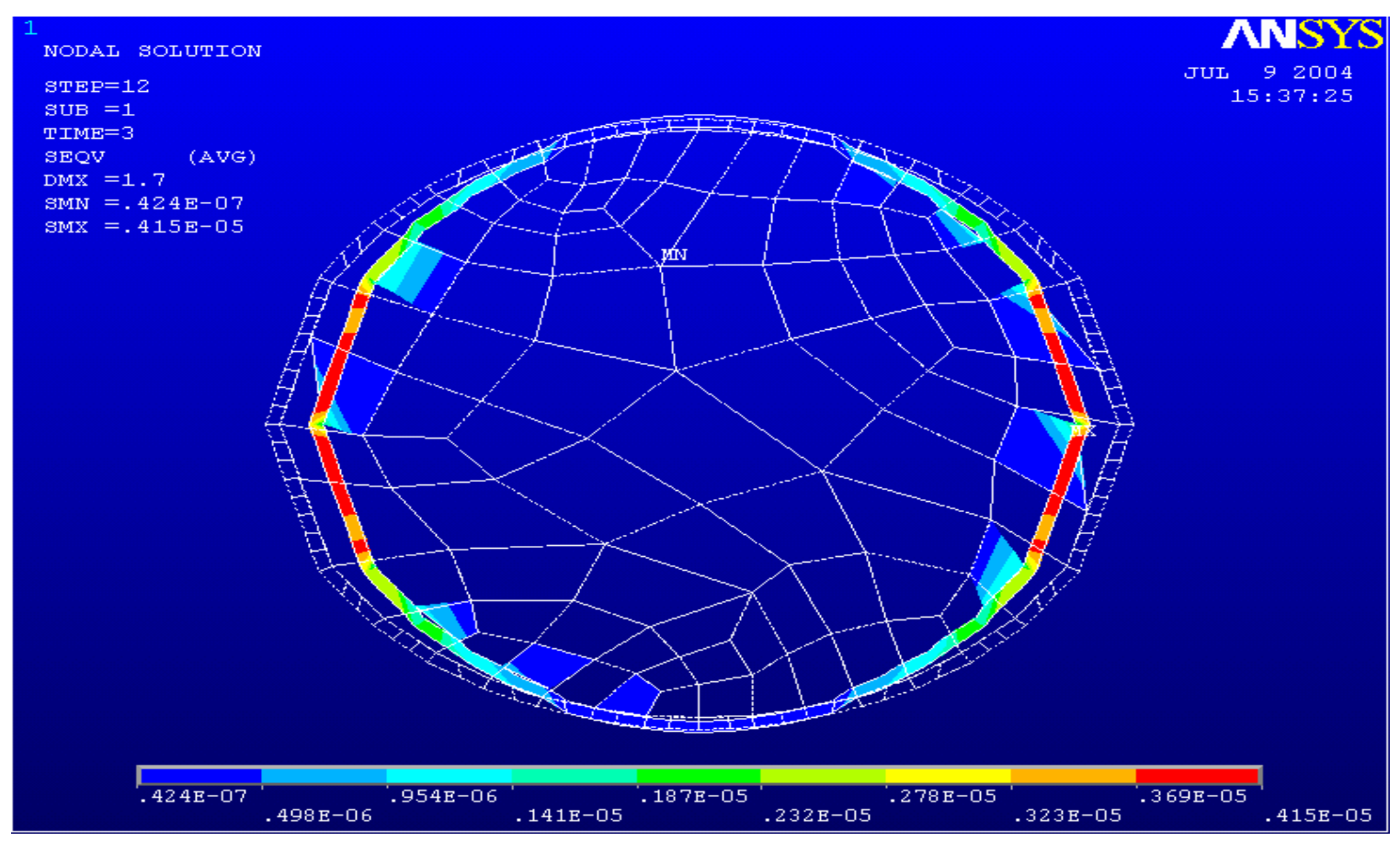

Figure 48 Von mises stress acting on the cell membrane with inner fluid element

\subsubsection{Conclusion}

From the above graphs and images it was clear that the pressure of the fluid decreases with increase in porosity and vice versa (Figure 45, 46). The Von mises stress acting on the cell membrane was higher with the presence of inner fluid when compared with the stresses acting on the cell membrane without any inner fluid (Figure48, 49). The model was validated through this simple analysis.

\subsection{Fluid solid interaction analysis for Day1 cell model}

The cell was modeled using MATLAB program. Four sets of dayl cell model are modeled and the analysis was done on all the four sets. The Dayl cell model was biologically called as Pre-chondrocytes. Displacements are applied on the cell membrane and the pressure and velocity variation of the fluid with respect to time was noted down. Von mises stress was also calculated for the cell membrane through the fluid 
solid interaction analysis. The pressure and velocity of the fluid found from this analysis was used to find the stresses acting in the individual actin filaments. A separate analysis was used to find the stresses acting on the actin filaments.

Material properties for solid element

Young's modulus $=0.1 \mathrm{Mpa}$

Thickness $=0.1 \mu \mathrm{m}$

Fluid properties (Water)

Density: $1000 \mathrm{e}-18 \mathrm{~kg} / \mu^{3}$

Viscosity: 0.798e-12 kg/ $\mu \mathrm{m}$-second [14]

Porosity: 0.301e $51 / \mu \mathrm{m}^{2}$

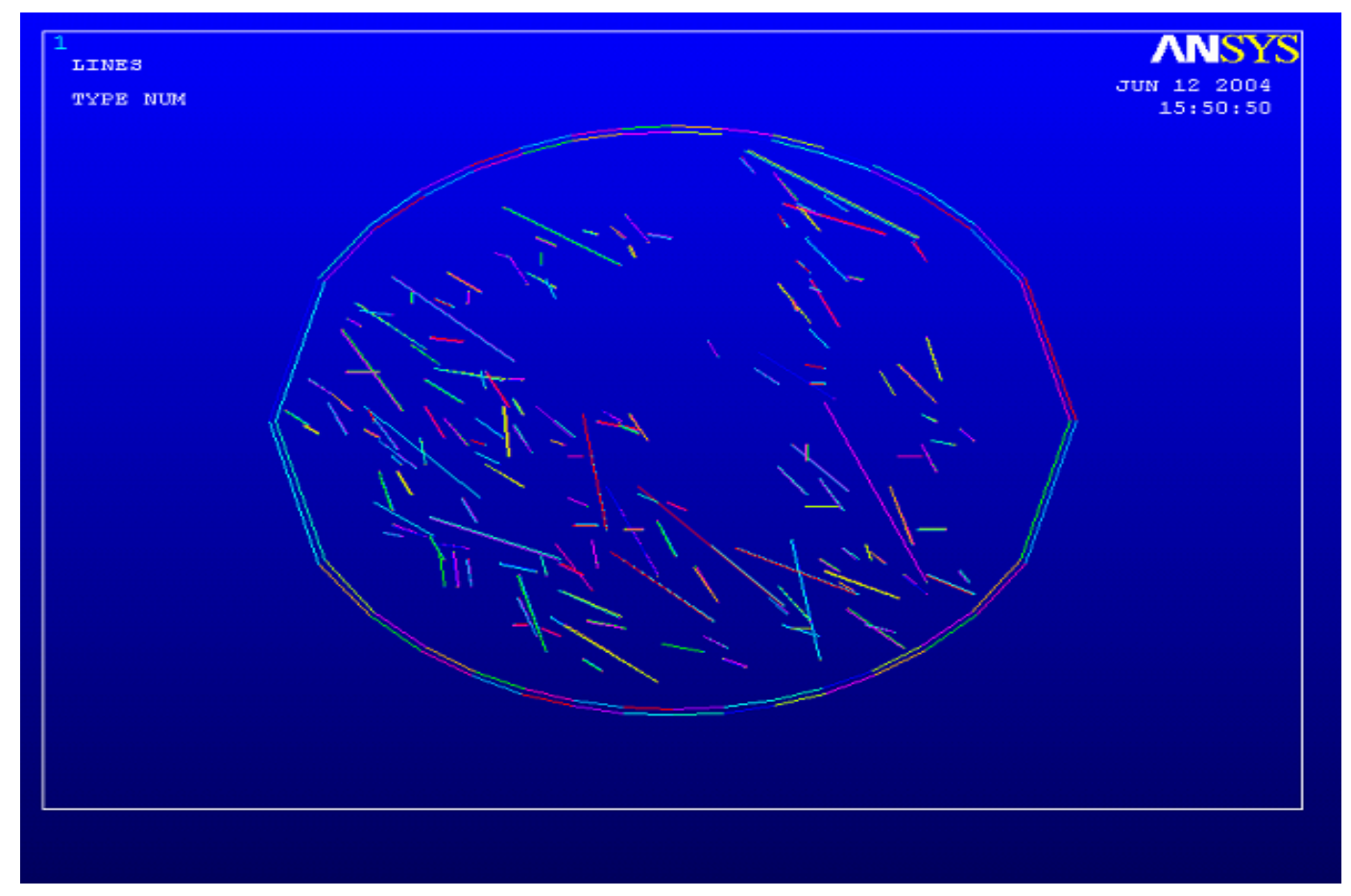

Figure 49 Day1 cell model (Pre-chondrocyte) with actin filaments 
Modeling:

A Dayl cell was modeled with cell membrane and fluid inside it. Plane 82 was assigned to the solid element and Fluid141 was assigned to the fluid element inside the cell. The ALE option was made on for the fluid element. The fluid element was first meshed and the porosity value for the fluid element was assigned to it. The fluid solid interaction boundary condition was given to the lines of the fluid element, which interacts with the solid. The velocity of the fluid was made zero by giving the initial boundary condition option. The material properties were then assigned to the solid element and then meshed. The fluid solid interaction boundary condition was given to the lines of the solid element, which interacts with the fluid. The same interface number was used when defining fluid solid interaction boundary condition. The Ur values, which are resolved into $\mathrm{U}_{\mathrm{x}}$ and $\mathrm{U}_{\mathrm{y}}$ values, were then applied as displacement on the cell membrane. The displacement was applied as a ramped load .The fluid properties and the solution option such as convergence, relaxation, and time increment and end time were specified. The analysis was made to run for 3 seconds with 0.25 seconds time increment. The pressure and velocity of the fluid and the von mises stress acting on the Dayl cell model was found out from this analysis. 


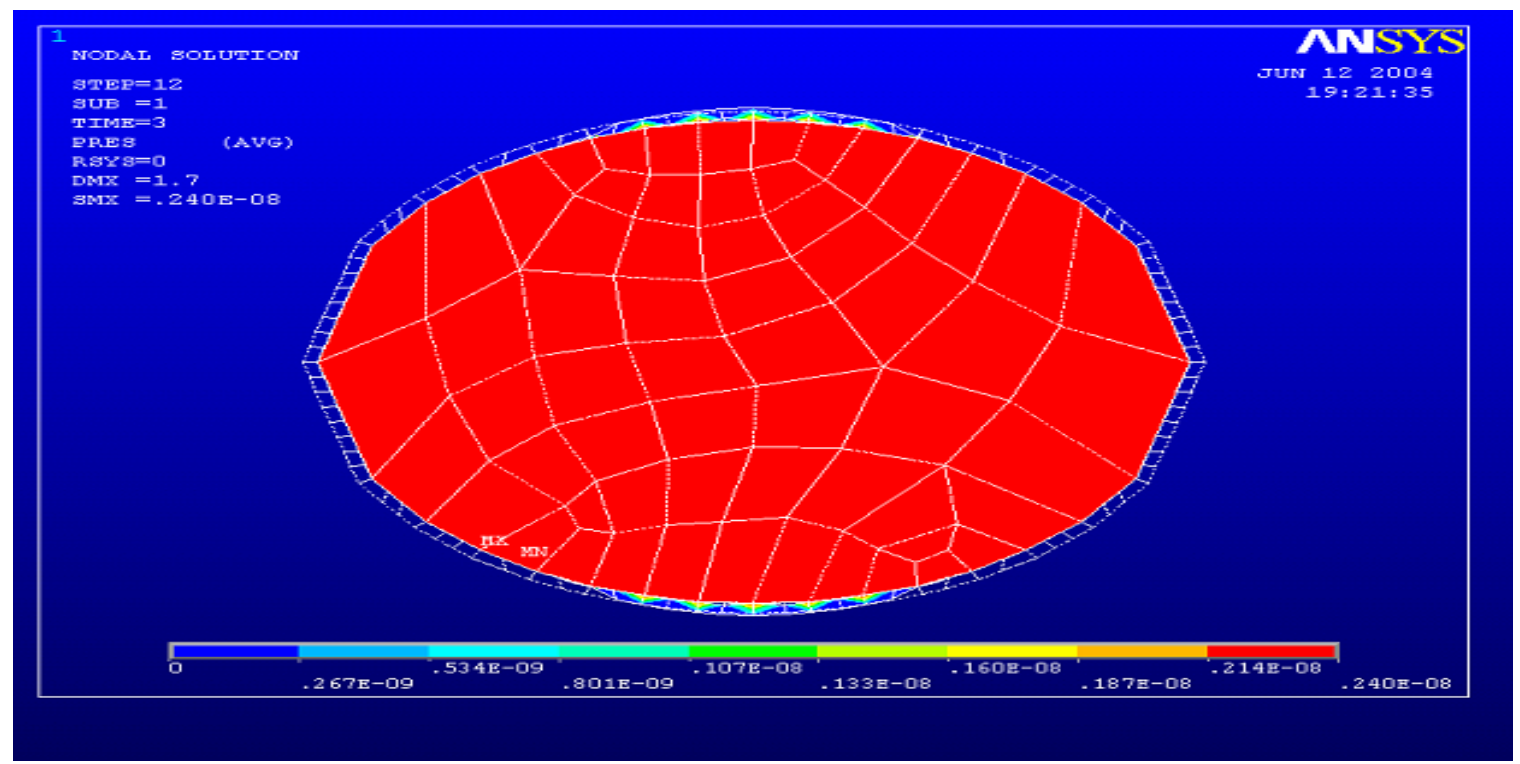

Figure 50 Intracellular fluid pressure in Day1 cell model

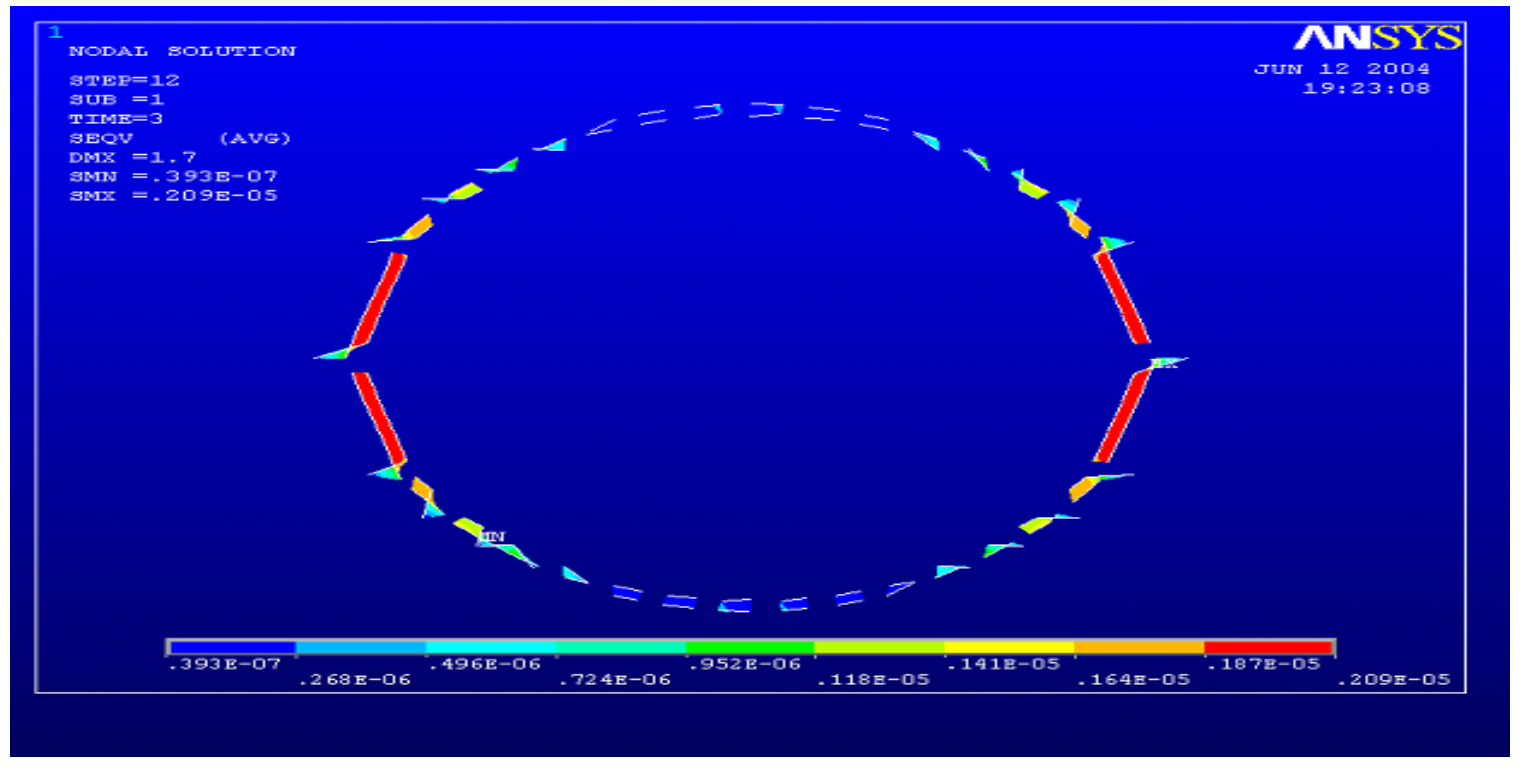

Figure 51 Von mises stress acting on the cell membrane in Day1 cell model 


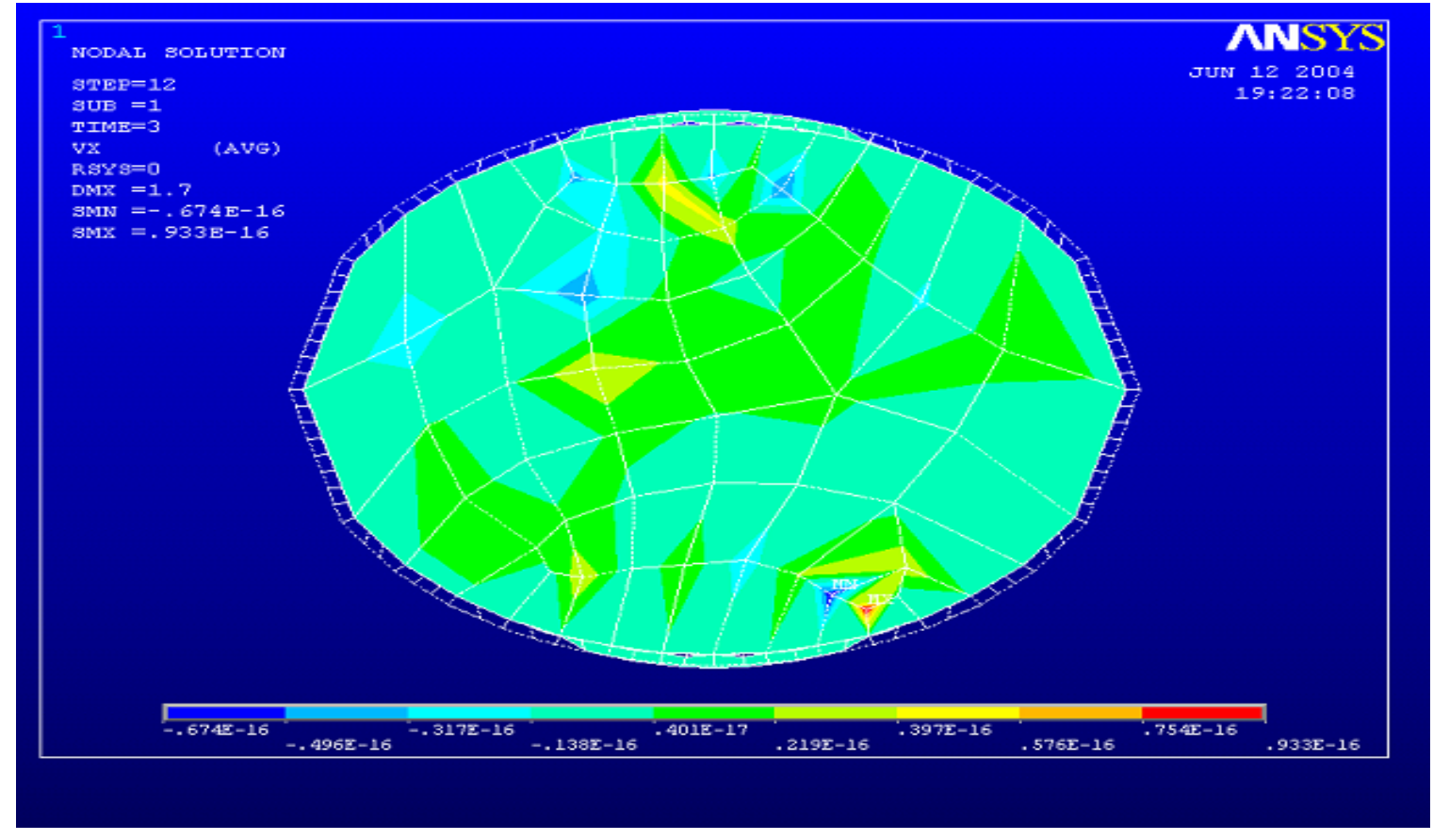

Figure 52 Velocity of the fluid element in X-direction for Day1 cell model

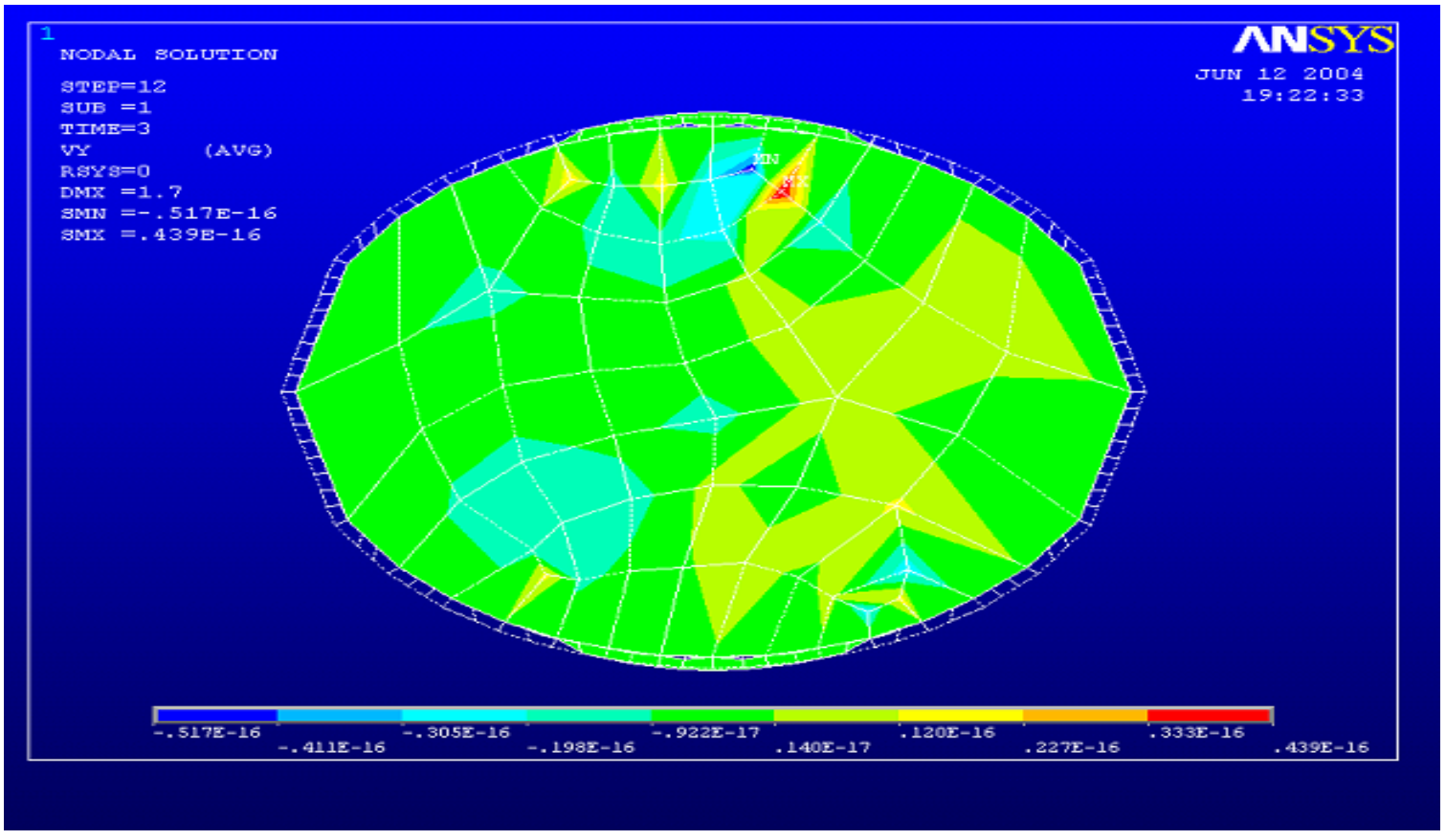

Figure 53 Velocity of the fluid element in Y -direction for Day1 cell model 
Fluid properties and the Von mises stress acting on the four different sets of Dayl cell model when subjected to compressive load was given in the following table

\begin{tabular}{|c|c|c|c|c|}
\hline Model & $\begin{array}{l}\text { Pressure } \\
\left(\mathrm{N} / \mu \mathrm{m}^{2}\right)\end{array}$ & $\begin{array}{l}\text { Von mises } \\
\text { stress }\left(\mathrm{N} / \mu \mathrm{m}^{2}\right)\end{array}$ & $\begin{array}{l}\text { Velocity in X- } \\
\text { Direction } \\
(\mu \mathrm{m} / \text { second })\end{array}$ & $\begin{array}{l}\text { Velocity in Y- } \\
\text { Direction }(\mu \mathrm{m} \\
\text { /second) }\end{array}$ \\
\hline 1 & $0-0.240 \mathrm{E}-08$ & $\begin{array}{l}0.393 \mathrm{E}-07- \\
0.209 \mathrm{E}-05\end{array}$ & $\begin{array}{l}-0.674 \mathrm{E}-16- \\
0.933 \mathrm{E}-16\end{array}$ & $\begin{array}{l}-0.517 \mathrm{E}-16- \\
0.439 \mathrm{E}-16\end{array}$ \\
\hline 2 & $0-0.217 \mathrm{E}-08$ & $\begin{array}{l}0.111 \mathrm{E}-07- \\
0.891 \mathrm{E}-06 \\
\end{array}$ & $\begin{array}{l}-0.613 \mathrm{E}-14- \\
0.173 \mathrm{E}-13 \\
\end{array}$ & $\begin{array}{l}-0.834 \mathrm{E}-14- \\
0.311 \mathrm{E}-14 \\
\end{array}$ \\
\hline 3 & $0-0.192 \mathrm{E}-08$ & $\begin{array}{l}0.553 \mathrm{E}-08- \\
0.829 \mathrm{E}-06\end{array}$ & $\begin{array}{l}-0.123 \mathrm{E}-13- \\
0.293 \mathrm{E}-14\end{array}$ & $\begin{array}{l}-0.596 \mathrm{E}-14- \\
0.441 \mathrm{E}-14\end{array}$ \\
\hline 4 & $0-0.246 \mathrm{E}-09$ & $\begin{array}{l}0.102 \mathrm{E}-07- \\
0.795 \mathrm{E}-06\end{array}$ & $\begin{array}{l}-0.286 \mathrm{E}-14- \\
0.620 \mathrm{E}-15 \\
\end{array}$ & $\begin{array}{l}-0.865 \mathrm{E}-15- \\
0.941 \mathrm{E}-15 \\
\end{array}$ \\
\hline
\end{tabular}

Table 2 Fluid properties and the Von mises stress acting on the four sets of Day1 cell model when subjected to compressive loading 


\subsection{Fluid solid interaction analysis for Day12 cell model}

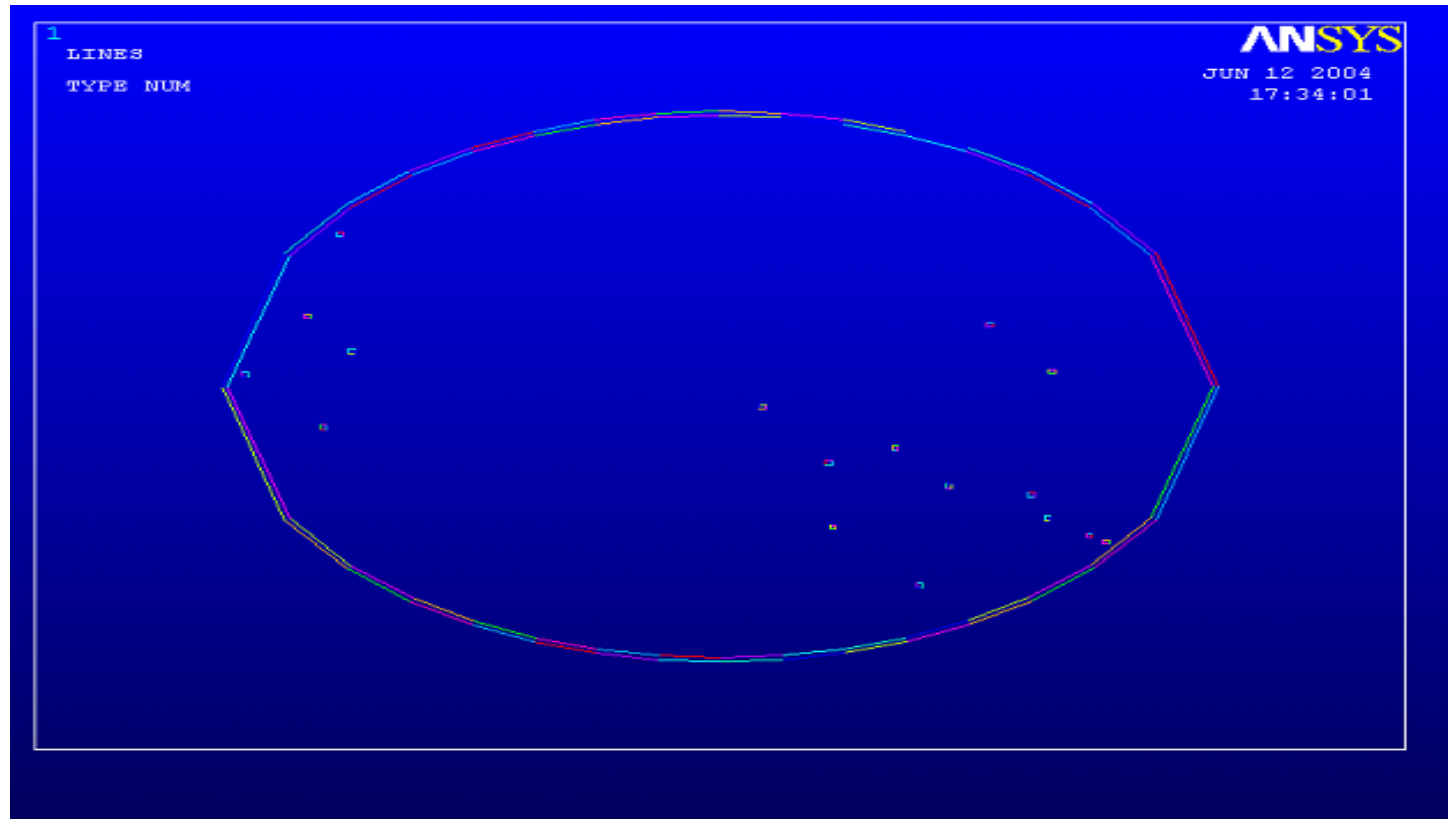

Figure 54 Day12 cell model (Chondrocyte) with actin filaments

Four sets of Day12 model were taken and the analysis was done on all the

fours sets. Similar to the Dayl cell model the Day12 cell model was also modeled. The Day12 cell model was biologically called as chondrocytes. In Day12 the actins have a 'punctuate' like appearance (Figure 55). The stresses acting in this actin filaments when the cell was subjected to compressive load were found by physics environment analysis, which was explained later in this chapter.

Material properties for solid element

Young's modulus $=0.1 \mathrm{Mpa}$

Thickness $=0.1 \mu \mathrm{m}$

Fluid Properties (Water)

Density: $1000 \mathrm{e}-18 \mathrm{~kg} / \mu^{3}$ 
Viscosity: $0.798 \mathrm{e}-09 \mathrm{~kg} / \mu \mathrm{m}$-second [14]

Porosity: $0.301233 \mathrm{e} 51 / \mu \mathrm{m}^{2}$

Modeling:

Plane 82 was assigned to the solid element and Fluid 141 was assigned to the fluid inside the cell. The ALE option was made on for the fluid element. The fluid element was meshed and the fluid solid interaction boundary condition was given to it. The initial fluid velocity was made zero. The material properties were then assigned to the solid element. The solid element was then meshed and the fluid solid interaction boundary conditions were given to the lines of the solid element, which interacts with the fluid. The displacements were then applied on all the lines of the solid element and the analysis was made to run for 3 seconds with 0.25 seconds time increment. 


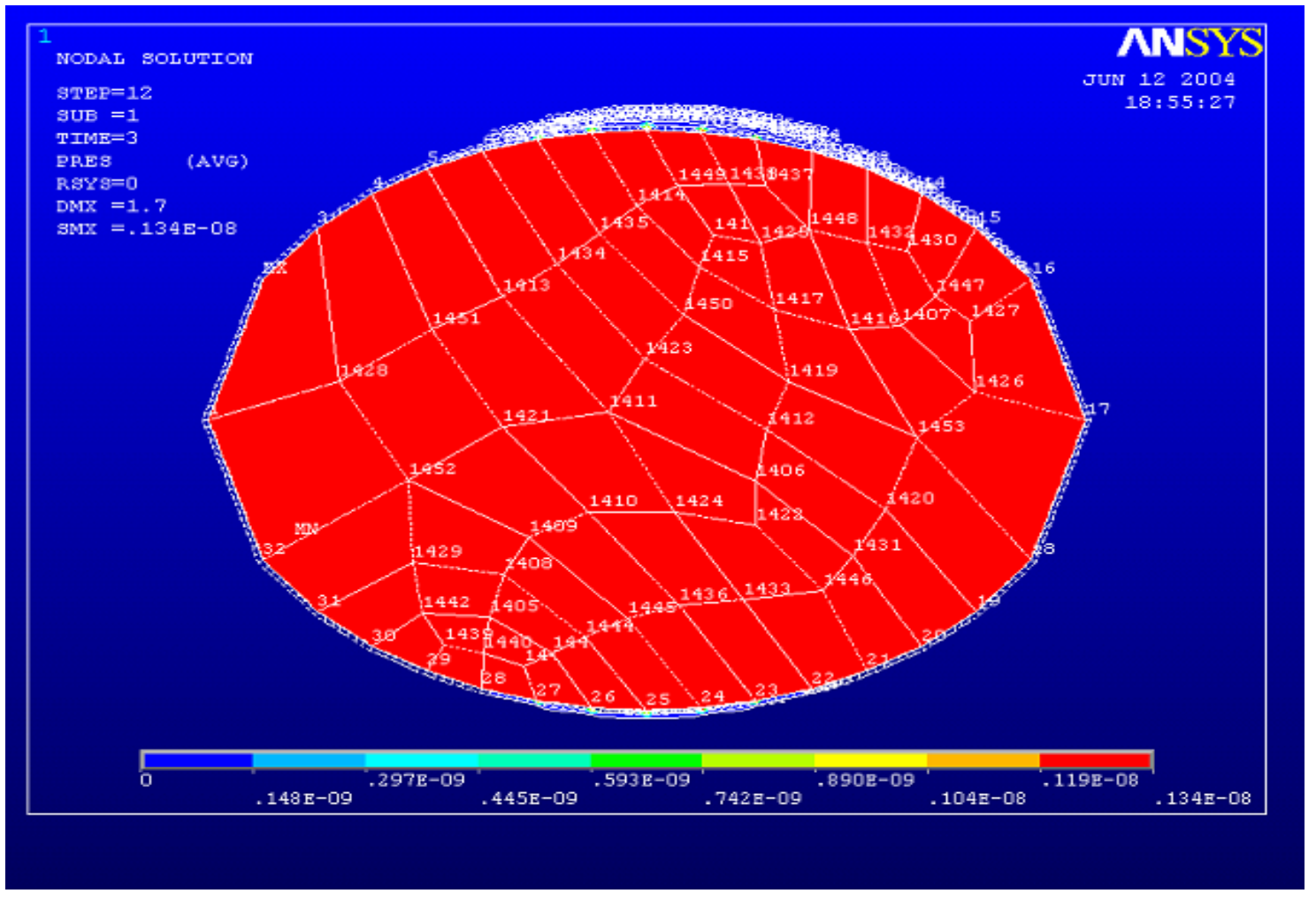

Figure 55 Intracellular fluid pressure in a Day12 cell model

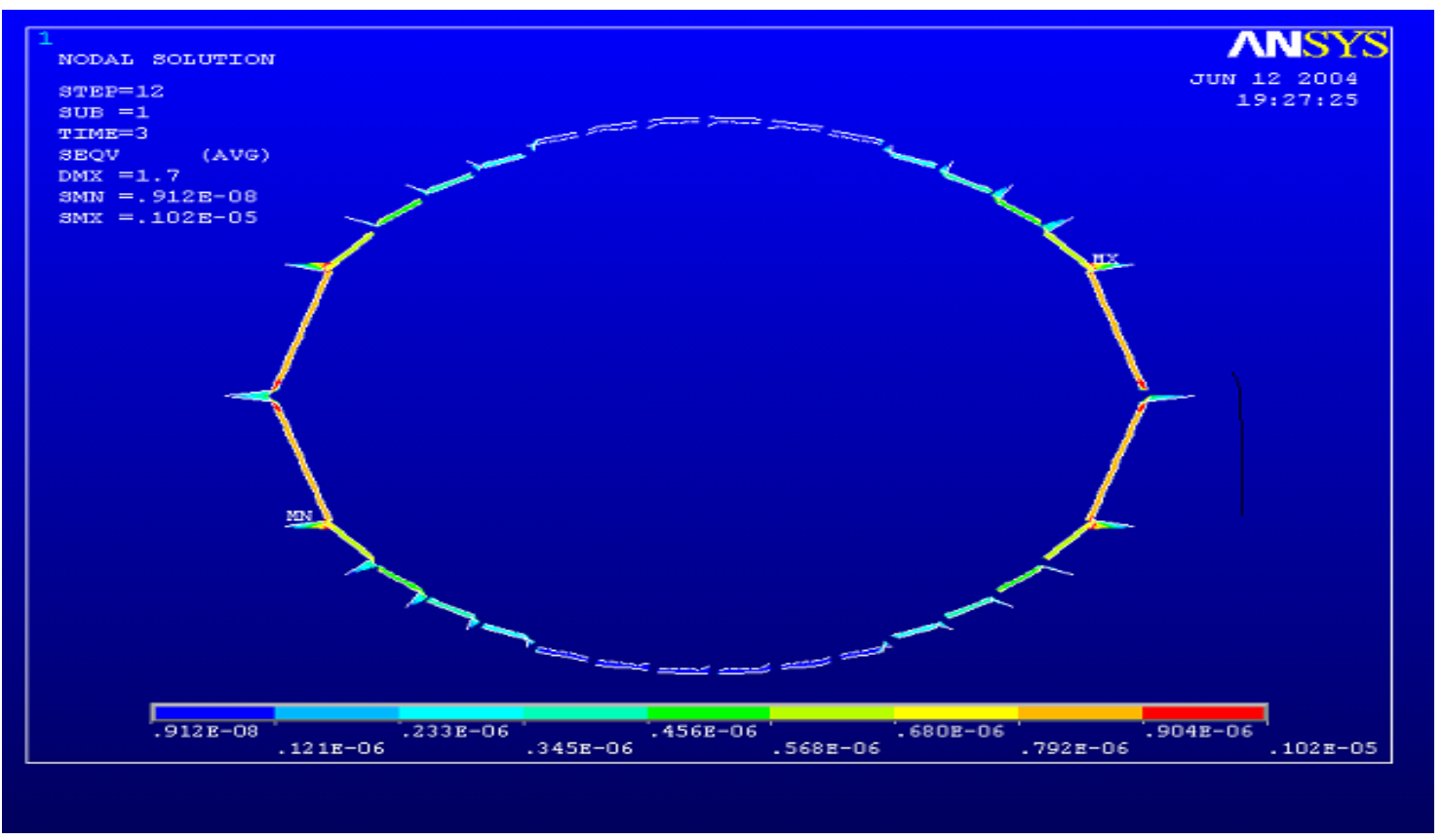

Figure 56 Von mises stress acting on the cell membrane in a Day1 cell model 


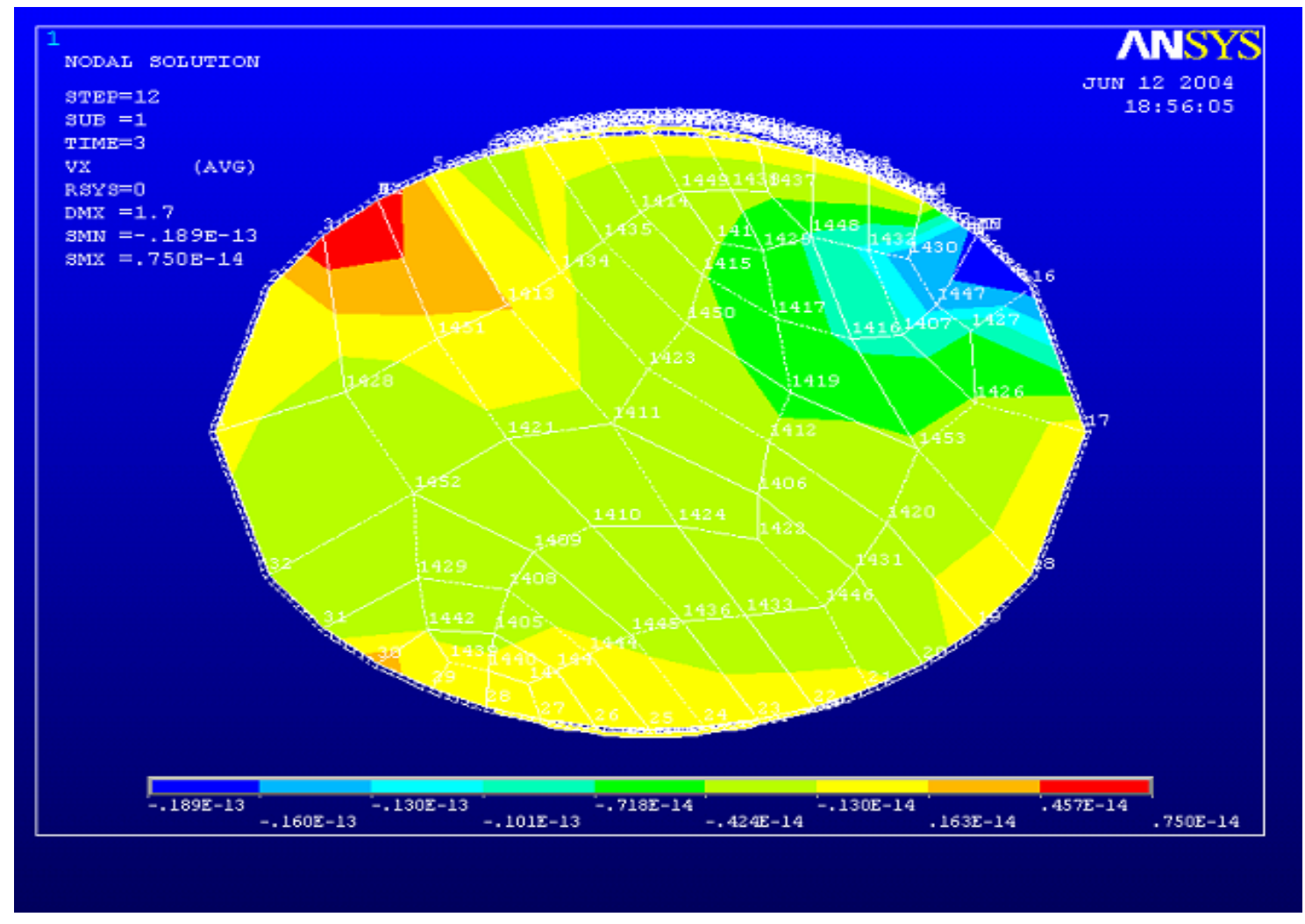

Figure 57 Velocity of the fluid element in X-direction for Day12 cell model

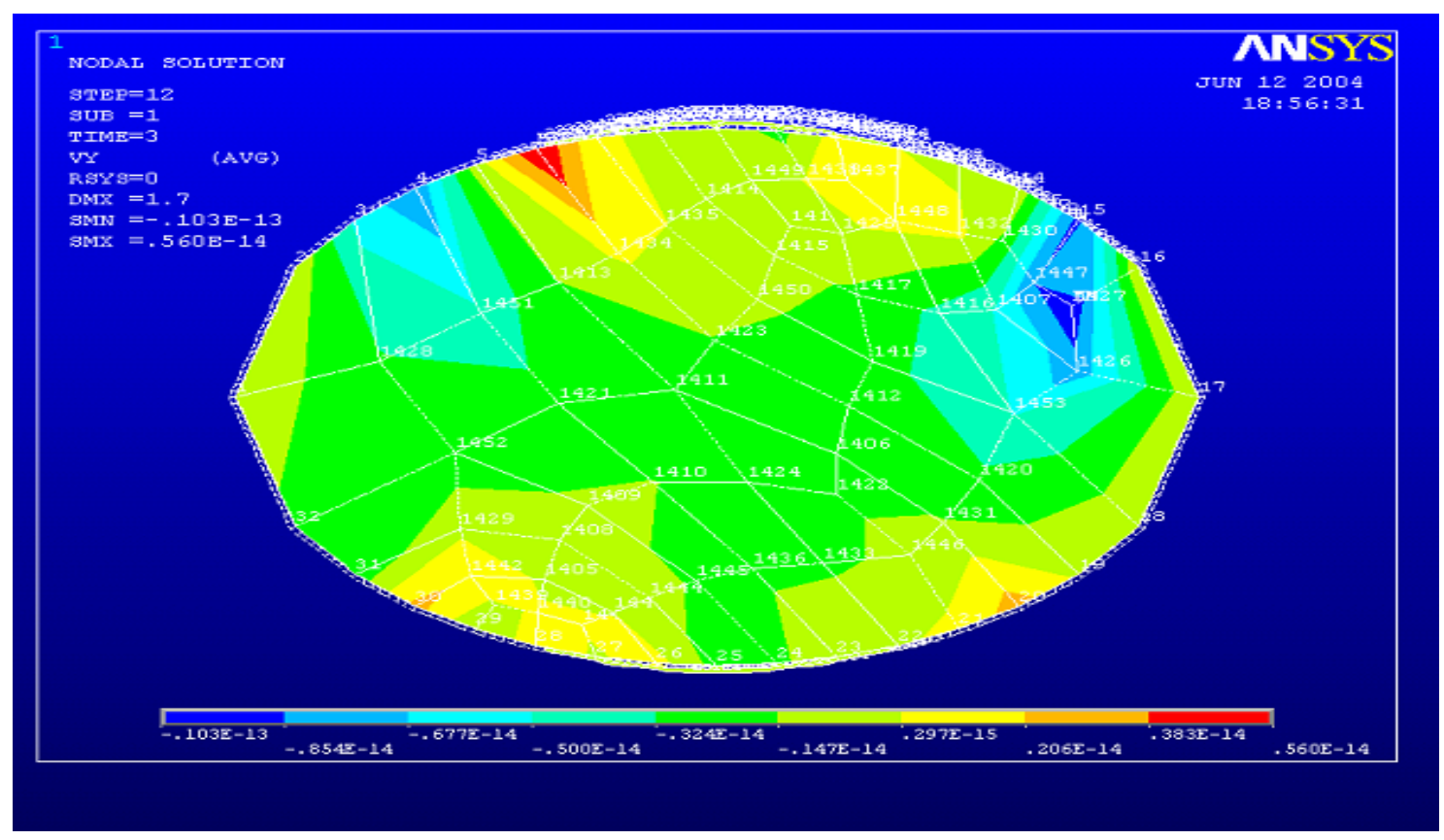

Figure 58 Velocity of the fluid element in Y-direction for Day12 cell model 


\begin{tabular}{|l|l|l|l|l|}
\hline Model & $\begin{array}{l}\text { Pressure } \\
\left(\mathrm{N} / \mu \mathrm{m}^{2}\right)\end{array}$ & $\begin{array}{l}\text { Von-mises } \\
\text { stress }\left(\mathrm{N} / \mu \mathrm{m}^{2}\right)\end{array}$ & $\begin{array}{l}\text { Velocity in X- } \\
\text { Direction } \\
(\mu \mathrm{m} / \mathrm{sec}-\mathrm{X} d)\end{array}$ & $\begin{array}{l}\text { Velocity in Y- } \\
\text { Direction } \\
(\mu \mathrm{m} / \mathrm{second})\end{array}$ \\
\hline 1 & $0-0.134 \mathrm{E}-08$ & $\begin{array}{l}0.912 \mathrm{E}-08- \\
0.102 \mathrm{E}-08\end{array}$ & $\begin{array}{l}-0.189 \mathrm{E}-13- \\
0.750 \mathrm{E}-14\end{array}$ & $\begin{array}{l}-0.163 \mathrm{E}-13- \\
0.560 \mathrm{E}-14\end{array}$ \\
\hline 2 & $0-0.948 \mathrm{E}-09$ & $0.446 \mathrm{E}-08-$ & $-0.157 \mathrm{E}-13-$ & $-0.391 \mathrm{E}-14-$ \\
& & $0.705 \mathrm{E}-06$ & $0.159 \mathrm{E}-13$ & $0.128 \mathrm{E}-13$ \\
\hline 3 & $0-0.460 \mathrm{E}-09$ & $0.290 \mathrm{E}-08-$ & $-0.371 \mathrm{E}-14-$ & $-0.407 \mathrm{E}-14-$ \\
& & $0.819 \mathrm{E}-06$ & $0.410 \mathrm{E}-14$ & $0.256 \mathrm{E}-14$ \\
\hline 4 & $0-0.584 \mathrm{E}-09$ & $0.102 \mathrm{E}-07-$ & $-0.815 \mathrm{E}-14-$ & $-0.636 \mathrm{E}-14-$ \\
& & $0.574 \mathrm{E}-06$ & $0.483 \mathrm{E}-14$ & $0.597 \mathrm{E}-14$ \\
\hline
\end{tabular}

Table 3 Fluid properties and Von mises stress acting on four sets of Day12 cell model when subjected to compressive load.

The results for all the fours sets for Day 1 and Day 12 cell model were noted down. Now these results are used to find the stresses acting in the actin filaments for both the Day1 and Day12 cell model.

\subsection{Fluid solid interaction analysis using physics environment}

Physics environment is one of the ways of doing a sequentially coupledfiled analysis. Physics environment creates a file, which contains all characteristics and operating parameter for a particular physics analysis.

The physics environment file can be created using the command PHYSICS, WRITE, title, filename, Ext,

This command creates a physics environment file by taking information such as element types, key opts, real constants, material properties, element coordinate system, analysis option, load options, constraint equations, coupled node set, boundary conditions and applied load, GUI settings and the analysis title from the ANSYS database [16].

PHYSICS, READ, title, file name, Ext,

The above command helps to read the file from the physics environment. The file can be read by using the filename or title of the file. 


\subsubsection{Sequentially coupled field analysis using physics environment}

The data flow for the physics environment has a single database, which contains the nodes and elements for all the physics analysis, which was used. Attribute numbers are defined for the solid model and the attributes should remain constant through out the analysis. The data flows were as follows:

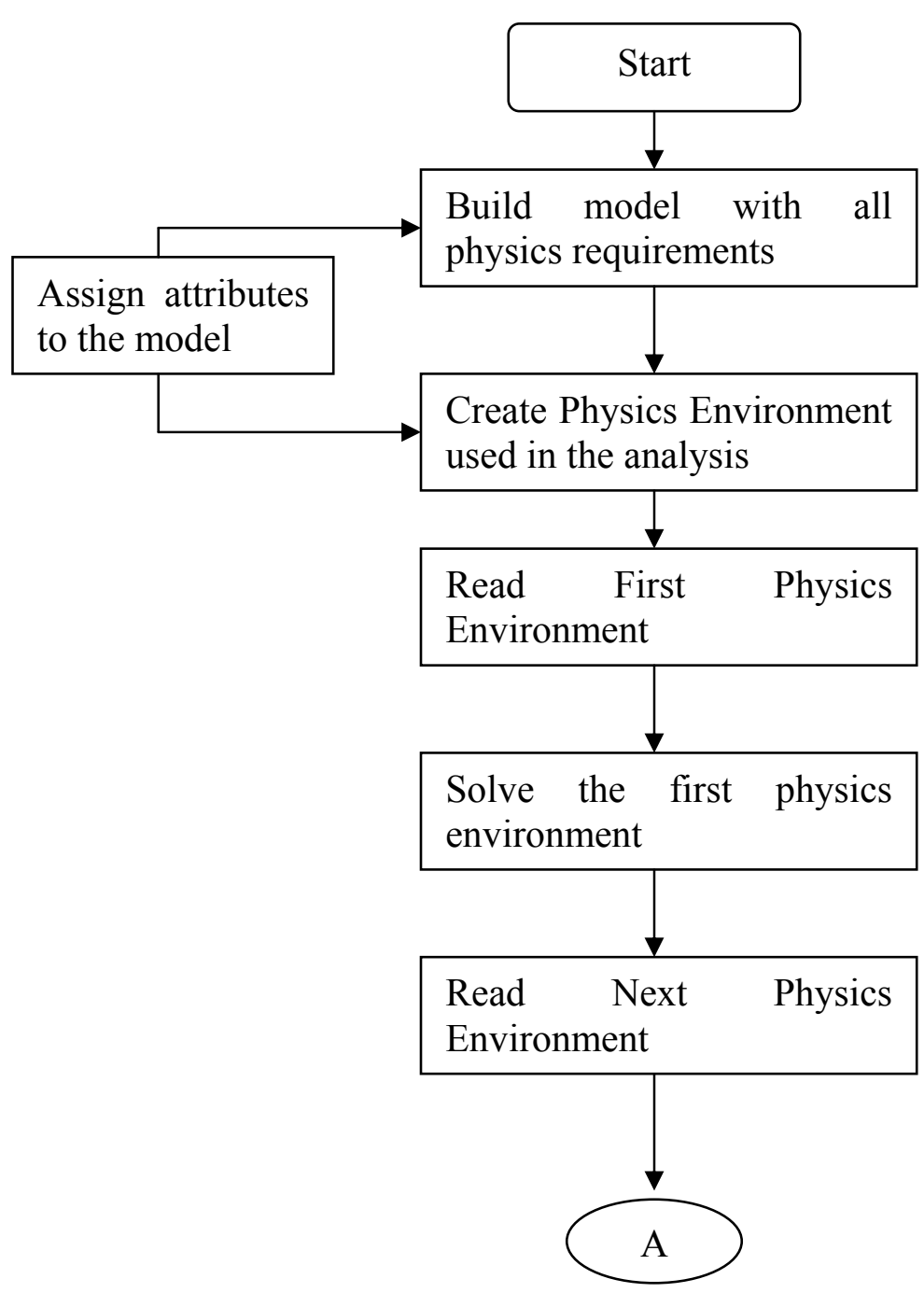




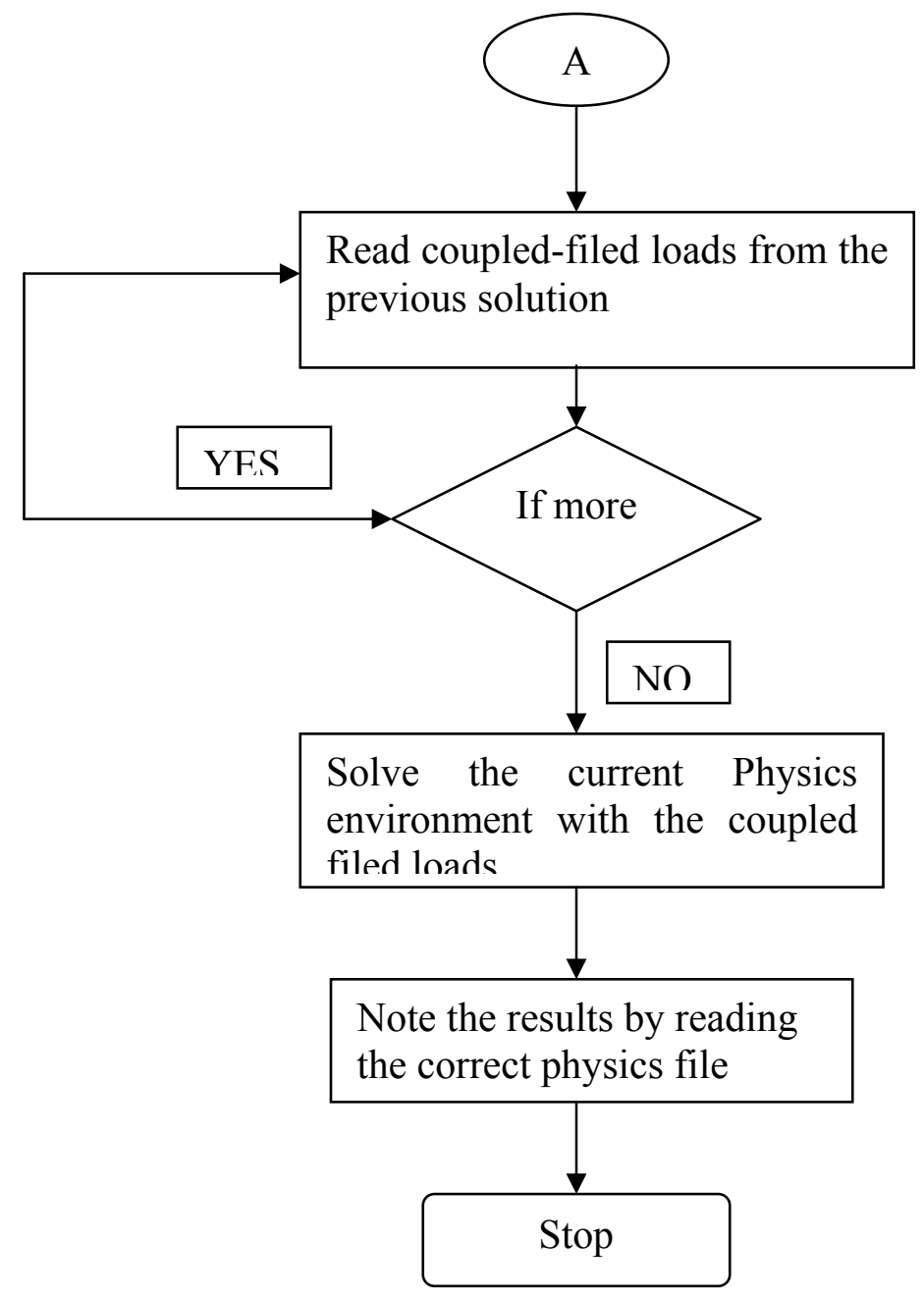

The physics environment approach was ideal for fully coupled scenarios requiring multiple passes between physics solution. Problems involving large defection steady state fluid structure interaction or induction heating can be solved using the physics approach [16].

\subsubsection{Stress acting on the actin filaments}

The chondrocyte was composed of three types of protein networks. They are actins, microtubules and intermediate filaments. Actins play an important role in a number of cellular events. When the cell is subjected to a compressive load the fluid inside the cell moves with a velocity and pressure and hits the inner elements of the cell 
causing stresses on them. From the previous fluid solid interaction analysis between the cell membrane and the fluid inside the cell the fluid velocity and pressure was found out. In this physics approach the pressure and the velocity of the fluid was inputted as load acting on the individual actin filaments and the stresses acting on them was found.

The fluid inside the cell was assumed to be water and the density and viscosity of water was given to the fluid element for this analysis.

Material properties of Actins

Young's Modulus $=0.363 \mathrm{e}-03 \mathrm{~N} / \mu \mathrm{m}^{2}$

Properties for fluid

Density $=1.0 \mathrm{e}-15 \mathrm{Kg} / \mu \mathrm{m}^{3}$

Viscosity $=0.798 \mathrm{e}-9 \mathrm{Kg} / \mu \mathrm{m}$-second

Modeling:

The analysis was done for two models (pre-chondrocytes and chondrocytes). The actins in pre-chondrocytes are long and slender and in chondrocytes it is short and stub. Fluid 141 was used for the fluid element and plane 42 was used for the solid element. The model was created and the elements are assigned to them and meshed. The physics environment for the fluid was created. In this case the fluid element 141 was assigned to the fluid model and null element was used for the solid model. The properties for the fluid and the boundary condition to the model were specified. The pressure and the velocity value obtained from the fluid solid interaction analysis were given as an inlet condition. The area that was needed for morphing is selected. These data are written to the physics file with title 'fluid'. Then it was cleared. Now the physics environment for the structure is created. Here the null element was used for the fluid 
model and plane 42 element was used for the solid model. The material properties and the boundary condition for the solid element were specified. The analysis is done for two different cases, one with actin fixed on one side and free on the other side and in the second case the actin is fixed on both the sides. These data are written to the physics file with title 'struc' to it. Now the results from the physics 'fluid' file are read and are input as load for the physics 'struc' file and then the analysis was solved.

\subsection{Pressure of the fluid as an input load}

The analysis is done for two different cases. In the first case the pressure of the fluid obtained from the fluid solid interaction analysis was made as input load to the actin and in the second case the velocity of the fluid obtained from the fluid solid interaction analysis was made as input load .The stresses acting on the actins were found for both the case.

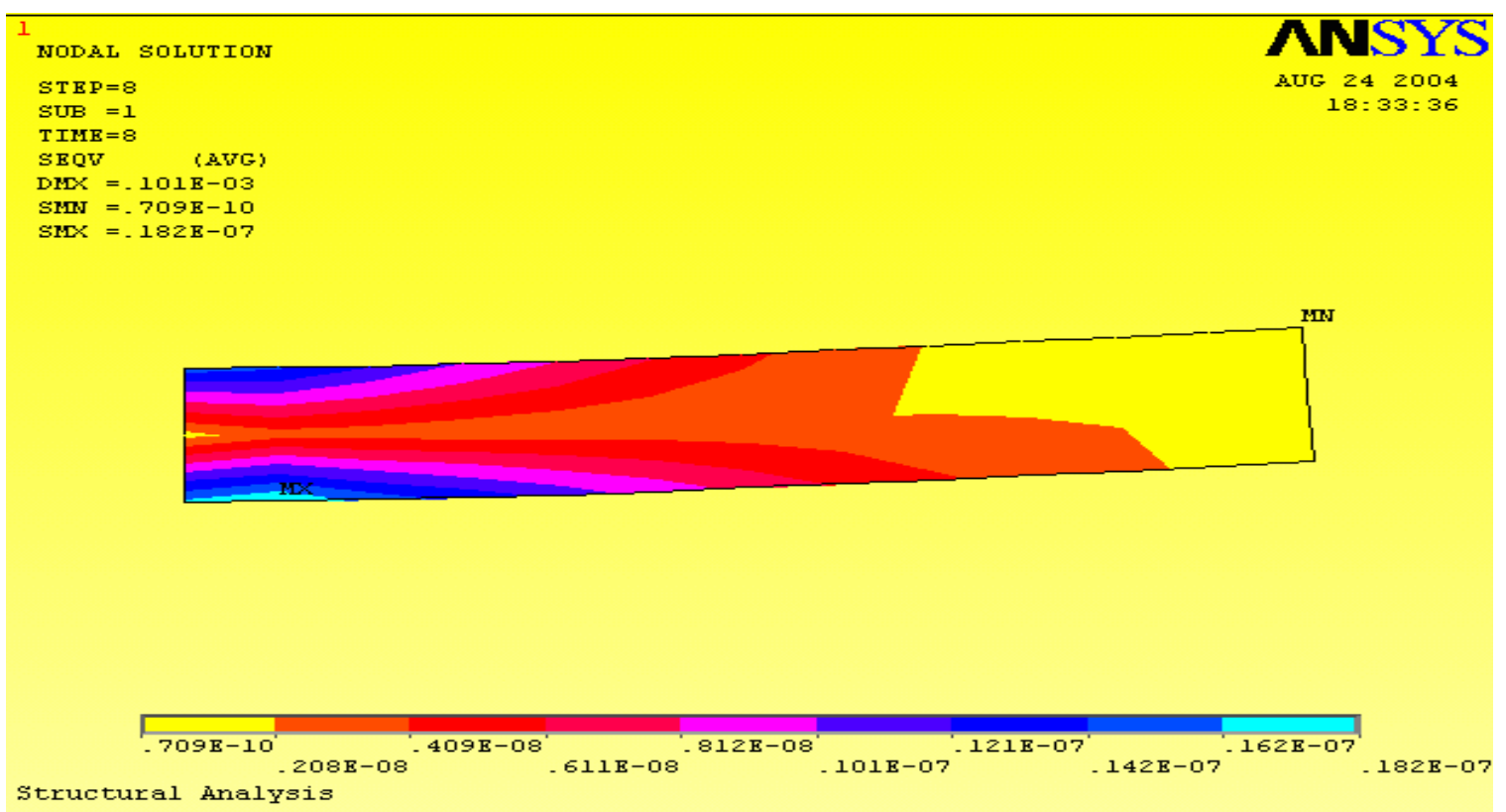

Figure 59 Von mises stress acting on the fixed-free actin filaments for a Prechondrocyte cell model 


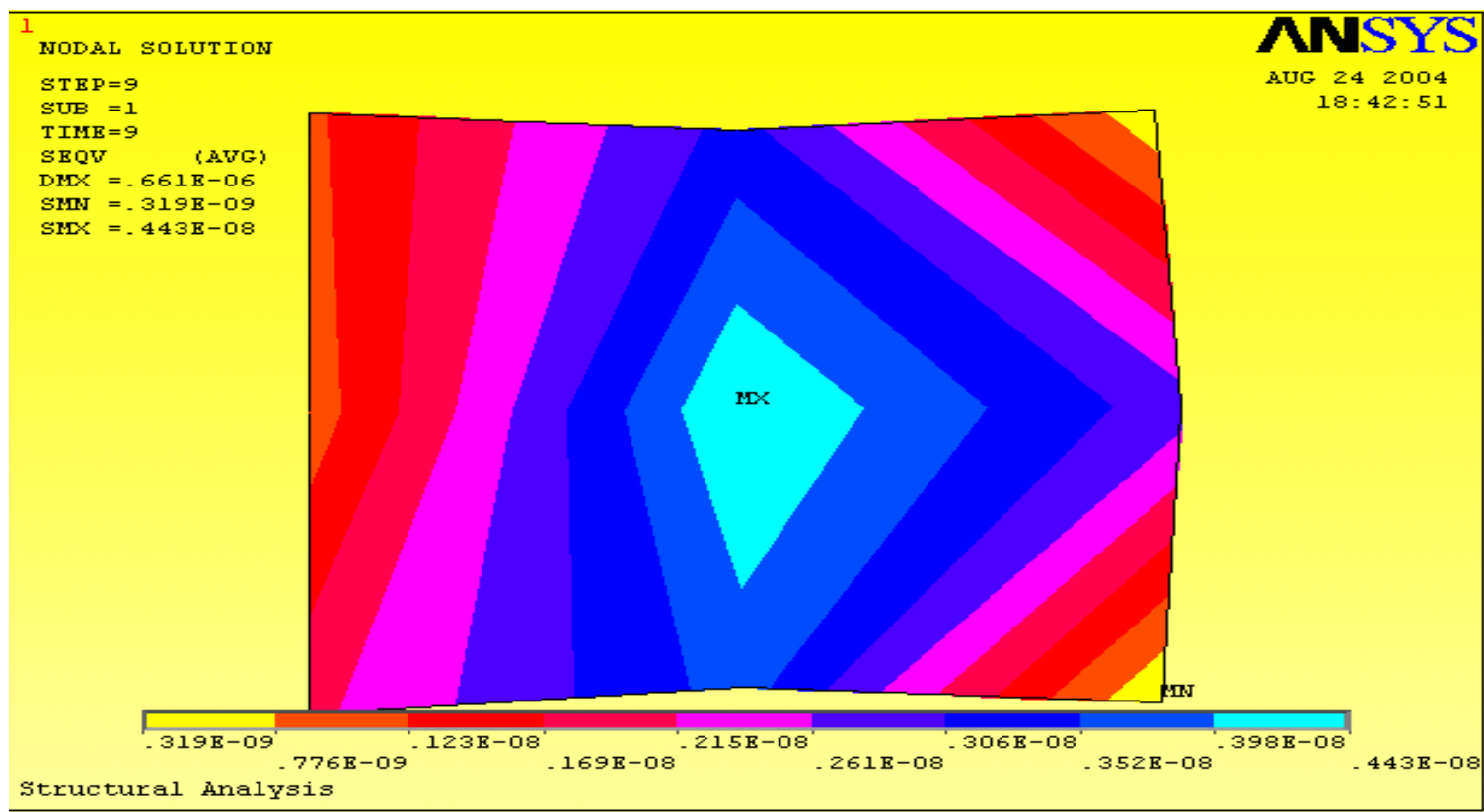

Figure 60 Von mises stress acting on the fixed-free actin filaments for a chondrocyte cell model

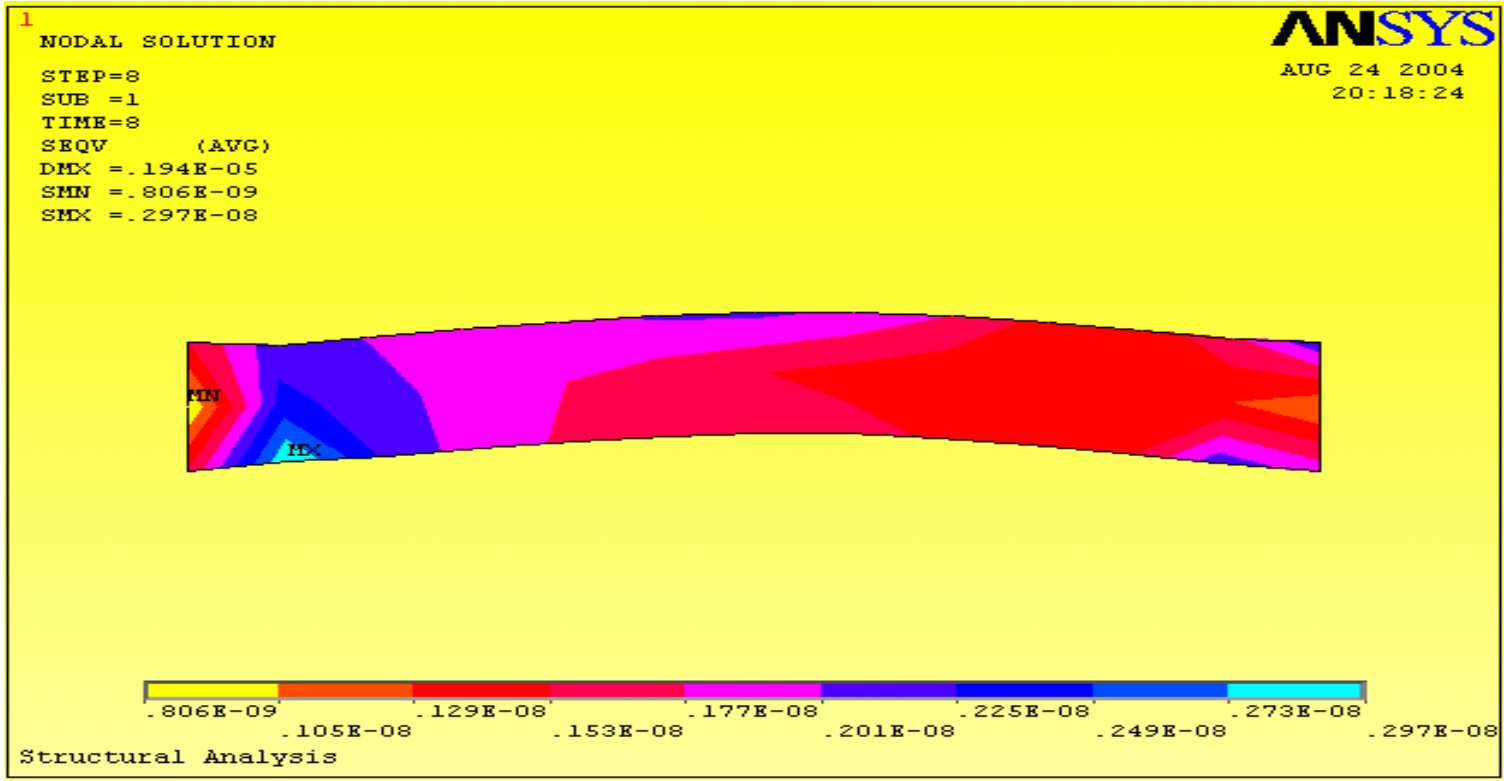

Figure 61 Von mises stress acting on the fixed-fixed actin filaments for a prechondrocyte cell model 


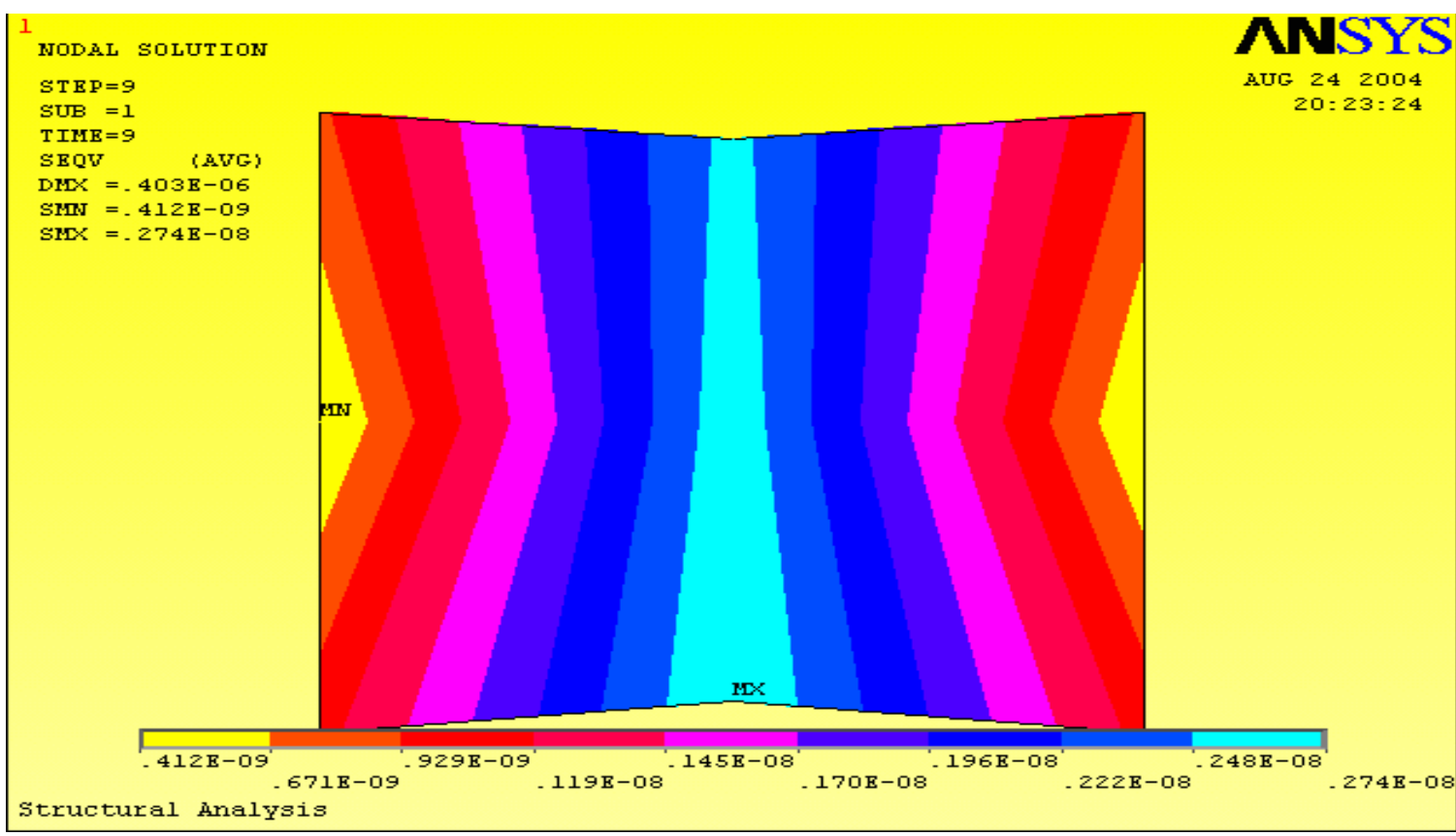

Figure 62 Von mises stress acting on a fixed-fixed actin filaments for a chondrocyte cell model

\subsection{Velocity of the fluid as input load}

In this case the velocity of the fluid obtained from the fluid solid interaction analysis was made as input load for the actin filaments to find the von mises stress acting on them. The analysis was done for a fixed-free actin filaments and fixedfixed actin filaments. 


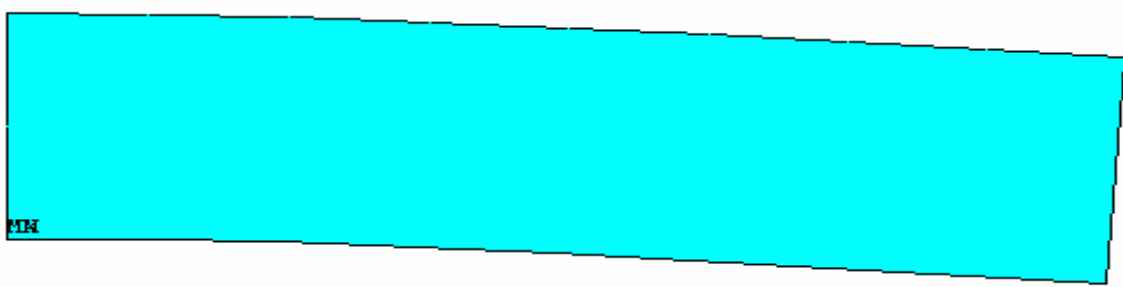

Structural Analysis

Figure 63 Von mises stress acting on the fixed-free actin filaments for a prechondrocyte cell model
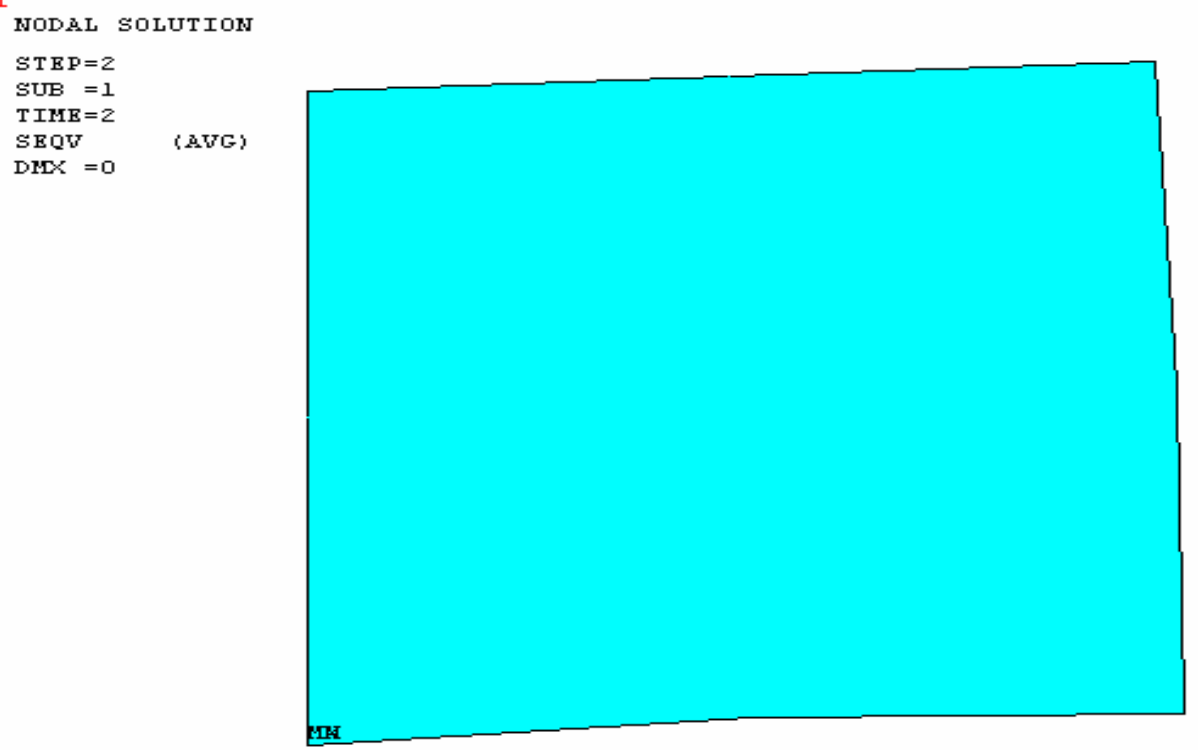

Figure 64 Von mises stress acting on a fixed-free actin filaments for a chondrocyte cell model 
TIME $=2$

SEQV

DNL $=0$

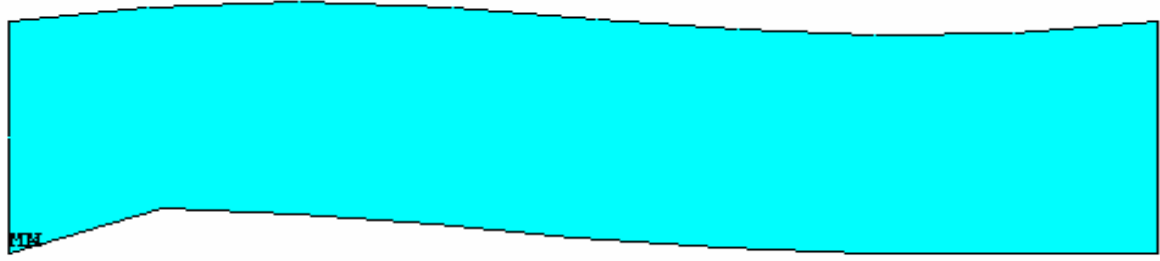

Structural Analysis

Figure 65 Von mises stress acting on a fixed-fixed actin filaments for a pre chondrocyte model

NODAL SOLUTION

NNSYS

STEP $=2$

SUB $=1$

T IME $=2$

SEQV

$\operatorname{DNX}=0$

(AVG)

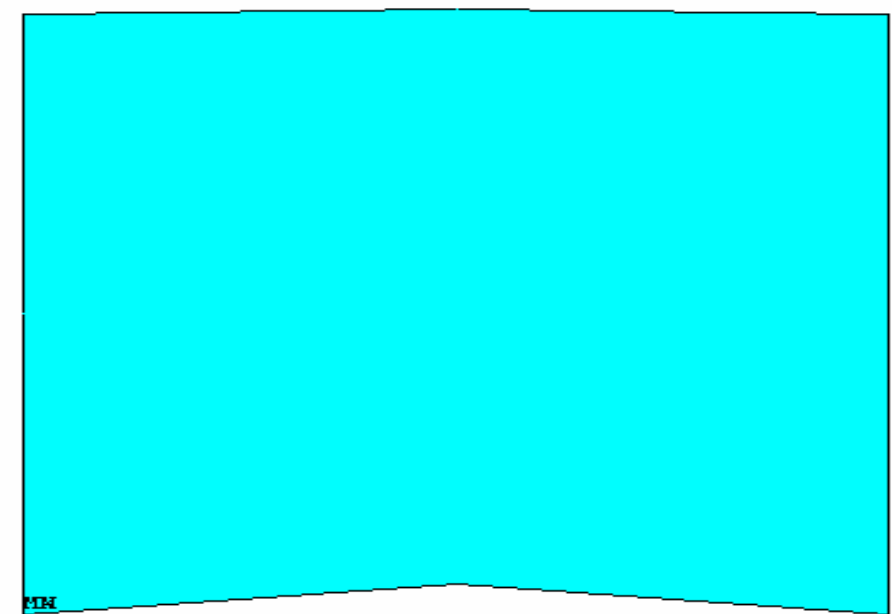

AUG $30 \quad 2004$ $14: 45: 53$

structural Analysis

Figure 66 Von mises stress acting on a fixed-fixed actin filament for a chondrocyte cell model 


\subsection{Conclusion}

From the above images (Figure 60 - 66) it was clear that the stress acting on the actin for a pre-chondrocyte cell model was higher than the stress acting on the actins for a chondrocyte cell model for both the fixed-free actin filaments and with a fixed-fixed actin filaments. The reason was in pre-chondrocyte the actin was long and slender and it deforms more whereas in chondrocyte the actin was short and stub and it deforms less and the stress will also be less. 


\section{Results discussion, limitations and future work}

\subsection{Discussion}

Applying the fluid solid interaction tool to known problems and verifying the results the analysis was validated. Then the fluid solid interaction analysis was applied to a complex model, which had a fluid inside the cell. Performing analysis the cell model obtained from MATLAB program was validated. Using this fluid solid interaction analysis the behavior of the fluid inside the cell when subjected to displacement was found out. The analysis was done for Day1 cells (pre-chondrocytes) and Day12 cells (chondrocytes). The fluid pressure was found to be in the range of $0.214 \mathrm{e}-08$ to $0.240 \mathrm{e}-08 \mathrm{~N} / \mu \mathrm{m}^{2}$ for Dayl cell model (Figure 43 ) and $0.119 \mathrm{e}-08$ to $0.134 \mathrm{e}-$ $08 \mathrm{~N} / \mu \mathrm{m}^{2}$ for Day12 cell model (Figure 48). The velocity of the fluid was found to less than the pressure of the fluid. The velocity in the x-direction for Dayl cell model was found to be in the range of $0.674 \mathrm{e}-16$ to $0.933 \mathrm{e}-16 \mu \mathrm{m} / \mathrm{second}$ (Figure 45 ) and the velocity in the $y$-direction is found to be $0.517 \mathrm{e}-16$ to $0.493 \mathrm{e}-16 \mu \mathrm{m} / \mathrm{second}$ (Figure 46 ). For Day12 cell model the velocity in the x-direction was found to be $0.189 \mathrm{e}-13$ to 0.750 $\mathrm{e}-14 \mu \mathrm{m} / \mathrm{second}$ (Figure 50) and the velocity in the y-direction were found to be $0.103 \mathrm{e}-$ 13 to $0.560 \mathrm{e}-14 \mu \mathrm{m} / \mathrm{second}$ (Figure 51). The Von mises stress acting on the cell membrane due to the internal fluid pressure was found to be in the range of $0.393 \mathrm{e}-07$ to $0.209 \mathrm{e}-05 \mathrm{~N} / \mu \mathrm{m}^{2}$ (Figure 44) for Dayl cell model and was found to be in the range of 0.912e-08 to $0.102 \mathrm{e}-05 \mathrm{~N} / \mu \mathrm{m}^{2}$ (Figure 49) for Day12 cell model. The fluid properties for Day1 and Day12 cell model differ because of the difference in the shape of the cell. These fluid flow parameters were then made as input load to find the Von mises stress acting on the pre-chondrocytes and chondrocytes. The following table gives the Von 
mises stress acting on the fixed-free and fixed-fixed actin filaments by inputting pressure of the fluid obtained from the fluid solid interaction analysis as boundary conditions.

\begin{tabular}{|l|l|l|}
\hline Cell model & Actin filaments & Von mises stress $\left(\mathrm{N} / \mu \mathrm{m}^{2}\right)$ \\
\hline Pre-chondrocyte & Fixed-Free & $0.709 \mathrm{e}-10-0.182 \mathrm{e}-07$ \\
\hline Chondrocyte & Fixed-Free & $0.319 \mathrm{e}-09-0.443 \mathrm{e}-08$ \\
\hline Pre-chondrocyte & Fixed-Fixed & $0.806 \mathrm{e}-09-0.297 \mathrm{e}-08$ \\
\hline Chondrocyte & Fixed-Fixed & $0.412 \mathrm{e}-09-0.274 \mathrm{e}-08$ \\
\hline
\end{tabular}

\section{Table 4 Von mises stress acting on the fixed-free and fixed-fixed actin filaments when the pressure of the fluid is made as an input load}

From the above table it was clear that the Von mises stress acting on the pre-chondrocyte was more than the stress acting on the chondrocytes for both the fixed-free and fixedfixed actin filaments.

\begin{tabular}{|l|l|l|}
\hline Cell model & Actin filaments & Von mises stress $\left(\mathrm{N} / \mu \mathrm{m}^{2}\right)$ \\
\hline Pre-chondrocyte & Fixed-Free & $0.374 \mathrm{e}-19$ \\
\hline Chondrocyte & Fixed-Free & 0 \\
\hline Pre-chondrocyte & Fixed-Fixed & 0 \\
\hline Chondrocyte & Fixed-Fixed & 0 \\
\hline
\end{tabular}

Table 5 Von mises stress acting on the fixed-free and fixed-fixed actin filaments when the velocity of the fluid is made as an input load

The velocity of the intra cellular fluid obtained from the fluid solid interaction analysis is very low when compared to the pressure of the intra cellular fluid. When this velocity is 
made as an input load the Von mises stress obtained is also low. The Von mises stress acting on the fixed-fixed actin filaments is too low so that the software takes the value to be zero. But in the fixed-free actin filaments there was a difference between the Von mises stress acting on the pre-chondrocyte and chondrocyte. Thus considerable differences in fluid flow induced stresses occurred around the actin filaments between pre-chondrocyte cells and chondrocyte cells and could explain the unique sensitivity of chondrocytes to mechanical loading. It is found that the pre-chondrocyte changes its actin structure in order to reduce the stresses acting on them.

\subsection{Limitations}

The fluid solid interaction analysis was one of the efficient ways of finding out the properties of the fluid inside the cell when the cell was subjected to compressive loading. The model of the cell created depends upon the accuracy of the cell image obtained from electron scanning microscope. A better image from the microscope helps to create a better model. The displacements applied to the cell model are obtained by interpolating the value obtained from the experiments. A correct data on the displacement or load acting on the cell will help in getting more accurate results for the model. The element used for the cell membrane is plane 82. Since not all the elements can be used for the fluid solid interaction analysis plane 82 element is used which has compatible displacement shapes and is well suited to model curved boundaries. Plane 82 elements also have plasticity, creep, swelling, stress stiffening, large deflection and large strain capabilities. 


\subsection{Future research work}

A 3-D cell model with all the inner elements such as actins, microtubules and intermediate filaments can be created and the fluid solid interaction analysis can be performed on that model. The fluid properties found out by this method will be more accurate and realistic. The cell membrane can be modeled as a highly corrugated one and the friction acting on the cell membrane can be found. The cell can be modeled with the inner fluid, cell membrane and the outer fluid (i.e.) the ECM. The force or load can be given to the outer fluid (ECM) and as a result of osmosis the change in fluid properties and the stress acting on the cell membrane can be found. 


\section{References}

1. Orthoteers, Cartilage \& Articular Cartilage, www. Orthoteers.co.uk.

2. Baaijens, Bader, Bouten, Biomechanics and Tissue Engineering.

3. M. Benjamin, B. Hillen, Mechanical influences on cells, tissues and organs, European Journal of Morphology 40, 69-73. (2002)

4. B. Alberts, Dennis Bray, Julian Lewis, Martin Raff, Keith Roberts, James D. Watson, Molecular biology of the cell, Third edition.

5. R.M Hochmuth, N.Mohandas, J biomech 5, 501-9. (1972)

6. F. Gittes, B. Mickey, J. Nettleton, J. Howard, J cell boil 120, 923-34. (1993).

7. A.E. Smith, Z.Zhang, C.R. Thomas, Chemical engineering science 55, 2031-2041 (2000).

8. F. Guilak, Geoffrey R. Erickson, H. Ping-Ting Beall, The effects of osmotic stress on the Viscoelastic and physical properties of Articular Chondrocytes, Biophysical Journal 82, 720-727. (2002)

9. M. Likhitpanichkul, P. Grace Chao, Clark T. Hung, and Gerard A Ateshian Measurement of Chondrocyte aggregate Modulus and permeability from osmotic loading experiments.

10. Coupled-Field Guide, Sequential Weak Coupling analysis, ANSYS 7.1 Version.

11. Distributed Resistance/ Source, Fluid element, ANSYS 7.1 Version.

12. V.C.Mow, DN Sun, XE Guo, CT Hung, WM Lai, Chondrocyte-extracellular matrix interactions during osmotic swelling, Orthopedic research laboratory.

13. E. Langelier, Rosmarie Suetterlin, Caroline D. Hoemann, Ueli Aebi and Michael d. Buschnamm, The chondrocyte cytoskeleton in mature articular cartilage: structure 
and distribution of actin, tubulin and vimentin filaments, Journal of Histochemistry and cytochemistry $48,1307-1320 .(2000)$

14. Dynamic and Kinematic viscosity of water in Imperial and SI units, The Engineering tools box.

15. Porous materials, The University of Edinburgh, Materials science and Engineering, 2001-2002.

16. Fluid -solid interaction analysis using physics environment, ANSYS 7.1 Version.

17. C .Christopher, B. Wang, X. Edward Guo, Dongning Sun, Van C. Mow, Gerard A. Ateshian, and Clark T Hung, The functional environment of chondrocytes within cartilage subjected to compressive loading: A theoretical and experimental approach, Department of Biomedical engineering, Columbia University 39,11-25, (2002).

18. A.E. Smith, K.E.Moxham, A.P.J. Middleberg, Chemical engineering science 53, 3913-3922 (1998).

19. D.E. Ingber, Journal of cell science 104, 613-627 (1993).

20. F.Guilak, V.C. Mow, Journal of biomechanics 33, 1663-1673 (2000).

21. V. L. Streeter, E. Benjamin Wylie, Fluid Mechanics, Seventh edition.

22. M. Ayyalasomayajula, Influence of rearrangement of actin cytoskeleton on the overall material properties of ATDC5 cells during chondrogenesis, Thesis, 2004. 


\section{Appendix 1}

Fluid solid interaction analysis in a piston cylinder arrangement

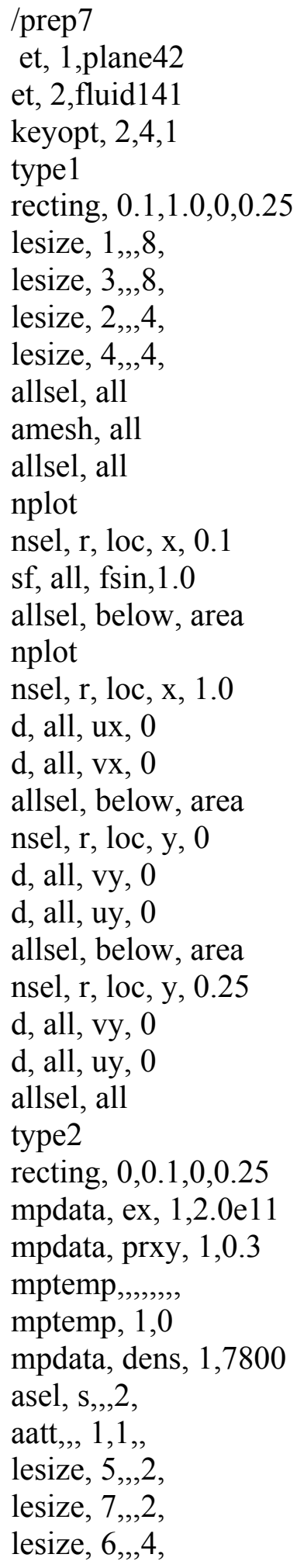


lesize, $8,, 4$,

allsel

amesh, all

allsel, all

aplot

asel, $\mathrm{s},,, 2$,

nsel, $r$, loc, $x, 0.1$

sf, all, fsin, 1.0

allsel, all

asel, s, , 2,

lsla, s, ,,

lplot

nsla,s, 1 ,

nplot

*set,_fncname, "disp"

! begin of equation : $0.85 * \sin (2.5 *\{$ time $\})$

*set, \% fncname $\%(0,0,1), 0.0,-999$

*set, \%_fncname $\% *(2,0,1), 0.0$

*set, \%_fncname $\%(3,0,1), 0.0$

*set, $\%$ fncname $\%(4,0,1), 0.0$

*set, \%fncanem $\%(5,0,1), 0.0$

*set, \%fncname $\%(6,0,1), 0.0$

*set, \% fncame $\%(0,1,1), 1.0,-1,0,2.5,0,0,1$

*set, \%_fncname $\%(0,2,1), 0.0,-2,0,1,-1,3,1$

*set, \%_fncname $\%(0,3,1), 0,-1,9,1,-2,0,0$

*set, \%_fncname $\%(0,4,1), 0.0,-2,0,0.85,0,0,-1$

*set, \% fncname\% $\%(0,5,1), 0.0,-3,0,1,-2,3,-1$

*set, \%_fncname $\%(0,6,1), 0.0,99,0,1,-3,0,0$

! end of equation: $0.85^{*} \sin \left(1.5^{*}\{\right.$ time $\left.\}\right)$

nsel, r, ext

d, all, ux, \%disp\%

d, all, uy, 0

allsel, all

nplot

fldata1,solu,flow, 1

fldata 1 ,solu,temp, 0

fldata1,solu,tran, 1

fldata1, solu, ale, 1

fldata2, time, glob, 10

fldata 7, prot, dens, air-si

fldata7, prot, visc, air-si

fini

/solu

fsan, on

fsco, all, 1.0e-2

fsre, all, 1.0 
fsou, 1.0

deltim, 0.0125

flda, time, step, 0.0125

fsit, 10

fsti, 1.0

fsdt, 0.0125

fsor, solid,

fstr, solid,

fstr, fluid,

save

solve 


\section{Appendix 2}

Analysis of a simplified plate with fluid

Without fluid solid interaction

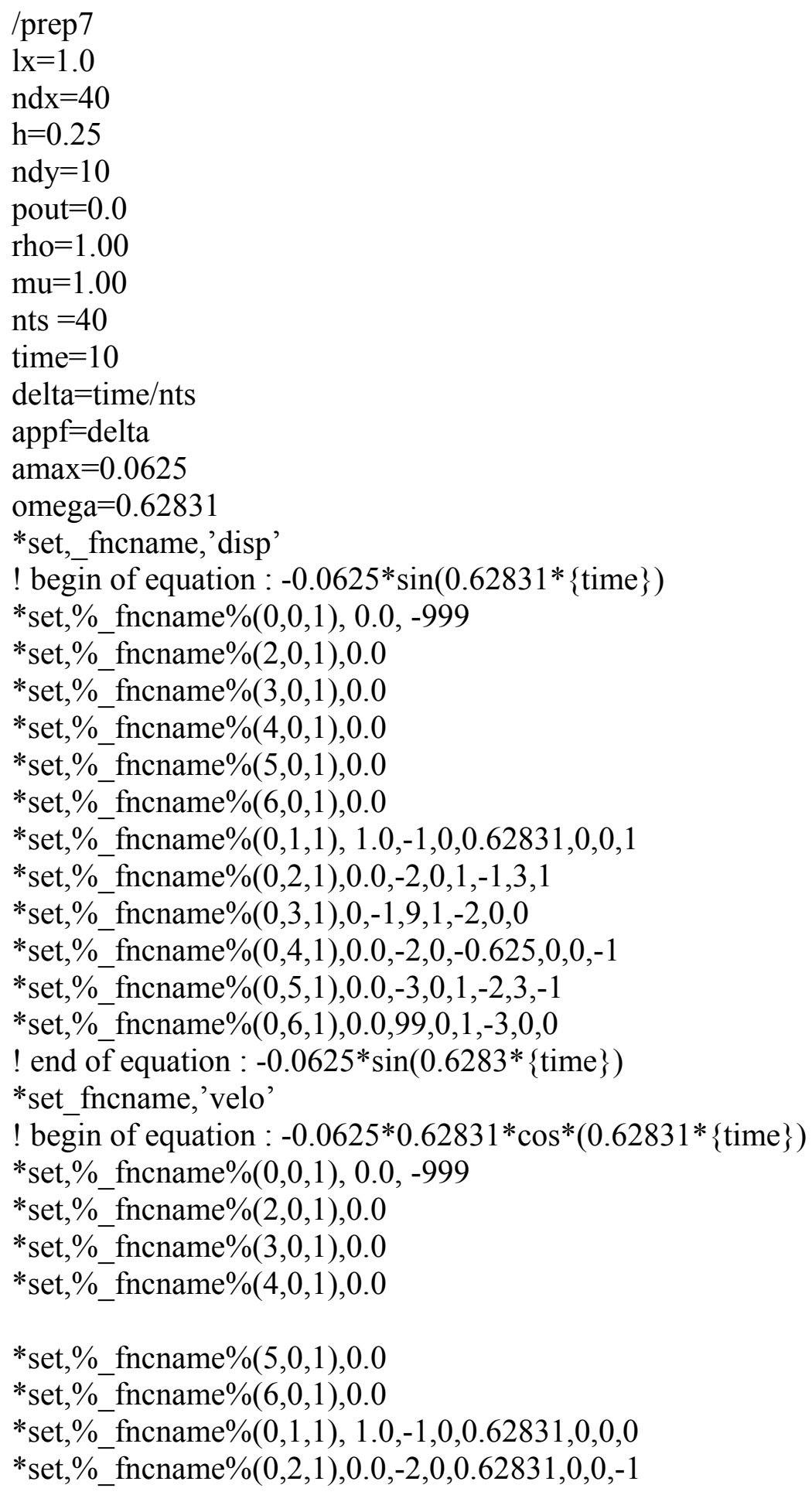




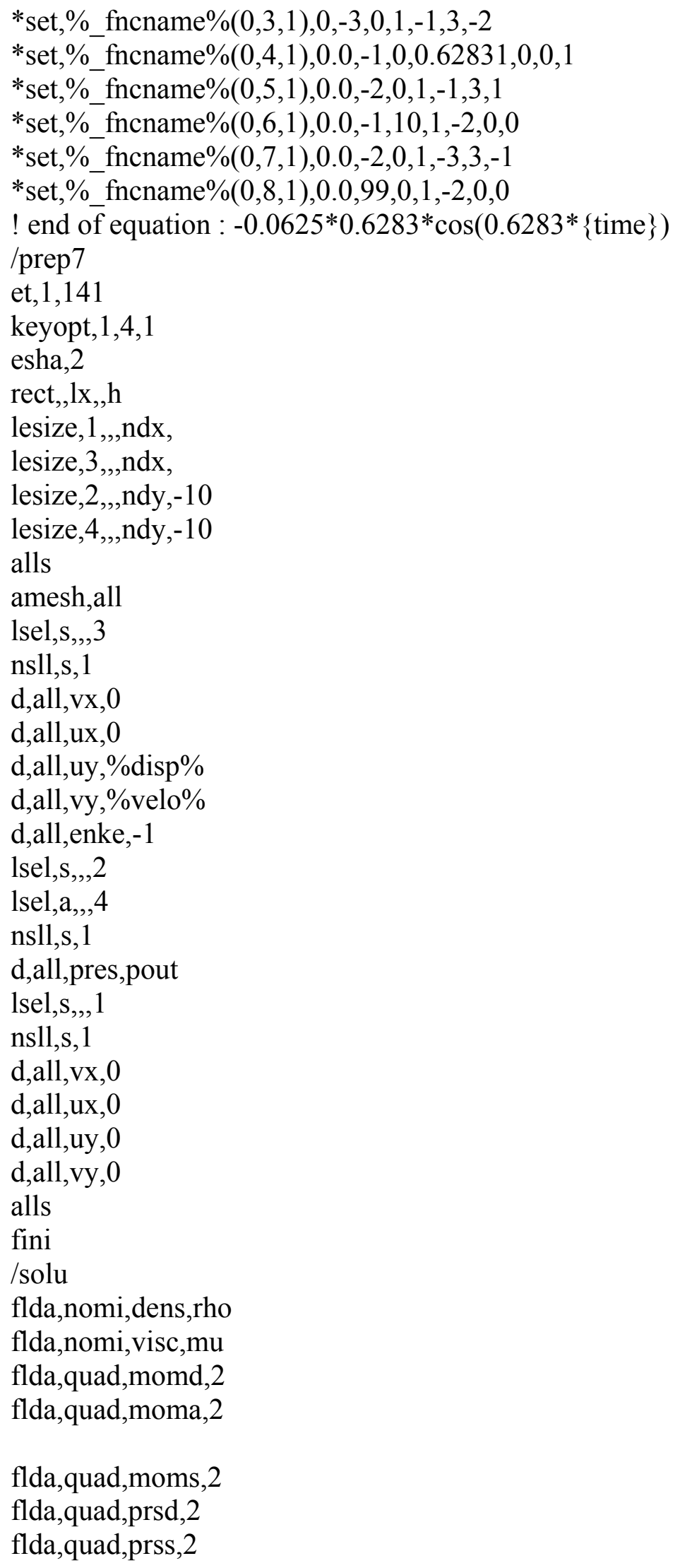

flda,quad,moms, 2

flda,quad,prsd,2

flda,quad,prss, 2 
flda,quad,tran,t

flda,time,step,delta

flda,time,numb,nts

flda,time,tend,time

flda,time,glob, 25

flda,time, appe,appf

flda,solu,ale,t

save

solve 


\section{Appendix 3}

Analysis of a simplified plate with fluid

With fluid solid interaction

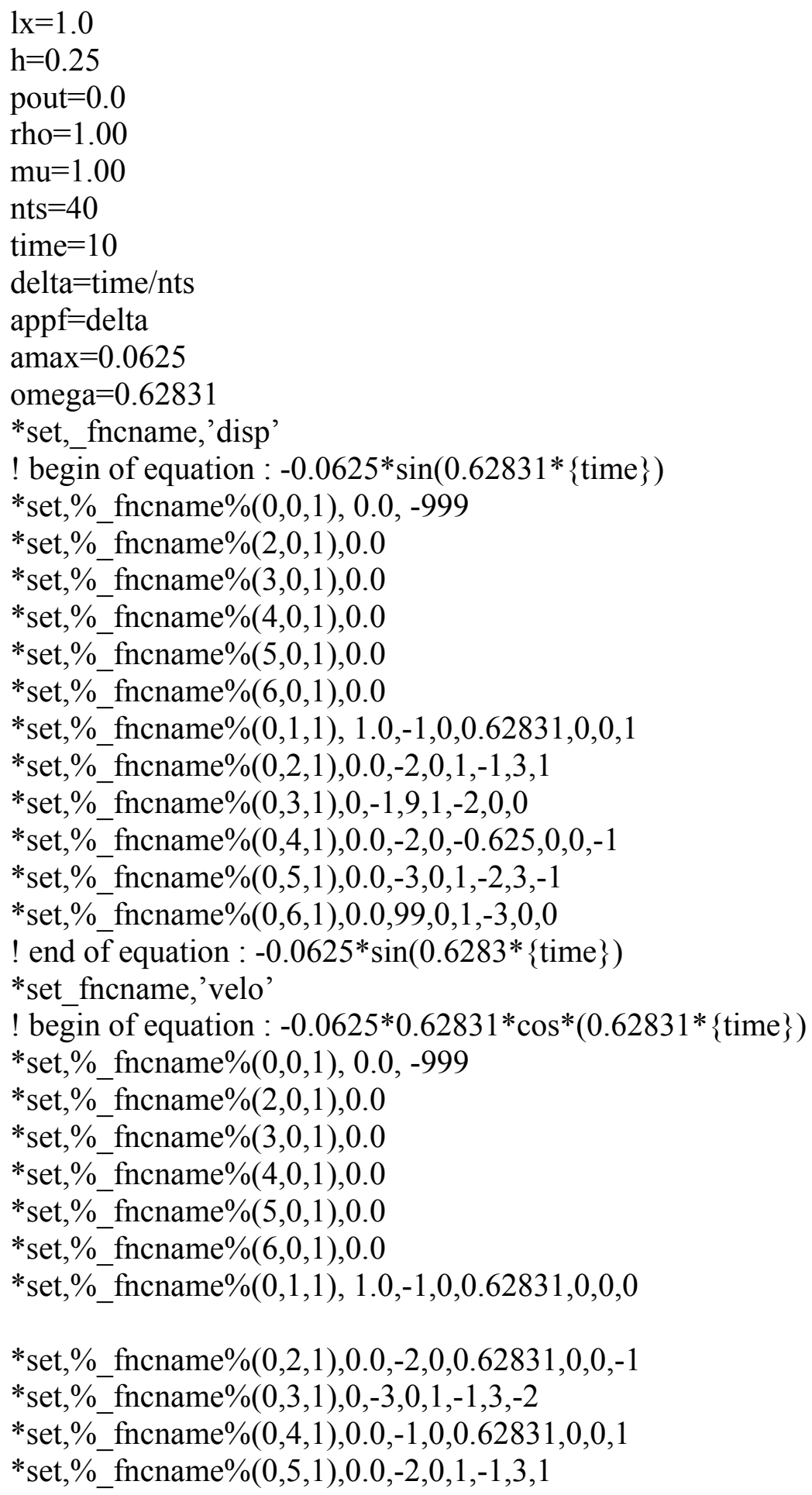


*set, $\%$ fncname $\%(0,6,1), 0.0,-1,10,1,-2,0,0$

*set, $\%$-fncname\% $\%(0,7,1), 0.0,-2,0,1,-3,3,-1$

*set, $\%$ fncname $\%(0,8,1), 0.0,99,0,1,-2,0,0$

! end of equation : $-0.0625^{*} 0.6283^{*} \cos \left(0.6283^{*}\{\right.$ time $\left.\}\right)$

/prep7

et, 1 , fluid 141

et, 2 , plane 42

keyopt, $1,4,1$

recting, $0,1,0,0.25$

lesize, $1,, 8$,

lesize, $3,, 8$,

lesize, $2,, 4$,

lesize, $4,, 4$,

alls

amesh,all

nplot

nsel, r, loc, $\mathrm{x}, 0,1$

d, all, pres, pout

allsel,below,area

nsel,r,loc,y,0

$\mathrm{d}$, all,vx, 0

d,all,ux, 0

d,all,uy, 0

d,all,vy, 0

nsel,r,loc,y, 0.25

sf,all,fsin, 1.0

allsel,below,area

recting, $0,1.0,0.25,0.26$

aplot

asel,s,,,2,

aatt, ,,2,1,

smrt, 4

amesh,all

asel,s, ,,2

lsla,s,",

lplot

nsla,s, 1 ,

nplot

nsel,r,loc,y, 0.25

sf,all,fsin, 1.0

asel,s,,,2

nsla,s, 1

nplot

d,all,ux,0

d,all,vx,0 


d,all,uy,\%disp\%
d,all,vy,\%velo\%
allsel,all
nplot
fldata1,solu,flow,1
fldata1,solu,temp,0
fldata1,solu,tran,1
fldata1,solu,ale,1
fldata2,time,glob,10,
flda,nomi,dens,rho
flda,nomi,visc,mu
fini
/solu
fsan,on
fsco,all,1.0e-2
fsre,all,1.0
fsou,1.0
deltim,0.25
flda,time,step,0.25
fsit,10
fsti,10
fsdt,0.25
fsor,solid,
fstr,solid,
fstr,fluid,
save
solve




\section{Appendix 4}

Finding the centroid of a irregular polygon using FORTRAN program

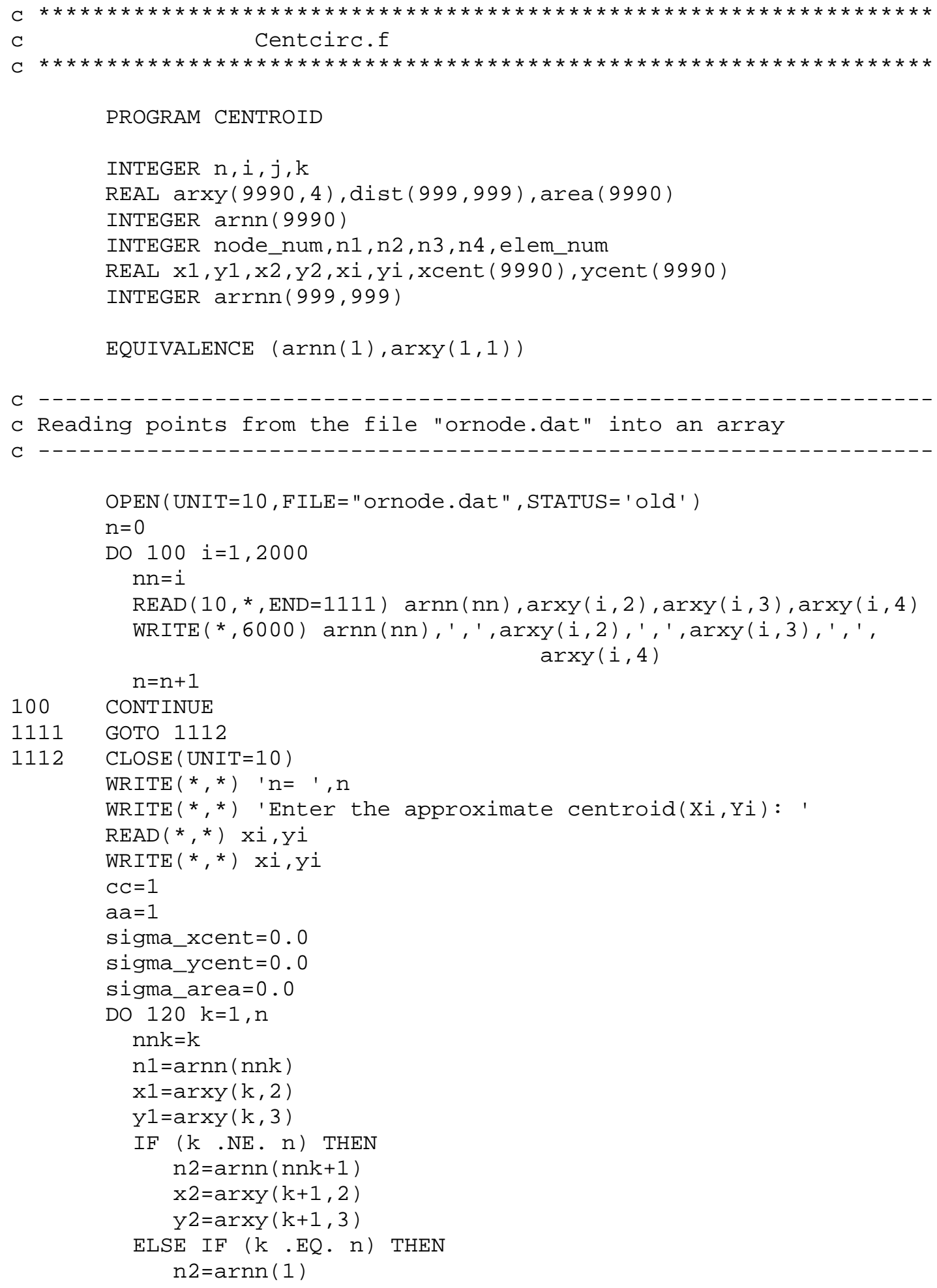




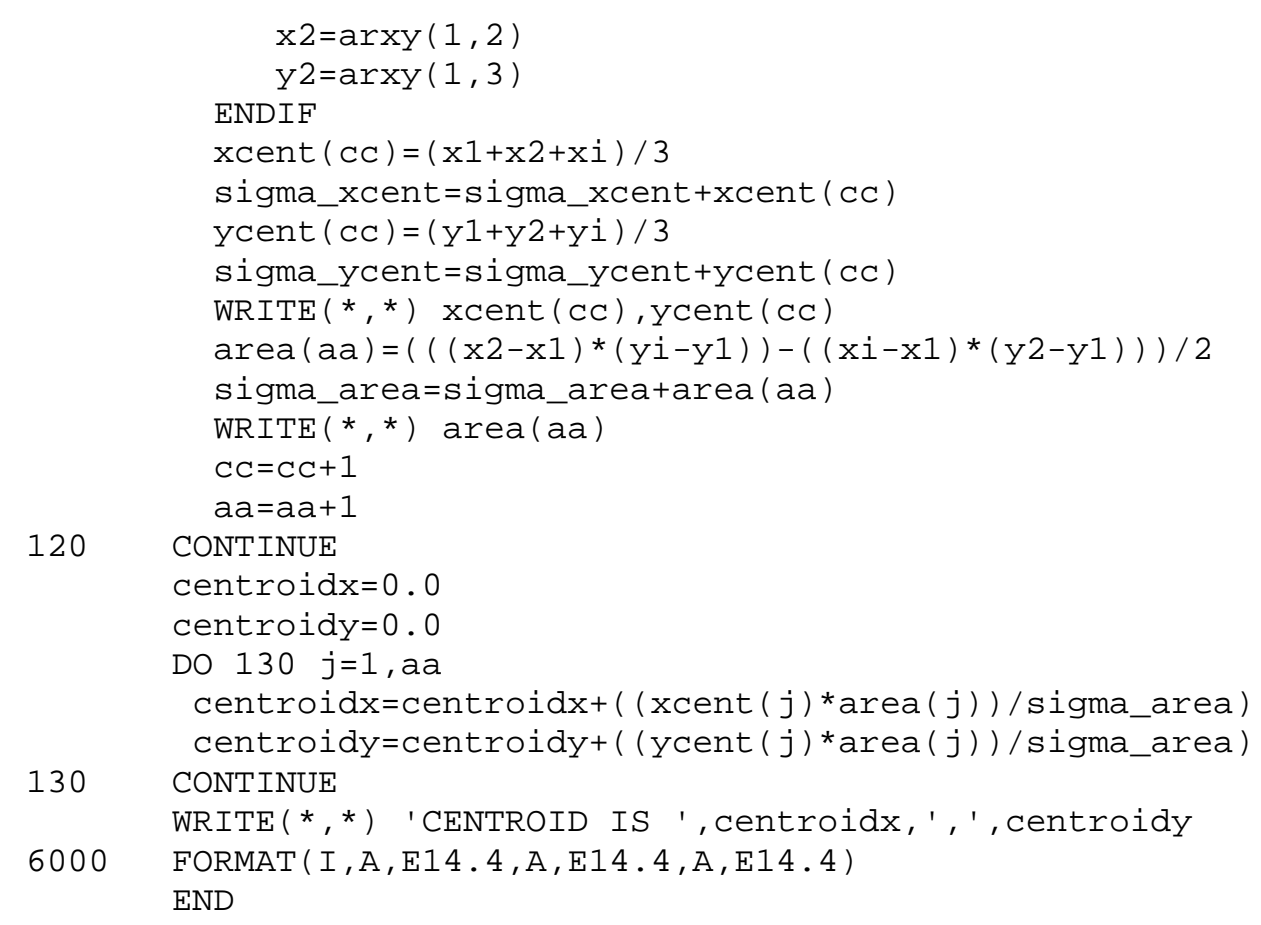




\section{Appendix 5}

Curve fitting of an ellipse

Function estimates $=$ fitcurvedemo

$\%$ FITCURVEDEMO

$\%$ Fit curve to data where user chooses equation to fit.

$\%$ Define function and starting point of fitting routine.

Fun=@expfun;

Starting $=\operatorname{rand}(1,2)$;

$\%$ First, we create the data

$X=[5.9708 ; 6.1065 ; 6.2423 ; 6.5137 ; 7.1243 ; 7.4635 ; 7.5314 ; 8.0742 ;$

$8.2099 ; \quad 8.8884 ; 9.4991 ; 9.7026 ; 10.1097 ; 10.8561 ; 10.9918 ; 11.3310$;

$13.2987 ; 13.5701 ; 14.0451 ; 14.5200 ; 14.7914 ; 15.9449 ; 16.1484 ; 16.6912$;

$16.7591 ; 16.8948 ; 17.0305 ; 17.0305 ; 17.0983 ; 17.5054 ; 17.5733 ; 17.3019$;

$17.2340 ; 17.1662 ; 16.8948 ; 16.8269 ; 16.7591 ; 16.4198 ; 16.0806 ; 15.9449$;

$15.7413 ; 15.1985 ; 14.8593 ; 14.3165 ; 13.7736 ; 13.2987 ; 12.8916 ; 11.5346$;

$11.0596 ; 10.3811 ; 10.1097 ; 9.9062 ; 9.4991 ; 9.0241 ; 8.8206 ; 8.1421$;

$8.0064 ; 7.6671 ; 7.5314 ; 7.3957 ; 7.2600 ; 7.0564 ; 6.9208 ; 6.1065 ; 5.9708$;

5.9708];

$\mathrm{Y}=[25.7153 ; 25.8510 ; 25.9867 ; 27.3437 ; 27.9544 ; 28.3615 ; 28.4294 ; 28.8365$;

$29.0400 ; 29.5150 ; 29.8542 ; 29.9221 ; 30.0578 ; 30.4649 ; 30.6006 ; 30.7363$;

$30.7363 ; 30.7363 ; 30.3292 ; 30.1935 ; 30.1256 ; 29.1079 ; 28.9722 ; 28.4294$;

$28.3615 ; 28.2258 ; 27.8187 ; 27.5473 ; 26.9366 ; 26.4617 ; 26.2581 ; 25.3761$;

$25.0368 ; 23.9512 ; 23.2727 ; 22.7978 ; 22.5942 ; 22.0514 ; 21.8479 ; 21.7122$;

$21.6443 ; 21.3051 ; 21.1015 ; 20.8301 ; 20.5587 ; 20.4908 ; 20.4908 ; 20.4908$;

$20.4908 ; 20.4908 ; 20.5587 ; 20.8301 ; 21.1015 ; 21.5765 ; 21.7122 ; 22.5264$;

$22.5942 ; 23.0013 ; 23.0692 ; 23.3406 ; 23.4763 ; 23.6120 ; 24.0869 ; 24.9690$;

25.3082; 25.7153];

$\mathrm{M}=[\mathrm{X} \mathrm{Y}]$

$\%$ Now, we can call FMINSEARCH:

options = optimset (' fminsearch'); \% Use FMINSEARCH defaults

Estimates $=$ fminsearch (fun, starting, options, t, y);

$\mathrm{Se}=$ size ( Estimates)

$\%$ To check the fir

plot $(\mathrm{X}, \mathrm{Y}$,

hold on

plot $\left(\mathrm{X}, \mathrm{Y}_{\text {cent }}+\left((\right.\right.$ Estimates $(2) /$ Estimates $(1)){ }^{*}\left(\left(\right.\right.$ Estimates $(1) .{ }^{*} \operatorname{Estimates}(1)-(\mathrm{X}-\mathrm{X} 1) *(\mathrm{X}-$

$\left.\left.\mathrm{X} 1)) .^{\wedge} 0.5\right)\right),{ }^{\prime} \mathrm{r}$ ')

xlabel ( ' $\mathrm{X}$ ')

ylabel (' $\mathrm{f}(\mathrm{X})$ ')

title (['Fitting to function', func2str(fun)]);

legend ( 'data', [ ' fit using', func2str(fun)])

hold off

function sse $=$ expfun $($ params,t,y) 
$\%$ Accepts curve parameters as inputs and outputs fitting the error for the equation $\% \quad \mathrm{y}=\mathrm{B} / \mathrm{A} * \operatorname{sqrt}\left(\mathrm{A}-\mathrm{t}^{*} \mathrm{t}\right)$

$\mathrm{A}=\operatorname{params}(1)$;

$\mathrm{B}=\operatorname{params}(2)$;

Fitted_Curve $\left.=\mathrm{Y}_{\text {cent }}+\left((\mathrm{B} / \mathrm{A})^{*}\left(\left(\mathrm{~A} * \mathrm{~A}-(\mathrm{X}-\mathrm{X} 1)^{*}(\mathrm{X}-\mathrm{X} 1)\right)\right)^{\wedge} 0.5\right)\right)$;

Error - Vector $=$ Fitted Curve $-\mathrm{y}$;

$\%$ When curve fitting, a typical quantity to minimize is the sume of squares error sse $=\operatorname{sum}\left(\right.$ Error_Vector.$\left.^{\wedge} 2\right)$; 


\section{Appendix 6}

Modeling the cell for Day1 with inner points using MATLAB program

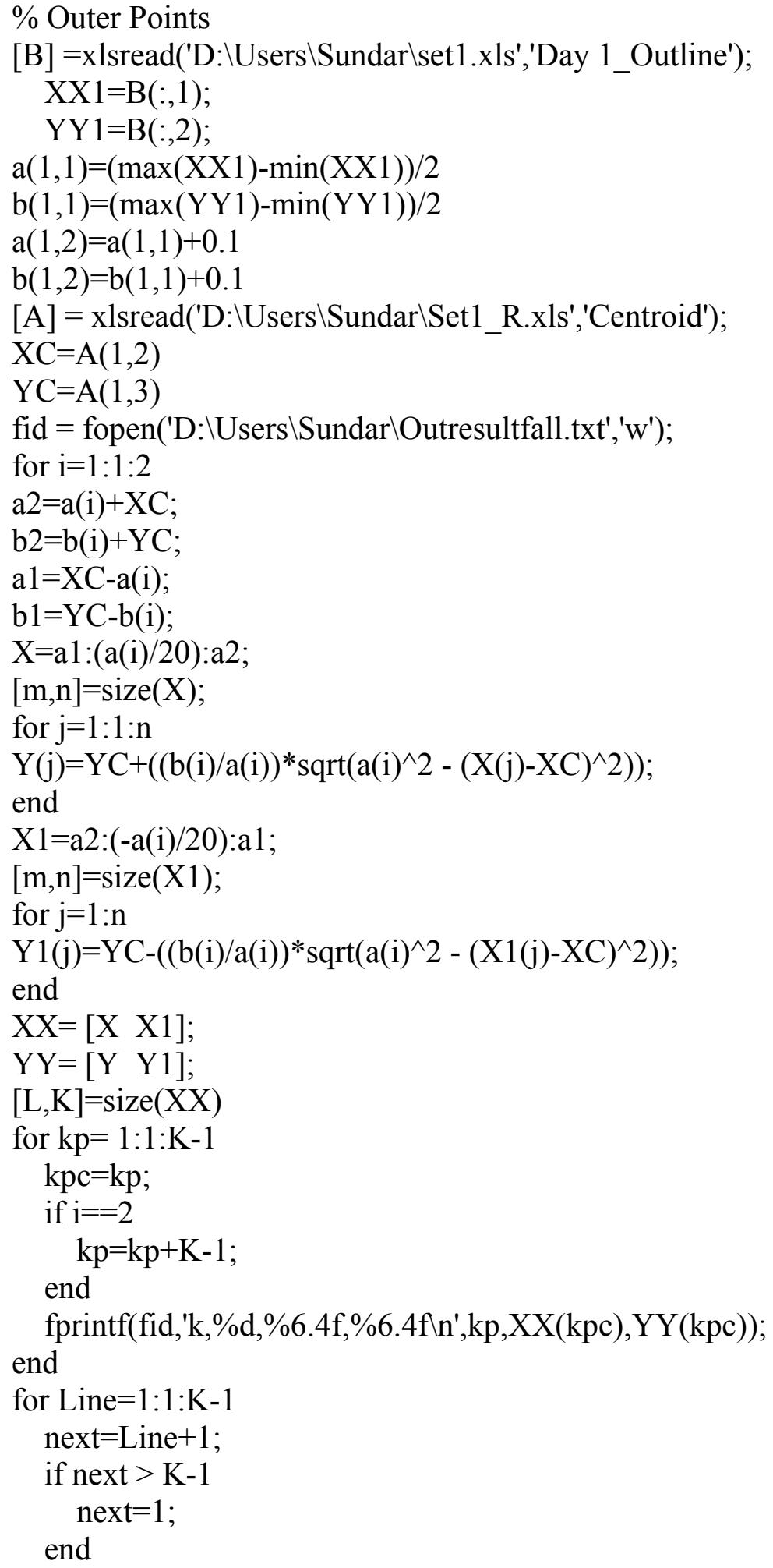




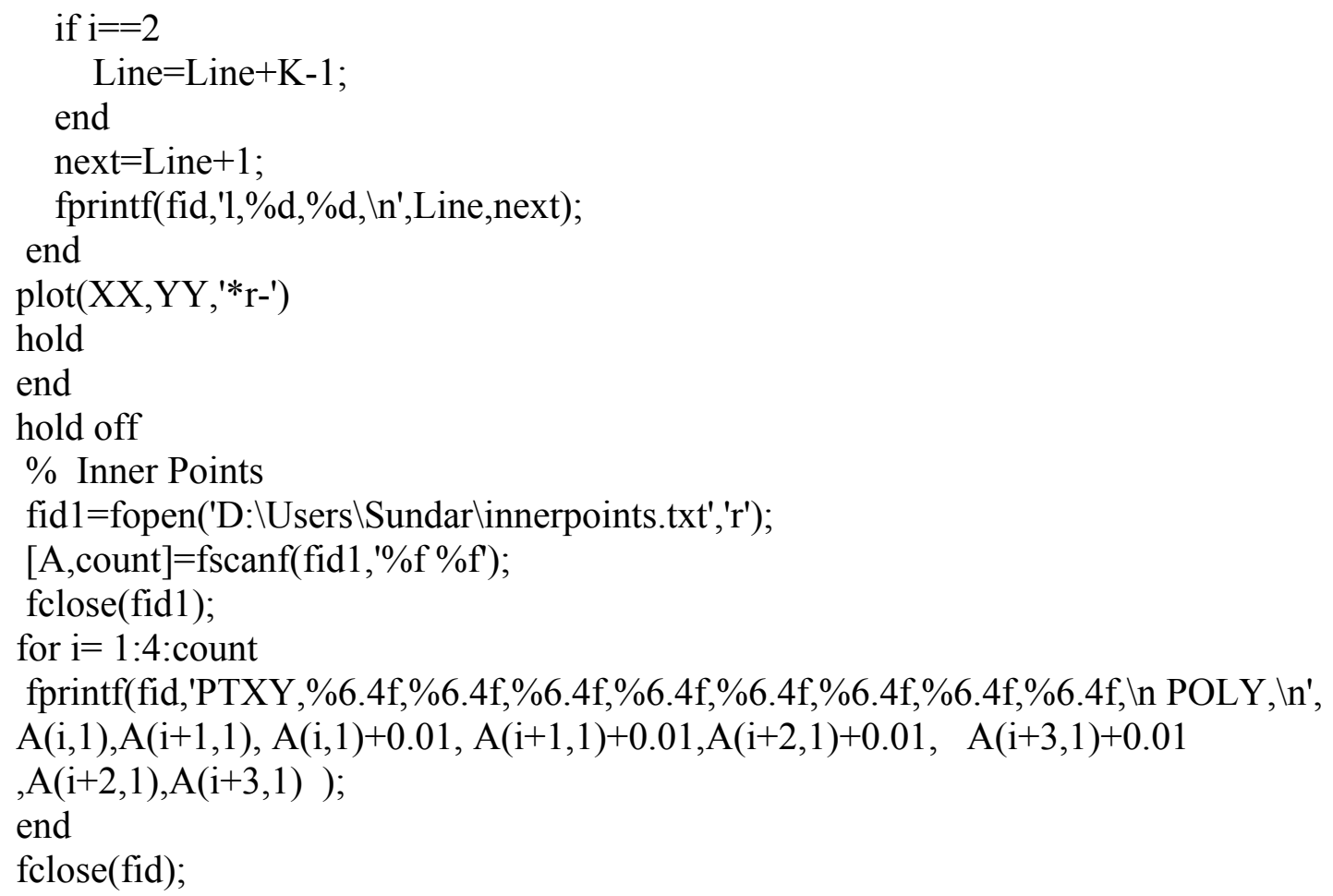




\section{Appendix 7}

Modeling the cell for Day 12 with inner points using MATLAB program

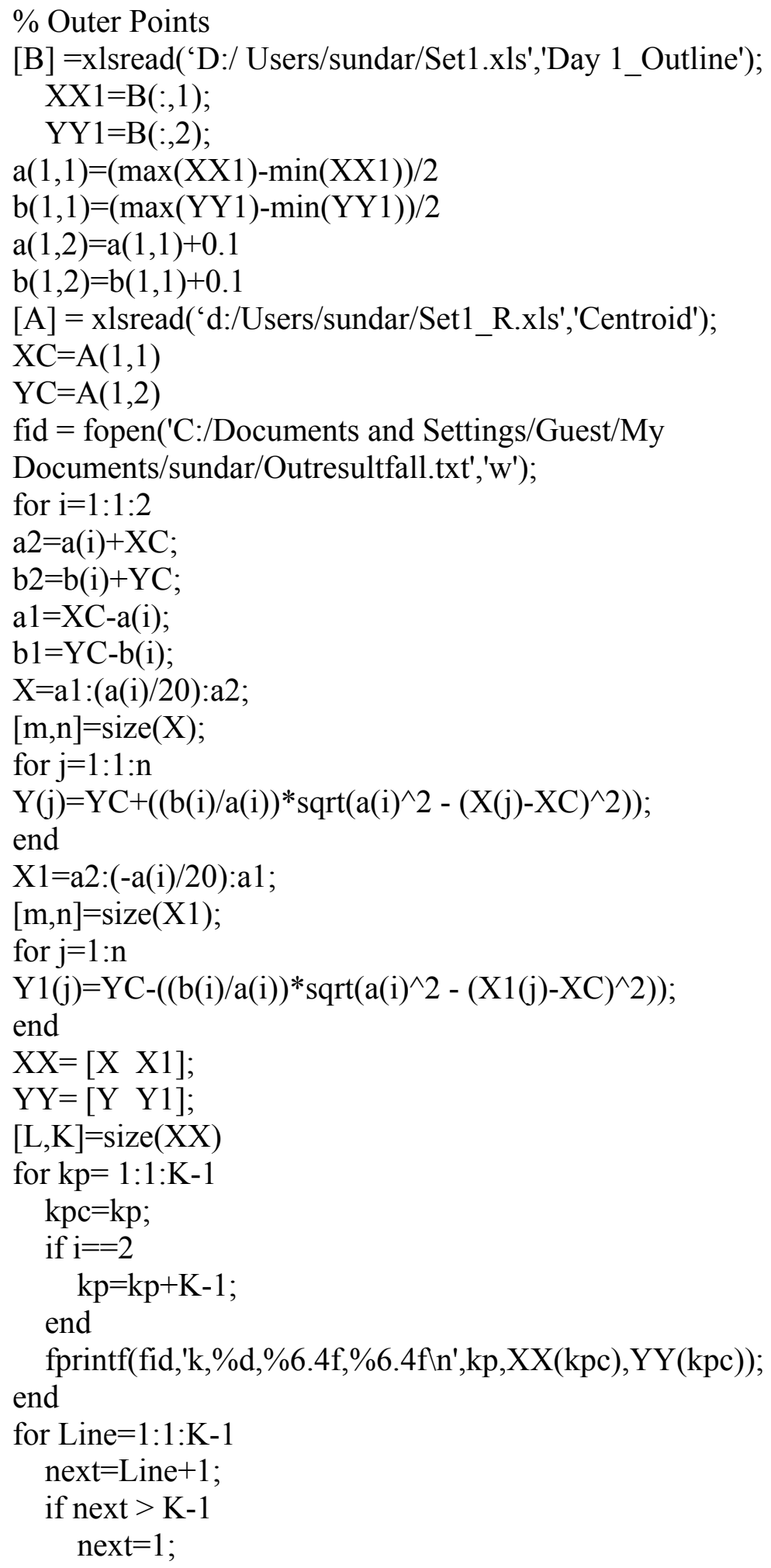




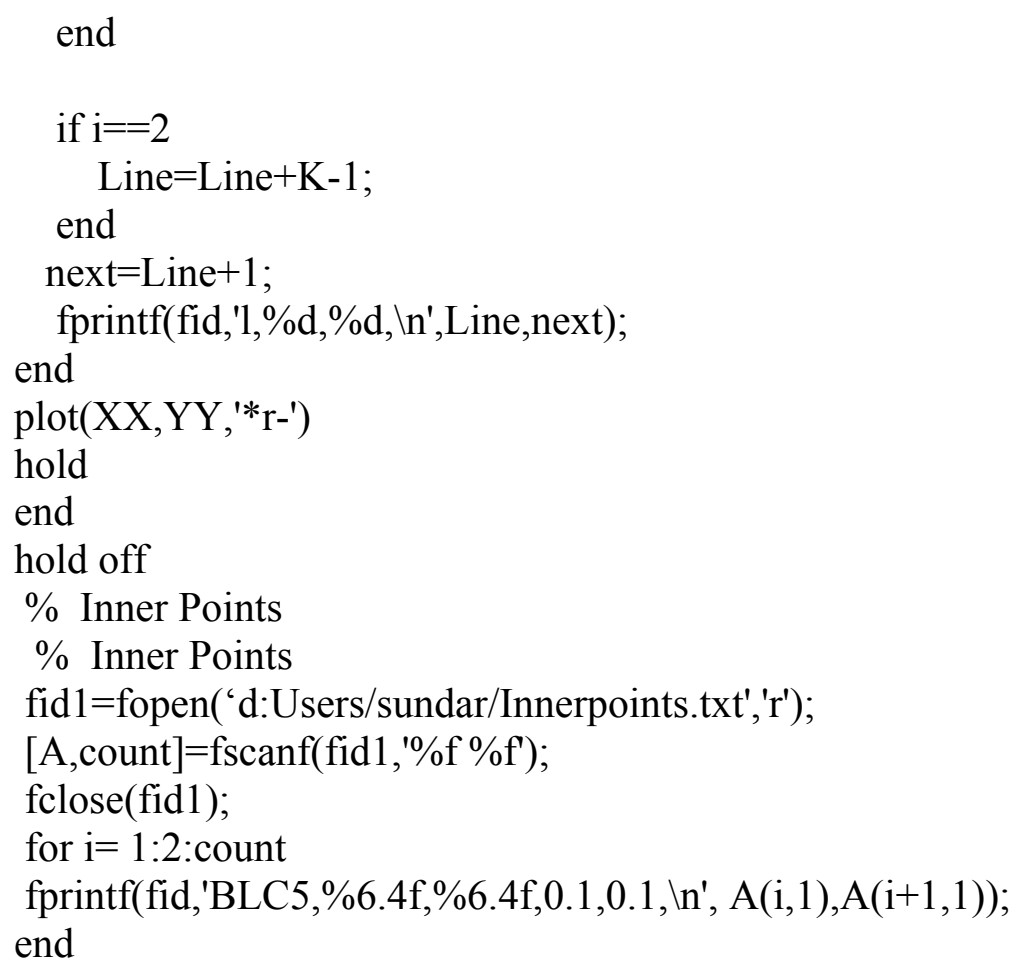




\section{Appendix 8}

Output of MATLAB file in ANSYS log file format for Day1 cell model

$$
\begin{aligned}
& \mathrm{k}, 1,6.2988,25.4000 \\
& \mathrm{k}, 2,7.0239,27.8800 \\
& \mathrm{k}, 3,7.7491,28.7884 \\
& \mathrm{k}, 4,8.4742,29.3989 \\
& \mathrm{k}, 5,9.1994,29.8364 \\
& \mathrm{k}, 6,9.9245,30.1489 \\
& \mathrm{k}, 7,10.6497,30.3601 \\
& \mathrm{k}, 8,11.3748,30.4826 \\
& \mathrm{k}, 9,12.1000,30.5227 \\
& \mathrm{k}, 10,12.8252,30.4826 \\
& \mathrm{k}, 11,13.5503,30.3601 \\
& \mathrm{k}, 12,14.2755,30.1489 \\
& \mathrm{k}, 13,15.0006,29.8364 \\
& \mathrm{k}, 14,15.7258,29.3989 \\
& \mathrm{k}, 15,16.4509,28.7884 \\
& \mathrm{k}, 16,17.1761,27.8800 \\
& \mathrm{k}, 17,17.9012,25.4000 \\
& \mathrm{k}, 18,17.9012,25.4000 \\
& \mathrm{k}, 19,17.1761,22.9200 \\
& \mathrm{k}, 20,16.4509,22.0116 \\
& \mathrm{k}, 21,15.7258,21.4011 \\
& \mathrm{k}, 22,15.0006,20.9636 \\
& \mathrm{k}, 23,14.2755,20.6511 \\
& \mathrm{k}, 24,13.5503,20.4399 \\
& \mathrm{k}, 25,12.8252,20.3174 \\
& \mathrm{k}, 26,12.1000,20.2772 \\
& \mathrm{k}, 27,11.3748,20.3174 \\
& \mathrm{k}, 28,10.6497,20.4399 \\
& \mathrm{k}, 29,9.9245,20.6511 \\
& \mathrm{k}, 30,9.1994,20.9636 \\
& \mathrm{k}, 31,8.4742,21.4011 \\
& \mathrm{k}, 32,7.7491,22.0116 \\
& \mathrm{k}, 33,7.0239,22.9200 \\
& 1,1,2, \\
& 1,2,3, \\
& 1,3,4, \\
& 1,4,5, \\
& 1,5,6, \\
& 1,6,7, \\
& 1,7,8, \\
& 1,8,9, \\
&
\end{aligned}
$$


$1,9,10$,

$1,10,11$,

$1,11,12$,

$1,12,13$,

$1,13,14$,

$1,14,15$,

$1,15,16$,

$1,16,17$,

$1,17,18$,

$1,18,19$,

$1,19,20$,

$1,20,21$,

$1,21,22$,

$1,22,23$,

$1,23,24$,

$1,24,25$,

$1,25,26$,

$1,26,27$,

$1,27,28$,

$1,28,29$,

$1,29,30$,

$1,30,31$,

$1,31,32$,

$1,32,33$,

$1,33,34$,

$\mathrm{k}, 34,6.0988,25.4000$

$\mathrm{k}, 35,6.8489,27.9769$

$\mathrm{k}, 36,7.5991,28.9207$

$\mathrm{k}, 37,8.3492,29.5551$

k,38,9.0994,30.0096

$\mathrm{k}, 39,9.8495,30.3343$

$\mathrm{k}, 40,10.5997,30.5537$

$\mathrm{k}, 41,11.3498,30.6810$

$\mathrm{k}, 42,12.1000,30.7227$

$\mathrm{k}, 43,12.8502,30.6810$

$\mathrm{k}, 44,13.6003,30.5537$

$\mathrm{k}, 45,14.3505,30.3343$

$\mathrm{k}, 46,15.1006,30.0096$

$\mathrm{k}, 47,15.8508,29.5551$

$\mathrm{k}, 48,16.6009,28.9207$

$\mathrm{k}, 49,17.3511,27.9769$

$\mathrm{k}, 50,18.1012,25.4000$

$\mathrm{k}, 51,18.1012,25.4000$

$\mathrm{k}, 52,17.3511,22.8231$

$\mathrm{k}, 53,16.6009,21.8793$

$\mathrm{k}, 54,15.8508,21.2449$ 


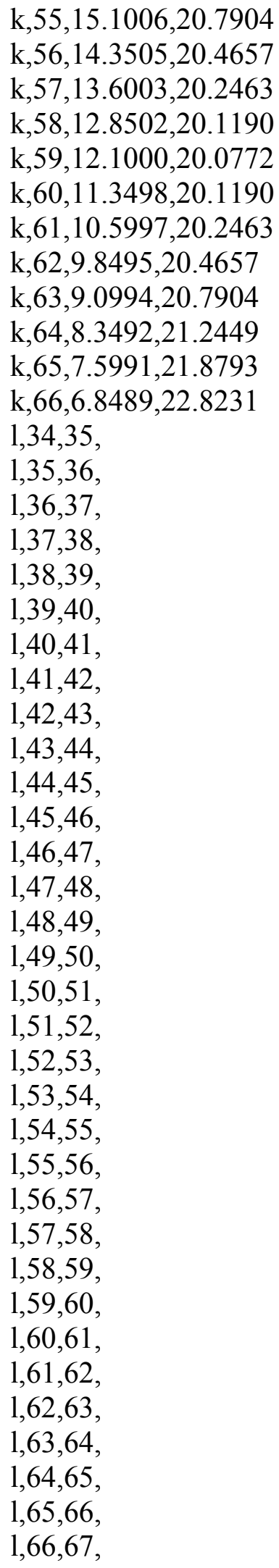


POLY,

PTXY,13.0951,30.0578,13.1051,30.0678,13.3087,29.7964,13.2987,29.7864, POLY,

PTXY,13.5701,29.7864,13.5801,29.7964,13.9194,29.3214,13.9094,29.3114, POLY,

PTXY,14.3165,29.3793,14.3265,29.3893,14.6657,29.1179,14.6557,29.1079, POLY,

PTXY,13.7058,29.2436,13.7158,29.2536,15.2085,28.7108,15.1985,28.7008, POLY,

PTXY,13.9094,29.2436,13.9194,29.2536,14.2586,28.7786,14.2486,28.7686, POLY,

PTXY,13.9094,29.2436,13.9194,29.2536,14.2586,29.0500,14.2486,29.0400, POLY,

PTXY,9.6348,29.1757,9.6448,29.1857,11.3410,28.1680,11.3310,28.1580, POLY,

PTXY,11.3989,29.0400,11.4089,29.0500,11.7481,28.5751,11.7381,28.5651, POLY,

PTXY,13.6379,29.0400,13.6479,29.0500,13.7836,28.8465,13.7736,28.8365, POLY,

PTXY,11.1953,28.8365,11.2053,28.8465,11.4089,28.6429,11.3989,28.6329, POLY,

PTXY,10.7882,28.7686,10.7982,28.7786,11.0018,28.7108,10.9918,28.7008, POLY,

PTXY,11.7381,28.7008,11.7481,28.7108,12.0874,28.6429,12.0774,28.6329, POLY,

PTXY,10.1097,28.6329,10.1197,28.6429,10.3911,28.5072,10.3811,28.4972, POLY,

PTXY,14.0451,28.6329,14.0551,28.6429,14.6657,27.8966,14.6557,27.8866, POLY,

PTXY,15.6056,28.5651,15.6156,28.5751,15.8192,28.2358,15.8092,28.2258, POLY,

PTXY,11.4667,28.4972,11.4767,28.5072,11.5446,28.3037,11.5346,28.2937, POLY,

PTXY,9.4991,28.3615,9.5091,28.3715,9.7126,28.3037,9.7026,28.2937, POLY,

PTXY,10.1776,28.3615,10.1876,28.3715,10.1876,28.1680,10.1776,28.1580, POLY,

PTXY,9.7026,28.2937,9.7126,28.3037,9.9840,27.8287,9.9740,27.8187, POLY,

PTXY,13.9094,28.2258,13.9194,28.2358,14.1229,28.0323,14.1129,28.0223, POLY,

PTXY,8.8206,28.0223,8.8306,28.0323,9.3055,27.6930,9.2955,27.6830, POLY,

PTXY,9.9740,28.0223,9.9840,28.0323,10.3911,27.7609,10.3811,27.7509, POLY,

PTXY,8.0064,27.9544,8.0164,27.9644,9.7805,26.4717,9.7705,26.4617, 
POLY,

PTXY,14.6557,27.9544,14.6657,27.9644,14.8693,27.8966,14.8593,27.8866, POLY,

PTXY,10.2454,27.8866,10.2554,27.8966,10.3911,27.5573,10.3811,27.5473, POLY,

PTXY,14.1129,27.8866,14.1229,27.8966,14.5300,27.0823,14.5200,27.0723, POLY,

PTXY,13.6379,27.8187,13.6479,27.8287,14.1229,27.1502,14.1129,27.1402, POLY,

PTXY,14.1129,27.7509,14.1229,27.7609,14.2586,27.6930,14.2486,27.6830, POLY,

PTXY,8.2778,27.6830,8.2878,27.6930,8.2878,27.4894,8.2778,27.4794,

POLY,

PTXY,9.0920,27.6830,9.1020,27.6930,9.1020,27.4894,9.0920,27.4794, POLY,

PTXY,8.6170,27.5473,8.6270,27.5573,8.8984,27.4216,8.8884,27.4116, POLY,

PTXY,13.8415,27.5473,13.8515,27.5573,13.9194,27.3537,13.9094,27.3437, POLY,

PTXY,7.4635,27.4794,7.4735,27.4894,8.4913,26.6752,8.4813,26.6652, POLY,

PTXY,7.5314,27.3437,7.5414,27.3537,8.0164,27.2859,8.0064,27.2759, POLY,

PTXY,7.2600,27.0045,7.2700,27.0145,8.1521,25.5896,8.1421,25.5796, POLY,

PTXY,14.1129,27.0045,14.1229,27.0145,14.3943,26.6752,14.3843,26.6652, POLY,

PTXY,8.5492,26.8688,8.5592,26.8788,9.0341,26.8109,9.0241,26.8009, POLY,

PTXY,15.8092,26.8688,15.8192,26.8788,16.0227,26.1324,16.0127,26.1224, POLY,

PTXY,12.6202,26.8009,12.6302,26.8109,12.7659,26.5395,12.7559,26.5295, POLY,

PTXY,8.2778,26.7331,8.2878,26.7431,8.6949,26.4038,8.6849,26.3938, POLY,

PTXY,13.3665,26.5974,13.3765,26.6074,14.4622,25.7932,14.4522,25.7832, POLY,

PTXY,14.0451,26.3938,14.0551,26.4038,14.3265,26.3360,14.3165,26.3260, POLY,

PTXY,15.4021,26.3938,15.4121,26.4038,15.9549,25.7253,15.9449,25.7153, POLY,

PTXY,8.6170,26.3260,8.6270,26.3360,9.6448,26.1324,9.6348,26.1224, POLY,

PTXY,13.2987,26.3260,13.3087,26.3360,13.6479,26.0646,13.6379,26.0546, POLY,

PTXY,7.3278,26.2581,7.3378,26.2681,7.8128,26.2681,7.8028,26.2581, 
POLY,

PTXY,9.2955,26.2581,9.3055,26.2681,9.3734,25.9967,9.3634,25.9867, POLY,

PTXY,9.3634,26.2581,9.3734,26.2681,9.7126,25.6575,9.7026,25.6475, POLY,

PTXY,15.1307,26.2581,15.1407,26.2681,15.3442,25.8610,15.3342,25.8510, POLY,

PTXY,6.7851,26.1224,6.7950,26.1324,7.1343,25.8610,7.1243,25.8510, POLY,

PTXY,8.4813,26.1224,8.4913,26.1324,9.0341,25.7253,9.0241,25.7153, POLY,

PTXY,9.7026,26.1224,9.7126,26.1324,9.9162,26.1324,9.9062,26.1224, POLY,

PTXY,14.1129,26.0546,14.1229,26.0646,14.3265,26.0646,14.3165,26.0546, POLY,

PTXY,7.1243,25.8510,7.1343,25.8610,7.4057,25.5896,7.3957,25.5796, POLY,

PTXY,9.7705,25.7832,9.7805,25.7932,9.9162,25.5218,9.9062,25.5118, POLY,

PTXY,7.0564,25.7153,7.0664,25.7253,7.3378,25.1825,7.3278,25.1725, POLY,

PTXY,14.3165,25.7153,14.3265,25.7253,15.8192,22.5364,15.8092,22.5264, POLY,

PTXY,7.5992,25.6475,7.6092,25.6575,9.3055,24.0291,9.2955,24.0191, POLY,

PTXY,8.4813,25.6475,8.4913,25.6575,8.7627,25.1147,8.7527,25.1047, POLY,

PTXY,9.6348,25.6475,9.6448,25.6575,9.7126,24.7754,9.7026,24.7654, POLY,

PTXY,10.1097,25.6475,10.1197,25.6575,10.6625,25.1147,10.6525,25.1047, POLY,

PTXY,6.4458,25.5796,6.4558,25.5896,6.7950,25.3182,6.7851,25.3082, POLY,

PTXY,11.0596,25.5796,11.0696,25.5896,11.3410,25.3861,11.3310,25.3761, POLY,

PTXY,10.7882,25.5118,10.7982,25.5218,11.1375,23.4863,11.1275,23.4763, POLY,

PTXY,11.4667,25.5118,11.4767,25.5218,11.7481,25.0468,11.7381,25.0368, POLY,

PTXY,15.7413,25.5118,15.7513,25.5218,15.9549,25.3861,15.9449,25.3761, POLY,

PTXY,7.7350,25.4439,7.7450,25.4539,8.0842,24.9111,8.0742,24.9011, POLY,

PTXY,8.7527,25.4439,8.7627,25.4539,9.1020,24.9790,9.0920,24.9690, POLY,

PTXY,9.2277,25.4439,9.2377,25.4539,9.6448,25.1147,9.6348,25.1047, 
POLY,

PTXY,10.9918,25.3761,11.0018,25.3861,11.6124,25.2504,11.6024,25.2404, POLY,

PTXY,6.7172,25.3082,6.7272,25.3182,6.9307,25.1825,6.9208,25.1725, POLY,

PTXY,9.7705,25.3082,9.7805,25.3182,10.0519,24.8433,10.0419,24.8333, POLY,

PTXY,11.3310,25.3082,11.3410,25.3182,11.6124,25.1825,11.6024,25.1725, POLY,

PTXY,16.2841,25.2404,16.2941,25.2504,16.4977,25.0468,16.4877,25.0368, POLY,

PTXY,9.1598,25.0368,9.1698,25.0468,9.3734,24.9790,9.3634,24.9690, POLY,

PTXY,10.3133,25.0368,10.3233,25.0468,10.5268,24.9790,10.5168,24.9690, POLY,

PTXY,15.8770,25.0368,15.8870,25.0468,16.2263,24.9790,16.2163,24.9690, POLY,

PTXY,13.8415,24.9690,13.8515,24.9790,14.6657,24.1648,14.6557,24.1548, POLY,

PTXY,14.0451,24.9690,14.0551,24.9790,14.0551,24.7076,14.0451,24.6976, POLY,

PTXY,9.2277,24.8333,9.2377,24.8433,9.5769,24.6397,9.5669,24.6297, POLY,

PTXY,10.5847,24.7654,10.5947,24.7754,10.7982,24.7754,10.7882,24.7654, POLY,

PTXY,9.3634,24.6297,9.3734,24.6397,9.9162,24.2326,9.9062,24.2226,

POLY,

PTXY,13.6379,24.5619,13.6479,24.5719,14.0551,24.0969,14.0451,24.0869, POLY,

PTXY,7.8028,24.4940,7.8128,24.5040,8.0164,23.8255,8.0064,23.8155, POLY,

PTXY,11.1275,24.2226,11.1375,24.2326,11.8838,22.6721,11.8738,22.6621, POLY,

PTXY,11.6024,24.2226,11.6124,24.2326,13.7158,22.1293,13.7058,22.1193, POLY,

PTXY,15.2664,24.2226,15.2764,24.2326,15.6156,23.2149,15.6056,23.2049, POLY,

PTXY,11.6024,24.0869,11.6124,24.0969,11.8838,23.9612,11.8738,23.9512, POLY,

PTXY,9.0241,24.0191,9.0341,24.0291,9.2377,23.6220,9.2277,23.6120,

POLY,

PTXY,10.5847,24.0191,10.5947,24.0291,10.8661,23.8934,10.8561,23.8834, POLY,

PTXY,7.7350,23.9512,7.7450,23.9612,8.6270,23.3506,8.6170,23.3406, POLY,

PTXY,12.0095,23.9512,12.0195,23.9612,12.2909,23.8255,12.2809,23.8155, 
POLY,

PTXY,14.0451,23.8834,14.0551,23.8934,14.5300,23.8934,14.5200,23.8834, POLY,

PTXY,8.5492,23.6798,8.5592,23.6898,10.4590,22.9435,10.4490,22.9335, POLY,

PTXY,11.8738,23.6120,11.8838,23.6220,12.1552,23.0113,12.1452,23.0013, POLY,

PTXY,8.0064,23.5441,8.0164,23.5541,8.4913,23.3506,8.4813,23.3406, POLY,

PTXY,10.6525,23.5441,10.6625,23.5541,11.0018,23.5541,10.9918,23.5441, POLY,

PTXY,11.3989,23.4763,11.4089,23.4863,11.6803,23.4863,11.6703,23.4763, POLY,

PTXY,15.6735,23.4763,15.6835,23.4863,16.0906,23.4863,16.0806,23.4763, POLY,

PTXY,7.8707,23.4084,7.8807,23.4184,8.1521,23.3506,8.1421,23.3406,

POLY,

PTXY,10.9239,23.2727,10.9339,23.2827,11.0018,22.8078,10.9918,22.7978, POLY,

PTXY,13.8415,23.2727,13.8515,23.2827,14.2586,21.1794,14.2486,21.1694, POLY,

PTXY,10.3811,23.2049,10.3911,23.2149,10.9339,22.4007,10.9239,22.3907, POLY,

PTXY,14.9271,23.2049,14.9371,23.2149,15.0050,22.9435,14.9950,22.9335, POLY,

PTXY,14.5879,23.1370,14.5979,23.1470,14.8014,22.9435,14.7914,22.9335, POLY,

PTXY,8.6849,23.0692,8.6949,23.0792,8.7627,22.4685,8.7527,22.4585, POLY,

PTXY,8.8884,23.0692,8.8984,23.0792,8.9663,22.4685,8.9563,22.4585, POLY,

PTXY,11.1953,23.0692,11.2053,23.0792,12.6980,21.8579,12.6880,21.8479, POLY,

PTXY,14.9950,23.0692,15.0050,23.0792,15.2085,22.8756,15.1985,22.8656, POLY,

PTXY,10.1776,23.0013,10.1876,23.0113,10.2554,22.6721,10.2454,22.6621, POLY,

PTXY,9.0920,22.9335,9.1020,22.9435,9.1698,22.4685,9.1598,22.4585, POLY,

PTXY,14.2486,22.9335,14.2586,22.9435,14.5300,22.7399,14.5200,22.7299, POLY,

PTXY,9.5669,22.8656,9.5769,22.8756,10.1197,22.7399,10.1097,22.7299, POLY,

PTXY,10.4490,22.8656,10.4590,22.8756,10.7982,22.6721,10.7882,22.6621, POLY,

PTXY,14.3165,22.7299,14.3265,22.7399,15.4121,22.2650,15.4021,22.2550, 
POLY,

PTXY,16.2841,22.7299,16.2941,22.7399,16.4298,22.5364,16.4198,22.5264, POLY,

PTXY,9.8383,22.6621,9.8483,22.6721,10.2554,21.3151,10.2454,21.3051, POLY,

PTXY,15.4699,22.6621,15.4799,22.6721,15.8192,22.3328,15.8092,22.3228, POLY,

PTXY,15.8092,22.6621,15.8192,22.6721,16.4977,22.3328,16.4877,22.3228, POLY,

PTXY,14.5200,22.5264,14.5300,22.5364,14.7336,22.4007,14.7236,22.3907, POLY,

PTXY,10.4490,22.3907,10.4590,22.4007,11.3410,21.9257,11.3310,21.9157, POLY,

PTXY,9.8383,22.2550,9.8483,22.2650,10.1197,21.5865,10.1097,21.5765,

POLY,

PTXY,14.6557,22.0514,14.6657,22.0614,15.4799,21.3829,15.4699,21.3729, POLY,

PTXY,10.3133,21.9157,10.3233,21.9257,10.5947,21.7222,10.5847,21.7122, POLY,

PTXY,9.7705,21.7800,9.7805,21.7900,9.9840,21.7900,9.9740,21.7800, POLY,

PTXY,10.5168,21.7800,10.5268,21.7900,11.8838,20.7722,11.8738,20.7622, POLY,

PTXY,14.9271,21.7800,14.9371,21.7900,15.3442,21.6543,15.3342,21.6443, POLY,

PTXY,10.7882,21.1694,10.7982,21.1794,11.0696,20.9758,11.0596,20.9658, POLY,

PTXY,7.3278,27.2080,7.3378,27.2180,7.5414,27.0823,7.5314,27.0723, POLY,

PTXY,7.6671,25.5796,7.6771,25.5896,7.7450,25.3861,7.7350,25.3761, POLY,

PTXY,7.5992,25.2404,7.6092,25.2504,7.8128,25.1147,7.8028,25.1047, POLY,

PTXY,8.4135,25.1047,8.4235,25.1147,8.4913,24.6397,8.4813,24.6297, POLY,

PTXY,7.8028,25.0368,7.8128,25.0468,8.3556,24.5719,8.3456,24.5619, POLY,

PTXY,15.7413,24.9690,15.7513,24.9790,15.9549,24.5040,15.9449,24.4940, POLY,

PTXY,8.0064,24.7654,8.0164,24.7754,8.1521,24.6397,8.1421,24.6297,

POLY,

PTXY,15.4021,24.7654,15.4121,24.7754,15.7513,24.7754,15.7413,24.7654, POLY,

PTXY,8.0742,24.4940,8.0842,24.5040,8.2878,24.0969,8.2778,24.0869, POLY,

PTXY,14.2486,24.3583,14.2586,24.3683,14.5979,23.8255,14.5879,23.8155, 
POLY,

PTXY,8.5492,23.3406,8.5592,23.3506,8.7627,22.9435,8.7527,22.9335,

POLY,

PTXY,8.6849,23.2049,8.6949,23.2149,9.1020,23.1470,9.0920,23.1370, POLY,

PTXY,13.0273,23.1370,13.0373,23.1470,14.8014,22.3328,14.7914,22.3228, POLY,

PTXY,12.4166,22.7978,12.4266,22.8078,12.7659,22.1971,12.7559,22.1871, POLY,

PTXY,13.6379,22.4585,13.6479,22.4685,14.1229,21.8579,14.1129,21.8479, POLY,

PTXY,13.5022,22.2550,13.5122,22.2650,13.7836,21.9936,13.7736,21.9836, POLY,

PTXY,10.8561,21.8479,10.8661,21.8579,11.4089,21.7222,11.3989,21.7122, POLY,

PTXY,13.7058,21.7800,13.7158,21.7900,14.2586,21.5865,14.2486,21.5765, POLY,

PTXY,10.1776,21.7122,10.1876,21.7222,10.4590,21.5865,10.4490,21.5765, POLY,

PTXY,13.8415,21.7122,13.8515,21.7222,14.1229,21.7222,14.1129,21.7122, POLY,

PTXY,12.5523,21.5765,12.5623,21.5865,12.9016,21.3829,12.8916,21.3729, POLY,

PTXY,11.9417,21.4408,11.9517,21.4508,12.5623,21.3151,12.5523,21.3051, POLY,

PTXY,12.8237,21.1694,12.8337,21.1794,13.1730,21.0437,13.1630,21.0337, POLY, 


\section{Appendix 9}

Output of MATLAB file in ANSYS log file format for Day 12 cell model

$$
\begin{aligned}
& \mathrm{k}, 1,10.1988,21.3000 \\
& \mathrm{k}, 2,10.9239,23.7800 \\
& \mathrm{k}, 3,11.6491,24.6884 \\
& \mathrm{k}, 4,12.3742,25.2989 \\
& \mathrm{k}, 5,13.0994,25.7364 \\
& \mathrm{k}, 6,13.8245,26.0489 \\
& \mathrm{k}, 7,14.5497,26.2601 \\
& \mathrm{k}, 8,15.2748,26.3826 \\
& \mathrm{k}, 9,16.0000,26.4228 \\
& \mathrm{k}, 10,16.7252,26.3826 \\
& \mathrm{k}, 11,17.4503,26.2601 \\
& \mathrm{k}, 12,18.1755,26.0489 \\
& \mathrm{k}, 13,18.9006,25.7364 \\
& \mathrm{k}, 14,19.6258,25.2989 \\
& \mathrm{k}, 15,20.3509,24.6884 \\
& \mathrm{k}, 16,21.0761,23.7800 \\
& \mathrm{k}, 17,21.8012,21.3000 \\
& \mathrm{k}, 18,21.8012,21.3000 \\
& \mathrm{k}, 19,21.0761,18.8200 \\
& \mathrm{k}, 20,20.3509,17.9116 \\
& \mathrm{k}, 21,19.6258,17.3011 \\
& \mathrm{k}, 22,18.9006,16.8636 \\
& \mathrm{k}, 23,18.1755,16.5511 \\
& \mathrm{k}, 24,17.4503,16.3399 \\
& \mathrm{k}, 25,16.7252,16.2174 \\
& \mathrm{k}, 26,16.0000,16.1773 \\
& \mathrm{k}, 27,15.2748,16.2174 \\
& \mathrm{k}, 28,14.5497,16.3399 \\
& \mathrm{k}, 29,13.8245,16.5511 \\
& \mathrm{k}, 30,13.0994,16.8636 \\
& \mathrm{k}, 31,12.3742,17.3011 \\
& \mathrm{k}, 32,11.6491,17.9116 \\
& \mathrm{k}, 33,10.9239,18.8200 \\
& 1,1,2, \\
& 1,2,3, \\
& 1,3,4, \\
& 1,4,5, \\
& 1,5,6, \\
& 1,6,7, \\
& 1,7,8, \\
& 1,8,9, \\
& 1,9,10,
\end{aligned}
$$


$1,10,11$, $1,11,12$, $1,12,13$, $1,13,14$, $1,14,15$, $1,15,16$, $1,16,17$, $1,17,18$, $1,18,19$, $1,19,20$, $1,20,21$, $1,21,22$, $1,22,23$, $1,23,24$, $1,24,25$, $1,25,26$, $1,26,27$, $1,27,28$, $1,28,29$, $1,29,30$, $1,30,31$, $1,31,32$, $1,32,33$, $1,33,34$, $\mathrm{k}, 34,9.9988,21.3000$ $\mathrm{k}, 35,10.7489,23.8769$ $\mathrm{k}, 36,11.4991,24.8207$ $\mathrm{k}, 37,12.2492,25.4551$ $\mathrm{k}, 38,12.9994,25.9096$ k,39,13.7495,26.2343 $\mathrm{k}, 40,14.4997,26.4537$ $\mathrm{k}, 41,15.2498,26.5810$ $\mathrm{k}, 42,16.0000,26.6228$ $\mathrm{k}, 43,16.7502,26.5810$ $\mathrm{k}, 44,17.5003,26.4537$ $\mathrm{k}, 45,18.2505,26.2343$ $\mathrm{k}, 46,19.0006,25.9096$ $\mathrm{k}, 47,19.7508,25.4551$ $\mathrm{k}, 48,20.5009,24.8207$ $\mathrm{k}, 49,21.2511,23.8769$ $\mathrm{k}, 50,22.0012,21.3000$ $\mathrm{k}, 51,22.0012,21.3000$ $\mathrm{k}, 52,21.2511,18.7231$ k,53,20.5009,17.7793 k,54,19.7508,17.1449 $\mathrm{k}, 55,19.0006,16.6904$ 


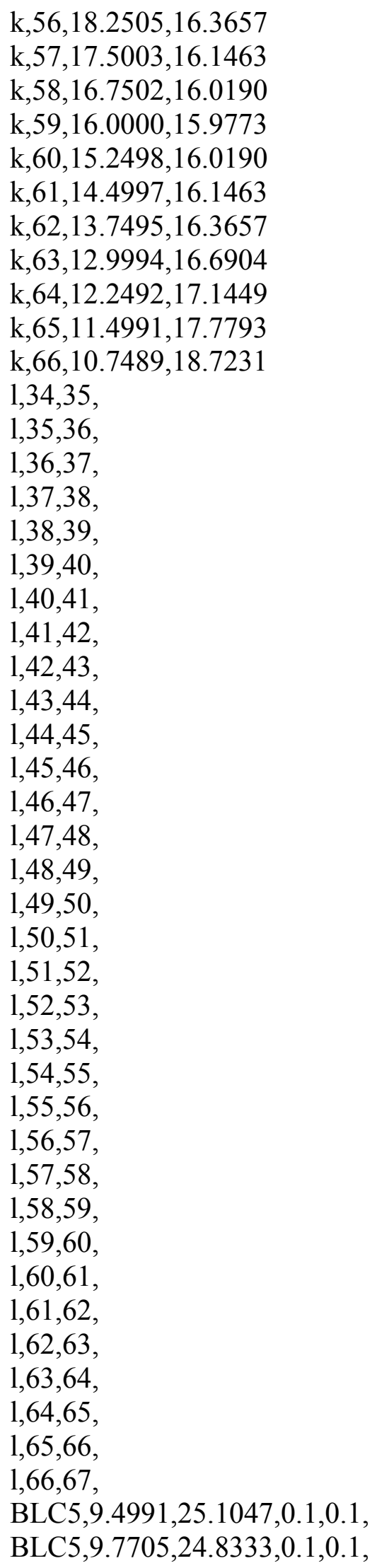


BLC5,9.2277,22.9335,0.1,0.1, BLC5,9.9740,22.1193,0.1,0.1, BLC5,20.4230,22.7299,0.1,0.1, BLC5,21.4408,21.6443,0.1,0.1, BLC5,8.2099,21.5765,0.1,0.1, BLC5,9.4991,20.3551,0.1,0.1, BLC5,16.6912,20.8301,0.1,0.1, BLC5, 17.7768,19.5409,0.1,0.1, BLC5,18.8624,19.8802,0.1,0.1, BLC5,19.7445,18.9981,0.1,0.1, BLC5,21.1015,18.7946,0.1,0.1, BLC5,22.3228,17.7090,0.1,0.1, BLC5,21.3729,18.2518,0.1,0.1, BLC5,22.0514,17.8447,0.1,0.1, BLC5, 17.8447,18.0482,0.1,0.1, BLC5,19.2695,16.6912,0.1,0.1, 


\section{Appendix 10}

Fluid solid interaction analysis in a cell

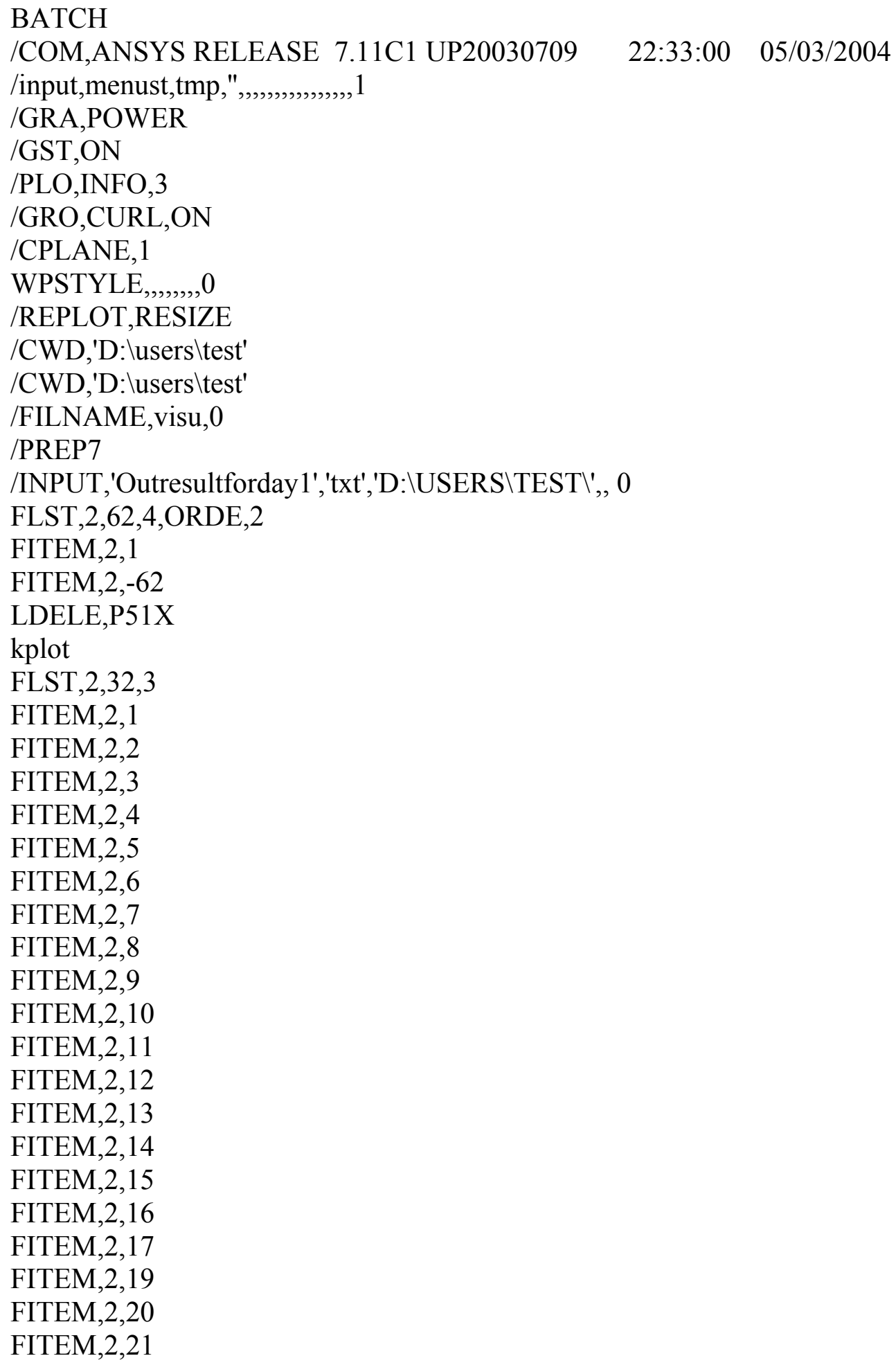


FITEM,2,22

FITEM,2,23

FITEM,2,24

FITEM,2,25

FITEM,2,26

FITEM,2,27

FITEM,2,28

FITEM,2,29

FITEM,2,30

FITEM,2,31

FITEM,2,32

FITEM,2,33

A,P51X

FLST,2,32,3

FITEM,2,34

FITEM,2,35

FITEM,2,36

FITEM,2,37

FITEM,2,38

FITEM,2,39

FITEM,2,40

FITEM,2,41

FITEM,2,42

FITEM,2,43

FITEM,2,44

FITEM,2,45

FITEM,2,46

FITEM,2,47

FITEM,2,48

FITEM,2,49

FITEM,2,50

FITEM,2,52

FITEM,2,53

FITEM,2,54

FITEM,2,55

FITEM,2,56

FITEM,2,57

FITEM,2,58

FITEM,2,59

FITEM,2,60

FITEM,2,61

FITEM,2,62

FITEM,2,63

FITEM,2,64

FITEM,2,65

FITEM,2,66 


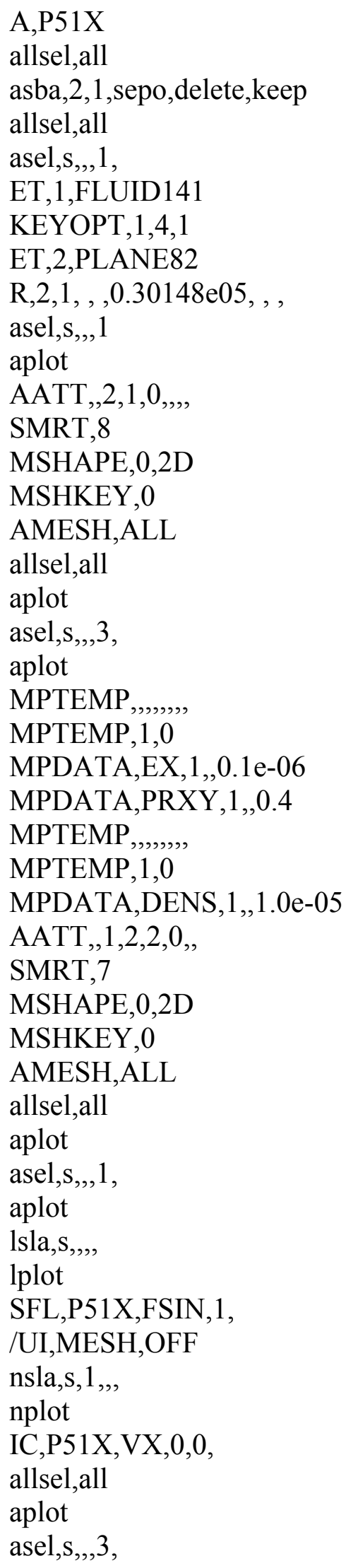




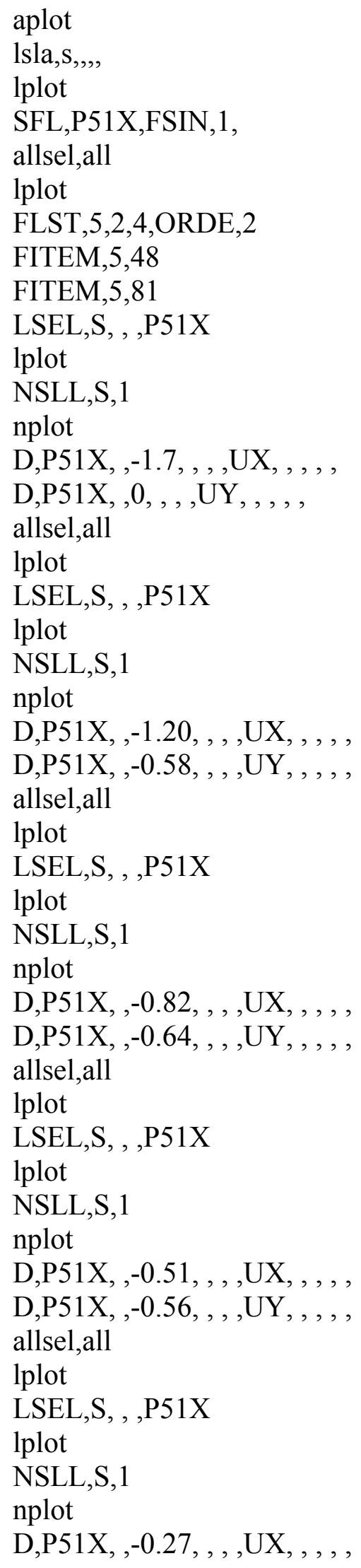


D,P51X, ,-0.41, , , ,UY, , , , ,

allsel,all

lplot

LSEL,S, , ,P51X

lplot

NSLL,S,1

nplot

D,P51X, ,-0.007, , , ,UX, , , ,

D,P51X, ,-0.02, , , ,UY, , , , ,

allsel,all

Iplot

LSEL,S, , ,P51X

lplot

NSLL,S,1

nplot

D,P51X, ,0.0155, , , ,UX, , , , ,

D,P51X, ,0.11, , , UY, , , , ,

allsel,all

lplot

LSEL,S, , ,P51X

lplot

NSLL,S,1

nplot

D,P51X, ,0, , ,UX, , , ,

D,P51X, ,0.2, , , ,UY, , , , ,

allsel,all

lplot

LSEL,S, , ,P51X

lplot

NSLL,S,1

nplot

D,P51X, ,1.7, , , ,UX, , , , ,

D,P51X, ,0, , ,UY, , , , ,

allsel,all

lplot

LSEL,S, , ,P51X

lplot

NSLL,S,1

nplot

D,P51X, ,1.20, , , ,UX, , , , ,

D,P51X, ,-0.58, , , ,UY, , , , ,

allsel,all

lplot

LSEL,S, , ,P51X

lplot

NSLL,S, 1 


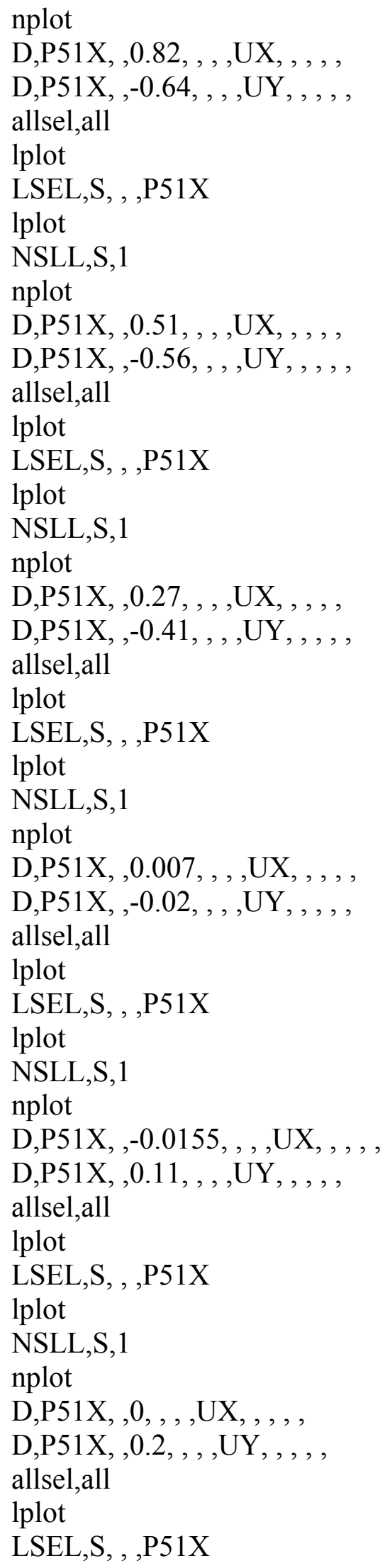




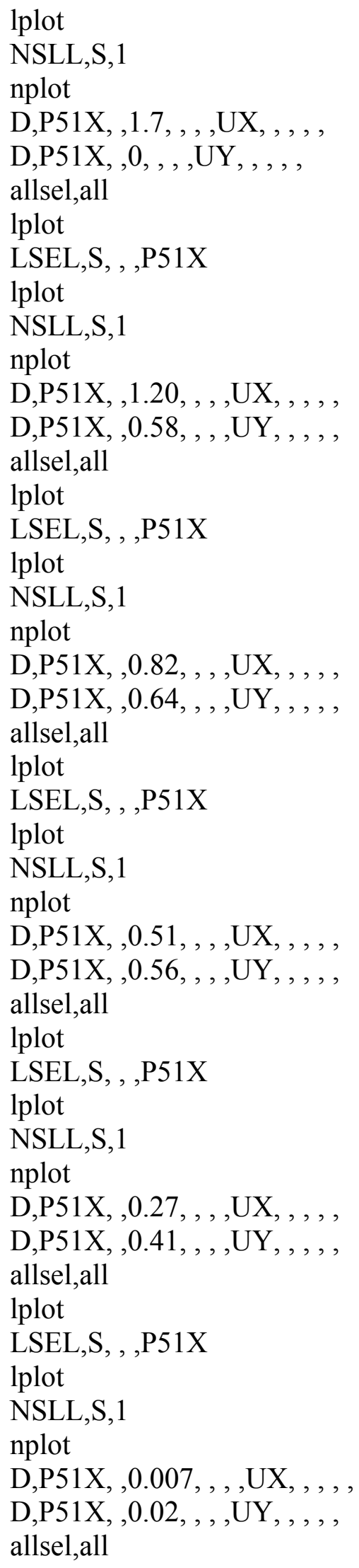




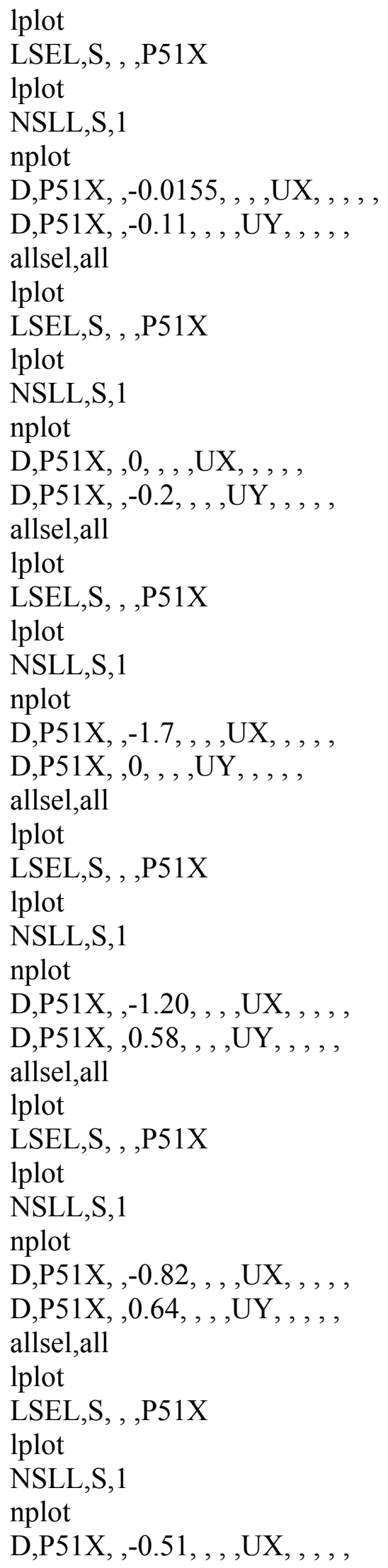


D,P51X, ,0.56, , ,UY, , , , ,

allsel,all

lplot

LSEL,S, , ,P51X

lplot

NSLL,S, 1

nplot

D,P51X, ,-0.27, , , UX, , , ,

D,P51X, ,0.41, , ,UY, , , ,

allsel,all

Iplot

LSEL,S, , ,P51X

lplot

NSLL,S,1

nplot

D,P51X, ,-0.007, , , ,UX, , , ,

D,P51X, ,0.02, , , UY, , , , ,

allsel,all

Iplot

LSEL,S, , ,P51X

lplot

NSLL,S, 1

nplot

D,P51X, ,0.0155, , ,UX, , , , ,

D,P51X, ,-0.11, , , ,UY, , , , ,

allsel,all

lplot

LSEL,S, , ,P51X

lplot

NSLL,S,1

nplot

D,P51X, ,0, , ,UX, , , ,

D,P51X, ,-0.2, , ,UY, , , ,

allsel,all

lplot

nplot

*SET,mu, 1002e-15

*SET,rho, 1.0e-09

fldata1,solu,flow, 1

fldata 1 ,solu,temp, 0

fldata1,solu,tran,1

fldata1,solu,ale, 1

fldata2,time,glob, 10,

fini

/solu

flda,nomi,dens, rho 
flda,nomi,visc, mu

fsan,on

fsco,all,1.0e-2

fsre,all, 1.0

fsou, 1.0

deltim, 0.25

flda,time,step, 0.25

fsit, 10

fsti, 2.0

fsdt, 0.25

fsor,solid,

fstr,solid,

fstr,fluid,

save

$\mathrm{KBC}, 0$

/solu

solve 


\section{Appendix 11}

Fluid solid interaction analysis using physics environment

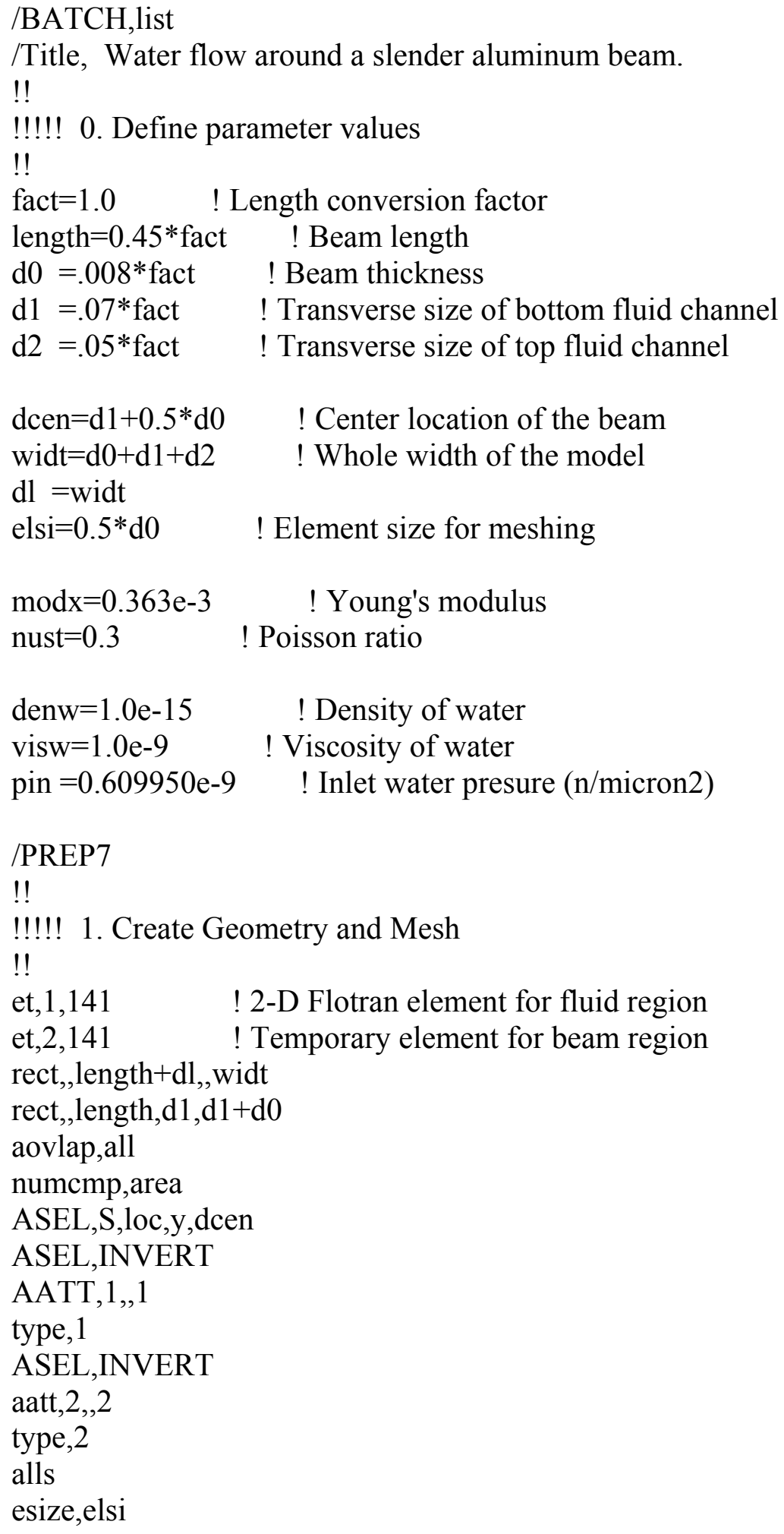


amesh,all

alls

fini

/prep7

!!

!!!!! 2. Create Physics Environment for the Fluid

!!

et, 1,141

et,2,0 ! Assign null type element for the beam

!! CFD Solution Control

flda,solu,flow, 1

flda,solu,turb, 1

flda,advm,mome,supg

flda,advm,turb,supg

flda,iter,exec, 100

flda,outp,sumf, 10

!! CFD Property Information

flda,prot,dens, constant

flda,prot,visc, constant

flda,nomi,dens, denw $\quad ! 1000 \mathrm{~kg} / \mathrm{micron}^{3}$ for density - water

flda,nomi,visc,visw $\quad$ ! 4.6E-4 kg-s/micron (viscosity of water)

flda,conv,pres,1.E-9 ! Tighten pressure equation convergence

!! CFD Boundary Conditions (Applied to Solid Model)

lsel,s,loc, $\mathrm{x}, 0$

lsel,u,loc,y,dcen

dl,all,,pres,pin,1 ! Inlet Condition

lsel,s,loc,y,0

lsel,a,loc,y,widt

dl,all,,vx,0.,1 ! Outer Walls

dl,all,,vy,0., 1

asel,s,type, 2

1sla,s

dl,all,,vx,0.,1 ! Structure boundary conditions

dl,all,,vy, $0 ., 1$

lsel,s,loc,x,length $+\mathrm{dl}$

dl,all,,pres,0., 1 ! Outlet pressure condition

asel,s,type, 1

$\mathrm{cm}$,area2,area ! Fluid area component for morphing

alls

fini 
/title,Fluid Analysis

physics, write,fluid,fluid

physics, clear

/prep7

!!

!!!!! 3. Create Physics Environment for the Structure

!!

et, 1,0

et, 2,42

! Structural element type for beam

mp,ex,2,modx

mp,nuxy,2,nust

LSEL,S,LOC,Y,dcen

LSEL,R,LOC,X,0

$\mathrm{dl}, \mathrm{all}, \mathrm{UX}, 0 \quad$ ! Bar constraints at $\mathrm{X}=0$

$\mathrm{dl}, \mathrm{all}, \mathrm{UY}, 0$

alls

fini

/title,Structural Analysis

physics, write,struc,struc

physics, clear

!!

!!!!! 4. Run FSSOLV macro with restart option and default

!!!!! convergence tolerances

!!

FSSOLV,'fluid','struc',2,'area2', ,,,,25,40,1,1 